DOE-HDBK-1062-96

August 1996

\title{
DOE HANDBOOK
}

FIRE PROTECTION

VOLUME I

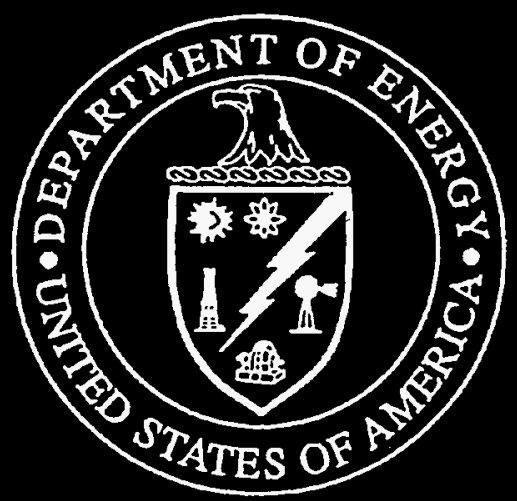

U.S. Department of Energy

Washington, D.C. 20585 
This document has been reproduced directly from the best available copy.

Available to DOE and DOE contractors from the Office of Scientific and Technical Information, P. O. Box 62, Oak Ridge, TN 37821; (423) 576-8401.

Available to the public from the U. S. Department of Commerce, Technology Administration, National Technical Information Service, Springfield, VA 22161; (703) $487-4650$. 


\section{DISCLAIMER}

This report was prepared as an account of work sponsored by an agency of the United States Government. Neither the United States Government nor any agency thereof, nor any of their employees, makes any warranty, express or implied, or assumes any legal liability or responsibility for the accuracy, completeness, or usefulness of any information, apparatus, product, or process disclosed, or represents that its use would not infringe privately owned rights. Reference herein to any specific commercial product, process, or service by trade name, trademark, manufacturer, or otherwise does not necessarily constitute or imply its endorsement, recommendation, or favoring by the United States Government or any agency thereof. The views and opinions of authors expressed herein do not necessarily state or renlect those of the United States Government or any agency thereof. 



\section{FOREWORD}

1. This Department of Energy (DOE) Handbook is approved for use by the Office of Environment, Safety and Health and is available to all DOE components and their contractors.

2. Specific comments (recommendations, additions, deletions, and any pertinent data) to enhance this document should be sent to:

Dennis Kubicki

Office of Environment, Safety and Health

Office of Worker Health and Safety

Bellemead Building

U.S. Department of Energy

19901 Germantown Road

Germantown, MD 20874-1290

3. The DOE Fire Protection Handbook replaces the DOE Fire Protection Resource Manual that was issued in October, 1991. DOE handbooks are part of the DOE directives system and are issued to provide supplemental information regarding the Department's expectations for fulfilling its requirements as contained in rules, Orders, notices, and regulatory standards. The handbooks may also provide acceptable methods for implementing these requirements. Handbooks are not substitutes for requirements, nor do they replace technical standards that are used to describe established practices and procedures for implementing requirements.

4. Nothing in this Handbook prevents or discourages the implementation of alternate or innovative fire protection configurations and practices that will achieve a level of fire safety comparable to that attained by literal conformance with DOE fire safety criteria or those established by the fire protection industry through the consensus standards process. 


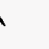




\section{DISCLAIMER}

Portions of this document may be illegible in electronic image products. Images are produced from the best available original document. 



\section{INTRODUCTION}

The Department of Energy (DOE) Fire Protection Program is delineated in a number of source documents including; the Code of Federal Regulations (CFR), DOE Policy Statements and Orders, DOE and national consensus standards (such as those promulgated by the National Fire Protection Association), and supplementary guidance.

This Handbook is intended to bring together in one location as much of this material as possible to facilitate understanding and ease of use. The applicability of any of these directives to individual Maintenance and Operating Contractors or to given facilities and operations is governed by existing contracts. Questions regarding applicability should be directed to the DOE Authority Having Jurisdiction for fire safety.

The information provided within includes copies of those DOE directives that are directly applicable to the implementation of a comprehensive fire protection program. They are delineated in the Table of Contents. The items marked with an asterisk $\left({ }^{*}\right)$ are included on the disks in WordPerfect 5.1 format, with the filename noted below. The items marked with double asterisks are provided as hard copies as well as on the disk. For those using MAC disks, the files are in Wordperfect 2.1 for MAC.

Also included are tabs for Bulletins/Notes, DOE Interpretations, DOE Program Office, DOE Field Office, Exemptions/Equipvalencies, Additional Criteria, and Index. Updates will be provided for these sections through mailouts and access through the DOE Technical Information System on the World Wide Web and also via the DOE Fire Protection Home Page. The URL for the Home Page is: http://www.tis.eh.doe.gov/docs/fire/fire.html.

\begin{tabular}{|l|l|l|}
\hline Document Name & Disk Number & Filename \\
\hline DOE 5480.7A - Fire Protection & 1 & doe-5480.7a \\
\hline DOE O 420.1 - Facility Safety & 1 & 420 -ord.fin \\
\hline $\begin{array}{l}\text { DOE O 420.1 - Contractors Requirements } \\
\text { Document }\end{array}$ & 1 & 420 -crd.fin \\
\hline $\begin{array}{l}\text { DOE O 440.1 - Worker Protection } \\
\text { Managment for DOE Federal and Contractor } \\
\text { Employees }\end{array}$ & 1 & 440 -ordr.fin \\
\hline $\begin{array}{l}\text { DOE O 151.1 - Comprehensive Emergency } \\
\text { Management System }\end{array}$ & 1 & 151-ord.fin \\
\hline $\begin{array}{l}\text { DOE O 231.1 - Environment, Safety, and } \\
\text { Health Reporting }\end{array}$ & 1 & 231-ordr.fin \\
\hline DOE M 231.1 - Manual & 1. & 231-manl.fin \\
\hline DOE O 360.1 - Training & 1 & 360-ord.fin \\
\hline
\end{tabular}





\section{TABLE OF CONTENTS VOLUME I}

$\underline{\text { Section }}$

$\underline{T a b}$

DOE Policy

September 27, 1990, Halon Policy Statement . . . . . . . . . . . . . . P-1

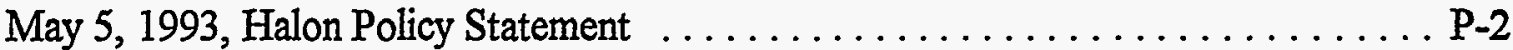

DOE Orders

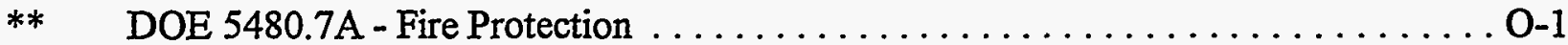

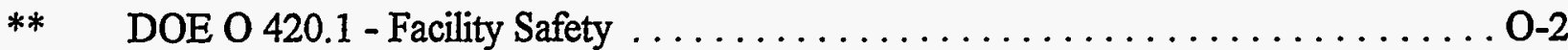

** DOE C 420.1 - Contractors Requirements Document

** DOE O 440.1 - Worker Protection Management for DOE Federal ............ O-3 and Contractor Employees

DOE O 151.1 - Comprehensive Emergency Management System ............ O-4

** DOE O 231.1 - Environment, Safety, and Health Reporting ............. O-5

** DOE M 231.1-1 Manual

DOE 0232.1 - Occurrence Reporting and Processing of Operations Information . . . O-6

**

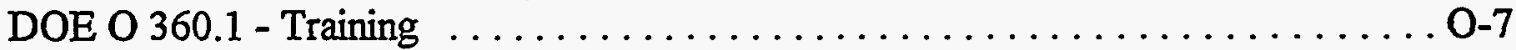

DOE Technical Standards

* DOE-STD-1066-YR, Fire Protection Design Criteria ................ S-1

* DOE-STD-1088-95, Fire Protection for Relocatable Structures . . . . . . . . . . S-2

DOE-Wide Standard, Fire Protection Qualification Standard ............ S-3

DOE Fire Protection Guidance

September 29, 1988, NFPA 1500 Implementation Plan ................ G-1

November 7, 1991, Guidance on Performance of Fire Hazard Analysis . . . . . . . . . G-2

August 10, 1992, Guidance on Fire Protection for Fuel Cycle Facilities . . . . . . . . G-3

June 30, 1994, Nuclear Criticality Safety Guide for Fire Protection $\ldots \ldots \ldots \ldots$ G-4

Professionals in DOE Nuclear Facilities

* October 1994, Guidance for the Quality Assurance of Fire Protection Systems . . . . . G-5

December 15, 1994, DOD Fire and Emergency Services Program . . . . . . . . . G-6

March 7, 1995, Implementation of NFPA $25 \ldots \ldots \ldots \ldots \ldots \ldots \ldots \ldots$ G-7

March 7, 1995, Interim Guidelines for Fire Protection of Abandoned ........... G-8

Facilities and for Facilities Undergoing Decontamination

and Decommissioning

April 14, 1995, Guidelines for Developing Medical Standards for Firefighters . . . . . G-9

* September 30, 1995, Final Implementation Guide for Use with DOE .......... G-10

Orders 420 and 440.1 Fire Safety Program 
' 


\section{TABLE OF CONTENTS \\ VOLUME II}

Section

$\underline{\mathrm{Tab}}$

Models

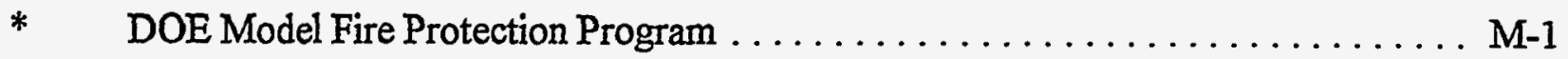

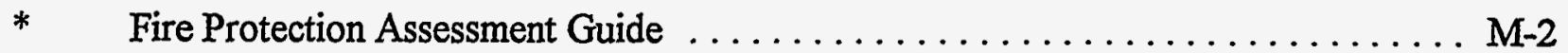

* Fire Hazard Analysis for Building $9203 \& 9203$ A Complex . . . . . . . . . . . . M-3

* Fire Hazard Analysis for Building $9116 \ldots \ldots \ldots \ldots \ldots \ldots \ldots \ldots \ldots \ldots \ldots$

* Baseline Combined Fire Hazard Analysis and Fire Protection Facility . . . . . . . . M-5 Assessment for Building 9203 \& 9203A

* Combined Fire Hazard Analysis and Fire Protection Facility Assessment

M-6 For Building 9116

* Baseline Fire Protection Facility Assessment for Building 9203 M-7 and 9203A Complex

* Baseline Fire Protection Facility Assessment for Building $9116 \ldots \ldots \ldots \ldots$ M-8

* DOE Model Fire Protection Baseline Capabilities . . . . . . . . . . . . . M-9

Bulletins/Notes $\ldots \ldots \ldots \ldots \ldots \ldots \ldots \ldots \ldots \ldots \ldots \ldots \ldots \ldots \ldots \ldots \ldots \ldots \ldots$ Bulletins

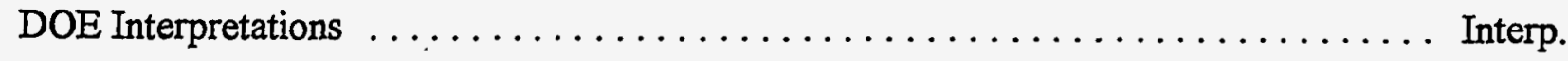

DOE Program Office $\ldots \ldots \ldots \ldots \ldots \ldots \ldots \ldots \ldots \ldots \ldots \ldots \ldots \ldots \ldots \ldots$ Program Office

DOE Field Office $\ldots \ldots \ldots \ldots \ldots \ldots \ldots \ldots \ldots \ldots \ldots \ldots \ldots \ldots \ldots \ldots \ldots \ldots \ldots$ Field Office

Exemptions/Equivalencies $\ldots \ldots \ldots \ldots \ldots \ldots \ldots \ldots \ldots \ldots \ldots \ldots \ldots \ldots \ldots \ldots$ Exemptions

Additional Criteria $\ldots \ldots \ldots \ldots \ldots \ldots \ldots \ldots \ldots \ldots \ldots \ldots \ldots \ldots \ldots \ldots$ Additional Criteria

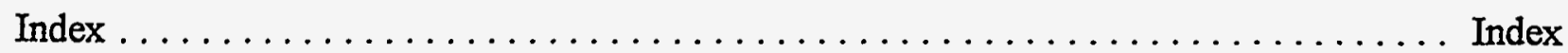


. 


\section{nemorandum}

DARE: SEP 2.71990

IPLY TO

TTN OF:

$$
\text { EH-322 }
$$

JBJECT:

Interim Position on the Installation of New Halon 1301 Fixed Fire Suppression Systems and Halon Portable Fire Extinguishers TO:

Distribution

Concerns over environmental deterioration caused by the proliferation of chlorofluorocarbons (CFCs) and halon compounds in the atmosphere have prompted an international effort to mitigate the damage. A degree of consensus has been reached as evidenced by the adoption of the Montreal Protocol by 59 countries as of June 1990. Further, these Parties agreed to adjust the protocol to fully phase out use of CFCs and halons by the year 2000 where adequate substitute products or processes exist.

The Department of Energy (DOE) has responded to these initiatives by undertaking an effort to develop a'DOE-wide policy on the issue which would include administrative and facility design restrictions on CFC and halon use. A draft DOE Order is in preparation under the joint leadership of the office of Project and Facilities Management and the Federal Energy Management Program. Final approval of that policy, however is not anticipated for some time. In the interim, and reflecting our responsibilities in the area of worker and facility safety, we offer the following guidance when confronting the issue of the use of halon 1211 and 1301 for fire suppression.

The underlying position for this guidance is.that DOE.will. be actively discouraging the installation of new halon systems and portable extinguishers.

Effective the date of this memorandum:

1. No new halon fire suppression systems shall be proposed to mitigate fire and Iife safety hazards. Alternative protection in the form of carbon dioxide fire suppression systems, "pre-action" type sprinkler. systems or "wet pipe" sprinkler systems coupled with 
automatic fire detectors shall be considered. Automatic sprinklers are the preferred alternative although it is recognized that facility-specific design considerations may warrant the use of carbon dioxide.

2. No new halon portable fire extinguishers shall be purchased.

3. In Title II designs which have not yet reached 30 percent completion, projects shall cencel plans and specifications to use halon systems. Alternative protection as described above shall be considered.

4. Halon systems for which contracts exist and where substantial pre-installation development costs have been incurred should be completed. Where local consensus cannot be reached on this issue such systems should not be completed.

5. Existing Halon systems should be maintained pending issuance of a final DOE position on CFCs/Halons (reference above draft order).

6. Varlances from the above guidance, will be considered on a case-by case basis in consultation with the appropriate program office, EH and, if necessary to resolve conflicting opinions, the DOE Fire Safety Committee.

Future revisions to DOE Order 6430.1A, General Design Criteria and 5480.7, Fire Protection will incorporate the above. In the meantime, the widest possible distribution of this position should be made.

Questions pertaining to the above position should be directed to Mr. Dennis Kubicki, Ey-322, on (FTS) 233-4794.

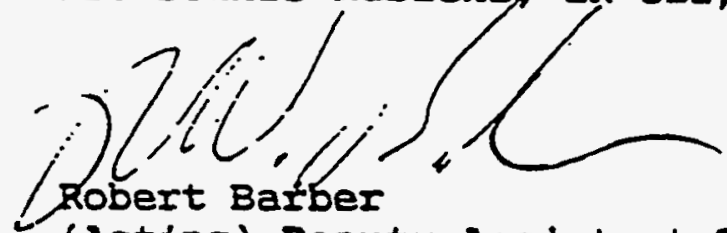

(Acting) Deputy Assistant Secretary Safety \& Quality Assurance

ce:

P. Ziemer, EH-I

W. Young, NE-I

J. Tuck, DP-1

J. Decker, ER-1

S. Blush, NS-I

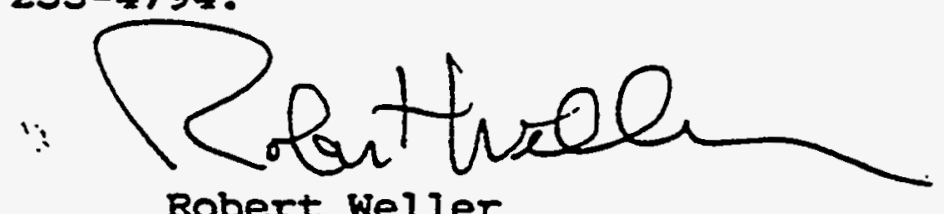

Robert Weller

(Acting) Director

Office of Projects 8

Facilities Management 


\section{nemorandum}

date: MAY j 1993

AEPLY TO

ATTN OF: $E H-31.3$

SUBJeCT: Managed Phase Out of Halon Fixed Fire Suppression Systems

TO: Distribution

The purpose of this memorandum is to provide additional interim departmental criteria on the management of the reduction and potential elimination of Halon fire extinguishing systems within the Department of Energy (DOE). This memorandum supplements the joint Office of Safety and Quality Assurance/Office of Projects and Facilities Management memorandum of September 27, 1990, in which guidance was provided on the installation of new Halon 1301 fixed fire suppression systems and Halon 1211 portable fire extinguishers.

Concerns over environmental deterioration caused by the proififeration of chlorofluorocarbons (CFCS) and Haion compounds in the atmosphere have prompted an international effort to reduce or eliminate the use of these substances. A degree of consensus has been reached as evidenced by the adoption of the Montreal Protocol and subsequent amendments. Further, these Parties agreed to adjust the protocol to fully phase out use of CFCs and Halons. Reflecting the Department's responsibilities to protect workers and maintain facility safety while protecting the environment, the following policy was established for dealing with the continued use of Halon 1211 and 1301 for fire suppression.

The underlying position for this policy is that DOE should be aggressively pursuing alternate fire protection configurations in 7 ieu of Halon fire protection systems where currently installed.

Accordingly, all DOE Field Elements should:

- Within 1 year after the date of issuance of this memorandum, anaiyze and decide which existing Halon systems can safely be deactivated. This decision should be based on an analysis which realistically reflects the risks of fire in relation to existing levels of fire protection, excluding the Halon system. (A sprinkler system will provide an equivalent level of safety. A fire detection/alarm and signalling system, coupled with a capable emergency response force may provide an acceptable level of fire safety.) When such a decision is reached, the system should be deactivated as soon as practical to minimize the risk of inadvertent discharge.

- Within I year after the date of issuance of this memorandum, analyze and decide which existing Halon systems can be converted from automatic to manual activation. This course of action 
is suggested for those situations where the Haion system has already been defined as "Essential" and where timely human intervention-to activate the system in the event of a fire will be assured. A preliminary step has been taken in this direction in conjunction with efforts to respond to the JuTy 13, 1992, "Essential Use" survey that was requested by the Office of Environment, Safety and Health. As above, when this decision is reached, an expeditious schedule for conversion should be implemented.

Where timely response to fire emergencies cannot be assured and where conversion to manual activation cannot be justified for safety reasons, appropriate measures should be implemented to minimize the potential for false discharge of the Haion systems. This should include expeditious remedial action on maintenance work orders for these systems. This could also include the modification of the existing system to feature "cross-zone" detector discharge, delayed discharge, abort switches, and other technical means. Facility specific training of operating personnel on Halon system operating characteristics would also be prudent.

- - Prioritize existing Halon systems in order of importance to safety so that if one discharges and there is no more Haion availabie to replenish it, the capability exists to deactivate other system(s) that are of lesser priority.

Store excess quantities of Halon on site in their original containers. Provisions for a central DOE repository and transfer facjility for banked Haion are being developed. (DOE is considering participation in an external Haion banking program.)

Maintain portable extinguishers in place where there is no site policy for their removai. Inspect and maintain the extinguishers periodically as required by industry standaras and return them to service. (The Department is exploring the possibility of extending the hydrostatic test interval:)

- Have a contingency plan in place for interim compensatory measures (such as fire watches) to be implemented if a Halon system is rendered inoperable and cannot be restored within a reasonable period of time.

Expedite planning for projects to replace Halon systems with alternate means of protection.

Be conscious of the fact that situations beyond DOE controi may require that some or all of the existing Halon systems in our inventory be deactivated and portable extinguishers removed sooner than anticipated. 
We request that, in light of the planned termination of production of Halons, the widest possible distribution of this position should be made.

The Office of Safety and Quality Assurance (EH-30) will be the clearinghouse on Halon-related fire protection information.

Questions pertaining to the above position shouid be directed to Mr. Dennis Kubicki on 301-903-4794.
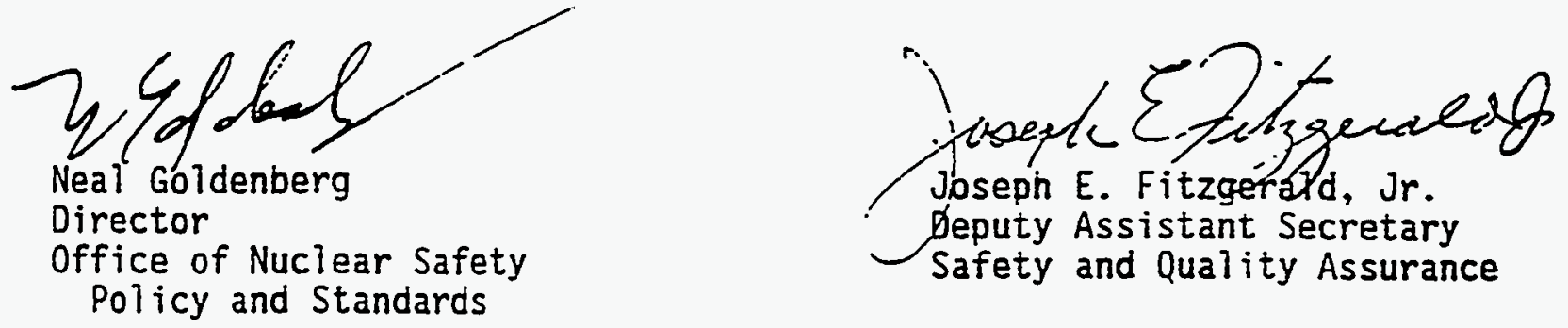

CC:

P. Brush, EH-1

E. C. Brolin, NE-1

L. Sye, $A D-1$ 


\section{U.S. Department of Energy \\ Washington, D.C.}

1. PURPOSE. To establish requirements for a comprehensive fire protection and related perils protection program sufficient to attain Department of Energy (DOE) objectives.

2. CANCELLATION. DOE 5480.7, FIRE PROTECTION, of 11-16-87.

3. SCOPE.

\section{a. Provisions:}

The provisions of this Order apply to all Departmental Elements. It specifically applies to personnel and property at a71 DOE-owned or - Teased structures. This Order has primacy over all other DOE Orders with respect to matters concerning fire protection.

The Naval Nuclear Propulsion.Program, as stipulated below, is exempt from the provisions of this Order.

DOE facilities, projects and programs that are Ticensed by the Nuclear Regulatory Commission (NRC) or an NRC Agreement State shall use the requirements specified by the NRC or NRC Agreement State in lieu of this Order where requirements overlap NRC or NRC Agreement State regulations.

b. Application to Contracts:

The provisions of this Order are to be applied to covered contractors and they will appiy to the extent implemented under a contract or other agreement. A covered contractor (including Management and Operating contracts) is a seller of supplies or services performing on-site at a DOE-owned or -leased facility and awarded a procurement contract or a subcontract. The term "procurement contract" does not include small purchases.

4. OBJECTIVES. The objectives of this Order are as follows:

a. Minimize the potential for the occurrence of a fire.

b. Ensure that fire does not cause an on-site or off-site release of radiological and other hazardous material that will threaten the public health and safety or the environment. 
c. Establish requirements that will provide an acceptable degree of 1 ife safety to DOE and contractor personnel and that there are no undue hazards to the public from fire and its effects in DOE facilities.

d. Ensure that process control and safety systems are not damaged by fire or related perils.

e. Ensure that vital DOE programs will not suffer unacceptable delays as a result of fire and its effects.

f. Ensure that property damage from fire and related perils does not exceed an acceptable level.

5. MANDATORY FIRE PROTECTION CRITERIA. Fire protection criteria, delineated in. the following codes, standards and other documents are the minimum requirements for the implementation of the DOE Fire Protection Program. These criteria are mandatory as a result of statutory requirements or DOE policy requirements. Where conflicts in the application of these codes and standards arise; the more restrictive requirements apply.

a. Code of Federal Regulations (CFR) 29, Part 1910

b. CFR 29, Part 1926

c. National Fire Protection Association (NFPA) Codes and Standards

d. DOE 5480.4, ENVIRONMENTAL PROTECTION, SAFETY, AND HEALTH PROTECTION STANDARDS, of 5-15-84, which specifies requirements for the application of environmental protection, safety, and health standards.

e. DOE 6430.1A, GENERAL DESIGN CRITERIA, of 4-6-89, which provides general design criteria for use in the acquisition of the Department's facilities:

f. DOE/EP-0108, "Standard for Fire Protection of AEC Electronic Computer Data Processing Systems".

g. DOE/EV-0043, 8-79, "Standard on Fire Protection for Portable Structures".

h. Other DOE Orders and statutory requirements, not listed above, that contain requirements of a more limited extent relating to the DOE Fire Protection Program. 
NOTE:

APPLICATION OF CODES AND STANDARDS. The fire protection related codes and standards in effect when facility design commences (code of record) remain in effect for the life of the facility. When modifications of a substantial nature occur, as determined by the authority having jurisdiction (AHJ), the current edition of the code shall apply to the modification. EXCEPTION: If there is a significant hazard that endangers building occupants or the public, as determined by the AHJ, the facility shall be upgraded to the requirements of the current edition of the code or standard.

6. DOE REFERENCED CRITERIA. The following references contain additional criteria and guidelines pertaining to the DOE Fire Protection Program:

a. DOE Fire Protection Resource Manual.

b. "General Fire Fighting Guidance for Nuclear Weapons," (this document is Confidential Restricted Data) (TP20-11) (DOE).

c. DOE 5482.1B, ENVIRONMENT, SAFETY, AND HEALTH APPRAISAL PROGRAM, of 9-23-86, which establishes the environmental protection, safety, and health protection appraisal program.

d. DOE 5484.1, ENVIRONMENTAL PROTECTION, SAFETY, AND HEALTH PROTECTION INFORMATION REPORTING REQUIREMENTS, of 2-24-81, which establishes procedures for the reporting of information having environmental protection, safety, or health protection significance.

e. DOE 5500.1B, EMERGENCY MANAGEMENT SYSTEM, of 4-30-91, which establishes procedures for planning for emergencies involving DOE or requiring $D O E$ assistance.

f. National Fire Protection Association Handbooks.

g. Factory Mutual Loss Prevention Data Sheets.

h. Society of Fire Protection Engineers (SFPE) Handbook.

i. DOE Explosives Safety Manual, DOE/EV/06194.

j. Local and State fire protection criteria.

k. American Petroleum Institute Guidelines.

1. NFPA guides, manuals and recommended practices.

m. "Product Directories of Underwriters Laboratories, " together with the periodic supplements (UL).

n. "Factory Mutual Research Corporation Approval Guide" (FM). 
7. DEFINITIONS.

a. Acceptable. When applied to fire safety, "acceptabie" is a level of protection which the Authority Having Jurisdiction, after consultation with the cognizant DOE fire protection engineer(s), considers sufficient to achieve the objectives defined above. In some instances, it is a level of protection necessary to meet a code or standard. In other instances it is a level of protection that deviates (plus or minus) from a code or standard as necessary and yet adequately protects against the inherent fire hazards.

b. Authority Having Jurisdiction (AHJ). The decision making authority in matters concerning fire protection. Except as directed by the Program Secretarial officers, the Heads of Field Organizations or designee is the AHJ. Decisions impacting fire safety shall be made by the AHJ only after consultation with the cognizant DOE fire protection engineer(s). Where an Area Office or Site Office exists within the DOE organization, a formal, clearly defined delegation of fire protection responsibility shall be established regarding the AHJ.

c. DOE Fire Protection Program. Those fire protection requirements, hardware, administrative controls, procedures, guidelines, plans, personnel, analyses, and technical criteria that comprehensively ensure that DOE objectives relating to fire safety are achieved.

d. Equivalency. The approved alternate means of satisfying the technical provisions of a fire protection code or standard. (Deviations from specific requirements of occupational safety and health standards, as delineated in the Code of Federal Regulations, are treated as variances as defined in the Department's Occupational Safety and Health Program).

e. Exemption. The approved deviation from a non-statutory code, standard or DOE Order. (Deviations from specific requirements of occupational safety and health standards, as delineated in the Code of Federal Regulations, are treated as variances as defined in the Department's Occupational Safety and Health Program).

f. Fire Area. A location bounded by construction having a minimum fire resistance rating of 2 hours with openings protected by appropriately fire-rated doors, dampers, or penetration seals. The boundaries of exterior fire areas (yard areas) shall be as determined by the authority having jurisdiction.

g. Fire LosS. The dollar cost of restoring damaged property to its pre-fire condition (refer to DOE 5484.1). In determining loss, the estimated damage to the facility and contents shall include replacement cost, less salvage value. Losses will exclude costs of restoration of:

(1) Property that is scheduled for demolition.

(2) Property:

(a) decommissioned and not carried on books as a value, or 
(b) where there is no loss potential.

Inciude the cost of decontamination and cleanup, the loss of production or program continuity, the indirect costs of fire extinguishment (such as damaged fire department equipment), and consequent effects on related areas, in all property loss amounts.

h. Fire Protection. A broad term which encompasses all aspects of fire safety, including: building construction and fixed building fire features, fire suppression and detection systems, fire water systems, emergency process safety control systems, emergency fire fighting organizations (fire departments, fire brigades, etc.), fire protection engineering, and fire prevention. Fire protection is concerned with preventing or minimizing the direct and indirect consequences of fire. It also includes aspects of the following perils as they relate to fire protection: explosion, natural phenomenon, smoke and water damage from fire.

i. Fire Protection System. Any system designed to detect, extinguish, and 1 imit the extent of fire damage or enhance life safety. Where redundant fire protection systems are required, any two of the following will satisfy that requirement. These include:

(1) Automatic suppression systems, such as fire sprinklers, foam, gaseous, explosion suppression, or other specialized extinguishing systems plus appropriate alarms. An adequate supply, storage and distribution system is an essential element.

(2) Automatic fire detection, occupant warning, manual fire alarm, and fire alarm reporting systems combined with properiy equipped and adequately trained fire departments or brigades.

(3) Fire barrier systems or combinations of physical separation and barriers for outdoor locations.

(4) Other systems,. such as alternate process controi systems, as approved by the AHJ.

j. Maximum Credible Fire Loss (MCFL). The property damage that would be expected from a fire, assuming that:

(1) All installed fire protection systems function as designed.

(2) The effect of emergency response is omitted except for post-fire actions such as salvage work, shutting down water systems, and restoring operation.

k. Maximum Possible Fire Loss (MPFL). The value of property, excluding land, within a fire area, unless a fire hazards analysis demonstrates a lesser (or greater) loss potential. This assumes the failure of both automatic fire suppression systems and manual fire fighting efforts. 
1. Property. All government-owned or leased structures and contents for which the Department has responsibility, including:

(1) All DOE land, structures, and contents.

(2) AlT leased locations.

(3) AT1 other Government property on DOE land or in DOE structures.

(4) Other property that occupy DOE land or are in DOE structures.

m. Qualified Fire Protection Engineer. A graduate of an accredited engineering curriculum and having completed not less than four years of engineering practice, three of which shall have been in responsible charge of diverse fire protection engineering work. If not such a graduate, a qualified engineer shall, either: demonstrate a knowledge of the principles of engineering and have completed not less than six years engineering practice, three of which shall have been in responsible charge of diverse fire protection engineering projects; be a registered professional engineer in fire protection; or meet the requirements for a Grade 11 or higher Fire Protection Engineer as defined by the Office of Personnel Management.

n. Related Perils. Aspects of the following as they relate to fire protection: explosion, natural phenomenon, smoke, and water damage.

0. Risk. A term used to describe the overall potential for loss (refer to DOE

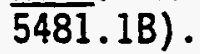

p. Safety Class Equipment. Systems, structures, or components including primary environmental monitors and portions of process systems, whose failure could adversely affect the environment, or the safety and health of the pubiic.

For nuclear reactors and non-reactor nuclear facilities, Class A Equipment includes those systems, structures, or components with the following characteristics:

- Those whose failure would produce exposure consequences that would exceed DOE established guidelines at the site boundary or nearest point of uncontroiled public access.

- Those required to maintain operating parameters within the safety limits specified in Technical Safety Requirements (Technical Specification or Operational Safety Requirements) during normal operations and anticipated operational occurrences.

- Those required for nuclear criticality safety. 
- Those required to monitor the release of radioactive materials to the environment during and after a design basis accident.

- Those required to monitior and maintain the facility in a safe shutdown condition.

- Those that control the safety class items described above.

q. Vital Program. A DOE program so defined by the Program Secretarial Officers.

\section{RESPONSIBILITIES AND AUTHORITIES.}

a. Program Secretarial officers.

For matters affecting facilities under their programatic responsibility, PSOs shall:

(1) Direct DOE fire protection programs for personnel and property under their responsibility.

(2) Evaluate and assess in accordance with this order, the adequacy of contractor fire protection programs so as to assure that the criteria in paragraph $8 \mathrm{~h}$ are met and the elements delineated in paragraph 9 are incorporated.

(3) Review and define each vital program and provide current information to the head of the field organization describing the maximum acceptable impact on the program if a property within the field organization is lost due to a fire. This shall include the maximum acceptable down time if less than 6 months and.fire loss if less than $\$ 150 M$.

(4) Establish and maintain a system to assure that the DOE fire protection program is documented and incorporated in the plans and specifications for alt new facilities and for major modifications of existing facilities. This includes oversight by a qualified fire protection engineer of plans, specifications, and testing of fire protection features.

(5) Review field organization requests for exemptions. Obtain EH-1 approval for proposed actions on exemption requests. (Coordinates with NS-1 when nuclear fire safety issues are involved.)

(6) Maintain or has access to an adequate fire protection staff, including one or more qualified fire protection engineers, to accomplish the above responsibilities. Continuing education and training should be provided to maintain and enhance the level of competency of the fire protection staff. 
b. The Assistant Secretary for Environment, Safety and Health (EH-I).

(1) Develops fire protection requirements and guidelines for programs and facilities. Coordinates the development of fire protection criteria with the Office of Organization, Resources and Facilities Management (AD-10), the Director of Nuclear Safety Policy and Standards (NE-70), PSOs, and other appropriate Headquarters organizations to assure the consistency of such criteria with the requirements of applicable fire protection codes and, DOE 5480.4, and this order.

(2) Evaluates and assesses, in accordance with this Order and DOE 5482.1B, the adequacy of DOE fire protection programs.

(3) Disseminates fire protection related technical information through the Annual Summary of DOE Fire Protection Programs and updates of the Fire Protection Resource Manual.

(4) Issues guidance and interpretations of the DOE fire protection program in coordination with $\mathrm{NE}-70$.

(5) Approves fire protection exemption requests. Action on exemption requests shall be completed within 60 days of receipt of the request. Approval of the Office of the Secretary (S-1) shall be solicited for any generic fire protection exemption request that has DOE-wide nuclear safety implications.

(6) Coordinates activities of the DOE Fire Safety Committee

(7) Maintains or has access to an adequate fire protection staff to accomplish the above responsibilities, including one or more qualified fire protection engineers. Continuing education and training should be provided to maintain and enhance the level of competency of the fire protection staff.

c. The Director of Nuclear Safety (NS-1).

(1) Evaluates and assesses, in accordance with this Order the adequacy of DOE Fire Protection Programs relative to nuclear safety.

(2) Concurs with fire protection exemptions that relate to nuclear fire safety. Action on exemption requests shall be completed within 60 days of receipt of the request.

(3) Maintains or has access to an adequate fire protection staff, including a qualified fire protection engineer, to accomplish the above responsibilities. Continuing education and training should be provided to maintain and enhance the level of competency of the fire protection staff. 
d. The Assistant Secretary for Nuclear Energy (NE-1).

(1) Reviews and concurs with fire protection policy and guidance developed by EH-1 that relate to nuclear safety. Provides interpretation and guidance concerning the fire protection criteria for nuclear facilities.

(2) Maintains or has access to an adequate fire protection staff, including a qualified fire protection engineer, to accomplish the above responsibilities. Continuing education and training should be provided to maintain and enhance the level of competency of the fire protection staff.

e. The Director of the Naval Nuclear Propul sion Program (NE-60).

Presidential Executive Order 12344, statutorily prescribed by Public Law 98-525, 42 U.S.C. 57158 note (1984), establishes the responsibilities and authorities of the Director, Naval Nuclear Propulsion Program (who is also the Deputy Assistant Secretary for Naval Reactors within the Department) over all facilities and activities which comprise the program, a joint Navy-DOE organization. These executive and Tegislative actions establish that the Director is responsible for all matters pertaining to naval nuclear propulsion for all program facilities and activities. Accordingly, the provisions of this order do not apply to the Naval Nuclear Propulsion Program.

f. The Director of Administration and Management (AD-1).

(1) Ensures that the requirements of this Order are included within DOE 6430.1A, GENERAL DESIGN CRITERIA.

(2) Evaluates and assesses the adequacy of fire protection for DOE Records Management Programs.

g. Heads of Field Organizations.

As directed by the PSO, the Heads of Field Organizations shall:

(1) Ensure a level of fire protection adequate to meet the objectives of this order for personnel and property within their responsibility. Where an area office exists within the organization, a clear, formal delegation of fire protection responsibilities shall be established.

(2) Establish and maintain a system to assure that the DOE fire protection program is documented and incorporated in the plans and specifications for a11 new facilities. and for major modifications of existing facilities. This includes oversight by a qualified fire protection engineer of plans, specifications, and testing of fire protection features. 
(3) Review implementation plans for compliance with recommendations resulting from fire protection assessments. Forwards a copy of compliance plans, exemption requests, equivalency determinations, compliance schedule approvals, and other requested data to the PSO.

(4) Approve contractor requests for fire safety equivalencies.

(5) Maintain a list of facilities/contractors for which they have fire protection appraisal responsibility in accordance with this order, indicating the assessment frequency for each.

(6) Conduct fire protection assessments of facilities and/or contractors according to the frequency and scope established by this order to assure that:

(a) The program described in paragraph 9 is being implemented.

(b) Effective action is being taken to correct deficiencies identified from previous appraisals, including prioritization, tracking, and implementation of interim compensatory measures.

(c) Losses, impairments, and unusual fire-related incidents have been investigated and analyzed to identify causes, corrective action(s), and preventive methods.

(7) Submit an annual summary to Office of Safety and Quality Assurance (EH-30) through the PSO covering the fire protection program and loss experience of the previous year, as required by DOE 5484.1 .

(8) Forward requests for fire protection exemptions prepared by the contractor to the PSO. Submit a recommendation for approval for these conditions to the PSO for those issues where, in the judgment of the Head of the Field Organization, compliance with specific program elements is not attainable and where an acceptable level of safety has been provided. The cognizant Headquarters fire protection engineer should be consulted on these issues as appropriate.

(9) Maintain or have access to an adequate fire protection staff, including one or more qualified fire protection engineers, to accomplish the above objectives. Continuing education and training should be provided to maintain and enhance the level of competency of the fire protection staff.

(10) Establish and maintain a method to disseminate fire protection information from Headquarters to the contractors and vice versa. 
(11) Where there is no PSO, the Head of the Field Organization shall assume the responsibilities as delineated in paragraph $8 \mathrm{a}$. Where there is no contractor, the Head of the Field Organization shall assume the responsibilities as delineated in paragraph $8 \mathrm{~h}$.

h. Heads of Headquarters Elements and Heads of Field Organizations.

The senior ranking DOE official at a DOE office location shall include the following in a procurement request package for each procurement requiring the application of this directive: (1) identification of the Directive, (2) identification of the specific requirements with which a contractor or other awardee is to comply, or, if this is not

practicable, identification of the specific paragraphs or other portions of this Directive with which a contractor or other awardee is to comply, and (3) requirements for the flowdown of provisions of this directive to any subcontract or subaward. For application to awarded management and operating contracts, Heads of Headquarters Elements and heads of field organizations may set forth this information in a written communication to the contracting officer rather than in a procurement request package.

i. Contractor Organizations.

As required by the PSO or the Heads of Field Organizations and directed by the Contracting officer, contractors shall be required to:

(1) Provide and maintain a level of fire protection to meet the objectives of paragraph 4 , and the criteria of paragraph 9.

(2) Provide and maintain a system to ensure that the requirements of the DOE fire protection program are documented and incorporated in the plans and specifications for all new facilities and.for major modifications of existing facilities. This includes review and comment by a qualified fire protection engineer of plans, specifications and test procedures and results for fire protection features.

(3) Assist DOE in coordinating fire safety assessments at those facilities included in the survey program, establish action plans for compliance with recommendations resuiting from the assessments, and forward compliance plans, exemption requests, and other requested data to DOE fieTd organizations.

(4) Establish and maintain a list of facilities for which the contractor has fire protection assessment responsibility.

(5) Conduct fire protection assessments of facilities according to the scope and frequency established by this order.

(6) Provide fire protection technical assistance to DOE. 
(7) Submit requests for exemptions and fire safety equivalencies to the Head of the Field Organization for those facilities where compliance with specific program elements is not attainable and where an acceptable level of safety has been achieved.

(8) Maintain or have access to an adequate fire protection staff, including a qualified fire protection engineer(s). Continuing education and training should be provided to maintain and enhance the level of competency of the fire protection staff.

\section{DOE FIRE PROTECTION PROGRAM REQUIREMENTS.}

A DOE facility shall be characterized by a level of fire protection sufficient to fulfill the requirements for the best protected class of industrial risks (Highly Protected Risk/Improved Risk). This program is characterized by the inclusion of a continuing, sincere interest on the part of management and employees in minimizing losses from fire and related perils and the inclusion of preventive features necessary to ensure the satisfaction of objectives related to safety.

Based upon the above paragraph, the DOE Fire Protection Program shall meet or exceed the minimum requirements established by the National Fire Protection Association as directed by the PSO. Basic requirements shall include: a reliable water supply of acceptable capacity for fire suppression; noncombustible construction of an acceptable nature for the occupancy of the facility; automatic fire extinguishing systems; a fully staffed, trained, and equipped emergency response force; a means to summon the emergency response force in the event of a fire; and a means to notify and evacuate building occupants in the event of a fire. For areas subject to significant life safety risks, serious property damage, program interruption, or loss of safety class equipment as defined in the relevant facility SAR, additional protection measures may be deemed necessary as determined by the AHJ.

This level of protection also includes: administrative procedures encompassing controls for hazardous substances/processes; inspection, maintenance, and testing of fire protection features; and other programmatic fire safety activities as defined below.

\section{a. Programmatic Elements.}

Fire protection programs shall incorporate the following elements to assure that the objectives of paragraph 4 are met:

(1) Fire Protection Criteria. A documented "Fire Protection Program" which includes:

(a) A statement of management commitment to achieve the above stated objectives.

(b) A policy statement that implements this Order and other DOE fire protection reiated mandatory codes and standards. 
(c) Fire protection criteria that reflect site-specific aspects of the fire protection program, including: the organization and responsibilities of the fire protection staff, administrative aspects of the fire protection program, and requirements for physical fire protection features.

(2) Assessments. Documented evaluations of the fire protection program, including field walkdowns of facilities, shall be performed as follows:

(a) Facilities/contractors shall be assessed to establish that they conform with DOE fire protection criteria.

(b) Minimum Frequency

Headquarters:

o PSO assessment of field offices................ 3 years

o $\mathrm{EH}$ assessment of program offices............... 3 years

Field Office:

- Field office assessment of the fire protection program of each contractor.............. 2 years

Contractors/Facility Managers:

- Annual fire protection assessments shall be made of facilities valued in excess of $\$ 50$ million; where considered to be a moderate (Category 2 Hazard) or high hazard (Category 1 Hazard) as defined in DOE 5481.1B, SAFETY ANALYSIS AND REVIEW SYSTEM, for nonnuclear facilities and in DOE 5480.23, NUCLEAR SAFETY ANALYSIS REPORTS, for nuclear facilities; or in which vital programs are involved.

- Fire protection assessments shall be made at least every two years of facilities plus equipment valued at $\$ 10$ million to $\$ 50$ million.

- Remaining facilities shall be assessed at least every three years or at frequencies determined by the $\mathrm{AHJ}$.

- Comprehensive assessments of fire protection program elements shall be made every two years.

- Copies of the two most recent assessment reports shall be kept on file. 
(c) Nature and Scope. Assessments shall include an evaluation of the following elements of the fire protection program:

Program-related:

- Comprehensiveness of the fire protection program.

o Procedures for engineering design and review.

- Procedures for maintenance, testing, and inspection.

- Fire protection engineering staff (number, qualifications, training).

- Fire suppression organization (personnel and training).

- Fire suppression mutual aid agreements.

- Management support.

- Exemptions and documented equivalencies.

Facility-related:

- Fire protection of safety class equipment.

- Life safety considerations.

- Fire protection of vital programs.

- Fire protection of high value property.

- Fire suppression equipment.

o Water runoff.

- Pre-fire plans.

- Fire apparatus accessibility.

- Completeness of fire hazards analyses.

- Fire barrier integrity.

- Completeness of fire loss potential (MPFL/MCFL) determinations.

- Fire safety training.

Combined Aspects (Program \& Faci7ity):

- Inspection, testing, and maintenance reports.

- Adequacy of facility appraisal reports.

- Tests of fire suppression systems, water supplies, and procedures for maintaining these in working order.

- Administrative controls.

- Temporary protection and compensatory measures.

- Status of findings from previous assessments.

o Conformance with applicable Orders, codes and standards. 
(3) Fire Hazards Analyses. The purpose of a fire hazards analysis (FHA) is to comprehensively assess the risk from fire within individual fire areas in a DOE facility in relation to existing or proposed fire protection so as to ascertain whether the objectives of paragraph 4, are met. A graded FHA, that reflects the risks from fire in a facility, shall be performed for new facilities as directed by DOE 6430.1A, for nuclear facilities where safety analyses are required by DOE 5480.23, and as directed by the PSO. A Safety Analysis Report (SAR) that addresses the following elements will satisfy the requirement for an FHA. A graded FHA shall contain, but not be limited to, the following elements:

(a) Description of construction.

(b) Protection of essential safety class equipment.

(c) Fire protection features.

(d) Description of fire hazards.

(e) Life safety considerations.

(f) Critical process equipment.

(g) High value property.

(h) Damage potential: Maximum Credibie Fire Loss (MCFL) and Maximum Possible Fire Loss (MPFL).

(i) Fire Department/Brigade response.

(j) Recovery potentia1.

(1) Potential for a toxic, biological and/or radiation incident due to a fire.

(m) Emergency planning.

(n) Security considerations related to fire protection.

(o) Natural hazards (earthquake, flood, wind) impact on fire safety.

(p) Exposure fire potential, including the potential for fire spread between fire areas.

An FHA shall be performed under the direction of a qualified fire protection engineer.

b. Physical Features of the Program.

DOE facilities shall incorporate the following elements to assure that the objectives of paragraph 4, are met:

(1) Safety Class Equipment. In areas where a fire could cause damage to safety class equipment and where no redundant safety capability exists, a redundant fire protection system shall be provided for the safety class equipment. For new facilities, redundant Safety Class Equipment shall located be in separate fire areas. Fire suppression systems shall be designed such that their actuation will not damage safety class equipment or cause a criticality incident. 
(2) Life Safety. Life safety provisions shall be provided for all facilities in accordance with the Life Safety Code (LSC), NFPA Standard 101. The methods out ined in NFPA 101M may be used to obtain an equivalent level of life safety where strict compliance is not possible. Exit requirements for toxic and explosive environments shall be as determined by the AHJ. In addition, for explosives environments, exits shall reflect the criteria contained in the DOE Explosives Safety Manual, (DOE/EV 06194). Where noncompliance with some Life Safety Code provisions may be required for public safety, as in some containment structures, additional protective systems and personnel limits should be maintained. Compliance with the Life Safety Code shall be considered to satisfy the exit requirements of the applicable building code and OSHA 29 CFR 1910.

(3) Automatic Fire Protection. Complete automatic fire suppression systems designed in accordance with applicable NFPA standards shall be provided as follows:

- (a) In all new structures over 5,000 square feet.

(b) In all structures having an MPFL in excess of $\$ 1,000,000$. or where the maximum credible fire will result in the loss of use of a vital structures for a period longer than that specified as acceptable bj the applicable PSO.

(4) Redundant Fire Protection.

(a) When the MPFL exceeds $\$ 50$ million, a redundant fire protection system is provided that, despite the failure of the primary fire protection system, will limit the loss to $\$ 50$ million.

(b) When the MPFL exceeds $\$ 150$ million, a redundant fire protection system and a 3 -hour fire barrier are required to limit the maximum possible fire loss to $\$ 150$ million.

(5) Testing and Maintenance. Fire protection systems shall be tested and maintained in accordance with the applicable NFPA standards and as supplemented by criteria in the DOE Fire Protection Resource Manual.

(6) Quality Construction. New permanent structures in excess of 5,000 square feet of area shall be of noncombustible or fire resistive construction. 
(7) Fire Department. A fully staffed, trained, and equipped fire department/brigade shall service all DOE facilities, except as determined by the PSO. (Refer to the fire protection positions on minimal staffing levels in the DOE Fire Protection Resource Manual.) DOE or Contractor-operated organizations with the responsibility for providing fire protection for DOE property may enter into mutual aid agreements with other fire departments in accordance with Public Law 46 (Title 42 USC Section 1856).

(8) Fire Protection Hater Supply An automatic water supply for fire protection having a minimum two hours stored water capacity shall be maintained. Municipal supplies having the same capability are acceptable. Facilities having a MPFL in excess of $\$ 50$ million shall be provided with an additional, independent source of fire protection water.

A water supply dedicated for fire protection may be necessary as determined by the PSO. A dedicated system shall be able to meet hose stream and sprinkler system demands,

A combined fire and process/domestic system shall be able to deliver the fire demand plus the maximum daily domestic demand for the required duration.

(9) Underground Piping. Mains shall be sized for the largest fire flows anticipated but in no case shall be less than 8 -inch diameter. Supply piping to individual fire sprinkler systems shall be at least as large as the fire sprinkier system riser.

(10) Liquid Run-off Control. Natural or artificial means of controlling liquid run offs from a maximum credible fire shall be provided so that contaminated or polluting liquids will not escape the site, including potentially contaminated water resulting from fire fighting operations. The amount of fire water that must be controlled and the design of the containment system shall be determined based on consultations with the cognizant DOE fire protection engineer.

(11) Fire Alarm Systems. Where fire suppression or fire alarm systems are provided, local alarms in the protected area and alarm transmission to an acceptable remote attended location shall be provided.

(12) Containment Systems for Ventilation. Facilities which require ventilation containment systems shall be protected from the effects from fire to preclude release of radioactive, toxic, or other hazardous materials. 
(13) Special Hazard Protection. Hazards unique to DOE and not addressed by the mandatory codes and standards listed in Paragraph 5 shall be protected by isolation, segregation or use of special fire control systems (inert gas, explosion suppression, etc.) as determined by the AHJ. In addition devices for limiting or controlling the effects of a fire (relief valves, filters, blast walls, emergency shutdown systems, scuppers, etc.) shalt be provided.

(14) Halon Usage. Future use of Halon will be governed under the conditions set forth in the DOE memorandum "Interim Position on the Installation of New Halon 1301 Fixed Fire Suppression Systems and Halon 1211 Portable Fire Extinguishers," dated September 27, 1990, and superseding documents.

(15) Seismic Criteria. The design of fire protection systems to withstand seismic events shall be in accordance with the criteria developed by the National Fire Protection Association, except as required by other DOE criteria.

(16) Impairment Control. A fire protection system impairment program shall be provided for control of operations and tracking of impairments during periods when fire protection systems are out of service.

(17) Higher Standard of Protection. A higher standard of protection, which includes fire protection features beyond those stipulated above, may be warranted under certain circumstances. These features shall be determined by the PSO. The following factors shall be considered:
(a) importance
(b) effect on production
(c) costs versus benefits
(d) future conditions

c. Administrative Features of the Program.

(1) Fire Prevention Procedures. Facilities shall have procedures governing the use and storage of combustible, flammable, radioactive and hazardous materials so as to minimize the risk from fire. Such procedures shail also exist for activities, such as smoking limitations, isolation of hot work, and other fire prevention measures, which contribute to the decrease in fire risk. 
(2) Assessment Resuits Tracking Program. There sha11 be a program to identify, prioritize and monitor the status of fire protection related assessment findings/recommendations unti] resolution is achieved. Resolution could be achieved by either: plant modification, procedure change, fire safety equivalency, or exemption.

(3) Interim Compensatory Measures. When final resolution of a finding/recommendation will be significantly delayed because of funding, scheduling, or other considerations, appropriate interim compensatory measures (e.g., fire watches, fire patrols, enhanced hazards control procedures, temporary fire protection features) shall be implemented to minimize the fire risk.

(4) Operability Specifications. Minimum requirements to establish "operability" shall be developed for fire protection features such as: fire doors, fire dampers, fire detection and suppression systems, fire protection water supplies, etc. Periodic tests, conducted to satisfy the applicable NFPA codes and standards or other DOE criteria shall confirm that these features are operabie. If fire protection will be inoperable for a significant period of time, interim compensatory measures shall be implemented until operability is restored.

(5) Emergency $\mathrm{P}$ lanning. Information from the fire protection program shall be incorporated in the Emergency Plan. The facility fire protection organization shall be involved in the development of the Emergency $\mathrm{Plan}$ and in all related training and drills.

(6) Training. Training shall be provided for the individuals within the fire protection organization, the fire department/brigade, and any other person with responsibilities for fire safety. Training programs shall reflect the criteria contained in the mandatory codes and standards listed in paragraph 5 , and sha 11 reflect site-specific considerations.

(7) Communications. Emergency communications shall be outlined in the emergency plan. The communications capability among potential responders to an emergency shall be coordinated to avoid confusion and interference. This capability shall be tested on a frequency established by the authority having jurisdiction in accordance with DOE criteria.

BY ORDER OF THE SECRETARY OF ENERGY: 
. 
1. OB.JECTIUE. The objective of this Order is to establish facility safety requireaents related to: nuclear safety design; criticality safety, fire protection and natural phenomena hazards aitigation.

2. CAKCELLATIOH. The Orders 1isted below are canceled. Cancellation of an Order does not, by itself, modify or. otherwise affect any contractual obligation to comply with such an Order. Canceled Orders which are incorporated by. reference in a contract shall remin in effect until the contract is nodified to delete the reference. to the requirements. In the canceled Orders.

2. DOE 5480.28, NATURAL PHENOHERA hazARDS MITIGATIOH

b. DOE 5480.7A, FIRE PROTECTIOA

c. DOE 6430.1A, GENERAL DESIGN CRITERIA (NUCLEAR AND EXPLOSIVES SAFETY

REQUIREMENTS)

d. DOE 5480.24, CRITICALITY SAFETY :

3. APPLICABILITY.

a. DOE Elements. Except for the exclusions in paragraph $3 c$, this Order applies to DOE Elements with responsibility for DOE-owned or leased facilities as follows (see Attachment 1, Table 1, "Facility and Activity App 7 icability"):

(1) 4.2, 4.4 All DOE nuclear and non-nuclear facilities.

(2) 4.1, 4.3 All DOE non-reactor nuciear facilities which are classified as Hazard Categories 1, 2, or 3; and explosives facilities.

b. Contractors. Except for the exclusions in paragraph $3 c$, the Contractor Requirements Document (CRD), Attachment 2, sets forth requirements that are to be applied to the universe of contractors awarded contracts for management and operating contracts. Contractor compliance. with the CRD wil7 be required to the extent set forth in a contract. Contractors shail be directed to continue to comply with the requirenents of orders canceled by this Order until their contracts are modified to delete the reference to the requirements of the canceled.Orders.

Vertical line denotes change.

DISTRIBUTION:

All Departmental Elements
INITIATED BY:

Office of Environment, Safety and Health 
c. Exclusions.

(1) Activities that are regulated through a license by the: Nuclear Reguitatory Comission (NRC) or a State under an. Agreenent with the HRC, including activities certified by the NRC under section 1701 of the Atomic Energy Act;

(2) Activities conducted under the authority of the Director, Naval Nuclear Propilision Progran, as described-in Public Law 98-525;

(3) Activities conducted under the fuclear Explosives and: Weapons Safety Progran relating to the prevention of accidental or unauthorized nuclear detonations to the extent a requirement under this part cannot be. implemented for a particular facility in a manner. that does not compromise the effectiveness of such activities:

(4) Activities that are regulated by the-Department of Transportation or pursuant to 49 CFR 173.7(b):

(5) Accelerator facilities that are covered by D.0E-Order 5480.25 (excluded from $\$ \$ 4.1$ and 4.3 but not from $\$ \$ 4.2$. and 4.4. );

(6) Fusion facilities (excluded from $\$ 54.1$ and 4.3 but not from $\$ 84.2$ and 4.4 .1 .

4. REOUIREAENTS: Each section of this Order has specific requirements, and where appropriate schedules for implementing requirements and specific exemptions, : which are.provided in the following corresponding sections of this Order. In complying with the provisions of this Order, determinations regarding the acceptability of design should include comparison with existing safety basis information; if available. All new construction shalt, as a minimum, conform to: the Model Building Codes applicable for the state or region, supplemented with additional safety requirements associated with the hazards in the facility in a graded. manner.

Guidance associated with this order are not mandatory requirenents. The . guidance provided in impiementation guides and standards. referenced therein are acceptable methods to satisfy the requirements of this: order. Aiternative methods that satisfy the requirements of this order. are aiso acceptable. Any implementation method selected must be justified to ensure that an adequate level of safety commensurate with the identified hazards is achieved. 
10-13-95

\subsection{Nuclear and Explosives Safety Design Criteria Nuclear Safety}

The objectives of section 4.1 for nuclear safety are to ensure that Department of Energy (DOE) non-reactor nuclear facilities are designed and constructed so as to assure adequate protection for the public, workers, and the environment from nuclear hazards. . The requirements of this section apply to the activities of design and construction of new Hazard Category 1, 2, and: 3 DOE non-reactor nuclear facilities and to the design and construction of modifications to existing DOE Hazard Category 1, 2, and 3 non-reactor nuclear facilities when the proposed modifications significantiy degrades the approved safety basis for the facility. Modifications to facility design and construction during the design and construction phase shall conform to the requirements for new facilities. Section 4.1 does not apply to the decision process to modify a facility, except to serve as a standard of comparison for safety requirements. Activities associated with facility deactivation at end of Tife are exempt if justified by a safety analysis.

\section{Explosives Safety}

The objective of section 4.1 for explosives safety is to establish mandatory standards for explosives safety in the design and construction of DOE. explosives facilities or modifications thereof. Explosives facilities are. those facilities or locations used for storage or operations with explosives or ammunition. When these facilities are also non-reactor nuclear facilities, the requirements for nuclear safety design also apply.

\subsubsection{Nuclear Safety}

\subsubsection{General Requirements}

Detailed application of these requirements shall be guided by safety anaiyses that estabiish the identification and functions of safety (safety class and safety significant) Structures, Systems, and Components (SSCs). for a facility and establish the significance to safety. of functions. performed by those SSCs. Safety analyses shali consider facility hazards, natural phenomena hazards, and external man-induced hazards. Factors such as proximity to nearby. facilities such as airports, pipelines, and barge traffic peculiar to the site shall be considered. A safety analysis shall be performed at the earliest practical point in conceptual or preliminary design, so that. required: functional attributes of safety SSCs can be specified in the detailed:design. Safety analyses shall be performed in accordance with. Safety Analysis Report. (SAR) guidance for safety analysis, as described in.DOE guidance documents.

\subsubsection{Design Requirements}

Non-reactor nuclear facilities shall be designed with the objective of providing multiple layers of protection to prevent or mitigate the unintended release of radioactive materials to the environment. Defense in depth shall include: siting, minimization of material at risk, the use of conservative 
design margins and quality assurance; the use of successive physical barriers for protection against the release of radioactivity; the provision of multiple means to ensure critical safety functions (those basic safety functions needed to control the processes, maintain them in a safe state, and to confine and mitigate radioactivity associated with the potential for accidents with significant public radiological impact); the use of equipment and administrative controls which restrict deviations from normal operations and provide for. recovery from accidents to achieve a safe condition; means to monitor accident releases required for emergency responses; and the provision of emergency plans for minimizing the effects of an accident.

Facilities shall be sited and designed in such a manner that gives adequate protection for the health and safety of the public and for workers, including those at adjacent facilities, from the effects of potential facility accidents involving the release of radioactive materials.

Facilities shall be designed to facilitate safe deactivation, decomissioning and decontamination at end of ife.

Facilities shall be designed to facilitate inspections, testing, maintenance, repair and replacement of safety SSCs as part of an overall reliability, availability, and maintainability program. The objective is that the facility can be maintained in a safe state, including during these operations, and in keeping with the as low as is reasonably achievable (ALARA) principle for occupational radiation exposure.

Facilities shall be designed to keep occupational radiation exposure within statutory limits and incorporate ALARA principles in design, including design provisions to facilitate decontamination during the operational period.

Facility process systems shail be designed to minimize the production of wastes and minimize the mixing of radioactive and non radioactive wastes.

Safety SSCs. identified in accordance with this section sha11, commensurate with the importance of the safety functions performed, be designed:- (1) so that they can perform their safety functions when called upon to operate; and (2) under a quality assurance program that satisfies I0 CFR 830.120.

\subsubsection{Explosives Safety}

The safety design of all new DOE explosives facilities and:all modifications to existing explosives facilities shall conform to the DOE explosives safety requirements established in the DOE Explosives Safety Manual, DOE M 440:1-1. Facility structural design and construction shall comply with the: requirements of TM5-1300; Structures to Resist the Effects of Accidental Explosions, and DOE/TIC-11268, A Manual for the Prediction of Blast and Fragment Loading of. Structures. B Bast-resistant design for personnel and facility protection shall be based on the TNT equivalency of the maximum quantity of explosives. and propellants permitted. In accordance with TM5-1300, the TNT equivalency shalt be increased by $20 \%$ for design purposes. 
DOE 0420.1 .

10-13-95

\subsubsection{Implementation}

An Implementation Plan describing the process that will. ensure that the requirements of.this section will be invoked during the design and construction sha7l be submitted to the DOE Cognizant Secretarial Officer or his designee in accordance with section 5. Deviations from applicable requirements shall be appropriately documented and justified.

\subsection{Fire Protection}

1. The objectives of section 4.2 are to establish requirements for a comprehensive fire and. related hazards protection program for facilities sufficient to minimize the potential for: (1) the occurrence of a fire or related event; (2) a fire that causes an unacceptable on-site or off-site release of hazardous or radiological material that will threaten the health and safety of employees, the public or the environment; (3) vital DOE programs suffering unacceptable interruptions as a result of fire and related hazards; (4) property losses from a fire and related events exceeding defined limits established by DOE; and (5) critical process controls and safety class systems being damaged as a resuit of a fire and related events:

2. Section 4.2 of this Order has primacy over all other DOE Orders with respect to matters concerning fire protection for facilities (refer to. DOE 440.1 for worker protection requirements). . To the extent that potential conflicts may arise resulting from the implementation of these requirements in relation to other DOE Orders or Directives, the cognizant fire protection Authority Having Jurisdiction (AHJ) within the Office of the Assistant Secretary for Environment, Safety and. Health shall be responsible for resolving the issue in concert with. the other. AHJs.

3. DOE.facilities, sites and activities (including design and construction) shall be characterized by a. level of fire protection that. is sufficient to fulfill the requirements of the best protected class of industrial risks ("Highly Protected Risk" or "Improved Risk") and shall be provided protection to achieve "defense-in-depth." This includes meeting the applicable building code and National Fire Protection Association: Codes. and Standards, or exceeding them (when necessary to meet safety objectives), unless an exemption has been granted. The applicable codes and standards are those in effect when facility design commences ("code of record"). When significant modifications to a facility occur;: the current edition of the code or standard shall apply to the modification.

\subsubsection{General Programmatic Requirements.}

DOE Elements and contractors shall develop, implement: and maintain an acceptable fire protection.progran with the following features:

1. A policy statement that incorporates the requirements of this Section, related DOE directives, and other applicable Federal, state and local fire protection requirements. The statement shall affirm management's 
commitment to support a level of fire protection and fire suppression capability sufficient to minimize losses from fire and related hazards consistent with the best class of protected property in private. industry.

2. Comprehensive, written fire protection criteria that reflect additional site-specific aspects. of the fire protection program, including the: organization, training and responsibilities of the fire protection staff, administrative aspects of the fire protection program, and requirements for the design, installation,. operability,. inspection; maintenance: and testing of fire protection systems.

3. Written fire safety procedures governing the use and storage of combustible, flammable, radioactive, and hazardous materials so as. to minimize the risk from fire. Such procedures shall aiso exist for fire protection system impairments and for activities such as smoking, hot work, safe operation of process equipment, and other-fire prevention measures which contribute to the decrease in fire risk:

4. A system to ensure that the requirements of the DOE fire protection program are documented-and incorporated in the plans and specifications for:-all new facilities and for significant modifications of existing facilities. This includes. a documented review by a qualified fire protection engineer of plans, specifications, procedures, and acceptance tests.

5. Fire hazards analyses (FHA) for all nuclear factilities, significant new facilities and facilities that represent unique or significant fire safety risks. The FHA shall be developed using a graded approach. The conclusions of the FHA shall be incorporated in the Safety Analysis Report (SAR) Accident Anaiysis and shall be integrated into design basis and beyond..design basis accident conditions.

6. Access to a qualified and trained fire protection staff; including a fire protection engineer $(s)$, technicians and fire fighting personnel to. implement the requirements of this Section.

7. A "baseline" needs assessment that establishes the minimum.required capabilities of site fire fighting forces. This includes minimum staffing, apparatus, facilities, equipment, training; fire-pre-plans, off-site assistance requirements, and procedures.. Information. from this assessment shall be incorporated into the site-Emergency Plan:

8. Hritten pre-fire strategies, plans, and standard operating procedures to enhance the effectiveness of site fire fighting. forces; where:provided: Such procedures include those governing the use of fire fighting water or other neutron moderating materials to suppress fire within or adjacent to moderation controlled areas. Restrictions on the use of water shall be fulty justified on the basis of criticality safety. 
10-13-95.

9. A comprehensive, documented fire protection seif-assessment program, which includes all aspects (program and facility) of the fire protection program.. Assessments shall be performed on a regular-basis at a frequency established by DOE.

10. A program to identify, prioritize and monitor the status of fire protection-related appraisal findings/recommendations until final resolution is achieved. When final resolution will be significantly delayed, $\cdot$ appropriate interim compensatory measures shall be. implemented to minimize the fire risk.

11. A process for reviewing and recommending approval of fire safety "equivalencies" and "exemptions" to the DOE Authority Having Jurisdiction for fire safety.

\subsubsection{Fire Protection Design Requirements}

DOE Elements and contractors shall develop, implement and maintain a comprehensive fire protection program for facilities that includes:

1. A reliable water supply of adequate capacity for fire suppression.

2. Noncombustible or fire-resistive.construction, where appropriate. Complete fire-rated barriers that are commensurate with the fire hazard to isolate hazardous occupancies and to minimize fire spread and loss potential consistent with defined limits as established by DOE.

3. Automatic fire extinguishing systems throughout all significant facilities and in all areas subject to loss of safety class systems, significant life safety hazards, unacceptable program interruption, or fire loss potential in excess of defined limits.

4. Redundant fire protection systems in areas where-safety ciass systems are vulnerable to fire damage and where no redundant safety capability exists outside of the fire area. In new facilities, redundant safety class systems shall be in separate fire areas. Redundant fire protection systems shall also be provided in areas where the maximum possible fire .loss (MPFL) exceeds limits established by DOE.

5. A.means to summon the fire department in the event of a fire, such as a . fire-alarm'signalling system.

6. A means to notify and evacuate building occupants in the event of a fire, such as a fire detection or fire alarm system and iliuminated, protected egress paths.

7. Physical access and appropriate equipment to facilitate effective intervention by the fire department, such as an interior standpipe system(s) in multi-story or large facilities with complex configurations. 
8. A means. to prevent the accidental rejease of significant quantities of contaminated products of combustion and fire fighting water to the.

environment, such as. ventilation control and filter systems and curbs and dikes. Such features would only be necessary if required by the FHA or SAR in conjunction with other facility or site environmental protection measures.

9. Fire and related hazards that are unique to DOE and are not addressed by industry codes and standards shall be protected by isolation, segregation. or use of special fire control systems, such' as inert gas or 'explosion suppression, as determined by the FHA.

10. Fire protection systems shall be designed such that their inadvertent operation, inactivation or failure of structural stability will not result in the loss of vital safety functions or inoperability of safety class systems as determined by the SAR.

\subsection{Nuclear Criticality Safety}

DOE Elements shall ensure that a contractor responsible for a DOE non-reactor nuclear facility shail establish a nuclear criticality safety program that (i) applies to fissionable materials that are produced, processed, stored, transferred, disposed, or otherwise handled, and (ii) includes the following elements in paragraphs 4.3.2 and 4.3.3.

\subsubsection{Objectives}

The objective shall be to estabiish nuclear criticality safety program requirements to ensure that:

1. Criticality safety is comprehensively addressed and. receives an objective review, with all identified risks reduced-to.acceptably low-levels and management authorization of the:operation is documented.

2. The public, workers, property, both government:and private; the environment, and essential operations are protected from the effects of a criticality accident.

\subsubsection{General Requirements.}

Operations-with fissionable materiais which pose a criticality accident hazard shall be evaluated and documented to demonstrate that the operation will be subcritical-under-both normal and credible abnormal conditions. Fissionable material operations shall be conducted in such a manner- that consequences to personnel and property that resuit from a criticality accident will be mitigated... No single credible event or failure shail result in a criticality accident having unmitigated consequences. 
$10-13-95$

The nuclear criticality safety program shall be evaluated and documented and shall include:

(i) Nuclear criticality safety evaluations for normal and credible abnormal conditions that document the parameters, limits, and controls required to ensure that the anaiyzed conditions are subcritical.

(ii) Impiementation of Timits and controls identified by the nuclear criticality safety evaluations.

(iii) Reviews of operations to ascertain that limits and controls. are being followed and that process conditions have not been altered such that the applicability of the nuclear criticality safety evaluation has been compromised.

(iv) Assessment of the need for criticality accident detection devices and alarm systems, and installation of such equipment where: total risk to personnel will be reduced.

\subsubsection{Specific Requirements}

Fissionable materials shall be produced, processed, stored, transferred, disposed, or otherwise handled in such a manner that the probability of a criticality accident is acceptably low, and, to the extent practical, all persons, all government, pubiic, and private.property, and the environment are protected from damaging effects. and undue hazards that may arise from a criticality accident.

The Contractor Criticality Safety Program for non-reactor nuclear facilities shall-include the following requirements:

a. Contractor-Criticality Safety Programs: (CCSPs) - shall appiy to operations involving fissionable materials that pose a criticality accident hazard. Fissionable nuciides of concern to this section are listed in Table 4.3-1. The assignment: of nuclides to the three columns in Table 4.3-1 is based on typical conditions. DOE Elements shall ensure that each contractor organization shall determine which column is appropriate to the fissionable nuclides existing in its inventory, whether listed in this table or not expressiy included. Specific technical information concerning differences in behavior of these nuclides relevant to theirdiffering abilities to support a self-sustaining nuclear chain reaction may be found in ANSI/ANS-8.1-1983, R88 and ANSI/ANS-8.151981, R87. 
Table 4.3-1. Fissionable Nuclides of Criticality Concern

\begin{tabular}{ll} 
Nuclide & Nuclide \\
\hline 92U233* & 93Np237 \\
92U235* & $94 \mathrm{Pu} 238$ \\
94Pu239* & $94 \mathrm{Pu} 240$ \\
& $94 \mathrm{Pu} 241$ \\
& $94 \mathrm{Pu242}$ \\
& $95 \mathrm{Am} 241$ \\
& $95 \mathrm{Am} 242 \mathrm{~m}$ \\
& $95 \mathrm{Am} 243$ \\
& $96 \mathrm{Cm} 243$ \\
& $96 \mathrm{Cm} 244$ \\
& $96 \mathrm{Cm} 245$ \\
& $96 \mathrm{Cm} 247$ \\
& $98 \mathrm{Cf} 249$ \\
& $98 \mathrm{Cf} 251$
\end{tabular}

Nuclide

91Pa231**

$924232 * *$

$92 \mathrm{U} 234 * \star$

$96 \mathrm{Cm} 246 * *$

$98 \mathrm{Cf} 250 * *$

98Cf252**

99Es254**

* existing in quantities and forms that lead to the major focus of nuclear criticality safety

** existing in.isolated quantities less than potential minimum critical mass (per ANSI/ANS-8.15-1981, R87, "Nuclear Criticality Control. of. Special Actinide Elements")

b. The basic elements and control parameters of programs for nuclear criticality safety shall satisfy the requirements of the following American Nuclear Society's ANSI/ANS nuclear criticality safety standards:

ANSI/ANS-8.1-1983,R88, "Nuclear Criticality Safety in · Operations with Fissionable Materiais Outside Reactors," however paragraphs 4.2.2 and 4.2.3, and paragraph 3.3 shall be followed as modified in section 4.3 .3 .d of this Order;

ANSI/ANS-8.3-1986, "Criticality Accident ATarm System,". however paragraphs 4.1.2, 4.2.1 and 4.2.2 shal 7 be followed as modified in section 4.3.3.c and $e$ of this Order;

ANSI/ANS-8.5-1986, "Use of Borosilicate-G1ass Raschig Rings. as a Neutron Absorber in Solutions of Fissile Material";

ANSI/ANS-8.6-1983,R88, "Safety in Conducting Subcritica Neutron-Multiplication Measurements in Situ," however paragraph 5.3 shall be followed as modified in section. 4.3.3.f of this Order; 
ANSI/ANS-8.7-1975,R87, "Guide for Nuclear Criticality Safety in the Storage of Fissile Materials," however paragraph 5.2 shall be followed as modified by section-4.3.3.c of this Order.

ANSI/ANS-8.9-1987, "Nuclear Criticality Safety Criteria for Steel-Pipe Intersections Containing Aqueous Solutions of Fissile Materials";

ANSI/ANS-8.10-1983,R88, "Criteria for Nuclear Criticality Safety.Controls in Operations with Shielding and Confinement";

ANSI/ANS-8.12-1987,R93, "Nuclear Criticality Control and Safety of Plutonium-Uranium Fuel Mixtures Outside Reactors";

ANSI/ANS-8.15-1981,R87, "Nuclear Criticality Control of Special Actinide Elements";

ANSI/ANS-8.17-1984,R89, "Criticality Safety Criteria for the Handling, Storage, and Transportation of LHR Fuel Outside Reactors," however paragraph 4.3 shall be followed as modified in section 4.3 .3 .9 of this Order;

ANSI/ANS-8.19-1984;R89; "Administrative Practices for Nuclear Criticality Safety;"

ANSI/ANS-8.21-1995, "Use of Fixed Neutron Absorbers in Nuclear Facilities Outside Reactors."

Revisions to any of the ANSI/ANS standards listed. above will place this Section under immediate review by DOE. Revised ANSI standards shall not be used unless an exemption is granted or it is incorporated into a DOE Order.

c. Al1 recommendations in the ANSI/ANS standards 1 isted in paragraph 4.3.3.b shall be addressed. When recommendations are not. implemented, justification shall be documented in a manner described in the Implementation Plan .

Two ANSI/ANS recommendations shall be requirements:

ANSI/ANS-8.3-1986, paragraph 4.1.2, the second sentence of which becomes, for this Order, "Where alarm systems are installed, emergency plans shall be maintained."

ANSI/ANS-8.7-1975,R87, paragraph 5.2, the last sentence of which becomes, for this Order, "The effects of more significant moderation shall be evaluated." 
d. For DOE application, the following sections of ANSI/ANS-8.11983,R88, "Nuclear Criticality Safety in Operations with Fissionable Materials Outside Reactors," shall be read as follows:

(1) Application of Double Contingency (paragraph 4.2.2, Double Contingency). Process designs shall incorporate sufficient factors of safety to require at least two unlikely, independent, and concurrent changes in process conditions before a criticality accident is possible. Protection shall be provided by either (i) the control of two independent process parameters (which is. the preferred approach, when practical; to prevent common-mode failure), or (ii) a system of multiple controls on a single process parameter. The number of controls required upon a single controlled process parameter shall be based upon control reliability and any features that mitigate the consequences of control failure. In all cases, no single credible event or failure shail result in the potential for a criticality accident,. except as referenced in the paragraph that follows:

An exception to the application of double contingency, where single contingency operations are permissible, is presented. in paragraph 5.1 of ANSI/ANS-8.10-1.983;R88. This exception applies to operations with shielding and confinement (e.g., hot cells or other shielded-facilities).

Double contingency shall be demonstrated by documented evaluations.

(2) Application of Geometry Control (paragraph 4.2.3, Geometry Control): Where a significant quantity of fissionable material is being processed and criticality safety is. a. concern, passive engineered controls such as. geometry. control shall be considered as a preferred control method. Where passive engineered control - is not feasible, the preferred Order of controls is: active engineered controls, followed by administrative controls. The double contingency analysis shall justify the chosen controls. Full advantage may be taken of any nuclear characteristics. of the process materiais and equipment. . All dimensions., nuclear properties, and other features upon-which reliance: is placed shal1. be documented and verified prior to beginning operations, and control shall be exercised to maintain them.

(3) Application of Definition of "Bias" (paragraph 3.3, Glossary of Terms). The uncertainty in the bias is interpreted as a measure of both the accuracy of the calculation and the precision of the experimental data. It is assumed also to include (a) the precision of the calculation if the calculation is stochastic (notwithstanding that such 
precision often can be made as great as desired), and (b) the accuracy of the experimental data if the experiment is a mock-up of a referenced system.

Deterministic computer calculations are assumed to have very high precision, or should be made to have very high precision. Stochastic computer calculations should be forced to have appropriately high precision. An experiment that is not a mock-up is exactly accurate by definition.

e. The requirements in ANSI/ANS-8.3-1986 relating to the. needs for an alarm system (paragraphs 4.2 .1 and 4.2 .2 ); are not applicable to this Order. For the purpose of this order, Criticality Accident Alarm Systems (CAS) and Criticality Detection Systems (CDS) shall. be required as follows:

\footnotetext{
In what follows, $10^{-6}$ per year is used as a measure of credibility, and does not mean that a probsbilistic risk assessment (PRA) has: to be performed. Reasonable grounds for incredibility may be presented on the basis of combonly sccepted ensineering judgment.
}

(1) In those facilities where the mass of fissionable material exceeds the limits established in paragraph 4.2 .1 of ANSI/ANS-8.3-1986 and the probability of a criticality accident is greater than $10^{-6}$ per year (as documented in a DOE-approved Safety Analys is Report (SAR) or in thesupporting analysis for an SAR), a CAS conforming to ANSI/ANS-8.3-1986 shall be provided to cover occupied areas in which the expected dose exceeds 12 rads in free. air, where a CAS is defined to include a criticality accident detection device and a personnel evacuation alarm.

(2) In those facilities where the mass of fissionable material exceeds the limits established in paragraph 4.2.1 of ANSI/ANS-8.3-1986 and the probability of a criticality accident is greater than $10^{\circ}$ per year, (as documented in a DOE-approved SAR or in the supporting analysis for an SAR), but there are no occupied areas in which the expected dose exceeds 12 rads in free air, a CDS.shall be provided, where a CDS is defined to be an appropriate criticality accident detection device but without an immediate evacuation alarm. The CDS response time should be sufficient to allow: for appropriate process-related mitigation and recovery actions. DOE Elements shall ensure that appropriate response guidance to minimize personnel exposure shall be provided by the contractor.

(3) In those facilities where the mass of fissionable material exceeds the limits established in paragraph 4.2.1 of ANSI/ANS-8.3-1986, but a criticality accident is determined to be impossible due to the physical form of the fissionable material, or the probability of occurrence is determined to 
be less than $10^{-6}$ per year (as documented in a DOE-approved SAR or in the supporting analysis for an SAR, or in other appropriate documentation), neither a CAS nor a CDS is required.

Neither a CAS nor a CDS is required for fissionable material during shipment when packaged in approved shipping containers, or when packaged in approved shipping containers awaiting transport provided that no other operation. invoiving fissionable material not so packaged is permitted on the shipping dock or in the shipment area.

(4) If a criticality accident is possible wherein a slow-(i.e., quasistatic) increase in reactivity could occur leading from subcriticality to supercriticality to self-shutdown without setting off emplaced criticality alarms; then-a CAS might not be adequate for protection against the consequences of such an accident.

To aid in protecting workers against the consequences. of slow criticality accidents in facilities where analysis has shown that slow criticality accidents are credible, CASs should be supplemented by warning devices such as audible personnel dosimeters (e.g., pocket chirpers/flashers, or their equivalents), area radiation monitors, area dosimeters, or integrating CASs. If these:devices: are used solely as criticality warning devices in accordance with this Section, they shall be exempt from the calibration requirement of DOE Order 5480.11 (Radiation Protection for Occupational Workers, 12-21-88).

(5) Neither a CAS nor a CDS is required to be installed..for handling or storage of fissionable material when: sufficient shielding exists that is adequate to.protect personnel (e.g., spent fuel pools, hot cells, or burial grounds); however a means to detect. fission product gasses or other volatile fission products should be-provided.in occupied areas immediately adjacent to such shielded areas, except for systems where no fission products are: likely to be released. .

f. For DOE application, in section 5.3 of ANSI/ANS-8.6-1983,R88, "Safety in Conducting Subcritical Neutron-Multiplication Measurements in Situ," "i.e." should.be-read as: "e.g."

g. For DOE application, in section 4.3 of ANSI/ANS-8.17-1984,R89, "Criticality Safety Criteria for the Handling, Storage, and Transportation of LWR Fuel Outside Reactors;" the: guidance on alarm systems is specifically modified in this Order. 
h. It is acceptable to DOE to follow DOE-STD-3007-93 (Guidelines for Preparing Criticality Safety Evaluations at Department of Energy non-Reactor Nuclear Facilities) when preparing Criticality Safety EvaTuations.

For DOE application, the following sections of DOE-STD-3007-93 shall be read as follows:

(1) II. DEFINITIONS. The definition of "BIAS" should. be: interpreted as discussed in paragraph 4.3.3.d.(3).

(2) 4.0 HETHODOLOGY. When computer neutronics calculations are used, the type of computing platform should be stated along with relevant code configuration control information and code development and user documentation.

i. DOE Elements shall ensure that the contractor shail have a program to detect inadyertent accumulation of significant quantities of fissionable material.

j. $\quad$ Transportation Requirements for Fijsionable Material.

(1) The requirements of this Section shall apply. to all activities where fissionabie material is transferred from one operation to another within a facility and from one onsite location to another.

(2) The requirements of DOE 0.460 .1 (Packaging and Transportation Safety, 9-27-95) shall be complied with regarding off-site shipment of fissionable material.

DOE 0460.1 (Packaging and Transportation Safety, 9-27-95) shall apply to the safe transportation of weapon components and special assemblies shipped in national defense.

k. Guidelines for Fire Fighting

The fire protection program (Section 4.2.1) shall establish guidelines for fire fighting within, or adjacent to, moderation controlled areas. These guidelines shall be based on comparisons of risks and consequences of a criticality accident with : the risks and consequences of postulated fires for the respective area(s). Risk and consequence comparisons may be a qualitative evaluation. The basis for the guidelines shall be documented.

\subsection{Natural Phenomena Hazards Mitigation}

The objectives of this section are to ensure that all DOE facilities are designed, constructed, and operated so that the general public, workers, and the environment are protected from the impact of Natural Phenomena Hazards 
(NPHs).The provisions of this section apply to DOE sites and facilities. The provisions. of this section cover all natural phenomena: hazards such as seismic, wind, flood, lightning. Where no specific requirements arespecified, model building codes or national consensus industry standards shall be used.

\subsubsection{General Requirements}

For hazardous facilities, safety analyses shall include the ability of Systems, Structures, Components (SSCs). and personnel to perform their intended safety functions under the effects of natural phenomena.

\subsubsection{Natural Phenomena Nitigation Design Requirements}

Systems, structures and components shall be designed, constructed and operated to withstand the effects of natural phenomena as necessary to ensure the confinement of hazardous material, the operation of essential facilities, the protection of government property; and the protection of life safety for occupants. of DOE buildings. The design process sha11 consider potential damage and failure of systems, structures and components due to both direct and indirect natural phenomena effects, including common cause effects and interactions from failures of other systems, structures and components. Furthermore, the seismic requirements of Executive Order 12699 shall be addressed.

Systems, structures and components for new DOE facilities, and additions or major modifications to existing systems, structures and components shall be designed, constructed and operated to meet the requirements in the previous paragraph. Any additions and modifications to existing DOE facilities: shall not degrade the performance of existing. systems, structures and components to the extent that the objectives in this Section cannot. be achieved. under the effects of natural phenomena.

\subsubsection{Evaluation and Upgrade of Existing DOE Facilities}

Systems, structures and components in existing. DOE facilities shall be evaluated in accordance with Section 4.4 .2 when there $;$ is a significant degradation in the safety basis for the facility. Furthermore, the seismic requirements of Executive Order 12941 , shal1 be addressed.

policy, requirements, guidance, and technical standards, and. providing advice and assistance, as requested, concerning implementation of DOE safety policy as it relates to this order at DOE facilities; and for monitoring and reviewing the implementation of all aspects of this Order, including field organizations and contractor performance. 
$10-13-95$

7. IMPLEMENTATION PLANS. Contractors shall submit an Implementation Plan to DOE to implement the requirements of this order. The Implementation Plan shall be submitted after this order is incorporated into applicable contracts and shall be developed with an integrated safety review process commensurate with the hazards.

BY ORDER OF THE SECRETARY OF. ENERGY: 

TABLE 1 .

FACILITY AND ACTIVITY APPLICABILITY

\begin{tabular}{|c|c|c|c|c|c|c|c|c|c|c|c|}
\hline SECTION & $\begin{array}{l}\text { MEWNU } \\
\text { C }\end{array}$ & $\begin{array}{l}\text { MEN } \\
\text { HON } \\
\end{array}$ & $\begin{array}{l}\text { EXISTING } \\
\text { HUC }\end{array}$ & \begin{tabular}{|l} 
EXISTING \\
NOH
\end{tabular} & $\begin{array}{l}\text { HODS } \\
\text { NUC }\end{array}$ & $\begin{array}{l}\text { MODS } \\
\text { NON }\end{array}$ & $\begin{array}{l}\text { ACC \& } \\
\text { Fusion }\end{array}$ & KEN & EXISTING & 1600S & $\begin{array}{l}\text { ACTIVIIIES } \\
\text { (Note 3) }\end{array}$ \\
\hline 3.0 & YES & YES & YES & YES & YES & YES & Hote 2 & YES & NO & YES & HO \\
\hline 3.1 & YES & Hote 1 & Note 1 & Note 1 & YES & YES & NO. & YES & NO & YES. & HO ${ }^{\circ}$ \\
\hline 3.2 & YES & YES & YES & YES & YES & YES & YES & YES & YES & YES & HO \\
\hline 4.3 & YES & NO & YES & HO & YES & NO & NO & YES & YES & YES & NO. \\
\hline 4.4 & YES & YES & YES & YES & YES & YES & YES & YES & YES & YES & NO \\
\hline
\end{tabular}

Hote 1: Refer to each section

Hote 2: See-Orders and Standards on Accelerators and Fusion Facilities

Hote 3: Activities within weapons facilities relating to the prevention of accidental or. unaithorjzed nuclear detonations are subject to the 5600 series of o0E Orders

!UC - Nuclear factlity categorized as Hazard Category 1,2 , or 3

HOH = AIJ other facilities 

DOE 0420.1

10-13-95
Attachment 2

Page 1
CONTRACTOR REQUIREMENTS DOCUMENT

FACILITY SAFETY

\subsection{REQUIREMENTS}

Each section of this Document has specific requirements, and where appropriate schedules for implementing requirements and specific exemptions,. Which are provided in the following corresponding sections of this Document. In complying with the provisions of this Document, determinations regarding the acceptability of design should include comparison with existing safety.basis : information, if available. All new construction shall, as a minimum, conform to the Model Building Codes applicable for the state or region, supplemented with additional safety requirements associated with the hazards in the facility in a graded manner.

Guidance associated with this Document are not mandatory requirements. The guidance provided in implementation guides and standards referenced therein are acceptable methods to satisfy the requirements of this Document. Alternative methods that satisfy the requirements of this Document are also acceptable. Any implementation method selected must be justified to ensure that an adequate revel of safety commensurate with the identified hazards is achieved.

\subsection{Muclear and Expiosives Safety. Design Criteria}

In the performance of this contract, the contractor. is required to comply-with the following:

Nuclear Safety

The contractor. is, for nuclear safety, . required to ensure-that. Department of Energy (DOE) nuclear facilities are designed and constructed so: as - to assure adequate protection for the public, workers, and the:-environment: by application of the requirements contained herein. These requirements apply to the activities of design and construction of new DOE. nuclear facilities and of modifications to existing. DOE Hazard Category 1, 2, and 3 non-reactor nuclear facilities: when the proposed modifications significantly degrades the:approved safety basis for the facility. Modifications to. facility design and construction during the design and construction phase shall conform to the requirements for new facilities. Activities associated with-facility deactivation at" end of life are exempt if justified:by. safety analysis:-

\section{ExpTosives Safety}

The contractor shall apply the mandatory standards described herein for the design and construction of DOE explosives facilities or modifications thereof. Explosives facilities are those facilities or locations used for storage or operations with explosives or ammunition. When these: facilities are also nuclear facilities; the requirements for nuclear safety design aiso apply. 


\subsubsection{Nuclear Safety}

\subsubsection{General Requirements}

Detailed application of these requirements shall be guided by safety analyses that estabiish the identification and functions of safety (safety class and safety significant) Structures, Systems, and Components (SSCs) for a facility and estabiish the significance. to safety of functions performed by those SSCs. Safety analyses shall consider facility hazards, natural. phenomena hazards, and external man-induced hazards. Factors such as proximity to nearby facilities such as airports, pipelines, and barge traffic peculiar to the site shall also be considered. A safety analysis shall be-performed at the earliest practical point in conceptual or preliminary design, so that required functional attributes of safety SSCs can be specified in the detailed design. Safety analyses shall be performed in accordance with Safety Analysis Report (SAR) guidance for safety analysis, as described in DOE guidance documents.

\subsubsection{Design Requirements}

Nuclear facilities shall be designed with the objective of providing multiple Tayers of protection to prevent or mitigate the unintended release of: radioactive materials to the environment. Defense in depth shall-include: siting, minimization of material at risk, the use of conservative design margins and quality assurance; the use of successive physical barriers for protection against the release of radioactivity; the provision of multiple means to ensure critical safety functions (those basic safety functions needed to control the processes, maintain them in a safe state, and to continue and mitigate radioactivity associated with the potential for accidents with significant public radiological impact); the use of equipment and administrative controls which restrict deviations from normal operations and provide: for-recovery from accidents to achieve a safe condition; means-to monitor: accident releases required for emergency responses; and the provision of emergency plans for minimizing the effects of an accident:.

Facilities shall be sited and designed in such a manner that gives adequate protection: for the health and safety of the public and. for workers, including those :at adjacent facilities, from the effects of potential facility accidents involving the release of radioactive materials.

Facilitiess shall be designed to facilitate safe deactivation; decommissioning, and decontamination at end of life.

Facilities shall be designed to facilitate inspections, testing, maintenance, repair and replacement of safety SSCs as part of an overall. reliability, availability, and maintainability program: The objective is that the facility can be maintained in a safe state, including during these operations, and in keeping with the as low as reasonabiy achievable (ALARA) principle for. occupational radiation exposure. 
DOE 0420.1

$10-13-95$

Attachment 2

- Page 3

Facilities: shall be designed to keep occupational radiation exposure within statutory limits and incorporate ALARA. principles in design, including design provisions'to facilitate decontamination during the operational period.

Facility process.systems shall be designed to minimize the production of wastes and minimize the mixing of radioactive and non radioactive wastes.

Safety SSCs, identified in accordance with this section shall, commensurate with the importance of the safety functions performed; be-designed: (1) so that they can perform their safety functions when cal led upon to operate, and (2) under a quality assurance program that satisfies 10 CFR 830.120.

\subsubsection{Explosives Safety}

The safety design of all new-DOE explosives facilities and all modifications to existing explosives facilities shall conform to the DOE explosives safety requirements: established in the DOE.Explosives Safety Manual, DOE:H-440:1-1. Facility structural design and construction shall comply with-the requirements of TM5-1300;. Structures to Resist the. Effects of Accidental Explosions; ... and. DOE/TIC-11268, A Manual for the Prediction of Blast. and Fragment. Loading of Structures.. Blast-resistant design for persannel and facility protection. shall be based on the TNT equivalency of the maximum quantity of explosives and propellants permitted. In accordance with TM5-1300,. the TNT equivalency shall be increased by $20 \%$ for design purposes:

\subsubsection{Implementation}

An Implementation Plan describing the process that wili ensure that the requirements of this section will be invoked during the. design and construction shall be submitted.to the DOE Cognizant Secretarial Officer or his designee in accordance with section 5 . Deviations from:applicablerequirements: shall be appropriately documented. and:justified.:

\subsection{Fire Protection}

In the performance of this contract, the contractor is to develop, implement and maintain-a comprehensive fire protection program that is sufficient to meet the DOE's objectives for fire safety; as stated below.

DOE objectives: are to. estab7ish requirements: for a comprehensjve fire-and related hazards protection: program for: facil ities sufficient to -minimize the potential: for:-. (1) the occurrence of a fire: or related:event; $:$ (2) a fire that causes an unacceptable on-site or off-site release of hazardous or radiological material that.will threaten the health and safety of employees, the public: or - the environment; (3) vital DOE: programs- suffering unacceptable interruptions as a result of fire and related hazards; (4) property losses from.a fire and related events. exceeding defined limits established by DOE; and $(5)$ critical process controis and safety. class: systems being damaged as a resuit of a fire and related events. 
DOE facilities, sites and activities (including design and construction) sha]l be characterized by a level of fire protection that is sufficient to fulfill the requirements of the best protected class of industrial risks ("Highiy Protected Risk" or. "Improved.Risk") and shall be provided protection to achieve "defense-in-depth." This includes meeting the applicable building code and National Fire Protection Association Codes and Standards, or exceeding them (when necessary to meet safety objectives), unless explicit written relief has been granted by DOE.

\subsubsection{General Programmatic Requirements}

To meet the above delineated objectives, the contractor shall develop, implement and maintain an acceptabie fire protection program with the following features:

1. A policy statement that incorporates the requirements of DOE 420 , related DOE directives, and other applicable Federal, state, and local fire protection requirements. The statement shall affirm management's commitment to support a level of fire protection and fire suppression capability sufficient to minimize losses from fire and related hazards consistent with the best class of protected property in private industry.

2. Comprehensive, written fire protection criteria that reflect additional site-specific aspects of the fire protection program, including the organization, training, and responsibilities of the fire protection. staff, administrative aspects of the fire protection program, and requirements for the design, installation, operability, inspection, maintenance, and testing of fire protection systems.

3. Written fire safety procedures governing the use and storage of combustible, flammable; radioactive, and hazardous. materiais so as to minimize the risk from fire. Such procedures shall also exist for fire protection system impairments and for activities such as smoking, hot work, safe operation of process equipment, and other fire prevention measures which contribute to the decrease in fire risk.

4. A system to ensure that the requirements of the DOE fire protection program are documented and incorporated in the plans and specifications for all new facilities and for significant modifications of existing facilities. This includes a documented review by a qualified fire. protection engineer of plans, specifications, procedures, and: acceptance tests.

5. Fire hazards analyses (FHA) for ali nuclear facilities, significant new facilities, and facilities that represent unique or significant fire safety risks. The. FHA shall be developed using a graded approach. The conclusions of the FHA shall be incorporated in the SAR Accident Analysis and shall be integrated into design basis and beyond design. basis accident conditions. 
6. Access to a qualified and trained fire protection staff, including. a fire protection engineer(s), . technicians and fire fighting personnel to implement the requirements of this order.

7. A "baseline" needs assessment that estabiishes. the minimum required capabilities of site fire fighting forces. This includes minimum staffing, apparatus, fácilities, equipment, training, fire pre-plans, off-site assistance requirements, and procedures. Information-from this assessment shall be incorporated into the site Emergency Plan.

8. Written pre-fire strategies, $p l a n s$, and standard operating procedures to enhance the effectiveness of site fire fighting forces, where provided.

Such procedures include those governing the use of fire fighting water or other neutron moderating materials to suppress fire within or adjacent to moderation controlled areas. Restrictions on the use of water shall be fully justified on the basis of criticality safety.

9. A comprehensive, documented fire protection self-assessment program, which includes all aspects (program and facility) of the fire protection program. Assessments shall be performed on a reguilar basis at a frequency estabiished by DOE.

10. A program to identify, prioritize and monitor the status of fireprotection-related appraisal findings/recommendations until final resolution, is achieved. When final resolution will be significantly delayed, appropriate interim compensatory measures shall be implemented to minimize the fire risk.

11. A process for reviewing and recommending approval of fire safety "equivalencies" and "exemptions" to the DOE Authority Having Jurisdiction for fire safety.

\subsubsection{Fire Protection Design Requirements}

DOE elements and contractors shall develop, implement, and maintain a comprehensive fire protection program for facilities that includes:

1. A reliable water suppiy of adequate capacity for fire suppression.

2. Noncombustible or fire-resistive construction, where appropriate: Complete fire-rated barriers that are commensurate: with the-fire-hazard to isolate hazardous occupancies and to minimize fire: spread. and. loss potential consistent with defined limits as established by DOE.

3. Automatic fire extinguishing systems throughout all significant facilities and in all areas subject to loss of safety class systems, significant life safety hazards, unacceptable program interruption, or fire loss potential in excess of defined limits. 
Attachment 2

DOE 0420.1

Page 6

10-13-95

4. Redundant fire protection systems in areas where safety class. systems are vuinerable to fire damage and where no redundant safety capability exists outside of the fire area. In new facilities, redundant safety class systems shall be in separate fire areas.. Redundant fire protection systems shall also be provided in areas where the maximum possible fire loss (MPFL) exceeds limits established by DOE.

5. A means to summion the fire department in the event of a fire, such as a fire alarm signalling system.

6. A means to notify and evacuate building occupants in the event of a fire, such as a fire detection or fire alarm system and illuminated, protected egress paths.

7. Physical access and appropriate equipment to facilitate effective intervention by the fire department, such as an interior standpipe system(s) in multi-story or large facilities with complex configurations.

8. A means to prevent the accidental release of significant quantities of contaminated products of combustion and fire fighting water, to the environment, such as ventilation control and filter systems and curbs and dikes.' Such features would only be necessary if required by the FHA or SAR in conjunction with other facility or site environmental protection measures.

9. Fire and related hazards that are unique to DOE and are not addressed by industry codes and standards shall be protected by isolation, segregation or use of special fire control systems, such as inert gas or explosion suppression, as determined by the FHA.

10. Fire protection systems shall be designed such that their inadvertent operation, inactivation or failure of structural stability will not result in the loss of vital safety functions or inoperability of safety class - systems as determined by the SAR.

The contractor shall direct compliance with these requirements: to the extent incorporated into the contract. Interpretations of the language of this document in relation to the contract shall be the responsibility of the DOE Contracting Officer after consultation with the cognizant DOE authority for fire protection.

\subsection{Nuclear Criticality Safety}

In the performance of this contract, the contractor is required to establish a nuclear criticality safety program that (i) applies to fissionable materials that are produced, processed, stored, transferred, disposed, or otherwise handled, and (ii) includes the following elements. 


\subsubsection{General Requirements}

Operations with fissionable materials which pose a criticality accident hazard shall be evaluated and documented to demonstrate that the operation will be subcritical under both normal and credible abnormal conditions. Fissionable material operations shall be conducted in such a manner that consequences to personnel and property that resu7t.t from a criticality accident will be mitigated. No single credible event or failure shall result in a criticality accident having unmitigated consequences.

The nuclear criticality safety program shall be evaluated and documented and shall include:

(i) Nuclear criticality safety evaluations for normal and credible abnormal conditions that document the parameters, limits, and controls required to ensure that the analyzed conditions are subcritical.

(ii) Implementation of limits and controls identified by the nuclear criticality safety evaluations.

(iii) Reviews of operations to ascertain that limits and controls are being followed and that process conditions have not been.altered such that the applicability of the nuclear criticality safety evaluation has been compromised.

(iv) Assessment of the need for criticality accident detection devices and alarm systems, and installation of such.equipment where total risk to personnel will be reduced.

\subsubsection{Specific Requirements}

Fissionable materials shall be produced, processed, stored, transferred; disposed, or otherwise handled in such a manner that the probability of a criticality accident is acceptably low, and, to the extent. practical, all persons, all government, public, and private property, and the environment are protected from damaging effects and undue hazards that may arise from a. criticality accident.

The Contractor Criticality Safety Program for nuclear facilities shall include the following requirements:

a. Contractor Criticality Safety Programs (CCSPs) shall apply to operations involving fissionable materials that.pose a criticality accident hazard. Fissionable nuclides of concern to this Contractor Requirements Document (CRD) are listed in Table-4.3-1. The assignment of nuclides to the three columns in Table 4.3-1 is based on typical conditions. Each contractor-organization shal1 determine which column is appropriate to the fissionable nuclides existing in its inventory, whether listed in this table or not expressiy included. Specific technical information concerning 
differences in behavior of these nuclides relevant to their differing abilities to support a self-sustaining nuclear chain reaction may be found in ANSI/ANS-8.1-1983,R88 and ANSI/ANS-8.151981, R87.

Table 4.3-1. Fissionable Nuclides of Criticality Concern

Nuclide

92U233*

92U235*

94Pu239*
Nuclide

$93 \mathrm{~Np} 237$

$94 \mathrm{Pu} 238$

$94 \mathrm{Pu} 240$

94Pu241

$94 \mathrm{Pu} 242$

95Am241

95Am242m

95Am243

$96 \mathrm{Cm} 243$

$96 \mathrm{Cm} 244$

$96 \mathrm{Cm} 245$

$96 \mathrm{Cm} 247$

98Cf249

98Cf251
Nuclide

$$
\begin{aligned}
& \text { 91Pa231** } \\
& \text { 92U232** } \\
& \text { 92U234** } \\
& \text { 96Cm246** } \\
& \text { 98Cf250** } \\
& \text { 98Cf252**} \\
& \text { 99Es254**- }
\end{aligned}
$$

* existing in quantities and forms that lead to the.major focus of nuclear criticality safety

**- existing in isolated quantities less than potential minimum critical mass (per ANSI/ANS-8.15-1981,R87, "Nuclear Criticality Control of Special Actinide Elements")

b. The: basic elements and control parameters of programs for nuclear criticality safety shall satisfy the requirements of the following American Nuclear Society's ANSI/ANS nuclear criticality safety standards:

ANSI/ANS-8.1-1983,R88, "Nuclear Criticality.Safety in Operations with Fissionable Materials Outside Reactors," however paragraphs 4.2 .2 and 4.2 .3 , and paragraph 3.3 shall be followed: as modified in section 4.3.2.d. of this CRD;

ANSI/ANS-8.3-1986, "Criticality Accident Alarm System," however paragraphs 4.1.2, 4.2.1, and 4.2.2 shall be. followed, as modified in section $4: 3.2 . C$. and. e- of this CRD;

ANSI/ANS-8.5-1986, "Use of Borosilicate-Glass Raschig Rings as a Neutron Absorber in Solutions of Fissile Material";

ANSI/ANS-8.6-1983,R88, "Safety in Conducting Subcritical Neutron-Multiplication Measurements in Situ," however paragraph 5.3 shall be followed as modified in section 4.3.2.f of this CRD; 
ANSI/ANS-8.7-1975,R87, "Guide for Nuclear Criticality Safety in the Storage of Fissile Materials," however paragraph 5.2 shall be followed as modified by section $4.3 .2 . c$ of this CRD;

ANSI/ANS-8.9-1987, "Nuclear Criticality Safety Criteria for Steel-Pipe Intersections Containing Aqueous Solutions of Fissile Material.s.";

ANSI/ANS-8.10-1983,R88, "Criteria for Nuclear Criticality Safety Controls: in Operations with Shielding and Confinement" ;

ANSI/ANS-8.12-1987,R93, "Nuclear Criticality Control and Safety of Plutonium-Uranium Fuel Hixtures Outside Reactors";

ANSI/ANS-8.15-1981,R87, "Nuclear Criticality Control of. Special Actinide Elements";

ANSI/ANS-8.17-1984,R89, "Criticality Safety Criteria:for the Handling, Storage, and Transportation of LHR Fuel Outside Reactors," however paragraph 4.3 shall be followed as modified in section 4.3 .2 .9 of this CRD;

ANSI/ANS-8.19-1984,R89., "Administrative Practices for Nuclear Criticality Safety;"

ANSI/ANS-8.21-1995, "Use of Fixed Neutron Absorbers in Nuclear Facilities Outside Reactors."

Revisions. to any of the ANSI/ANS standards 1 isted above will place the Order related to this CRD under immediate review by DOE. Revised ANSI standards-shall not be used:unless.an exemption is granted or it is incorporated into a DOE Order.

c. Contractors shall regard al7 recommendations in the ANSI/ANS standards listed in paragraph 4.3.2.b. When recommendations are not implemented, justification shall be documented in a manner described in the Implementation Plan.

Contractors shall. interpret two ANSI/ANS recommendations: as: requirements:

ANSI/ANS-8.3-1986, paragraph 4:1.2, the second. sentence of which becomes, for this CRD, "Where alarm systems are installed, emergency plans șall be maintained."

ANSI/ANS-8.7-1975,R87, paragraph 5.2, the. 1ast sentence of which becomes, for this CRD, "The effects of more significant moderation shall be evaluated." 
d. For DOE application, the following sections of ANSI/ANS-8.11983,R88, "Nuclear Criticality Safety in Operations with

Fissionable Materials Outside Reactors," shall be read as follows:

(1) Application of Double Contingency (paragraph 4.2.2, Double Contingency). Process designs shall incorporate sufficient factors of safety to require at least two unlikely, independent, and concurrent changes in process conditions before a criticality accident is possible. Protection shall be provided by either (i) the control of two independent process parameters (which is the preferred approach, when practical, to prevent common-mode failure), or (ii) a system of multiple controls on a single process parameter: The number of controls required upon a single controlled process parameter shall be based upon control reliability and: any features that mitigate the consequences of control faiTure. In all cases, no singie credible event or-faijure shall result in the potential for a criticality accident, except as referenced in the paragraph that follows.

An exception to the application of double contingency, where singie contingency operations are permissible, is presented in paragraph 5.1 of ANSI/ANS-8.10-1983, R88. This exception applies to operations with shielding and confinement (e.g., hot cells or other shielded facilities).

Double contingency shall be demonstrated by documented evaluations.

(2) Application of Geometry Control (paragraph 4.2.3, Geometry Control). Where a significant quantity of - fissionable material is being processed. and criticality safety is. a concern; passive engineered controls such as geometry. control shall be considered as a preferred. control method. Where passive engineered control is not feasible, the preferred order of controls is: active engineered controls, followed by administrative controls. The double contingency analysis shall justify the chosen controls. Full advantage may be taken of any nuclear characteristics. of the process materials and equipment. All dimensions, nuclear.

properties, and other features upon-which reliance: is p.laced shat 1 be documented and verified prior to beginning. operations, and control shall be exercised to maintain them.

(3)

Application of Definition of "Bias" (paragraph 3.3, Glossary of Terms). The uncertainty in the bias is interpreted as a measure of both the accuracy of the calculation and the precision of the experimental data. It is assumed also to include (a) the precision of the calculation if the calculation is stochastic (notwithstanding that such 
precision often can be made: as great as desired), and (b) the accuracy of the experimental data if: the experiment is a mock-up of a referenced system:

Deterministic computer calculations are assumed to have very high precision, or should be made: to have very high -. precision. Stochastic computer calculations should. be forced to have appropriately high precision. An experiment that is. not a mock-up: is exactly accurate by definition.

e. The requirements in ANSI/ANS-8.3-1986 relating to the needs for an alarm system (paragraphs 4.2.1 and 4.2.2) are not applicable to this CRD. For the purpose of this CRD, Criticality Accident Alarm Systems-(CAS) and Criticality Detection Systems (CDS) shall be required as follows:

In what follows, $10^{-6}$ per year-is used:as.a measure $=$ of credibility, and does not mean that a probabilistic risk assessment (PRA) has to be performed: Reasonable grounds for incredibility may be presented on the basis of commoniy accepted engineering judgement.

(1) In those facilities where the mass of fissionable material exceeds the Timits established in paragraph 4.2.1 of ANSI/ANS-8.3-1986 and the probabi]ity of a criticality accident is greater than $10^{-6}$ per year (as documented in a DOE-approved SAR or in the supporting analysis for an SAR), a CAS conforming to ANSI/ANS-8.3-1986 shalT be provided to cover-occupied areas in which the expected dose exceeds. 12 rads in free air, where a CAS is defined to include a criticality accident detection device:-and.a personnel evacuation alarm.

(2) In those facilities where the mass of fissionable material. exceeds the 7 imits established: in paragraph 4.2.1 of ANSI/ANS=8.3-1986. and the probability of a criticality accident is greater than $10^{-6}$ per-year; (as documented in a DOE-approved SAR or in the supporting analysis for an SAR), but there are no occupied areas: in. which the expected dose exceeds:- 12 rads. in free air, a CDS shall be provided, where a CDS is defined to be: an appropriate-criticality accident detection device but without: an immediate:evacuation alarm. The CDS response time should be sufficient-to. allow for appropriate. process-related mitigation and recovery actions. Appropriate response guidance to minimize personnel exposure shall be provided by the contractor.

(3) In those facilities where the mass-of fissionable:material exceeds the limits established in:paragraph 4.2.1 of ANSI/ANS-8.3-1986, but a criticality accident is determined to be impossible due to the physical form of the fissionable 
material, or the probability of occurrence is determined to be less than $10^{-6}$ per year (as documented in a DOE-approved SAR or in the supporting analysis for an SAR, or in other appropriate documentation); neither a CAS nor a CDS is required.

Neither a CAS nor a CDS is required for fissionable material during shipment when packaged in approved shipping containers, or when packaged in approved shipping containers awaiting transport provided that no other operation involving fissionabie material not so packaged is permitted on the shipping dock or in the shipment area.

(4) If a criticality accident is possible wherein a slow (i.e., quasistatic) increase in reactivity could occur leading from subcriticality to supercriticality to self-shutdown without setting off emplaced criticality alarms, then a CAS might not be adequate for protection. against the consequences of such an accident.

To aid in protecting workers against the consequences of slow criticality accidents in facilities where analysis has shown that slow criticality accidents are credible, CASs - should be supplemented by warning devices such as audible personnel dosimeters (e.g.: pocket chirpers/flashers, or their equivalents), area radiation monitors, area dosimeters, or integrating CASs. If these devices are used solely as criticality warning devices in accordance with. this CRD, they shall be exempt from the calibration requirement of DOE Order 5480.11 (Radiation Protection for Occupational Workers, 12-21-88).

(5) Neither a CAS nor a CDS is required to be installed for handling or storage of fissionable material when sufficient shielding exists that is adequate to protect personne? (e.g., spent fuel pools, hot cells, or burial grounds); however a means to detect fission product gasses or other volatile fission products should be provided in occupied areas immediately adjacent to such shielded areas, except for systems where no fission. products are likely to be released.

f. For DOE application, in section 5.3 of ANSI/ANS-8.6-1983, R88, "Safety in Conducting Subcritical Neutron-Multiplication Measurements in Situ," "i.e." should be read as "e.g."

g. For DOE application, in section 4.3 of ANSI/ANS-8.17-1984,R89, "Criticality Safety Criteria for the Handling, Storage, and Transportation of LWR Fuel Outside Reactors, "the guidance on alarm systems is specifically modified in this CRD. 
h. It is acceptable to DOE to follow DOE-STD-3007-93 (Guidelines for Preparing Criticality Safety Evaluations at Department of Energy non-Reactor Nuclear Facilities) when preparing Criticality Safety Evaluations.

For DOE application, the following sections of DOE-STD-3007-93 shall be read as follows:

(1) II. DEFINITIONS. The definition of "BIAS" should be interpreted as discussed in paragraph 4.3.2.d.(3).

- (2). 4.0 METHODOLOGY. When computer neutronics calculations are used, the type of computing platform should be stated along with relevant code configuration control information and code development and user documentation:

i. The contractor shall have a program to detect inadvertent accumulation of significant quantities of fissionable material.

j. Transportation Requirements for Fissionable Material.

(1) The requirements of this CR'D shall apply to all activities where fissionable material is transferred from one-operation to another within a facility and from one on-site location to another.

(2) The requirements of DOE 0460.1 (Packaging and Transportation Safety; 9-27-95) shali be complied with regarding off-site shipment of fissionable material.

DOE 0 460.1 (Packaging and Transportation Safety, 9-27-95) shall apply to the safe transportation of: weapon components and special assemblies shipped in national defense:-

k: Guidelines for Fire Fighting

The fire protection program (Section 4.2.1) shall establish guidelines for fire fighting within, or adjacent to, moderation controlled areas. These guidelines shall be based on comparisons of risks and consequences of a criticality accident with the risks and consequences of postulated fires for the respective area(s). Risk and consequence comparisons may be a.qual itative evaluation. The basis for the guidelines shall be-documented.

\subsection{Matural Phenomena Hazards Mitigation for DOE Facilities}

In the performance of this contract, the contractor is required to design, construct, and/or operate, the facility as specified in the contract. so that . the general public, the workers, and the environment-are protected from the impact of all Natural Phenomena Hazards (NPHs). Where no specific requirements are specified, model building codes or national consensus industry standards shall be used. 


\subsubsection{General Requirements}

For hazardous facilities, the contractor shall perform safety analyses that include the ability of SSCs and personnel to perform their intended safety functions under the effects of natural phenomena.

\subsubsection{Natural Phenomena Mitigation Design Requirements}

The contractor shall:

1. Design, construct, and/or operate, the facility as specified in the contract so that SSCS will withstand the effects of natural phenomena as necessary to ensure the confinement of hazardous material, the operation of essential facilities, the protection of government property, and the protection of life safety for occupants of DOE buildings.

2. Consider potential damage and failure of SSCS due to both direct and indirect natural phenomena effects, including common cause effects and interactions from failures of other SSCS.

3. Address seismic requirements of Executive Order 12699.

4. For new facilities the contractor shall meet the general requirements of section 4.4.1 and requirements 1,2 , and 3 of section 4.4.2.

5. For additions and major modifications of existing facilities the contractor shall meet the general requirements of section 4.4.1 and requirements 1,2 , and 3 of section 4.4.2 and ensure that the modifications do not degrade the performance of existing SSCS to the extent that they will not withstand the effects of natural phenomena as necessary to ensure the confinement of hazardous material, the operation of essential facilities, the protection of government property, and the protection of life safety for occupants of DOE buildings.

\subsubsection{Evaluation and Upgrade of Existing DOE Facilities}

For existing DOE facilities the contractor shall:

1. Evaluate the SSCS. against the general requirements of section 4.4 .1 and requirements 1 and 2 of section 4.4 .2 when the following circumstances apply:

(a) There is a significant degradation in the safety basis for the facility.

(b) Address seismic requirements of Executive Order 12941,

2. If any of the conditions in requirement 5 of section 4.4 .2 are satisfied, then the contractor/operator shall establish a plan for. evaluating the affected SSCS. The plan shall incorporate a schedule for 
evaluation taking into account programmatic mission considerations and the safety significance of the potential failure of-SSCs due to natural phenomena.

3. If the evaluation of existing SSCs -identifies natural phenomena.

- mitigation deficiencies, the contractor/operator shall establish an. upgrade plan for the affected SSCs. The upgrade plan shall incorporate a prioritized schedule for upgrading the SSCs. The upgrade planrshall address possible time or funding constraints as well as programmatic mission considerations.

\subsubsection{Matural Phenomena Hazards Assessment}

The contractor/operator shall:

Base the design and evaluation of facilities to withstand natural phenomena on an assessment of the likelihood. of future natural phenomena occurrences. The natural phenomena hazards assessment shall be conducted commensurate: with a graded approach and commensurate with the potential hazard of the facility.

For new sites the contractor/operator shall: ,

1. Conduct a natural phenomena hazards assessment commensurate with a graded approach to the facility.

2. Consider the consequences of all types of natural phenomena hazards - in site planning.

For existing sites the contractor/operator shall:

1. Review and update the natural phenomena hazards assessments, as. necessary, if there are significant changes in natural phenomena. hazards assessment methodology or site-specific information.

2. Conduct a review of the natural phenomena hazards assessment at jeast every 10 years. The review shall include recommendations to DOE on the need for updating the existing natural phenomena hazards assessments based on identification of any significant changes in methods or data.

\subsubsection{Natural Phenomena Detection}

For facilities or sites with hazardous materials, the contractor/operator shall provide instrumentation or other means to detect and record the. occurrence and severity of seismic events.

\subsubsection{Post-Natural Phenomena Procedures.}

For facilities or sites with hazardous materials contractor/operator-shall provide and use procedures that include, inspecting the facility for-damage caused by severe naturai phenomena, and placing the facility into a safe configuration when such damage has occurred. 
Attachment 2 .

DOE 0420.1

Page 16

\subsection{Implementation Plan}

Contractors shall submit an Implementation PIan to DOE to implement the above requirements. The Implementation Plan shall be submitted after the requirements are incorporated into the applicable contract and shall be developed with an integrated safety review.process commensurate with the hazards. 

AND CONTRACTOR EMPLOYEES

Approved: $09-30-95$

- Sunset Review: 09-30-97

Expires: 09-30-99

1. OBJECTIVE. To establish the framework for an effective worker protection . program that will reduce or prevent accidental '1osses, injuries, and illnesses by providing DOE Federal and contractor workers with a safe and healthful. workplace.'

2. CANCELLATION. Canceltation of an Order does not, by itself, modify or otherwise affect any contractual obligation to comply with such an Order. Canceled Orders that are incorporated by reference in. a contract, shall remain in effect until the contract is modified to delete the reference to the requirements in the canceled Orders. The following Orders are canceled:

a. DOE 3790.1B, FEDERAL EMPLOYEE OCCUPATIONAL SAFETY AND HEALTH PROGRAM; Of 1-7-93, except-Chapter VIII,. "Federal-Employee - Occupational Medical .Program."

b. Attachment 2, paragraph 2c, 2d(2)-(3), $2 \mathrm{e}(1)-(8)$; and Attachment 3, paragraph $2 c, 2 d(2)-(3), 2 e(1)-(7)$, of DOE 5480.4 , ENVIRONMENTAL PROTECTION, SAFETY, AND HEALTH PROTECTION STANDARDS, Of 5-15-84.

c. DOE 5480.7A, FIRE PROTECTION, of 2-17-93.

d. DOE 5480.8A, CONTTACTOR OCCUPATIONAL MEDICAL PROGRAM, of 6-26-92.

e. DOE 5480.9A, CONSTRUCTION PROJECT SAFETY AND HEALTH MANAGEMENT, Of 4-13-94.

f. DOE 5480.10, CONTRACTOR INDUSTRIAL HYGIENE PROGRAM, of 6-26-85.

g. DOE 5480.16A, FIREARMS SAFETY, of 3-4-94.

h. DOE 5483.1A, OCCUPATIONAL SAFETY AND HEALTH PROGRAM FOR DOE CONTRACTOR EMPLOYEES AT GOYERNMENT-OHNED CONTRACTOR-OPERATED FACILITIES, Of 6-22-83.

3. APPLICABILITY.

a. DOE Elements. Except for the exclusions in paragraph $3 c$, this order (including Attachment 1) applies to all DOE Elements.

b. Contractors. Except for the exclusions in paragraph $3 c$, Attachment 2, Contractor Requirements Document (CRD), sets forth requirements that shall be applied to all contractors awarded contracts and subcontracts for performing work for DOE on DOE-owned or -leased facilities.

DISTRIBUTION:

A77 Departmental Elements
INITIATED BY:

Office of Environment, Safety and Health 
Contractor compliance with the CRD will be required to the extent -set forth in a contract. Contractors shall be directed to continue to comply. with the requirements of Orders canceled by this Order until - their contracts are modified to delete the reference to the requirements of the canceled Orders:

c. ExcTusions.

(1) Activities conducted under the authority of the Director, Naval Nuclear Propulsion Program, as described in Public Law 98-525.

(2) Activities conducted under the Nuclear Explosives and Heapons Safety Program relating to the prevention of accidental or unauthorized nuclear detonations to the extent a requirement under this part cannot be implemented. for a particular facility in a manner that does not compromise the effectiveness of such activities.

4. REQUIREMENTS. DOE ETenients shall:

a. Implement a written worker protection program that:

(1) provides a place of employment free from recognized hazards that - are causing or are likely to cause death or serious. physical harm to their employees; and

(2) integrates all requirements contained in paragraphs $4 a$ through 4.7 of this Order; program requirements, contained in Title 29 Code of Federal Regulations (CFR) Part 1960, "Basic Program Elements for Federal Employee Occupational Safety and Health Programs and Related Matters"; applicable functional area requirements contained in Attachment 1; and other related site-specific worker protection activities.

b. Establish written policy, goals, and objectives for the worker protection program.

c. Use qualified worker protection staff to direct and manage the worker protection program.

d. Assign worker protection responsibilities, evaluate personnel performance, and hold personnel accountable for worker protection performance.

e. Encourage the involvement of employees in the development of program goals, objectives, and performance measures and in the identification and control of hazards in the workplace.

f. Provide workers the right, without reprisal, to: 
(1) accompany :DOE worker protection personnel during workplace inspections;

(2) participate in activities provided for in this order on official time;

(3) express concerns related to worker protection;

(4) decline to perform an assigned task because of a reasonable belief that, - under the circumstances, the task poses an imminent risk of death or serious bodily harm to that individual, coupled with a reasonable belief that there is insufficient time to seek effective redress through the normal hazard reporting and abatement procedures established in accordance with this order;

(5) have access to DOE worker protection publications, DOE-prescribed standards, and the organization's own worker protection standards or procedures applicable to the workplace;

(6) observe monitoring or measuring of hazardous. agents and: have access to the results of exposure monitoring;

- (7) be notified when monitoring results indicate they were overexposed to hazardous materials; and

(8) receive results of inspections and accident investigations upon request.

g. Implement procedures to allow workers, through their supervisors, to stop work when they discover employee exposures to imminent danger conditions or other serious hazards. The procedure shall ensure that any stop work authority is exercised in a justifiable and responsible manner.

h. Inform workers of their rights and responsibilities by appropriate means, including posting the appropriate DOE Worker Protection Poster in the workplace where it is accessible to a17 workers.

i. Identify existing and potential workplace hazards and evaluate the risk of associated worker injury or illness.

(1) Analyze or review:

(a) designs for new facilities and modifications to existing facilities and equipment;

(b) operations and procedures; and

(c) equipment, product, and service needs: 
(2) Assess worker exposure to chemical, physical, biological, or ergonomic hazards through appropriate workplace monitoring (including personal, area, wipe, and bulk sampling), biological monitoring, and observation. Monitoring results shalt be recorded. Documentation shall describe the tasks and locations where monitoring occurred, identify workers monitored or represented by the monitoring, and identify the sampling methods and durations, control measures in place during monitoring (including the use of personal protective equipment), and any other factors that may have affected sampling results.

(3) Evaluate workplaces and activities accomplished routinely by workers, supervisors, and managers and periodically by qualified worker protection professionals.

(4) Report and investigate accidents, injuries, and illnesses (reference DOE 0 231.1, ENVIRONMENT, SAFETY AND HEALTH REPORTING; DOE 0 232.1, OCCURRENCE REPORTING AND PROCESSING OF OPERATIONS INFORMATION; and DOE 0 225.1, ACCIDENT INVESTIGATIONS) and analyze related data for trends and lessons learned (reference DOE 0 210.1, PERFORMANCE INDICATORS PROGRAM AND ANALYSIS OF OPERATIONS).

(5) Maintain a counterfeit/suspect parts program.

(a) Identify, document, test, and remove counterfeit or suspect parts.

(b) Report all suspect/counterfeit products to the responsible program office and the Office of the Inspector General in accordance with DOE 0 231.1, DOE 0 232.1, and DOE 2030.4B, REPORTING, FRAUD, WASTE AND ABUSE TO THE OFFICE OF INSPECTOR GENERAL, Of 5-18-92.

(c) Ensure quality of products purchased from vendors supplying parts or goods whose failure could cause system failure or could harm workers.

(d) Maintain current, up-to-date knowledge of counterfeit or v suspect parts or goods and associated.vendors.

j. Implement a hazard prevention/abatement process to ensure that all identified hazards. are managed through final abatement or control.

(1) For hazards identified either in the facility design or during the development of procedures, controls are incorporated in the appropriate facility design or procedure.

(2) For existing hazards identified in the workplace, abatement actions prioritized according to risk to the worker are promptly implemented, interim protective.measures are implemented pending 
final abatement, and workers are protected immediately from imminent danger conditions.

(3). Hazards are addressed when selecting or purchasing equipment, products, and services.

(4) Hazard control methods are selected based on the following hierarchy:

(a) . Engineering controls.

(b) Work practices and administrative contrais that limit worker exposures.

(c) Personat protective equipment.

k. Provide workers, supervisors, managers, visitors, and worker protection professionals with worker protection training.

1. Comply. with the following worker protection requirements.

(1) American Conference of Governmental Industrial Hygienists (ACGIH), "Threshold Limit Values for, Chemical Substances and PhysicalAgents and Biological Exposure Indices" (most recent edition), when ACGIH Threshold Limit Values (TLVs) are lower (more protective) than Occupational. Safety. and Health Administration. (OSHA) Permissible Exposure Limits. [When ACGIH TLVs are used as exposure limits, DOE operations shail nonetheless comply with the other provisions of any applicable OSHA-expanded heaith standard.] The TLVs for exposures to Taser emissions in the ACGIH Indices, are excluded from this requirement.

(2) American National Standards Institute 2136.1, Safe Use of Lasers. [Only the exposure 7 imits and technical requirenents apply. Programmatic components of American National Standards Institute Z136. 1 do not apply.]

(3) American National Standards Institute 288.2, Practices for Respiratory Protection.

m. Additional requirements for specific functional areas are contained in Attachment 1, Functional Area Requirements for DOE Elements.

5. RESPONSIBILITIES.

a. Assistant Secretaries.

(1) Ensure that program-specific worker protection goais and objectives are developed and resources are provided. 
(2) Ensure that worker protection policies and requirements are effectively implemented.

(3) Develop or participate in recognition programs that encourage the improvement of worker protection programs.

(4) When contractors report directiy to the Cognizant Secretarial Officer or an Assistant Secretary, ensure that the responsibilities of paragraph $5 b$ (and applicable responsibilities in the specific functional areas contained in Attachment 1) and the requirements of the CRD (Attachment 2) are implemented.

(5) Assist in the resolution of significant worker protection issues and the improvement in cost effectiveness and efficiency of worker protection programs.

(6) Review and be approving authority for exemptions to requirements contained in this order. Requests for exemptions to ail requirements except those exemptions related to OSHA standards imposed on contractors by this Order may be delegated.

b. Heads of Departmental Elements and Heads of Field Elements.

(1)- Ensure through the Contracting officer that contractors implement effective worker protection programs.

(2) Review contractor worker protection program budgets and provide recommendations to the funding official on the-appropriateness of the budget request.

(3) Provide contractors with technical direction on and criteria for the development of contractor goals, objectives, and performance measures.

(4) Hold DOE line personnel accountable for providing technical direction to contractors that is consistent with the requirements contained in this order.

(5) Evaluate the need for and direct the development of formal written agreements between organizations on their sites. These agreements shall outl ine the respective roles, responsibilities, and authorities of each organization as they relate to compliance with DOE worker protection requirements and the resolution of crosscutting worker protection-related issues.

c. Operations Office Managers (and Heads of Field Elements, where applicable).

(1) Ensure that unannounced worker protection inspections of contractor workplaces are conducted at least annualiy. 
(2) Ensure immediate and effective remedial actions are taken for imminent danger situations discovered during worker protection inspections to ensure employees are removed from the hazard or the hazard is eliminated; conduct an inspection as soon as possible after an imminent danger situation has been corrected to ensure that. appropriate actions have been taken, to preclude recurrence.

(3) Determine whether adequate protection can most effectively be achieved by continuing to operate under the terms of existing contracts requiring compliance with old orders or by modifying the contract to incorporate the CRD (Attachment 2) requirements.

(4) Ensure that initiators of procurement requests specify therein whether requirements in the CRD (Attachment. 2) are to be applied to the resulting award or subawards.

d. Associate Deputy Secretary for Field Management. Facilitate resolution of conflicting worker protection programs, policies, and procedures among Heads of Departmental Elements and field organizations.

e. Assistant Secretary for Environment: Safety and Health. Establish committees as necessary to assist in the development of Departmenta] - requirements and guidance.

f. Contracting officers. Require contractors to comply with worker protection requirements as identified by. paragraph $3 \mathrm{~b}$ or otherwise identified in procurement requests.

-6. CONTACTS.

a. For additional information or technical interpretation of this Order, contact the Office for Worker Health and Safety (EH-51) at (301) 903-6456.

b. For technical interpretations of DOE-prescribed worker protection standards, consult the DOE Technical Information Services database, or ca17 the DOE Response Line at (800) 292-8061.

c. Consult the DOE Directives Checklist for current Implementation Guides and Safety Manuals associated with this Order. This checklist is available from the Office of Organization and Management (HR-6) at (202) $586-4716$.

BY. ORDER OF THE SECRETARY OF ENERGY:

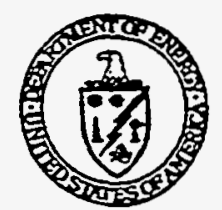

ARCHER L. DURHAM

Assistant Secretary for Human Resources and Administration 



\section{FUNCTIONAL AREA REQUIREMENTS FOR DOE ELEMENTS}

1. CONSTRUCTION SAFETY. : The following requirements and responsibilities apply for construction projects above the monetary threshold established by the Davis-Bacon Act (40 U.S.C. 276a) at Government-owned or -7eased facilities where the contract clause "Safety and Health (Government-Owned or -Leased Facility)" applies.

a. Requirements. See Attachment 2, Contractor Requirements Document, for construction safety requirements related to contractors.

b. Responsibilities.

Heads of Departmental Elements and Heads of Field Elements.

(a) Designate a project manager for each construction project.

(b) Ensure that project managers are provided with the training, resources, and technical support necessary to perform the duties prescribed by this order.

(c) Develop formal written agreements/implementing instructions as needed to del ineate the respective construction safety responsibilities/duties of DOE project management and technical support staffs as well as affected site contractors.

(d) Review safety and health programs developed for site maintenance and operational activities to determine their applicabiitity and cost effectiveness on construction projects.

(e) Direct the development and implementation of a system for evaluating the effectiveness of construction contractor safety and heaith programs on fixed-price construction. projects and apply this system to the determination of bidder responsibility on future construction projects. (Refer to Federal Acquisition-Regulation (FAR) 36.201.)

(f) Ensure that applicable requirements of this order are specified within construction project acquisition documents.

(2) Construction Project Managers.

(a) Determine the necessity for requiring dedicated construction contractor safety and health personnel on project workplaces.

(b) Ensure that construction project acquisition documents provide information or reference to existing documentation 
that describes known hazards to which project workers may be exposed.

(c) Ensure that a prework safety meeting is conducted with the construction contractor to review project.safety and health requirements..

(d) Ensure that the project safety and health $p$ lan is approved prior to any on-site project.work and that required hazard analyses are completed and approved.prior to start of work on affected construction operations.

(e) Ensure that project safety and health plans and hazard. analyses are revised, as necessary, to address identified deficiencies in project safety and health performance or changes in project operations, contractors, or personne?.

(f) Through personal on-site involvement and/or formal delegation to support staff and/or the.construction.manager, perform frequent and regular documented on-site reviews of construction contractor safety and health program effectiveness.

(g) Ensure documentation of all 'formal contract actions taken to enforce construction contractor compliance with project safety and health requirements.

2. FIRE PROTECTION. Implement a comprehensive fire protection program with the - objective of providing an acceptable level of safety from fire and-related" hazards for DOE Federat personnel and for the public. This includes appropriate facility and site-wide fire protection (refer to DOE.0 420.1, FACILITY SAFETY), fire aiarm notification and egress features, and access to a fulty staffed, trained, and equipped fire department. that is capable of. responding: in a timely and effective manner to site emergencies. An acceptable fire protection program includes those fire protection criteria and procedures, analyses, hardware and systems, apparatus and equipment, and personnel that comprehensively ensure that the above objective is met. This includes meeting-applicable building codes and National Fire ProtectionAssociation Codes and Standards or exceeding them (when necessary to meet. safety objectives), unless explicit written relief has been granted by DOE.

3. FIREARMS SAFETY.

a. Requirements.

(1) Establish firearms safety poticies and procedures to ensure proper accident prevention controls are in place. Hritten procedures shal7 address safety concerns and the personal protective 
equipment required. As a minimum, procedures must be established for:

(a) storage, handling, cleaning, and maintenance of firearms and associated ammunition;

(b) activities:such as joading, untoading, and exchanging firearms;

(c) use of pyrotechnics and/or explosive projectiles;

(d) handling misfires and duds;

(e) Tive fire operations; and

(f) training and exercjses using engagement simulation systems.

(2) Ensure that staff members responsible for the direction and operation of the firearms safety program are.professionally qualified and have sufficient time and authority to implement the e.jtablished program. Firearms instructors and armorers shall be Safeguards and Security Central Training Academy-certified to conduct the level of activity provided.

(3) Conduct formal appraisals assessing implementation of procedures, personnel responsibilities, and duty assignments to ensure overail policy objectives and performance criteria are being met by qualified safety personnel.

(4) . Implement safety provisions related to firearms safety training, qualification, or requalification.

(a) Personnel shall successfully complete and demonstrate understanding of initial firearms safety training before being issued any firearms.

(b) Personnel authorized to: carry firearms shal1 have access to instruction manuals for each type of firearm with which they are.armed.while on duty.

(c) Authorized armed personnel shall demonstrate both technical and practical knowledge. of firearms handling and safety on a semi-annual basis. This demonstration shall be supported by Timited scope performance tests and the results of such testing shalT be documented.

(d) A11 firearms training lesson plans shall incorporate safety for all aspects of firearms training task performance standards. Lesson plans shall follow the standards and criteria set forth by the Safeguards and Security Central Training Academy's standard training program. Safety 
briefings shal1 be conducted before any live fire training commences.

(e) A safety anaiysis approved by the Operations Office Manager shall be developed for the facilities and.operation of each live fire range. A.safety analysis shajl be completed and approved prior to implementation of any new-training. Results of these analyses shall be incorporated into procedures, lesson plans, exercise plans, and limited scope performance tests.

(f) Site-specific firing range safety procedures shall be conspicuousiy posted at all ranges.

(g) Live fire ranges shall be properiy sited to protect personnel on the range, as well as personnel and property not associated with the range.

(5) Ensure that the transportation, handling, placarding, and storage of munitions conform to the appTicable requirements of DOE $M$

- 440.1-1, DOE EXPLOSIVES SAFETY MANUAL (Formeriy DOE/EV/06194).

b. Responsibilities.

(1) Operations Office Managers.

(a) Ensure effective implementation and control of the firearms safety program.

(b) Approve the location and use of the contractor's live fire ranges.

(2) Office of Security Affairs. Approve the location of Tive fire ranges for the Safeguards and Security Central Training Academy.

4. EXPLOSIVES SAFETY. Ensure that applicable explosives operations compiy with DOE M 440.1-1, DOE EXPLOSIVES SAFETY MANUAL (FormerTy DOE/EV/06194). Faci7ity management shall determine the applicability of the requirements to research. and development laboratory type operations consistent. with the DOE Tevel of protection criteria in the manuat. The administration and management of the Explosives Safety Manual and any deviations from it shall follow the process specified in Chapter I, Sections 3 and 4 , of the manual. Revisions to the manual are made through concurrence of the DOE Explosives Safety Committee.

5. INDUSTRIAL HYGIENE. Implement a comprehensive and effective industrial hygiene program to reduce the risk of work-related disease or i11ness at affected facilities. Industrial hygiene programs shall include the following elements:

a. Initial or baseline surveys of all work areas or operations to identify and evaluate potential worker health risks. 
b. Coordination with planning and design personnel to anticipate and control health hazards that proposed facilities and operations would introduce.

c. Periodic resurveys and/or exposure.monitoring as appropriate.

d. Documented exposure assessment for chemical, physical, and biological agents and ergonomic stressors using recognized exposure assessment methodologies and use of accredited industrial hygiene laboratories.

e. Specification of appropriate engineering, administrative, work practice, and/or personal protective control methods to 1 imit hazardous exposures to acceptable levels.

f. Horker education, training, and involvement.

g. Coordination with cognizant occupational medical, environmental, health. physics, and work planning professionals:

h. Use of DOE-accepted respiratory protection when National Institute of

- Occupational Safety and Heal th-approved respiratory protection does not exist for DOE tasks.

i. Policy and procedures to mitigate the risk from identified and potential occupational carcinogens.

j. Use of appropriate industrial hygiene standards.

k. Professionally and technicalty qualified industrial hygienists to manage and implement the industrial hygiene program.

\section{PRESSURE SAFETY REQUIREMENTS.}

a. Requirements.

(1), Ensure that all pressure vessels, boilers, air receivers, and supporting piping systems conform to:

(a) the American Society of Mechanical Engineers (ASME) Boiler and Pressure Vessel Safety Code;

(b) the American National Standards Institute/ASME B.31 Piping Code; and/or

(c) the strictest applicable State and local codes.

(2) When national consensus codes are not applicable (because of pressure range, vessel geometry, use of special materials, etc.), implement measures to provide equivalent protection and ensure safety equal to or superior to the intent of the ASME code. Measures shall include the following: 
(a) Design drawings, sketches, and-calculations shall be reviewed and approved by an independent design professional. Documented organizational peer review is acceptable.

(b) Qualified personnel shall be used to perform examinations and inspections of materials, in-process fabrications, nondestructive tests, and acceptance tests.

(c) Documentation, traceability, and accountability shall be maintained for each pressure vessel or. system, including descriptions of design, pressure, testing, operation, repair, and maintenance.

7. MOTOR VEHICLE SAFETY. Implement a Motor Vehicle Safety Program to protect the safety and health of all drivers and passengers in Government-owned or - leased motor vehicles and powered industrial equipment (i.e., fork trucks, tractors, platform lift trucks, and other similar'specialized equipment powered by an electric motor or an internal combustion engine). The Motor Vehicle Safety. Program shall be tailored for the individual DOE site or facility, based on an anaiys is of the needs of that particular site or facility, and shall address the following areas.

a. Minimum licensing requirements (including appropriate testing and medical qualification) for personnel operating motor vehicles and powered industrial equipment.

b. Requirements for the use of seat belts and provision of other safety devices.

c. Training for specialty vehicie operators.

d. Requirements for motor vehicle maintenance and inspection.

e. Uniform traffic and pedestrian controt devices and road signs.

f. On-site speed limits and other traffic rules.

g. Awareness campaigns and incentive programs to encourage safe driving.

h. Enforcement provisic:-: 


\section{CONTRACTOR REQUIREMENTS DOCUMENT}

\section{HORKER PROTECTION MANAGEMENT FOR DOE CONTRACTOR EMPLOYEES}

The contractor. shall comply with the requirements contained herein.

1. Implement a written worker protection program that:

a: provides a place of employment free from recognized hazards that are causing or are likely to cause death or serious physical harm to employees; and

b. integrates ail requirements contained in this attachment and other related site-specific worker protection activities.

2. Establish written policy, goals, and objectives for the worker protection program:

3. Use qualified worker protection staff to direct and manage the worker protection program.

4. Assign worker protection responsibilities, evaluate personnel performance, and hold personnel accountable for worker protection performance.

5. Encourage employee involvement in the development of program goals, objectives, and performance measures and in the-identification and control of hazards in the workplace.

6. Provide workers the right, without reprisal, to:

a. accompany DOE worker protection personnel during workplace inspections;

b. participate in activities provided for herein on official time;

c. express concerns related to worker protection;

d. deciine to perform an assigned task because of a reasonable belief that, under the circumstances, the task poses an imminent risk of death or serious bodily harm to that individual, coupled with a reasonable belief that there is insufficient time to seek effective redress through the normal hazard reporting and abatement procedures established: in . accordance with the requirements herein;

e. have access to DOE worker protection publications, DOE-prescribed standards, and the organization's own worker protection standards or procedures applicable to the workplace;

f. observe monitoring or measuring of hazardous agents and have access to the results of exposure monitoring;

g. be notified when monitoring results indicate they were overexposed to hazardous materials; and 
h. receive results of inspections and accident investigations upon request.

7. Impiement procedures to allow workers, through their supervisors, to stop work when they discover employee exposures to imminent danger conditions or other serious hazards. The procedure shall ensure that any stop work authority is exercised in a justifiable and responsible manner.

8. Inform workers of their rights and responsibilities by appropriate means, including posting the appropriate DOE Worker Protection Poster in the workplace where it is accessible to all workers.

9. Identify existing and potential workplace hazards and evaiuate the risk of associated worker injury or illness.

a. Analyze or review:

(1) designs for new facilities and modifications to existing facilities and equipment;

(2) operations and procedures; and

(3) equipment, product, and service needs.

b. Assess-worker exposure to chemical, physical, biological, or ergonomic hazards through appropriate workplace monitoring (including personal, area, wipe, and bulk sampling); biological monitoring; and observation: Monitoring results shall be recorded: Documentation shall describe the tasks and locations where monitoring occurred, identify workers monitored or represented by the monitoring, and identify the sampling methods and durations, control measures in place during monitoring (including the use of personal protective equipment), and any other factors that may have affected sampling results.

c. Evaluate workplaces and activities (accomplished routinely by workers, supervisors, and managers and periodically by qualified worker protection professionals).

d. Report and investigate accidents, injuries, and illnesses, and analyze related data for trends and lessons Tearned (reference DOE 0 210.1).

e. Maintain a counterfeit/suspect parts program.

(1) Identify, document, test, and remove counterfeit or suspect parts.

(2) Report all suspect/counterfeit products to the responsible program office and to the Office of the Inspector General in accordance with DOE 0 231.1, DOE 0232.1 , and DOE 2030.4B. 
(3) Ensure quality of products purchased from vendors suppiying parts. or goods whose failure could cause system failure or could harm workers.

(4) Maintain current, up-to-date knowiledge of counterfeit or suspect parts or goods and associated vendors.

10. Impiement a hazard prevention/abatement process to ensure that ail identified hazards are managed. through final abatement. or control.

a. For hazards identified either in the facility design or. during the development of procedures, controls are incorporated in the appropriate facility design or procedure.

b. For existing hazards identified in the workplace, abatement actions prioritized according. to risk to the worker are promptly implemented, interim protective measures are impiemented pending final abatement, and workers are protected immediately from imminent danger conditions.

c. Hazards are addressed when selecting or purchasing equipment, products, - 'and services.

d. Hazard control methods are selected based on the following hierarchy.

(1) Engineering controis.

(2). Work practices and administrative controls that limit worker - exposures

(3) Personal protective equipment.

11. Provide: workers, supervisors, managers, visitors, and worker protection professionals with worker protection training.

12. Comply with the following worker protection requirements.

a. Title 29 of the Code of Federal Regulations (CFR), Part 1910, "Occupational Safety and.Health Standards."

b. Title 29 CFR, Part 1915, "Shipyard Employment."

c. Title 29 CFR, Part 1917," "Marine Términals:"

d. Title 29 CFR, Part 1918, "Safety and Health Regulations forLongshoring."

e. Titie 29 CFR, Part 1926, "Safety and Health Regulations for Construction."

f. Title 29 CFR, Part 1928, "Occupational Safety and Health Standards for Agriculture." 
g. American: Conference of Governmental Industrial Hygienists (ACGIH), "Threshold Limit Values for.Chemical-Substances and Physical Agents and Biological Exposure Indices" (most recent edition, as specified in the contract), when ACGIH Threshold Limit Values (TLVs) are lower (more protective) than Occupational Safety and Health Administration (OSHA) Permissible Exposure timits. [When ACGIH TLYs are used as exposure limits, DOE. operations shall nonetheless comply with the other provisions of any app I icable OSHA-expanded health standard.] The TLVs . for exposures to laser emissions in the ACGIH Indices are excluded from this requirement.

h. American National Standards Institute Z136.1, Safe Use of Lasers. [On1y the exposure 7 imits and technical requirements apply. Programmatic components of American National Standards Institute 2136.1 do not apply:]

i. American National Standards Institute 288.2, Practices for Respiratory Protection.

Requirements for specific functiona] areas are contained in paragraphs 13 through 20 and only apply if the contract is involved in these activities.

\section{CONSTRUCTION SAFETY.}

a. The following requirements and responsibilities apply for construction projects above the monetary threshold established by the Davis-Bacon Act (40 U.S.C. 276a) at Government-owned or--leased facilities where the contract clause "Safety and Health (Government-Owned or -Leased Facility)" applies.

(1) Hazard Analyses. For each construction operation presenting hazards not experienced in previous project. operations or for work performed by a different subcontractor, the construction contractor shall prepare a hazard analysis and have. it approved prior to commencement of affected work. These: analyses shall identify foreseeable hazards and planned protective measures; provide drawings and/or other documentation of protective measures that a Professional Engineer or other competent person is required to prepare, and define the qualifications of competent persons required for workplace inspections.

(2) Horker Hazard Awareness. Workers shal1 be informed of foreseeable hazards and the required protective measures described within the approved hazard analysis prior to commencement of work on the affected construction operation.

(3) Horkplace Inspections and Hazard Abatement: During periods of active construction, the construction contractor shall have a designated representative on site at all times. This individual shall conduct and document daily inspections of the workplace to identify and correct hazards and instances of noncompliance..with project safety and health requirements. If immediate corrective 
action is not possible or the hazard falls outside of project scope, the construction contractor shall immediately notify affected workers., post appropriate warning signs, implement needed interim control measures, and notify the construction manager of actions taken.

Project Safety and Health PIan. The construction contractor shall prepare and have approved prior to commencement of any on-site project work a written project safety and heaith plan that provides a proposal for implementing the above requirements. The construction contractor shall also designate the individual(s) responsible for on-site implementation of the plan, specify qualifications for those individuals, and provide a list of those project operations for which a hazard analysis is to be performed.

14. FIRE PROTECTION. Implement a comprehensive fire protection program with the objective of providing an acceptable level of safety from fire and related hazards for DOE contractor personnel and for the public. This includes appropriate facility and site-wide fire protection, fire alarm notification and egress features, and access to a fully staffed, trained, and equipped fire department that is capable of responding' in a timeiy and effective manner to site emergencies. An acceptable fire protection program includes those fire protection criteria. and procedures, analyses, hardware and systems, apparatus and equipment, and personnel that comprehensively ensure that the above objective is met. This includes meeting the applicable building code and National Fire Protection Association Codes and Standards or exceeding them (when necessary to meet safety objectives), uniess explicit written relief has been granted by DOE.

\section{FIREARMS SAFETY.}

a. Establish firearms safety poticies and procedures to ensure proper accident prevention controls are in place. Hritten procedures shall address safety concerns and the personal protective equipment required. As a minimum, procedures must be established for:

(1) storage, handling, cleaning, and maintenance of firearms and associated ammunition;

(2) activities such as loading, unloading, and exchanging firearms;

(3) use of pyrotechnics and/or-explosive projectiles;

(4) handling misfires and duds;

(5) Tive fire operations; and

(6) training and exercises using engagement simulation systems.

b. Ensure that staff members responsible for the direction and operation of the firearms safety program are professionally qualified and have sufficient time and authority to implement the established program. 
Firearms instructors. and armorers shal1 be Safeguards and Security Central Training Academy-certified to conduct the level of activity provided.

c. Conduct formai appraisals assessing implementation of procedures, personnel responsibilities, and duty assignments to ensure overall policy objectives and performance criteria are being met by qualified safety personnel.

d. Implement safety provisions related to firearms safety training, qualification, or requalification.

(1) Personnel shal1 successfully complete and demonstrate understanding of initial firearms safety training before being issued any firearms.

(2) Personnel authorized to carry firearms shall have access to instruction manuals for each type of duty firearms with which they are armed while on duty.

(3) Authorized armed personne: shal7 demonstrate both technical and practical knowledge of firearms handling and safety on a semiannual basis. This demonstration shal1 be supported by, limited scope performance tests, and the results of. such testing shall be documented.

(4) All firearms training lesson plans shall iricorporate safety for all aspects of firearms training task performance standards. The iesson plans sha71 follow the standards and criteria set forth by the Safeguards and Security Central Training Academy's standard training programs. Safety briefings shall be conducted before any live fire training commences.

(5) A safety analysis approved by the Operations Office Manager sha11 be developed for the facilities and operation of each live fire range. A safety analysis shall be completed and approved prior to implementation of any new training. Results of these analyses shall be incorporated into procedures, lesson plans, exercise plans, and Timited.scope performance tests.

(6) Site-specific firing range safety procedures shall be conspicuously posted at all ranges.

(7) Live fire ranges shall be properiy sited to protect personnel on the range, as well as personnel and property not associated with the range. Request approval from the DOE Operations Office for the location and use of a live fire range.

e. Ensure that the transportation, handling, placarding; and storage of munitions conform to the applicable requirements of DOE $M 440.1-1$, DOE EXPLOSIVES SAFETY MANUAL (Formerly DOE/EV/06194). 
16. EXPLOSIVES SAFETY. Ensure that applicable explosives operations comply with DOE M 440.1-1, DOE EXPLOSIVES SAFETY MANUAL (Formeriy DOE/EV/06194). Contractor facility management shall determine the applicability of the requirements to research and development l laboratory type operations consistent with the DOE level of protection criteria in the manual. The administration and management of the ExpTosives. Safety Manual and any deviations from it shall follow the process specified in Chapter I, Sections 3 and 4 , of the manual. Revisions to the manual are made through concurrence of the DOE Explosives Safety Committee.

17. INDUSTRIAL HYGIENE.: Implement a comprehensive and effective industriaI hygiene program to reduce the risk of work-reiated disease or iliness at affected facilities. Industrial hygiene programs shall include the following elements:

a. Initial or baseline surveys of all work areas or operations to identify and evaluate potential worker health risks.

b. Coordination with planning and design personnel to anticipate and - control health hazards that proposed facilities and operations would - introduce.

c. Periodic resurveys and/or exposure monitoring as appropriate.

d. Documented exposure assessment for chemical, physical, and biological agents and ergonomic stressors using recognized exposure assessment methodologies and use of accredited industrial hygiene laboratories.

e. Specification of appropriate engineering, administrative, work practice, and/or personal protective control methods to 1imit hazardous exposures to acceptable levels.

f. Horker education; training, and invoivement.

g. Coordination with cognizant occupational medical, environmental, health physics, and work planning professionals..

h. Use of DOE accepted respiratory protection when National Institute of Occupational Safety and Health-approved respirator protection does not exist: for DOE tasks.

i. Policy and procedures to mitigate the risk from identified and potential occupational carcinogens.

j. Use of appropriate industrial hygiene standards.

k. Professionally and technically qualified industrial hygienists to manage and implement the industrial hygiene program. 
18. OCCUPATIONAL MEDICAL.

a. Integration.

(1) - The establishment of a contractor occupational medical program shall be a basic worker protection requirement.

(2) A formal, written contractor occupational medical program detailing the methods and procedures used to implement the occupational medical requirements necessary for worker protection and the promotion of a healthful work environment shall be established, maintained, reviewed, and updated.

(3) The contractor occupational medical program shall provide occupational health services to contractor employees. The goal of these services shall be the earliest possible detection and mitigation of occupational illness. and injury.

(4) To carry out this goal, the contractor occupationat medical professional staff shail participate as members of a worker protection team.

b. Implementation. The physician responsible for delivery of medicai services shal1 be responsible for the planning and implementation of the occupational medical program.

c. Maintenance of a Healthful Work Environment.

(1) Occupational medical physicians and selected medical staff sha7?:

(a) Coordinate with other safety and health professionals (industrial hygienists, health physicists, safety specialists/managers) to identify work-related or work site hazards and their possible health risks to employees;

(b) Possess a current knowledge of actual or potential workrelated hazards (physical, chemical, biological);

(c) Perform targeted examinations based on an up-to-date knowledge of work site risk;

(d) Identify potential or actual health effects resulting from work site exposures; and

(e) Communicate the results of health evaluations to management and to those responsible for mitigating work site hazards.

(2) Contractor management shall provide to the physician responsible for delivery of medical services:

(a) Employee job task and hazard analysis information; 
(b) Summaries of potential work site exposures of employees prior to mandatory health examinations; and

(c) The opportunity to participate in worker protection team meetings and committees.

\section{d. Employee Health Examinations.}

(1) Health examinations shall be conducted by an occupational health examiner under the direction of a Ticensed physician in accordance with current sound and acceptable medical practices.

(2) The content of health examinations shali be the responsibility of the physician responsible for the delivery of medical services.

(3) The following classes of examinations are required for the purpose of providing initial and continuing assessment of employee health as determined by the physician responsible for delivery of medical services:

(a) preplacement in accordance with the Americans with Disabilities Act,

(b) qualification examinations,

(c) fitness for duty,

(d) medicat surveitlance and health monitoring,

(e) return to work health evaluations,

(f) termination examinations.

(4) The occupational medical department shall be informed of a71 job transfers and shall determine whether a medical evaluation is necessary.

(5) The physician responsible for the delivery of medical services or his/her designee shail inform contractor management of appropriate employee work restrictions.

e. Monitored Care.

(1) The occupational medical program shall be responsible for the review. of all monitored care of $i 11$ and injured employees to maximize their recovery and safe return to work, and to minimize lost time and its associated costs.

(2) Contractor management shall notify the physician responsible for the delivery of medical services or his designee when an employee has been absent because of an injury or illness for more than 5 consecutive workdays or experiences excessive absenteeism. 
f. Emplovee Counseling and Health Promotion. The physician responsible for delivery of medical services sha71:

(1) review and approve the medical aspects of contractor-sponsored or -supported employee assistance, alcohol, and other substance abuse rehabilitation programs;

(2) approve and coordinate al1 contractor-sponsored or -supported weitness programs; and

(3) ensure that immunization programs for blood-borne pathogens and biohazardous waste programs conform to OSHA regulations and Centers for Disease Control guidelines for those employees at risk to these forms of exposure.

g. Medical Records.

(1) An employee medical record shall be developed and maintained:for. each employee for which medical services are provided.

(2) - The confidentially of all employee medical records shall be observed.

(3) Employee medical-records shall be adequately protected and stored permanently.

h. Emergency and Disaster Preparedness.

(1) The physician responsible for the delivery of medical services shall be responsible for the medical portion of the site emergency and disaster plan.

(2) The plan shall be integrated with the overall site plan and with the surrounding community emergency and disaster plan.

i. Organizational Staffing.

(1) The physician responsible for the delivery of medical services shall be a graduate of a school of medicine or osteopathy who meets the licensing requirements applicable to the location in which the physician works.

(2) Occupational medical physicians, occupational health nurses, physician's.assistants, nurse practitioners, psychologists, and other occupational health personnel shall be graduates of accredited school.s and shall be 7 icensed, registered, or certifiedas required by Federal or State 1 aw where-employed.

19. PRESSURE SAFETY.

a. Ensure that all pressure vessels, boilers, air receivers, and supporting piping systems conform to: 
(1) the American Society of Mechanical Engineers (ASME) Boiler and Pressure Vesse] Safety Code;

(2) the American National Standards Institute/ASME B.31 Piping. Code; and/or

(3) the strictest applicable state and local codes.

b. When national consensus codes are not applicable (because of pressure range, vessel geometry, use of special materials, etc.), implement measures to provide equivalent protection and ensure safety equal to or superior to the intent of the ASME code. Measures shall include the following.

(1) Design drawings, sketches, and calculations shall be reviewed and approved by an independent design professional. Documented organizational peer review is acceptable.

(2) Quatified personnel shall be used to perform examinations and inspections of materials, in-process fabrications, non-destructive tests, and acceptance tests.:

(3) Documentation, traceability, and accountability shall be maintained for each unique pressure vessel or system, including descriptions of design, pressure, testing, operation, repair, and maintenance.

20. MOTOR VEHICLE SAFETY. Implement a Motor Vehicle Safety Program to protect the safety and health of all drivers and passengers in Government-owned or -leased motor vehicles. and powered industrial equipment (i.e., fork trucks, tractors, platform lift trucks, and other similar specialized equipment powered by an electric motor or an internal combustion engine). The Motor Vehicle Safety Program shall be tailored for the individual DOE site.or facility, based on an analysis of the needs of that particular site or facility, and shall address the following areas.

a. Minimum 7 icensing requirements (including appropriate testing and medical qualification) for personnel operating motor vehicles and powered industrial equipment.

b. Requirements for the use of seat beits and provision of other safety devices.

c. Training for specialty vehicle operators:

d. Requirements for motor vehicle maintenance and inspection.

e. Uniform traffic and pedestrian control devices and road signs.

f. On-site speed 1 imits and other traffic rutes.

g. Awareness campaigns and incentive programs to encourage safe driving. 
h. Enforcement provisions:

21. Ensure that subcontractors performing work on DOE-owned or -leased facilities comply with this Contractor Requirements Document and the contractor's own site worker protection standards (where applicable). 


\section{U.S. Department of Energy}

Washington, D.C.

DOE 0151.1

Approved: 09-25-95

- Review Date: 09-25-97

SUBJECT: COMPREHENSIVE EMERGENCY MANAGEMENT SYSTEM

Chg 1: 10-26-95

\section{OBJECTIVES.}

a. To establish policy, and assign and describe roles and responsibilities for the Department of Energy (DOE) Emergency Management System. The Emergency Management System provides the framework for development, . coordination, control, and direction of all emergency planning, preparedness, readiness assurance, response, and recovery actions.

b. To establish requirements for comprehensive planning,. preparedness, response, and recovery activities of emergency management programs for DOE or for organizations requiring DOE assistance.

c. To describe an approach to effectively integrate planning, preparedness, response, and recovery activities for a comprehensive, ali-emergency - management concept.

d. To integrate public information and emergency planning to provide. accurate, candid, and timely information to site workers and the public during all emergencies:

e. To promote more efficient use of resources through greater flexibility. (i.e., the: graded approach) in addressing emergency management needs consistent with the changing missions of the Department and its facilities.

f. To ensure that the DOE Emergency Management System is ready to respond promptly, efficiently, and effectively to any emergency involving DOE facilities, activities, or operations, or requiring DOE assistance.

g. To integrate various requirements promulgated by other agencies into the Department's Emergency Management System.

h. To eliminate duplication of emergency management effort within the Department.

2. CANCELLATIONS. The-Orders listed below are canceled. Cancellation of an Order does not, by itself, modify or otherwise affect any contractual obligation to comply with such an Order. Canceled Orders incorporated by reference in a contract will remain in effect until the contract is modified. to delete the reference to the requirements in the canceled Orders.

a. DOE 5500.1B, EMERGENCY MANAGEMENT SYSTEM,. of 4-30-91.

Vertical line denotes change.

DISTRIBUTION:

A11 Departmental Elements
INITIATED BY:

Office of Nonproliferation and National Security 
b. DOE 5500,2B, EMERGENCY CATEGORIES, CLASSES, AND NOTIFICATION AND REPORTING REQUIREMENTS, Of 4-30-91.

c. DOE 5500.3A, PLANNING AND PREPAREDNESS FOR OPERATIONAL EMERGENCIES, Of 4-30-91.

d. DOE 5500.4A, PUBLIC AFFAIRS POLICY AND PLANNING REQUIREMENTS FOR EMERGENCIES; of 6-8-92.

e. DOE 5500.5A, PUBLIC AFFAIRS POLICY AND PLANNING REQUIREMENTS FOR A FUEL SUPPLY DISRUPTION EMERGENCY, Of 6-8-92.

f. DOE 5500.7B, EMERGENCY OPERATING RECORDS PROTECTION PROGRAM; Of 10-2391.

g. DOE 5500.8A, ENERGY EMERGENCY PLANNING AND MANAGEMENT, of 7-8-92.

h. DOE 5500.9A, EMERGENCY PLANNING, PREPAREDNESS, AND RESPONSE TO CONTINUITY OF GOVERNMENT EMERGENCIES, of 7-8-92.

i. - DOE 5500.10, EMERGENCY READINESS ASSURANCE PROGRAM, of 4-30-91.

3. APPLICABILITY.

a. DOE.Elements. Except for the exclusions below, this order applies to a11 DOE Elements.

b. Contractors. Except for the exclusions below, Attachment 1 sets forth requirements to be appijed to the universe of contractors awarded DOE procurement contracts involving the management and operation of DOEowned and -leased facilities and activities, contractors awarded performance based management contracts, or contractors with responsibility for providing. Emergency Assistance. Contractor requirements shall be supplemented, as necessary, by the DOE Field Elements to implement the requirements of this Order. Contractors shat1 be directed to continue to comply with the requirements of Orders canceled by this Order until their contracts are modified to delete the reference to the requirements of the canceled Order.

c. Exclusions.

(1) The facilities and activities of the Naval Nuclear Propulsion Program and the Power Marketing Administrations are exempt from the requirements of this Order.

Vertical line denotes change: 
9-25-95

(2) Ali DOE facilities subject to Nuclear Regulatory Commission (NRC) license requirements are specifically exempted from the requirements of this . Order.

(3) If a DOE Element or contractor can demonstrate that it is subject to emergency management program requirements under the authority of. other Federal reguiatory agencies and those requirements are at least as stringent as the requirements of this order, then an exemption may be requested.

(4) Requests for exemptions from the requirements of this Order shall document the basis for each exemption and shall establish and justify alternatives equivalent to, or exceeding, this order. Requests for exemptions shall be submitted for approval by the Under - : Secretary. .

\section{REQUIREHENTS.}

\section{a. General.}

(1) DOE sites/facilities, including DOE transportation activities, Operations/Field Offices, and.DOE Headquarters offices shall deveTop and participate in an integrated and comprehensive Emergency Management System to ensure that:

(a) the Department can respond effectively and efficientiy to Operational Emergencies and Energy Emergencies, and can provide Emergency Assistance so that appropriate response measures are. taken to protect workers, the public, the environment, and the national security;

(b). emergencies are promptly recognized and classified, and parameters associated with the emergency are monitored to detect changed or degraded conditions;

(c) emergencies are reported and notifications are made; and

(d) reentry activities are properiy and safely accomplished, and recovery and post-emergency activities comence properly.

(2) Emergency planning shall include: identification of hazards and. threats, hazard mitigation, development and preparation of emergency. plans and procedures, and identification of personnel and-resources needed for an effective response.

(3) Emergency preparedness shall include acquisition and maintenance of resources, training, drills, and exercises. .

(4) Emergency response shall inciude the appijcation of resources to mitigate consequences to workers, the pubiic, the environment, and 
the national security, and the initiation of recovery from an emergency.

(5) Recovery shall include planning for and actions taken following termination of the emergency to return the facility/operations to normal.

(6) Readiness assurance shall include assessments and documentation to ensure that stated emergency capabilities are sufficient to implement emergency plans:

(7) The Headquarters Emergency Operations Center sha17 serve as the. point of contact for receipt of al1 emergency notifications and reports. Accordingly, the Headquarters Emergency Operations Center receives, coordinates, and disseminates emergency information to Headquarters Elements and Program Office emergency points of contact, the White House Situation Room, and other Federal agencies.

(8) The Assijstant Secretary for Environment, Safety and Health provides independent oversight of the Comprehensive:Emergency Management System.

(9) Implementation of a comprehensive emergency management progran at a DOE site/facility/activity shall be commensurate with the hazards present at that site/facility/activity (i.e., it shall be developed consistent with a graded approach).

(10) Responsibilities shall be established in accordance with Chapter I of this Order.

(11) A Headquarters Emergency Management Team shalf be established, as necessary, for Operational Emergencies, Energy Emergencies, and Emergency Assistance. See.-Chapter. II for team organization and functions.

(12) Each -DOE site/facility shàl1 have an Operational Emergency Base Progran that implements the requirements of applicable Federal, State, and local laws/regulations/ordinances. for fundamental worker safety programs (e.g., fire, safety, and security). These requirements are not unique to DOE operations. See Chapter. III.

(13) - In addition to the Operational Emergency Base Program, each DOE site/facility with significant quantities of hazardous materials (radiological and non-radiological). shall develop and maintain a quantitative hazards assessment and meet. more detailed. emergency planning requirements: Hazardous materials. are any solid,. liquid,. or gaseous material that is toxic, flamable, radioactive; corrosive, chemically reactive or unstable upon prolonged storage in quantities that could pose a threat to life, property, or the environment. $0 i 1$ is not included in this definition of hazardous 
materials. See Chapter IV for specific requirements pertaining to Operational Emergency Hazardous Materials Programs.

(14): Each DOE site/facility shall declare an Operational Emergency when events or conditions require time-urgent response from outside the immediate/affected site/facility or area of the incident. Such events or conditions cause, or have the potential to cause, serious health and safety impacts to workers or the public, serious detrimental effects on the environment, direct harm to people or the environment as a result of degradation of security or safeguards conditions, or loss of control over hazardous materials.. Each DODE site/facility shall further classify Operational Emergencies involving hazardous materials as an Alert, Site Area Emergency, or General Emergency, in order of increasing severity. 'See Chapter V.

(15) The Department's Energy. Emergency Program shall encompass events or conditions representing, causing, or having the potential to cause, a substantial impact on energy. supply or infrastructure in a limited Tocal area, region of the country, or the nation as a whole. See.

- Chapter VI.

(16) Directed by Executive Order or other binding agreements, the Department's Emergency Assistaice Program shall encompass a DOOE response to national security threats or other events or conditions requiring DOE assistance, expertise, resources, or assets, and inciuding . Continuity of Government and Continuity of Operations Programs.. Accordingly, the Emergency Assistance Program shall include all activities whereby Departmental resources, emergency response assets, personnel, and/or facilities. are used.to support Federal P.7ans, Presidential directions, and State;- local, or-Tribal agreements of mutual aid. See Chapter VII.

(17) Each DOE site/facility shall notify DOE and offsite officials when emergencies occur. The notification and reporting requirements within this Order-have-been coordinated with DOE requirements for non-emergency occurrence reporting. See.Chapter VIII.

(18) Each DOE site/facility shall provide accurate; candid, and timely information about emergencies to workers and the public. See Chapter IX.

(19) Each DOE site/facility shall establish a readiness assurance program to ensure that stated energency capabilities are sufficient to implement emergency plans. See Chapter $X$. 
(20) Each DOE site/facility, along with Operations/Field Offices, shall document the emergency management program in an Emergency Pian. See Chapter XI.

b.. Planning and Preparedness. Each site/facility and Department element shali assess its emergency management. needs to plan and implement a comprehiensive eniergency management program commensurate with the hazards present (i.e., consistent with a graded approach).

(1) Operational Emeraencies.

(a). Sites/Facilities/Activities. All Department elements and contractors with responsibilities for site/facility operations and activities shall participate in development of comprehensive emergency management programs: Such prograns shall contribute to the Department's comprehensive Emergency Management System by promoting effective and efficient integration of all applicable requirements, inciuding. those promulgated by other agencies.

(b) Operations/Field Offices. Operations/Field Offices shall have a trained emergency response staff and shall provide. sites/facilities/activities under their cognizance with:

1 direction to implement emergency management policy and requirements;

2 direction in emergency planning and preparedness activities;

3 support and assistäce during emergencies; and

4. support and assistance in resolving issues in. site/facility/activity emergency management programs; as wel1 as assessments of site/facility/activity emergency management programs.

(2) Eneray Emergencies. - The Energy Emergency. Program shal.1 be planned to ensure that the Department is capable of assisting..in the prevention and mitigation of energy, supply crises and. their associated economic impacts. The program shali also provide for DOE assistance for Presidentially declared emergencies invoking the Stafford Act (Public Law 93-288; as amended) and: as: implemented through the Federal Response P1an. The Energy Emergency Program may be implemented coincident with -Emergency Assistance.

(3) Emergency Assistance. Emergency Assistance planning and preparedness shall include preparation for deployment- of Departmental resources, emergency response assets, and personner; and/or use of facilities to support Federal interagency plans, 
Presidential directions, and State, Tocal,- or Tribal agreements of mutual aid. Emergency Assistance may be implemented coincident. with an Energy Emergency response.

(4) Headquarters.

(a) The Director. of Emergency Management is the single point of contact and control for all emergency management activities and issues all policy, requirements, and guidance for the Department's Emergency Management System.

(b) Cognizant Secretarial officers ensure implementation of policy and requirements for activities conducted by sites/facilities and Operations/Field Offices under their cognizance.

(c) The Assistant Secretary for Defense Programs provides programmatic direction for the Department's radiological emergency response assets. The Assistant Secretary for Environmental Management provides programmatic direction for the Transportation Emergency Preparedness Program. The Director of Nuclear Energy provides programmatic direction for space nuclear system applications, including space Taunch and space flight aborts. Programmatic direction for these programs shall be provided in coordination with the Director of Emergency Management.

c. Response.

-(1) Operational Emergency Response.

(a) Site/Facility. Personnel and resources at the site/facility level comprise the primary response capability for an Operational Emergency.

$1 \quad$ Sites/facilities shall direct appropriate emergency response actions within the area under their control and at the scene of the emergency, including effective coordination between the incident commander at the event scene and the individual in charge of overall management and coordination of site/facility response activities.

2 Sites/facilities shall promptly notify local, State, Tribal, DOE, and other regional Federal agencies when everits categorized as Operational Emergencies occur.

Vertical Tine denotes change. 
(b) Operations/Field Offices.

1 Operations/Field Offices shal monitor the facility response, provide support, and assist with issue resolution.

2 Operations/Field Offices shall monitor the notification process at the site/facility and make notifications of applicable DOE emergency.events as necessary or appropriate.

3 Operations/Field Offices shall coordinate interagency and public information activities at the regional level and coordinate directly with Headquarters.

4 The specific structure of Operations/Field Office Emergency Management Teams depends on the relationship (contractual and geographic) to the-site/facility. All Qperations/Field Office Emergency Management Teams shall have-a senior official who serves as an emergency manager with decision-making responsibilities'. Such individuals shall be supported by personnel with communications, technical, and liaison and public affairs expertise.

5 The Operations/Field Office Emergency Management Team may be activated for any emergency declaration.

(2) Energy Emergency Response. Response activities for Energy Emergencies are normally concentrated at DOE Headquarters. DOEresponsibilities for Energy Emergencies are delineated within interagency Federal response and recovery plans, Executive Orders, and international agreements. DOE. Headquarters shall monitor Energy Emergencies for changing requirements and brief the White House and Congressional offices.

(3) Emergency Assistance Response. - Response to events requiring DOE Emergency Assistance shall be directed to appropriate DOE Headquarters elements. DOE responsibilities for Emergency Assistance are delineated within interagency Federal response and recovery plans, Executive Orders, and/or-international agreements. DOE Headquarters shall monitor such events. for changing requirements, brief the White House and Congressional offices, and develop options for continuing Departmental operations and missions.

(4) Headquarters. DOE Headquarters shall receive information on the facility, site, or area response; monitor the -0perations/Field Office response; provide appropriate: support and assistance; assist with issue resolution; and coordinate interagency, Congressional, and public information activities at the national level. 
(a) - The Headquarters Emergency Management Team for Operational Emergencies, Energy Emergencies, and Emergency Assistance shal1 consist of an Executive Team and a Technical Operations Cadre (see Chapter II for team organization).

(b) The Executive Team shall provide strategic direction to the Department and evaluate the emergency's impact on Departmiental operations, missions, and functions.

(c) The Technical Operations Cadre shall use a matrix approach to provide technical and support personnel from appropriate Headquarters elements. The Cadre shall analyze information regarding the cause of and severity of the emergency and its potential impacts on workers, the public, the environment, and national security. The Cadre shall also coordinate any support needed from other. Federal agencies and prepare Departmental briefings on the emergency.

(d) The Headquarters Emergency Management Team shall be Ted by a predesignated Emergency Manager at the Principal Deputy Assistant Secretary or equivalent level. . The Under Secretary shall predesignate Emergency Managers. A minimum of three Emergency Managers shall be predesignated for:each emergency category (i.e., Operational, Energy, and Emergency Assistance). The Director of Emergency Management is the Chief of Staff (Operations Officer) for all activations of the Headquarters Emergency Management - Team.

(e) Activation of the Headquarters Emergency Management Team is at the direction of the Under Secretary, in coordination with the Emergency Manager and the Director of Emergency Management. The. Executive Team convenes at the direction of the Emergency Manager or the Under. Secretary.

(f) The Headquarters team is normalily activated only foremergencies that involve serious or potentially serious threats to the heaith and safety of workers and the public, the environment, or national security.

(g) At DOE Headquarters, the Emergency Manager in coordination with the Director of Emergency Management recommends to the Under Secretary when the Headquarters Emergency Management Team should be deactivated and if a recovery team is needed.

(5) Response Termination. In genera], response activities are terminated when the situation has been stabilized. At this point, potential threats to workers, the public, the environment, and national security have been. characterized, conditions no longer meet established emergency categorization criteria, and it appears. uni ikely that conditions will deteriorate. In coordination with 
response organizations, the emergency is then declared terminated and activities focus on recovery.

d. Recovery. Mitigative, cleanup, and restoration activities may begin prior to response termination. However, excluding recovery. pianning, recovery activities fully begin following response termination: Recovery activities require the coordinated efforts of the affected site/facility; its 7 ine management; the Office of Emergency Management; the Office of Environment, Safety and Health; the Office of Environmental Management; . General Counsel; and the Office of Congressional, Public and Intergovernmental Affairs. Specific recovery requirements and procedures are established on a case-by-case basi.s.

5. RESPONSIBILITIES. See Chapter I.

6. IMPLEMENTATION.

a: Sites/facilities shall deveilop implenentation schedules for-fuil compliance. These schedules shall be submitted to the Operations/Field Office Manager for approval with the next annual Emergency Readiness Assurance Plan.

b. Hazards surveys, changes to hazards assessiments, or new hazards assesșments shail be completed by September 30, 1997.

c. To fully comply with this Order, site/facility emergency management programs shall be completed by September 30, 1999.

d. Mon-mandatory implementation guidance for this order is published separately in the Emergency Management Guides (or replacements).

7. CONTACT. For assistance regarding this directive, contact the Director of Emergency Management at 202-586-9892.

BY ORDER OF THE SECRETARY OF ENERGY: 
9-25-95

TABLE OF COHTENTS

Page

\section{CHAPTER I - RESPOASIBILITIES}

1. Under Secretary . . ..................... I-1

2. Director of Nonproi iferation and Nationai Security ......... I-I

3. Director of Emergency Management . . . . . . . . . . . . I I-1

4. Standing Emergency Management Coordinating Committee ......... I-2

5. Emergency Management Advisory Committee . . . . . ........ I-3

6. Emergency Manager ................. I-3

7. Cognizant Secretarial officers .................. I-3

8. Operations/Field Offices Managers . ............. I-4

9. Site/facility Managers.$\ldots \ldots \ldots \ldots$ I-6

10. Initiators of Procurement Requests $\ldots \ldots \ldots \ldots$ I-7

CHUPTER II - HEADOUARTERS EXERGEHCY MAHAGEMENT TEAY

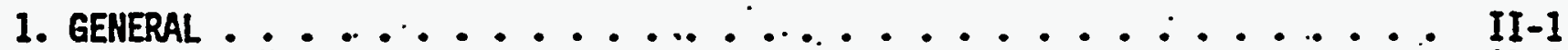

2. EXECUTIVE TEAM $\ldots \ldots \ldots \ldots$ II-1

3. TECHICAL OPERATIONS CADRE $\ldots \ldots \ldots \ldots \ldots$ II-2

CHAPTER III - OPERATIOHAL EYERGEHCY BASE PROGRAY

1. GEHERAL REQUIREMENTS ....................... III-1

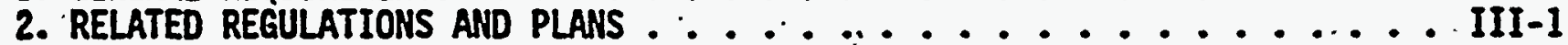

3. PLANHING PHASE ...................... IIII-2

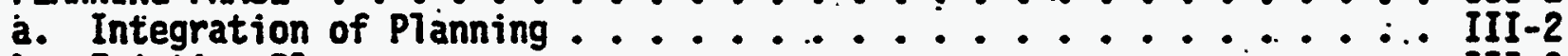

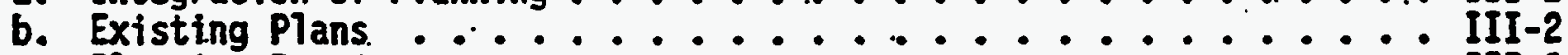

c. Planning Requirements ........................

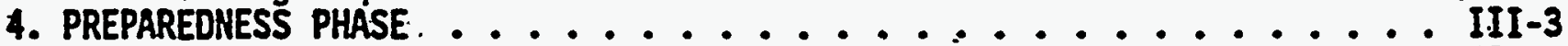

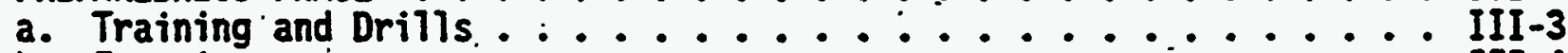

b. Exercises . ......................... III-4

5. RESPONSE PHASE ................................. III-4

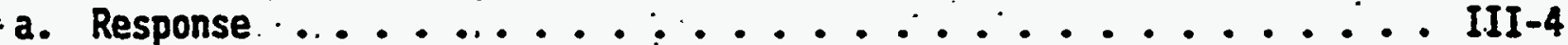

b: Termination and Recovery ................ III-4

CHAPIER IV = OPERATIOHAL EIERGEHCY HAZARDOUS MATERIAL PROGRAY

1: GEMERAL REQUIREMENTS ................. IV-1

2. RELATED REGULATIONS AND PLANS $\ldots \ldots \ldots \ldots \ldots$ IV-1

3. PLAHIIIG PHASE $\ldots \ldots \ldots \ldots$ IV-2

a. Hazards Assessment ................. IV-2

b. Planning Requirements ................. IV-3

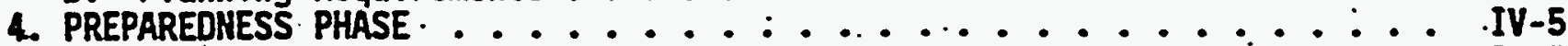

a. Training and Dritls ................... IV-5

b. Exercises ..................... IV-5

5: RESPONSE PHASE ................... IV-6

a. Response ........................... IV

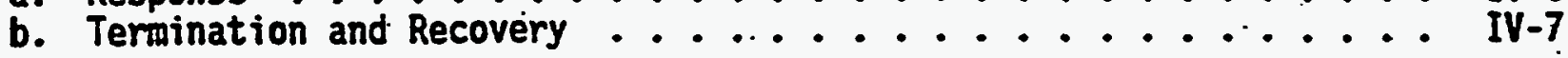


CHAPTER $V$ - OPERATIOHAL EMERGENCY EUENS AND CONDITIONS

1. GENERAL . . . .................. . . . . .

2. BASE PROGRAM EVENTS ...................

a. Health and Safety ................... V-1.

b. Environment .....................

c. Security and Safeguards .............. V-2

d. Offsite doE Transportation Activities : ....... . V-3

3. HAZARDOUS MATERIALS (RADIOLOGICAL AND NON-RADIOLOGICAL) $\because \ldots \ldots \ldots$

a. Alert . . . . . . . . . . . ...... V V-3

b. Site. Area Emergency .................. V-4

c. Generat Emergency .................. V-4

\section{CHAPTER YI - EIERGY EXERGEHCY PROGRAY}

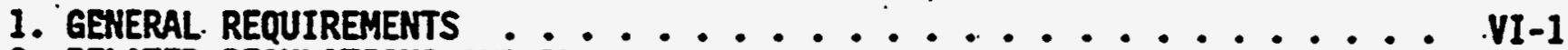

2. RELATED REgULATIONS AND PLANS $\ldots \ldots \ldots \ldots$ VI-1

3. PLANNING PHASE ............................ VI

a. Hazards Assessment ................... VI-I

b. Planning Requirements ................ vi-1

4. PREPAREDNESS PHASE $\ldots \ldots \ldots$ vI -2

5. RESPONSE PHASE $\ldots \ldots \ldots \ldots \ldots$ VI-2

\section{CHAPTER VII - EHERGEICY ASSISTALCE PROGRAN}

1. GENERAL REqUIREMENTS ................. vil-1

2. RELATEd REgULATIONS AND PLANS ................... VII-1

3. PLANNING PHASE ..................... VII-1

4. PREPAREDNESS PHASE: . $\ldots \ldots \ldots \ldots$

5. RESPONSE PHASE ........................... VII-2

\section{CHAPTER VIII - COWMHICATIOUS REOUIREXEITS}

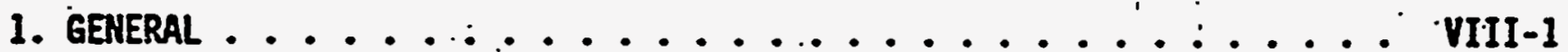

2. PLAENING PHASE $\ldots \ldots \ldots \ldots \ldots$ VIII-1

3. PRE AREDNESS PHASE .................. VIII-1

4. RESPOHSE PHASE . . . . . . . . . . VIII-1

a. Initial Emergency Notifications . ............ viII-1

b. Emergency Status Updates ................. vIII-2

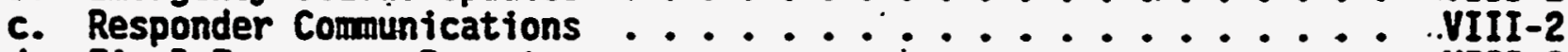

d. Final. Emergency Report ................... VIII -2

e. Recovery Reporting ................... VIII-2

f. Classified Information Reviews ............... VIII-2

g. Energy Emergencies and Emergency Assistance Response ..... VIIII-2

CHAPTER IX - PUBLIC AFFAIRS POLICY ALD PLANIIHG REOUIREYEITS

1. GEHERAL . . ........................ IX-I

2. PLANNING PHASE $\ldots \ldots \ldots \ldots$ IX-1

3. PREPAREDNESS PHASE $\ldots \ldots \ldots \ldots$ IX-2

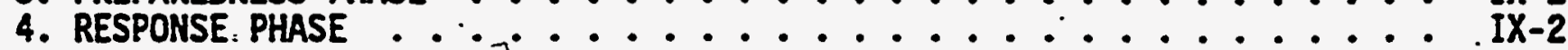




\section{CHAPTER $X$ - EYALUATIOAS AND READIHESS ASSURAHCE}

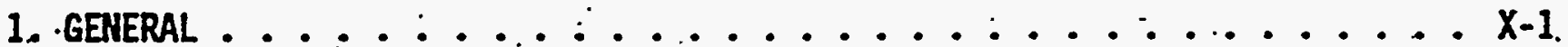

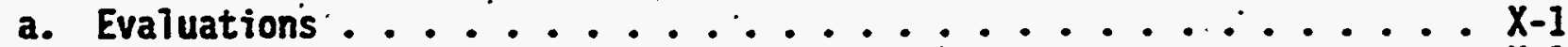

b. Emergency Readiness Assurance Plans (ERAPs) ........... X-1

c. Appraisal and Assessment Programs .............. . . X-1

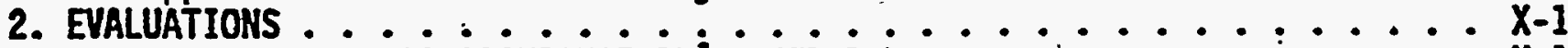

3. EHERGENCY READINESS ASSURANCE PLÃNS (ERAPS) ......... $\ldots$.

4. EHERGENCY READINESS ASSURANCE APPRAISALS AND ASSESSMENTS $\ldots . \ldots . . . \mathrm{X}-2$

\section{CHAPTER XI - PROGRAY ADNILISTRATION}

1. PERSONNEL REQUIREMENTS $\ldots \ldots \ldots \ldots$ XI-I

2. CLASSIFICATION REVIEW .................. XI-I

3. EMERGENCY-PLANS : .................... XI-1

4. EMERGENCY PLAN IMPLEMENTING PROCEDURES $\ldots \ldots \ldots \ldots$ XI-1

5. LESSONS LEARNED : . ................. XI-1

6. EMERGENCY OPERATING RECORDS PROTECTION PROGRAM: .......... XI-I 


$$
\begin{aligned}
& \therefore \\
& \begin{array}{cc}
\cdot & \cdot \\
\cdot & \\
\cdot & \cdot \\
& \cdot
\end{array} \\
& \text {. }
\end{aligned}
$$

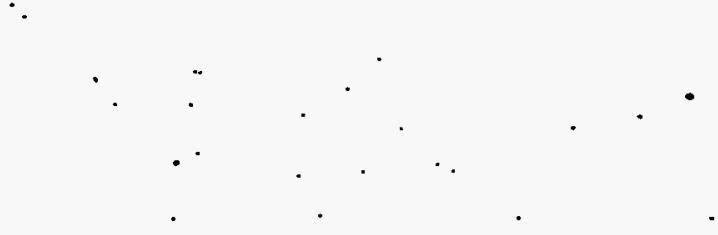




\section{CHAPTER I}

\section{RESPONSIBILITIES}

1. UHOER SECRETARY.

a. Serves as senior emergency management polịcy official.

b. In coordination with Cognizant Secretarial officers, designates Principal Deputy Assistant Secretaries to serve as Emergency Managers for Headquarters activations during emergency-responises or exercises.

2. DIRECTOR OF NONPROLIFERATION AND NATIONAL SECURITY (in addition to responsibilities as the Cognizant Secretarial Officer) provides overal1 : direction to the Director of Emergency Management for the management and allocation of resources and development of capabilities for emergency. management activitịes.

3. DIRECTOR OF EMERGENCY MANAGEMENT is the single point of contact and control - for al1 emergency management activities and has program management responsibilities and authorities for the following.

a. Issues al7 policy, requirements, and guidance-for the Department's Emergency Management System.

b. Coordinates and concurs on all emergency management activities, including intra- and inter-Departmental and international activities, Departmental comitments, and exercise and response activities.

.c. Ensures the Emergency Management System provides a comprehensive and integrated approach to emergency management, including planning, preparedness, response, and recovery.

d. Evaluates all line/program emergency management- activities. (TheAssistant Secretary for Environment, Safety and Health provides independent oversight.)

e. Ensures emergency management program integrity through integration of all programs, systems, assets, capabilities, training, and response:

f. Conducts emergency management program reviews and attends 1 ine management program reviews.

g. Establishes, charters, administers; convenes, and chairs the Standing Emergency Management Coordinating Committee.

h. Establishes, charters, administers, convenes, and chairs the Emergency Management Advisory Committee. 
i. Serves as budget and staffing advocate for emergency management programs.

j. Prepares and maintains $\mathrm{p} 7$ ans and procedures for DOE Headquarters response to emergencies, in coordination with Cognizant Secretarial Officers, and conducts al1 Headquarters Emergency Management System training.

k. Serves as Chief of Staff (Operations Officer) for the Headquarters Emergency Management Team for al1 emergency response/exercise activations.

1. Manages, maintains, and operates a 24-hour single point of contact for Headquarters emergency operations facili.ties and attendant management

- support capabilities; maintains a qualified cadre of Departmental experts capable of supporting an emergency.

m. Serves. as the point of contact for assessments. of hostile threats to Departmental facilities and all nuclear threat assessments, and for . DOE!'s technical, analytical, and research expertise, which may assist the law enforcement community.

n. With the Associate Deputy Secretary for Field Management and the Assistant Secretary for Environment, Safety and Heaith, and in coordination with the Cognizant Secretarial officer(s), ensures the. establishment of performance measures and criteria for development and. approval of facility and site emergency plans and Emergency Planning Zones.

0. Establishes systems and measures to monitor and evaluate Operations/Field Office and Headquarters offices emergency management programs.

p. Ensures the coordinated development and maintenance of Departmental portions of Federal interagency and international emergency management plans. and agreements.

q. Provides an annual status report to the Under: Secretary on-DOE readiness assurance.

4. STANDING EMERGENCY MANAGEMENT COORDINATING COMHITIFE.

a. Members include Deputy or Associate Deputy Assistant Secretaries or equivalent level from: Nonproliferation and National Security, Defense Programs, Environmental Management, Energy Research, Nuclear Energy; Fossil Energy, Energy-Efficiency, and Field Management. - Deputy- or. Associate: Deputy Assistant: Secretaries or equivalent: 1eve] from Policy and. Environment, Safety and Health serve as ex officio members. 
b. Identifies and resolves emergency management issues, or as necessary refers issues to the Executive Committee for resolution.

5. EMERGENCY MANAGEMENT ADUISORY COMHITTEE.

a. Members incTude representatives appointed by Headquarters Cognizant Secretarial Officers and Operations/Field Offices Managers.

b. Provides support to the-Director of Emergency Hanagement in identifying and resolving Department-wide emergency management issues.

6. EMERGENCY MANAGER.

a. Leads Headquarters Emergency Management Team and serves as Deputy Chair

of the Executive Team.

b. In coordination with the Director of Emergency Management activates the Headquarters Emergency Management Team at the direction of the Under. Secretary.

c. "In conjunction with the Under Secretary, convenes the Headquarters Executive. Team.

d. In coordination with the Director of Emergency Management recommends to the Under Secretary when the Headquarters Emergency Management Team. should be deactivated and if a recovery team is needed.

7. COGNIZANT SECRETARIAL OFFICERS.

a: Ensure impiementation of emergency management poicicy and requirements; maintain programs and systems consistent with policy and requirements.

.b. 'Ensure funding and resources are adequate for DOE facilities and activities for the continuing and effective implementation of emergency. management programs, and that emergency. response assets and.capabilities are appropriately maintained.

c. Develop; in coordination with the Operations/Field Office, the Associate. Deputy Secretary for Field Management, the Assistant Secretary for Environment, Safety and Health, and the Director of Emergency Management contractor performance measures and criteria.

d. Ensure full coordination with the Director of Emergency Management on all emergency management activities.

e. Within areas of programmatic responsibility, ensure the following:

(1) Readiness assurance activities are performed, and emergency preparedness activities, inciuding emergency response exercises, are fully coordinated with the Director of Emergency Management. 
(2). A system/program is established and maintained for 24-hour initial. receipt and further dissemination of emergency notifications; and a

- current 7isting of personinel designated to perform the function is maintained and routinely provided to the Director of Emergency. Management.

(3) Specialized technical representatives and subject matter experts are provided when a Headquarters Emergency. Management. Team is convened.

(4). Training and response is adequate in Operations/Field Office programs.

f. Conduct line management reviews of program-specific emergency management

- activities in coordination with the Director of Emergency Management.

g. Coordinate with the. Assistant Secretary for Congressional, Public and Intergovernmental Affairs; and the Director of Emergency Management to provide for the handling and control of information on emergency situations.

h. Assign:

(1) Principal Deputy (as designated by the Under Secretary) to serve as an Emergency Hanager for Headquarters activation during emergency responses or exercises;

(2) Deputy Assistant Secretary or Associate Deputy Assistant Secretary or equivalent level to serve on the Standing. Emergency. Management Coordinating Committee;

(3) Deputy Assistant Secretary or Associate Deputy: Assistant: Secretary or equivalent to serve as the Deputy Chief of Staff for-Technical Operations and to co-direct the Headquarters Technical Operations Cadre; and

(4) Senior representatives for the Emergency Management Advisory Coumittee.

8. OPERATIONS/FIELD OFFICE MANAGERS.

a. Implement emergency management policy and requirements, and maintaip programs and systems consistent with policy and requirements.

b. Establish and maintain an effective, integrated emergency management program.

c. Partner with the Cognizant Secretarial Officers, the Associate Deputy Secretary for Field Management, the Assistant Secretary for Environment, Safety and Health, and the Director of Emergency Hanagement to establish 
and maintain performance measures and criteria to implement this Order for facilities and activities under their cognizance, and to ensure that these performance measures and criteria are incorporated in contractual arrangements.

(1). Approve and. submit approved site Emergency Plans to the Director of Emergency. Management and the Cognizant Secretarial Officer(s).

(2) Approve and submit approved Emergency Planning Zones. to the Assistant Secretary for Environment, Safety and Health; the Director of Emergency Management; and the Cognizant Secretarial officer(s).

d. Coordinate with the Cognizant Secretarial Officer(s) to ensure resources are avajlable to implement this order for facilities and activities. under their cognizance.

e. Ensure development of appropriate emergency plan implementing procedures for timely and accurate energency classification, notification, and reporting of emergency events for facilities under their cognizance. Estabijish pre-authorization criteria when possible.

f. Ensure emergency public information planning. is integrated with the - development and maintenance of Emergency Plans.

g. Ensure effective communication systems and protocols are coordinated and maintained with the Headquarters Emergency Operations Center regarding emergencies involving or affecting facilities: or materials under. DOE jurisdiction or. requiring DOE assistance.

h. Review and approve Emergency. Readiness Assurance Plans (ERAP) that cover facilities under their supervision; prepare the Operations/Field office annual Emergency Readiness Assurance Plan; and submit it to the Cognizant Secretarial Officer and the Director of Energency Managenent for inclusion in the annual report of the Under Secretary on the status of the Energency Management System.

i. Where applicable, predesignate. a DOE employee as the On SceneCoordinator for Federal-responses under the National Contingency Plan and as the Ori Scene Commander and/or Senior. Energy. Official in accordance with the Federal Radiological Emergency Response Plan.'

j. Participate in the development and implementation: of mutual assistance agreements with State, Tribal, and local authorities.

k. Ensure that hazards assessments and hazards surveys for emergency planning purposes are adequately performed and documented. 
1. Ensure Operations/Field Offices and contractors participate in a continuing emergency preparedness program of training, dri17s, and exercises:

m. Conduct periodic assessments of facility emergency management programs and/or periodically review contractor self-assessment programs to ensure compliance with DOE directives and policy; provide the results/conclusions to the Cognizant Secretarial Officer and the Director of Emergency Hanagement. Ensure a maximum of one assessment . . per: site per year.

n. During an emergency, conduct appropriate and necessary emergency actions.

o. Implement corrective actions for lessons learned from actual emergency responses and based on findings from evaluations, assessments, and . appraisals.

p. Establish and maintain an Emergency Operations Center to respond to emergency events. Every DOE Emergency Operations Center shall be equipped with compatibie communication, photo/video, and automatic data processing support specified by. the Director of Emergency-Management.

q. Ensure that emergency plans and procedures are prepared, reviewed annually, and updated, as necessary, for all facilities under their purview and are integrated within the overal7 Operations/Field Office emergency preparedness program.

r. Assign senior representatives to the Emergency Management. Advisory Committee.

s. Comply with the requirements of the DOE 5530-series . Orders, which establish requirements for the radiological emergency response assets programs.

\section{SIIE/FACILITY MANAGERS.}

a. Develop, implement, maintain, and update, as necessary, an emergency management program, comensurate with the facility-specific hazards and consistent with Departmental directives and standards of performance.

b. Prepare and maintain emergency plans, procedures, and technical resource capabilities that address emergency. classification, notification;. reporting, response actions, training and drills, exercises, emergency public information, outreach and coordination, accident investigation, and applicable Federal statutes, State and Tocal Taws, DOE Orders; and implementing regulations and guidance. 
c. Prepare and submit to the cognizant Operations/Field Office Hanager for approval documentation to estab7 ish Emergency Planning Zones, Emergency. Plans, and .Emergency Readiness Assurance Plans.

d. Direct appropriate emergency response actions within the area under their control and at the scene of the emergency.

e. Participate in the development of mutual assistance agreements with State, Tribal, and local authorities.

$\dot{f}$. Ensure the effectiveness of a continuing emergency preparedness program.

g. Establish and.maintain an internal assessment program to ensure the readiness of emergency response capabilities, including developing and

- conducting a self-assessment program, as weil as estabijishing systems and. measures to monitor and evaluate line performance.

10. INITIATORS. OF. PROCUREMENT REOUESTS shait specify in procurement requests if the requirements in the Contractor Requirements Document for this Order are . to be.applied to the award or subaward resulting from the procurement . request. 
CHAPTER II

HEADQUARTERS EMERGEHCY MANAGEYEST TEAY

1. GEMERAL. The Headquarters Emergency Hanagement Team. led by a predesignated Emergency. Manager consists of an Executive Team and a Technical Operations Cadre.

\section{EXECUTIVE TEAH:}

a. The Headquarters Executive Team is chaired by the Under Secretary. The Emergency Manager serves as the Deputy. Chair. The Director of Emergency

$-$ Management serves as the Chief of Staff (Operations Officer).

b. The following individuals, or their designees, shall serve as core members of the Headquarters Executive Tean.

(1). Under Secretary.

(2) Secretary's Representative.

(5). Director of Nonproliferation and National Security.

(4) Assistant Secretary for Congressional, Public and Intergovernmental Affairs.

(5) Associate Deputy Secretary for Field Management.

(6) Assistant Secretary for Environment, Safety and Health.

c. The following individuals, or their designees, shall serve as members of the Headquarters Executive. Team for emergencies involving sites/facilities/activities under their cognizance or if they are requested by the Under Secretary.

(1) Assistant Secretary for Defense Programs.

(2) Assistant Secretary for Energy Efficiency.

(3) Administrator, Energy Information Administration.

(4) Director of Energy Research.

(5) Assistant Secretary for Environmental Mạnagement.

(6) Assistant Secretary for Fossil Energy.

(7) Director of Nuclear Energy. 
(8) Assistant Secretary for Policy.

(9) Headquarters Tiaison to the Power Marketing Administrations.

d. For Energy Emergencies, the core group shal7 be augmented, as appropriate, by the Assistant Secretary for Fossil Energy, the Assistant Secretary-for-Energy Efficiency and Renewable Energy, and the . Administrator of the Energy Information Administration.

\section{IECHNICAL OPERATIONS CADRE.}

a. The Technical Operations Cadre is co-directed by the Deputy Chief of Staff for Technical Operations and the Deputy Chief of Staff: for Emergency.Operations: The primary Affected Program Office provides the

- Deputy Chief of Staff for Technical Operations, and the Office of Emergency Management provides the Deputy Chief of Staff for Emergency Operations.

b. The following offices shail provide members to serve- on the Technical : Operations Cadre in various capacities.

(1). The Office of Emergency Management provides Emergency Operations Center Support Coordinators, emergency management specialists; and technical and administrative support.

(2) Affected Program Office(s) provide technical/scientific experts.

(3) The Assistant Secretary for Congressionat, Public and Intergovernmental Affairs provides public. affairs, congressional, and intergovernmental 1 iaison specialists.

(4) Other Progran Office(s) provide support as necessary.

(a) Office of Nuclear Energy (e.g., nuclear energy experts).

(b) Office of Environmental Management (e.g., waste and transportation experts).

(c) Office of Nonproliferation and Nationai Security (e:g., intelligence, security, safeguards, arms controt, and. nonproliferation experts).

(d). Office of Defense Programs (e.g.,. program manager for radiological energency response assets and nuclear weapons experts).

(e) Office of-Environment, Safety and Health-(e.g., industrial hygiene, fire protection, environmental, safety engineers, epidemiologists). 
(f) Office of Policy.

(g) Office of Fossil Energy (e.g., experts in fossii energy operations).

(h) Energy Information Administration (e.g., energy infrastructure experts). 


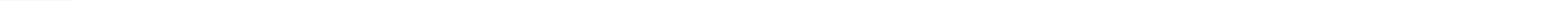




\section{OPERATIONAL EXERGEHCY BASE PROGRAY}

1. GEMERAL REOUIREMENTS. 'Each DOE site/facility shall have an Operational Energency.Base Program that provides the framework for response to serious events involving health and safety, the environment, safeguards, and security. These events are not unique to.DOE operations. Any everit involving the release of oil is within the scope of the Operational Energency Base Program.

2. RELATED REGULCATIONS AND PLANS. The Operational Emergency Base Program shall provide for compliance with the following regulations and pians developed by other Federal Agencies and DOE Offices, and with those State and Tocal. planning and preparedness requirements that apply:

a. . Occupational Safety and Health Administration requirements. for-employee evacuation plans. (29 CFR 1910.38) and notification systems (29 CFR 1910.165).

b. Federal property management reguiations for occupant emergency programs - (41 CFR 101-20.103-4) and accident and fire prevention:(41 CFR 10120.105).

c. Federal Emergency Management Agency requirements for energency operations plans for State and Tocal governments (44 CFR 302) that address similar. hazards.

d. Federal Energy Regulatory Comnission requirements for emergency plans (18 CFR 12.20) to protect the health and safety of members of the public. upstream and downstream of water projects (dams).

e. Environmental Protection Agency requirements, implementing the Clean . Water Act through the National Pollution Discharge Elimination Systen (40 CFR 100 series). Of particular note are requirements for contingericy.planning for oil spills through the 40 CFR 112 series, which mandates preparation of Spi11 Prevention Control and Countermeasure Plans:

f. Environmental Protection Agency requirements implementing the provisions of the Safe. Drinking Hater Act (40. CFR 141-142).

g. Environmental Protection Agency. requirements implementing the Comprehensive Environmental Response, Compensation, and Liability Act, . embodied in the 40 CFR 300 series, including Title III, the Emergency Planning and Community Right-to-Know Act, embodied at 40 CFR 355. 
h. DOE 0.420 .1 , FACILITY SAFETY, which addresses requirements for fire protection programs that include response by DOE or local community fire departments.

i. DOE 5480.8A (or replacement directive), which addresses requirements for planning for treatment of the injured during emergency or disaster - situations.

j. DOE 0 4700.1, SAFEGUARDS AND SECURITY PROGRAM, which addresses requirements for appropriate protection levels for. DOE interests and documentation in facility-specific Site Safeguards and Security Plans.

3. PLANMING.PHASE.

z. Integration of Planning. A hazards survey (i.e., qualitative examination) shall be used to identify the conditions to be addressed by the comprehensive emergency management program. Much of the hazards survey should already have been done in the course of meeting: other DOE and. Federal agency requirements.

(1) Each hazards survey shall:

(a) identify (e.g., in matrix or tabular. form) the emergency conditions (e.g., fires, work place accidents, natura 1 phenomena, etc.);

(b) describe the potential health, safety, or environmental. impacts; and

(c) summarize the planning and preparedness requirements that apply.

(2) Each hazards survey shall combine as many facilities as possible that are subject. to the same-types of hazards. For sites having facilities. that require development. of quantitative- hazards assessments as described in Chapter IV, the remaining facilities. may be covered by one hazards survey.

(3) Hazards surveys shall be updated whenever operations warrant a change, but not less than every 3 years:

b. Existing Plans. Existing plans, such as catastrophic earthquake plans or mass casualty plans detailing compliance with Federal, State, and local standards, may be incorporated directiy into the Operational Emergency Base Program or invoked by reference.

c. Planning Requirements. The Operational Emergency Base Program shall provide for integrated planning to meet the response requirements identified in the hazards survey. At a minimum, the Operational Emergency Base Program shall address the following. 
(1) Emergency Response Organization. Assignment of an individual (e.g., building or facility manager or similar.position) to manage and control all aspects of the site/facility response.

(2) Offsite Response Interfaces. Coordination with State, Tribal, and Tocal agencies and organizations responsible for offsite emergency response (e.g., "911" emergencies) and for protection of the heaith and safety of the public.

(3) Emergency Categorization.- Establishment of criteria for determining quickly if an event is an Operational Emergency. See Chapter $\mathbf{V}$.

(4) Communications: Prompt initial notification of workers, energency response personnel, and response organizations; including DOE elements and State, Tribal, and local organizations; continuing effective communication among response organizations throughout an emergency: See Chapter VIII:

(5) Protective-Actions: Evacuation or sheltering of empioyees, along with provisions to. account for employees after emergency evacuation has been completed; protection of workers involved in response and clean-up covered by 29 CFR : 1910.120.

- (6) Medical Support. In accordance with DOE 5480.8A (or the replacement directive), provision of medical treatment and pianning for mass casualty situations.

(7) Public Information. See Chapter I $\ddot{X}$

(8) Emergency Facilities and Equipment. Provision of facilities and equipment-adequate to support emergency response, inciuding the capability to notify employees of an emergency. to facilitate the safe evacuation of employees from the work place, immediate work area; or both:

(9) Program Administration. See Chapter XI.

4. PREPAREDNESS PHASE.

a. Training and Drills.

(1) Initial training and periodic drills shall be provided to:-all workers who may be required to take protective actions (e.g., assembiy, evacuation) when they are empioyed, when their expected actions change; or when the emergency plan changes.

(2) Refresher training shall be provided annually to.certified operators and-supervisors and those workers who are. likely to 
witness a hazardous material reiease and who are required to notify proper authorities of the release.

(3) Emergency-related information and training on site-specific conditions and hazards shall be made available to offsite personnel who may be. required to participate in response to an emergency at the DOE site/facility.

\section{b. Exercises.}

(1) At a minimum, each site/facility shall conduct building evacuation exercises consistent with Federal regulations [e.g., 41 CFR 10120.105-1(c)(1)], Tocal ordinances, or National Fire Protection Association Standards. Exercises shall be conducted as often as needed. to ensure that employees are able to safely evacuate their work area.

(2) For each site or facility, as applicable, the organization responsible for communications with DDE Headquarters, Operations/Field Offices, and offsite agencies, shall test communications systems at least annualiy or as often as needed to ensure that communications systems are operational.

\section{5: RESPONSE PHASE.}

a. Response.

(1) Re-entry planning shall include contingency planning to ensure the safety of re-entry personnel, such as pianning for the rescue. of re-entry teams. Ail individuals involved in re-entry shall receive a hazards/safety briefing prior to emergency response activities consistent with Federal, State, and local laws and reguiations.

(2) Events exceeding the threshold levels for Operational Emergencies as detailed in Chapter $V$ require notification in accordance with. Chapter. VIII.

b. - Termination and Recovery.- Recovery shall inciude notifications. associated with termination of an emergency and establ ishment: of . criteria for resumption of normal operations: 
i. GENERAL REQUIREMENTS. The Operational Emergency Hazardous Material Program adds to the Operational Emergency Base Program. Depending on the findings of the hazards survey (see Chapter III), DOE sites/facilities may be required to establish and maintain a quantitative hazards assessment, which will be used to define the provisions of the Operational Emergency Hazardous Material Program to ensure the program is commensurate with the hazards identified.' Such hazard assessments are required if the hazard survey identifies, per Chapter III, hazardous materials in quantities exceeding the lower of the Threshoid Quantities listed in 29 CFR 1910.119 or. 40 CFR 68.130; Threshold Planning Quantities; Tisted in 40 CFR 355; or quantities listed in 10 CFR 30.72 for radionuclides. The results of this assessmient provide the basis for establishing:a graded approach that will meet. the program requirements out ined in this chapter. .

2. RELATED REGULATIONS AND PLANS. The following reguiations and plans. have been developed by Congress, other Federal agencies, and DOE offices. They: establish requirements simillar to those required within the Operational Emergency Hazardous Material Program and shouldoje integrated, where applicable, to ensure a standard approach and continuity of effort. Newly. issued or revised regulations and plans should be-incorporated in accordance with corresponding implementation requirements or as soon as. reasonabiy achievable (e.g.; during the performance of the annual hazard assessment review/update).

a. Congress has directed that emergency planning and preparedness be: iaproved for hazardous material releases through provisions of the Resource Conseryation and Recovery Act, the 0il Pollution Act of 1990, and the Clean Air Act Amendments. of 1990. Impiementing regulations have been issued or are forthcoming.

b. The Environmental Protection Agency has begun to publish requirements requiring emergency planning for industries using hazardous materials in the 40. CFR 68 series.

c. The Environmental Protection Agency has published regulations regarding emergency planning for hazardous material waste- sites through the 40 . CFR 260 and 265 series. These requirements are generally implemented at DOE sites as part of the Resource Conservation and Recovery Act-Part B permit process, with an emergency pian being part of the permit submission.

d. The Environmental Protection Agency has established requirements in 40 CFR 116 and 117 for 7 imiting discharge of hazardous chemicais through. the National Pollution Discharge. El imination System permits. 
e. The Occupational Safety and Health. Administration has established requirements for preventing or minimizing the consequences of catastrophic release of toxic, reactive, flamabie, or explosive chemicals in 29 CFR 1910.119.

f. The Occupational Safety and Health Administration has established requirements for emergency planning, preparedness, and response in 29 CFR:1910:120.

g. The Nuclear Regulatory Commission (NRC) has established emergency planning and preparedness requirements as part of its licensing process for reactors, in 10 CFR 50, in particular Appendix E, and for other facilities using special nuclear materials, in 10 CFR 70. This applies oniy. to those facilities Ticensed by the NRC.

h. Thex Fedèral Radiological Energency Response Plan has been developed jointly by Federal agencies to guide Federal response to a peacetime radiological energency. .

i. The National 0 il and Hazardous Substances Pollution Contingency Plan, or National Contingency PTan, is published in 40 CFR 300 to provide the organizational structure and procedures for Federal preparation for and response to discharges. of oil and releases of hazardous substances:

j. The Environmental Protection Agency has published Protective Action Guides to which the exposure level resulting from radiological releases is compared for determining whether protective actions should be implemented.

k. The American Industrial Hygiene Association has publ ished: Emergency Response Planning Guidelines to which the exposure level resulting from the release of non-radiological material is compared for determining . whether protective actions should be implemented.

3. PLANNING: PHASE.

a. Hazards: Assessment.

(1) The release of or loss of control of hazardous materials: (radiological and non-radiological) shal1 be:quantitatively analyzed. . If the results of the analysis indicate: the: potential for an Alert, Site Area Emergency, or General Emergency, as defined in Chapter $y$, the results of the analysis shall be used to. determine the necessary personnel, resources, and equipment for the Operational Emergency Hazardous Materials Program.- If the hazards assessment : indicates that. a77 events would be-classified. as Tess than: an Alert; the minimum: program requirements shall encompass the requirements for Hazardous Waste Operations' and Emergency. Response found in 29 CFR 1910.120 and the requirements specified in Chapter III of this Order. 
(2) The hazards assessment shall be reviewed at least annualiy and updated prior to significant changes to the site/facility or hazardous material inventories.

(3) The hazards assessment shall include a determination of the size of the Emergency Planning Zone (EPZ). The EPZ is the geographic area surrounding the site/facility for which special planning and preparedriess actions are taken or need to be taken to reduce or minimize the impact to onsite personnel and public health and safety in the event of -an Operational Emergency involving hazardousmaterials. Assumptions, methodology, models, and evaluation techniques used in the hazards assessment shall be documented.

b. Planning Requirements.

(1) Emergency Response Organization. This organization shall be established and maintained for each site/facility with overall responsibility for the initial and ongoing response to and mitigation of an emergency. The Emergency Response Organization shall:

(a) establish effective control at the event/incident scene and

(b) integrate local. agencies and organizations that provide onsite response-services.

(2) Offsite Response Interfaces. Offsite response interfaces have the same requirements as for the Operational Emergency Base Program although additional offsite organizations may be involved.

(3). Emergency Classification. Provisions shall be established to categorize and classify emergency events.

(a) Hazardous material emergencies involving DOE facilities shall be classified in accordance with Chapter $V$.

(b) Site/facility-specific Emergency Action Levels -shall be developed for the spectrum of potential Operational. Emergencies identified by the hazards assessment.

(4) Communications. See Chapter VIII.

(5) Conseouence Assessment. Provisions shall be established-to adequately assess the potential or actual onsite and offsite consequences of an emergency. Consequence assessments shall:

(a) be timeiy throughout the emergency;

(b) be integrated with the event classification and protective action process; 
(c) incorporate monitoring of. specific indicators and field measurements; and

(d). be coordinated with Federal, State, local, and Tribal. organizations.

(6) Protective Actions. Protective actions shall be predetermined for onsite personnel and the public and shall include:

(a) methods for controlling, monitoring, and maintaining records of personnel exposures to hazardous materials fradiologgical and non-radiological);

(b) plans for timely sheltering and/or evacuation of workers;

(c) methods for controlling access to contaminated areas and for decontaminating personnel or equipment exiting the area;

(d) actions that may be taken to increase the effectiveness of protective actions (i.e., heating, ventilation, and air conditioning (HVAC) shutdown during sheltering);

(e) methods for providing timely recoumendations to appropriate State, Tribal, or local authorities of protective actions, such as sheltering, evacuation,- relocation; and food control; and

(f) Protective Action Guides (PAGs) and Emergency Response Planning Guidel ines (ERPGs), prepared in conformance with DOEapproved guidance applicable to the actual or potential release of hazardous materials to the environment, for use in protective action decision making.

(7) Medical Support: Medical support shall be planned in accordance with DOE 5480.8A (or replacement directive) for workers: contaminated by hazardous material. Medical support shall include documented arrangements with onsite and offsite medical facilities to accept and treat contaminated, injured personnel.

(8) Public Information. See Chapter IX.

(9) Emergency Facilities and Equipment. Facilities and equipment adequate to support emergency response shall be available and maintained as follows.

(a) A facility shall be available for use as a command center.

(b) Provisions shall be established for use of an alternate location if the primary command center is not available. 
(c) Adequate personal protective equipment and other equipment and supplies shall be available and operable to meet the needs determined by the results of the hazards assessment.

(10) Program Administration. See Chapter XI.

\section{PREPAREDNESS PHASE:}

a. Training and Drills. A coordinated program of training and drills for developing and/or maintaining specific emergency response capabilities shall be an integral part of the emergency management program. The program shall apply to emergency response personnel and organizations that the site/facility expects to respond to onsite emergencies. Emergency-related information shall be available to offsite response

- organizations. The program shall consist of self-study/homework, training, and drills.

(1) Iraining. Both initial training and annual refresher training shall be provided for the instruction and qualification of all

- personnel (i.e., primary and aiternate) comprising the emergency. response organization.

(2) Drills. Orills shall provide supervised, "hands-on" training for menbers of emergency response organizations.

b. Exercises. A formal exercise program shall be established to validate all elements of the emergency management program over a multi-year. period. Each exercise shall have specific objectives and shall be fully documented (e.g., by scenario packages that include. objectives, scope, timelines, injects, controller instructions, and evaluation criteria). Exercises shall be evaluated. A critique process, which includes gathering and documenting observations of the participants, shall bè estabi ished. . Corrective action items identified as a result of the critique process shall be incorporated into the emergency management program.

\section{(1) Sites/Facilities:}

(a) Each DOE facility subject to this chapter-shall exercise its emergency response capability annually and.include at. least facility-level evaluation and critique, Evaluations. of annual facility exercises by Departmental entities (e.g., Field/Operations Office or Headquarters Office of Emergency Management) shall be performed periodically so that each facility has external Departmental evaluation at least every 3 years.

(b) Site-Tevel emergency response organization elements and resources shall participate in a minimum of one exercise annually. This site exercise shall be designed to. test and 
demonstrate the site's integrated emergency response capability. For multiple-facility sites; the basis for the exercise shall be rotated among facilities.

(c) Offsite response organizations shall be invited to participate in site-wide exercises at least once every 3 years.

(2) Emergency Response Assets. Exercises of each of the Department's radiological emergency response assets shal1 be conducted at least : once every 3 years. These assets include the Accident Response Group (ARG), Nuclear Emergency Search Team (NEST), Federal Radiologicai Monitoring and Assessment Center (FRMAC), Aerial Measuring System (AMS), Atmospheric Release Advisory Capability (ARAC), Radiological Emergency Assistance Center/Training Site . (REAC/TS), and Radiological Assistance Program (RAP).

(3) Each DOE site or activity that achieves overall success with all objectives satisfied during an exercise evaluated by the Office of . Emergency. Management may be granted a 1-year respite from the annual exercise requirement if agreed to by the Office of Emergency Management and the Operations/Field Office Manager. (i.e., a 2-year period until the next site exercise or a 4-year period until the next exercise of the radiological emergency response asset).

5. RESPONSE PHASE.

a. Response. Emergencies invoiving hazardous materiais require time-urgent response actions. to minimize or prevent unacceptabie consequences. Events shall be classified on the basis of potential severity of the consequences as detailed in Chapter $V$. Response actions shall be implemented accordingly:

(1) Declaration of an Alert does not. necessarily require the activation of response centers, but does require availability of personnel and resources to:

(a) continuousiy assess pertinent information for DOE decision makers, offsite authorities, the public, and other appropriate entities;

(b) conduct appropriate assessments, investigations, or preliminary sampling and monitoring;

(c) mitigate the severity of the occurrence or its consequences; and

(d) prepare for other response actions shouid. the situation become more serious, requiring emergency response organizations to mobilize or activate resources. 
(2) Deciaration of a Site Area Emergency requires the same response as for an Alert:plus:

- (a) initiation of predetermined protective actions for onsite personnel;

(b) notification and assembly of emergency response personnel and equipment to activate response centers and to estabiish communications, consultation, and liaison with offsite authorịties;

(c) provision of information to the public and the media;

(d) implementation of or assistance in any evacuations and sheltering; and

(e) mobilization of appropriate emergency response groups or protective/securjty forces for. immediate dispatch should the situation become more serious.

(3) Declaration of a General Emergency requires the same response as for a Site Area Emergency plus the notification, mobilization, and dispatch of all appropriate emergency response personnel and equipment, including. appropriate DOE emergency response assets, and i iaison with offsite authorities for the recommendation of predetermined public protective actions.

b. Iermination and Récovery.

(1) Predetermined criteria for termination of emergencies shall be established/developed.

(2) The means shall exist for estimating exposure to hazardous materials (radiological and non-radiological) and for protecting workers and the general public from exposure during reentry and recovery activities.

(3) Recovery procedures shall inctude dissemination of information to Federal, State, Tribal, and local organizations regarding the emergency and possible relaxation of public protective actions; planning for decontamination actions; establishment. of a. recovery organization; development of reporting requirements; and establishment of criteria for resumption of normal operations.

(4) Emergencies, once categorized, shall not be downgraded (e.g., to. Unusual Occurrence) uniess the original categorization was incorrect. An event deterained to be an emergency will remain so until the emergency response is terminated. In general, the emergency classification (i.e., Alert, Site.Area Emergency, General Emergency) should not be downgraded untif termination of the event. However, emergency classification shall be: reviewed: periodically to ensure the classification is comensurate-with response activities. 


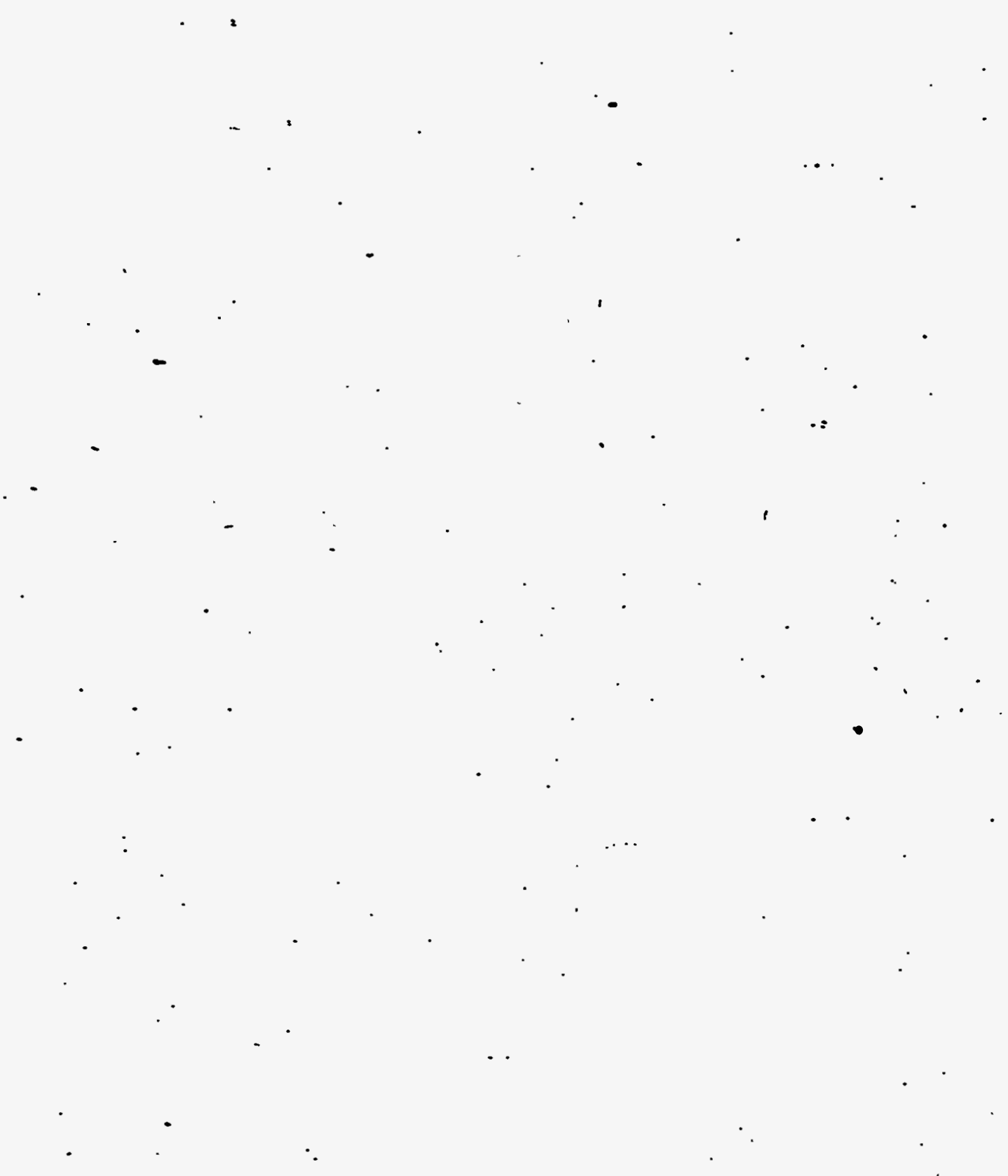




\section{CHAPTER V}

\section{OPERATIONAL ENERGEHCY EUEITS AND CONDITIONS}

1. GENERAL: Operational Emergencies are unplanned, significant events or conditions. that require time-urgent response from outside the imediate/affected-site/facility or area of the incident. Such emergencies are caused by, involve, or affect DOE facilities,. sites, or activities and represent, cause, or have the potential to cause the events or conditions described below. Incidents that can be controlled by employees or maintenance personnel in the immediate/affected facility or area are not Operational Emergencies. Incidents that do not pose a significant hazard to safety, health, and/or the environment and that do not require a time-urgent response are not Operational-Emergencies. Note that the initiating events described below are not all-inclusive. Other initiating events that warrant categorization as Operational Emergencies shał 7 be included in site/facility-specific procedures.' Less severe events are reported through the "Unusual Occurrence" and "Off-Normal Occurrence" process described in DOE 0_232.1... .

2. BASE-PROGRAM EVFUTS. An Operational Emergency shall be declared when events. that represent a significant degradation in the level of safety at a site/facility and that require-time-urgent response efforts from outside the site/facjitity occur. These events do not require further classification. (i.e., as Alert, Site Area Emergency, or General Emergency). Such events include the following.

a. Health and Safety. The following events or conditions represent, cause, or have. the potential to cause serious health and safety impacts to workers or. members of the public.

(1). Radioactive or other hazardous material contamination that is causing or may reasonably be expected to cause uncontrolied personnel exposures. exceeding protective action criteria..

(2) An offsite hazardous material event not associated with DOEE operations that is observed to have or is predicted to have an impact on a DOE site such that protective actions are required for onsite DOE workers.

(3) An occurrence that causes or can reasonably be expected to cause significant structural damage to DOE facilities, with-confirmed or suspected personnel injury. or death or substantial. degradation of heatth and safety.

(4) Any facility evacuation in response to an actual occurrence that requires time-urgent response by specialist personnel, such as hazardous material responders or mutual aid groups not normally assigned to the affected facility. 
(5) An unplanned nuclear criticality resulting in actual or potential . facility damage and/or release of radioactive material to the environment.

(6) Any non-transportation-related mass casualty event.

b. Environment. The following events or conditions represent, cause, or have the potential to cause serious detrimental effects on the: environment.

(1). Any actual or potential release of hazardous material or regulated pollutant to the environment, in a quantity greater than five times the Reportable Quantity (RQ) specified for such material in 40 CFR 302 , that could result in significant offsite consequences such as major wildlife kills, wetland degradation, aquifer contamination, or the need to secure downstream water supply intakes.

(2) Any release of greater than 1,000 gallons (24 barreis) of oil to inland waters; greater. than 10,000 gallons (238 barrels) of oil to coastal waters; or a quantity of oil that could resuit in significant off-site consequences (e.g., need to relocate people, major wildlife kills, wet-land degradation, aquifer contamination, need to secure downstream water supply intakes, etc.) [0i1. as. defined by the Clean . Hater Act (33 U.S.C. 1321) means any. kind of $0 i 7$ and includes petroleum.].

c. Security and Safequards. The following events or conditions represent, cause, or have the potential to cause degradation of security or safeguards conditions with actual or:potential direct harm to people or the environment.

(1) Actual unplanned detonation of an expiosive device or a credible threatened detonation resulting from the location of a confirmed or suspicious explosive device.

(2) An actuaj terrorịst attack or șabotage event involving a DOE site/facility or operation.

(3) Kidnapping or the taking of hostage(s) involving a DOE site/facility or operation.

(4) Actual theft or loss of a Category I or II quantity of Special Nuclear Materials or other hazardous material that, if released, could endanger workers, the pubijic, or the environment.

(5) Damage or destruction of a site or facility by natural or. malevolent means sufficient to expose classified. information to unauthorized disclosure. 
d. Offsite DOE Transportation Activities. The following events or conditions represent an actual or potential release of radiological or non-radiological hazardous. materials from a DOE shipment.

(i) The radiation dose from any release of radioactive material or the concentration in air from any release of other hazardous material is expected to require estabi ishment of an initial protective áction zone. ("Initial protective action zone" is defined: in DOT RSPA P 5800.6, as amended or updated, 1993 Emergency Response Guidebook).

(2) Failures in safety systems threaten the integrity of a.nuclear weapon, component, or test device.

- (3) Damage to a nuclear explosive; nuclear explosive-like assembiy, or Category I/II quantity of Special Nuclear Haterials as a result of a transportation accident.

3: HAZARDOUS MATERIALS (RADIOLOGICAL AND NON-RADIOLOGICAL). OperationaT Emergencies shai1 be classified as either, an Alert, Site Area Emergency, or General Emergency, in order of increasing severity, when events occur that represent a specific threat to workers and the pubijic due to the release or potential release of significant quantities of radiological and nonradiological hazardous materials. Classification aids in the rapid communication of critical information and the initiation of appropriate. time-urgent emergency response actions.

a. Alert. An Alert shall be declared when events are predicted, are in . progress, or have occurred that result in one or more of the following.

(1). An actual or potential substantial degradation in the level of control over hazardous materials (radiological and nonradiological).

(a): The radiation dose from any release: to the environment of radioactive material or a concentration in air of other hazardous material is expected to exceed either:

1 the applicable Protective Action Guide or: Emergency Response Planning Guideline-at or beyond 30 meters from the point of release to the:environment: or

2 a site-specific criterion corresponding to a șmall fraction of the applicable Protective Action Guide or Emergency Response Planning Guideline at or beyond the. facility boundary or exclusion zone boundary.

(b) It is not expected that the applicable Protective Action Guide or Emergency Response Planning Guideline will be exceeded at or beyond the facility boundary or exclusion zone boundary. 
(2) An actual or potential substantial degradation in the level of safety or security. of a nuclear weapon, component, or test device that would not pose an immediate threat to workers or the publice.

(3) An actual or potential substantial degradation in the level of safety. or security of a facility or process that could, with further degradation, produce a Site Area Energency or General Emergency.

b. Site Area Emergency. A Site Area Emergency shall be declared when events are predicted, in progress, or have occurred that result in one or more of the following situations.

(1) An actual or potential major failure of functions necessary for the protection of workers or the public. The radiation dose from any reiease of radioactive material or concentration in air from any release of other hazardous material is expected to exceed the applicable Protective Action Guide or Emergency Response: Planning Guideline beyond the facility boundary or exclusion zone boundary. The Protective Action Guide or: Emergency Response Planning Guideline is not expected to be exceeded at or beyond the site boundary.

(2) An actual or potential threat to the integrity of a nuclear weapon, component; or test device that may adversely-impact the health and safety of workers in the immediate area, but not the public.

(3) Actual or potential major degradation in the level of safety or security of a facility or process that could, with further degradation, produce a General Emergency.

c. General Emergency. A General Emergency shall be declared when events are predicted, in progress, or have occurred that result in one or more of the following situations.

(i) Actual or imminent catastrophic reduction of: facility safety or security systems with potential for the release of large quantities of hazardous materials (radiological or non-radiological) to the environment. The radiation dose from any release of radioactive material or a concentration: in air from:any release of other hazardous material is expected to exceed: the applicable-Protective Action Guide or Emergency Response Planning Guideline at or beyond the site boundary.

(2) Actual or likely catastrophic failures in safety or security systems threatening the integrity of a nuclear weapon, component, or-test device that may adversely impact the:health and safety of workers and the public. 


\section{CHAPTER YI}

\section{EHERGY EMERGEICY PROGRAY}

1. GENERAL REOUIREMENTS. The Energy Emergency Program shall ensure that the Department is capable of providing analysis and recommendations on mitigating potential energy supply crises, economic impacts; widespread energy distribution interruptions, and/or energy infrastructure recovery advice. The program recognizes' resources and expertise with in the Department may be requested to support an energy emergency response." The program also recognizes that DOE assistance may be: required in support of a Presidentia77y-declared emergency invoking the Stafford Act, as amended, and iuplemented through the Federal Response Plan. The Energy Emergency Program may be implemented coincident with implementation of. the Emergency Assistance Program (Chapter VII).

2. RELATED REGULIATIONS AND PLANS. .

a. DOE has established requirements. in 10 CFR 205.350 for maintaining current information regarding the status of electrical energy supply systems.

b. The Federal Emergency Management Agency has pub7ished the Federal Response Plan, which meets requirements established in Public Law 93-288, as amenied. The Federal Response Plan provides the framework for coordinated Federal response in support of State and local: governments.

3. PLANNING PHASE.

a. Hazards Assessment. Hazards assessments for energy. emergencies are routinely conducted by the Energy Information Administration and the Assistant Secretary for Policy.through short and long-range forecasts.

b. Planning Requirements. The Headquarters Energy Emergency Hanagement Plan and Implementing Procedures shall. iriclude the following.

(1) Plan for suipply crises due to, but not 1 imited to, international political situations, defense mobilization, natural or technological disasters, energy systen: sabotage, major accidents involving energy systems, and Tabor strikes or lockouts.

(2) Emergency Management Team procedures for energy emergencies,. including activation and staffing.

(3) Defining potential energencies for which the program: is responsible. and for which procedures will be developed: 
(4) Energy Emergency. Management Plan activation threshoids for plan implementation.

(5) The process for developing, maintaining, and activating procedures related to the Federal Response P1an Emergency Support Function \#12 (Energy) and other Emergency Support Functions (ESFs) where,DOE is a support agency.

(6) Specific planned Headquarters, Field, or Operations Office roles and resources required in response to energy emergency scenarios:

(7) Reporting formats for documenting the situation and the DOE response.

- (8) Processes for monitoring and analyzing the energy situation and for responding to an energy emergency including recovery.

4. PREPAREDNESS PHASE. The Headquarters Emergency Management Plan shal1 establish a readiness assurance program, inciuding training, drills, exercises, and evaluation of readiness for energy emergencies.

\section{RESPONSE PHASE.}

a. An energy emergency. shall be declared after events of significant magnitude have occurred, activation of ESF 12 (Energy) or other ESFs invoiving DOE as a support agency for energy-related activities, or as directed by the Under Secretary. See Chapter VIII.

b. Declaration of an energy emergency requires the availability of appropriate DOE personnel and resources to continuous $7 y$ assess pertinent information for DOE decision makers and to provide recommendations or coordination to other Federal agencies or industries to mitigate:the severity of the occurrence or its consequences.

c. At the request of the Under Secretary or as events warrant, appropriate members of the Emergency Management Team shall convene in the Headquarters. Emergency Operations Center to:

(1) provide timely assessments of the dimensions of the energy emergency as required under interagency plans or as requested by the Secretary;

(2) . establish communications, consultation; and liaison with appropriate energy industry entities and other Federal agencies, as appropriate; and

(3) notify appropriate energy emergency response assets, experts; and resources to respond according to the severity of the situation. 


\section{CHAPTER VII}

\section{EXERGEHCY ASSISTANCE PROGRAY}

1. GENERAL REQUIREXENTS. . The Emergency Assistance Program includes al1 activities whereby Departmental · resources, emergency response assets, personnel, and/or facilities are deployed in support of Federal interagency plans, international agreements, Presidential direction, and State; local, or Tribal agreements of mutual aid. The Emergency Assistance Program may be implemented coincident with implementation of the Energy Emergency Program - (Chapter VI).

2: RELLTED REGULLATIONS AND PLANS.

a. The FederaT-Radiological Emergency Response Plan has been developed: jointly by Federal agencies to guide Federal response to a peacetime radiological emergency.

b. The National $0 i 1$ and Hazardous Substances Pollution Contingency Plan (also called the National Contingency Plan) is published in 40 CFR 300 to provide the organizational structure and procedures for Federal. responses to discharges of oil and releases of hazardous substances.

c. The Continuity of Government Operations Plan provides the capability to maintain essential Government services and emergency functions in the most serious of events affecting national security.

d. The. Continuity of Operations Plan provides a capability to ensure that essential Departmental missions and functions can be performed without. disruption during an-emergency or other situation.

e. The DOE 5530-series Orders describe the programatic requirements of the Department's radiological emergency response assets.

3. PLANMTNG PHASE.

a. Emergency Assistance planning shall encompass, but not be 1 imited.to, the capability to provide:

(1) support and direction as prescribed in the: Federal Radiological Emergency Response Plan, the National Contingency PIan, and the. Federal Response Plan;

(2) the means to support Presidential-direction to continue operations of critical Departmental functions in the event that Headquarters facilities are inoperable; 
(3) direction and support as prescribed in the Presidential7y-mandated National Security Emergency Planning requirements and Continuity of Government concept of operations; and

(4). technical and response assistance to organizations and agencies with which the Department has entered into' mutual aid agreements.

b. The Headquarters Emergency Assistance Plan and Implementing Procedures sha71:

(1) document Emergency Management Team procedures for Emergency. Assistance including activation and staffing;

(2). define potential emergencies for which the program is responsible and for which procedures witl be developed;

(3) identify specific planned Headquarters, Field, or Operations office. roles and resources required in response to Emergency Assistance. scenarios; and

(4) establish reporting formats to document situation and DOE response activities.

c. Plans and procedures developed in accordance. with the D.0E 5530-series Orders for the Department's radiological emergency response assets shall be cross-referenced in the Headquarters Emergency. Assistance P1an and implementing procedures.

4. PREPAREDNESS PHASE. The Headquarters Emergency Assistance PIan shal1 establish a readiness assurance program, inciuding training and drills, exercises, and evaluation of readiness. for emergencies.

5. RESPONSE PHASE. The Assistant Secretary for Defense Programs has programatic responsibility for the deployment of the radiological- emergency response assets: The Chief of Staff of the Emergency Management. Team, for the Emergency Manager; sha71. coordinate with appropriate response teans (e.g., Defense Programs, Energy Information Administration, Field offices) and ensuré deployment of response-personnel. Response teams for Continuity of Government and Continuity of Operations will be directed from the Headquarters Emergency Management Team. Coordination with the Executive. Branch, other Federal agencies, or governments will be accomplished by DOE Headquarters. 


\section{CONHFICATIOHS REOUIREXENTS.}

1. GEAERAL. Requirements in this chapter:pertaining to notification and reporting apply to Operational Emergencies; Energy Emergencies, and Emergency Assistance. This section emphasizes Operationa] Emergencies because of the criticality of timely notification and reporting during such emergencies. Communications requirements for emergencies do not supplant other required notifications and reporting delineated under other 'legislation, implementing regulations,' and DOE Orders.

2. PLAHHIHG PHASE.

a. For Operational Emergencies, provisions shall be established for.prompt - initial notification of workers: and emergency response personnel and organizations, including appropriate DOE Elements and other Federal, State, Tribal, and local organizations. Provisions shall also be estabilished for continuing effective communication among the response organizations throughout an emergency.

b. Hstification and reporting responsibilities for Energy Emergencies and Energency Assistance shall be established to support appropriate plans and agreementṣ.

3. PREPAREDNESS PHASE. Adherence to Operational Emergency notification and reporting requirements shall be demonstrated in a.17 emergency managenent exercises. Preparedness responsibilities for Energy Energencies and Energency Assistance shall be established to support. appropriate plans and. agreenents.

4. RESPONSE PHASE:

a. Initial Emergency Notifications. For Operational Energencies; initial emergency notifications shall be made to workers, emergency response personnel, and organizations, including DOE.Elements and other local, . State, Tribal, and Federal organizations.

(1) The Manager/Adninistrator of each DOE- or Contractor-operated site/facility shall:

(a) notify State and Tocal officiais and the-DOE Fieid and Headquarters Emergency Operations Centers within 15 minutes and all other organizations within 30 minutes of the declaration of an Alert, Site Area Emergency, or General. Energency;

(b) notify the DOE-Field and Headquarters Emergency Operations Centers within $\mathbf{3 0}$ minutes of the declaration of an other than hazardous material Operational Emergency; and: 
(c) notify 1ocal, State, and Tribal organizations within 30 minutes or as estabiished in mutual agreements for declaration of an other: than hazardous material Operational Emergency.

(2) Headquarters Watch Office staff in the Headquarters Emergency Operations Center and Headquarters Emergency Management Team personnel shall be responsible for the following.

(a) Record incoming verbal notifications, receive emergency event .. information by other data transmission means or mechanisms, and disseminate such information to Cognizant Secretarial. Officer representatives and appropriate Headquarters organizations of other Federal agencies. The Emergency Operations Center shall disseminate notifications involving Energy Emergencies and Emergency Assistance to the appropriate Operations/Field Offices.

(b) Facilitate communications among Headquarters organizations, DOE fieid organizations, and contractor personne?.

b. Emeraency Status Updates. Emergency status reports shali be forwarded to the next-higher Emergency Management Team on a continuing basis until the emergency. is terminated.

c. Responder Communications. Effective communications methods shall be : established between event scene responders, emergency managers, and response facilities.

d. Final Emergenicy Report. Following termination of emergency response, and in conjunction with the Final Occurrence Report (see DOE 0 232.1), each activated Emergency Hanagement Team shall submit a final report on the emergency response to the Emergency Manager for submission to the Associate Deputy Secretary for Field Management and the Director of Emergency Management.

e. Recovery Reporting. Reporting requirements shall be specified during recovery planning.

f. Classified Information Reviews. All reports and reieases shall be reviewed for classified or Unclassified Controlled Nuclear Information prior to being provided to uncleared personnel, entered into unclassified data bases, or transmitted using non-secure communications equipment.

g. Enerav Emergencies and Emergency Assistance Response. Responsibilities for Energy Emergencies and Emergency Assistance shal7 be established to support appropriate plans and agreements. 


\section{CHAPTER IX}

\section{PUBLIC AFFAIRS POLICY AID PLALIIIIG REOUIREXEITS.}

1. GEHERAL. The-Department shall provide accurate, candid, and timely. information, consistent with requirements of the Freedom of Information Act and: the Privacy Act, to site workers and the public during all emergencies, so as to estabiish facts and avoid speculation.

2. PLANNING. PHASE.

a. Public affairs policy and planning requirements apply for all emergencies or when the Department is obligated by law; Executive Order,

- interagency agreement, or other accord to provide technical support and assistance in accidents, defense mobilization, war, or other.

- emergencies, including those involving another government agency, private: organization, or nation.

b. These policies and:planning requirements shall. appiy in conjunction with the United States' international commitments to the International Energy Program, the International Energy.Agency, the North Atlantic Treaty Organization, and the International Atomic Energy Agency, or through the Department's commitments under the Defense Production-Act.

c. The Department shalt establish an Emergericy Pub7ic Information Program that includes adequate plan's for al7 emergencies at DOE or contractor facilities, as well as. potential offsite emergencies that may involve. DOE resources or personnel.

d: Each Operation/Field Office and site/facility shall prepare an Emergency Public Information Plan, but the same plan can cover multiple facilities if located on a contiguous site. As necessary, facility-specific plans shall be prepared. The plans shall provide the following.

(1) Identification of personnel, resources, facilities, and coordination procedures necessary to provide. emergency public information.

(2) Training and exercises for Joint Information Center personnel.

(3): A methodology for informing workers and the public of DOE energency plans and protective actions, before and during emergencies.

(4) Coordination of public information efforts with State, local, and Tribal governments, and Federal emergency response. plans, as appropriate. 
3. PREPAREDNESS PHASE.. Adherence to emergency public information policies and requirements shal1 be demonstrated during exercise evaluations, technical . asșistance appraisals, and approved training programs.

4. RESPONSE PHASE:

a. This Order shall be applied during deployment of the Department's emergency response assets: the Aerial Measuring System, the Accident Response Group; the Atmospheric Release Advisory Capability, the Federal. Radiation Monitoring and Assessment Center, the Nuclear Emergency Search Team, the Radiological Assistance Program, and the Radiological Emergency Assistance Center and Training Site.

b. The DOE Operations/Field Office and contractor personnel shall cooperatively ensure that an adequate public information program is established and maintained, commensurate with site hazards, to ensure that information can be provided to the pubiic and the media during an emergency. An adequate emergency public information program includes a Joint Information Center to provide resources to comply with the integrated, comprehensive Emergency Management System, commensurate with hazards, during: an emergency. The Joint Information Center will be. established, directed, and coordinated by the senior DOE Operations/Field Office Public Affairs manager or a designee. - Th: energency public information program shall be adequately staffed with personnel trained to serve as. spokesperson and newswriter, and to provide support in media services, public inquiry, media inquiry, Joint Information Center management and administrative activities, and media monitoring. - Persons with technical expertise about the emergency and with spokesperson training shall also be assigned to the emergency public. information staff.

c. In situations invoiving classified information, the Department will provide sufficient unclassified information to explain the emergency response and protective actions required for the health and safety of workers and the-public.

d. Public announcements that contain information that may present a security risk shall be reviewed by an Authorized Derivative Classifier or reviewing official before release and released as appropriate.

e. A DOE or contractor pub7ic information officer shall be assigned to the emergency public information response team involved in a significant offsite response deployment.

f. A Headquarters official or team shall provide support to the affected Program Offices/Emergency Management Team and/or requesting Operations/ Fieild Office, as appropriate.

g. The Assistant Secretary for Congressional, Public and Intergovernmental Affairs, and the Headquarters Emergency Hanager shall be informed of all 
DOE energency public information actions. These notifications shall be made as soon as practicable but are not required prior to issuing news. releases or public statements.

h. Initial news releases or public statements shal] be approved by the DOE official responsible for emergency public information review and dissemination.. Following initial news. releases and public statements, updates shall be coordinated with the Assistant Secretary for Congressional, Public and Intergovernmental Affairs.

i. An emergency public information communications system shail be established among. Headquarters, Operations/Field Office, and on-scene Tocations. 

CHAPTER $\times X$

EVALUATIONS AND READIHESS ASSURAHCE

1. GEMERAL. Evaluations consist of line/program reviews conducted by the Director of Emergency Management. Readiness Assurance consists of Emergency Readiness Assurance Plans and Appraisal and Assessment Programs.

a. Evaluations validate or identify weaknesses and/or findings in emergency: management programs.

b. Energency Readiness Assurance Plans (ERAPS) ensure that emergency plans, implementing procedures; and resources are adequate and sufficientiy .

- maintained and exercised.

c. Appraisal and Assessment Programs ensure that emergency capabilities are sufficient to implement emergency plans and that appropriate and timeiy improvements are made in response to needs identified through coordinated emergency pianning, resource allocation; training, drills, and exercises.

2. EYALUATIONS: The Director of Emergency Management shall evaluate line/ program emergency management activities, to inciude the DOE radiological emergency response assets, using published criteria. Evaluation findings shall be-addressed. by the evaluated activity within 90 days. of receipt of. findings. The Director of Emergency Management shati determine closure of ail- open or unresolved evaluation findings.

a. The Director of Emergency Management's evaluation of a site/facility shall fuifill the requirement for the Operations/Field office and Cognizant Secretarial Officer assessment of the facility for the next 3

$\therefore$ years if no deficiencies and a Timited number of weaknesses are found.

b. Upon request, the Office of Emergency Management will schedule and: conduct periodic technical assistance appraisals of Headquarters Program Offices, Operations/Field offices, and sites/facilities, including DOE radiological emergency response assets, as needed. To ensure a coordinated review, the Office of Emergency Management shal7 request participation from Cognizant: Secretarial officer(s); the office of Environment, Safety and Health; and the Operations/Field Offices.

\section{EMERGENCY. READINESS ASSURANCE PLANS (ERAPS).}

a. Emergency planning and preparedness activities for each facility, site, and Operations/Field office shall be documented in ERAPs, which cover'a planning cycle of 5 fiscal years beginning the next October 1 . For example, an ERAP submitted September 30, 1996, will cover October 1, 1996, through September 30, 2001. 
b. The ERAP shall be a planning tool to identify and develop needed resources and improvements. ERAPs shall highlight- any significant changes in emergency management programs (i.e., planning bases, organizations, exemptions) from previous ERAPS, as well as comparing actual achievements to goals; milestones, and objectives. If applicable, ERAPs shall be reviewed for classified or controlled information prior to submittal.

c. ERAP Submittal and Approval.

(1) The Operations/Field Office Manager shall review and approve. ERAPs, which cover facilities under their supervision and subinit a consolidated ERAP to the Director of Emergency Management and the Cognizant Secretarial Officer by November 30 .

(2). The Director of Emergency Hanagement shall prepare; in coordination with the Cognizant Secretarial Officers, an annual-status report ". that summarizes the Operations/Field Office ERAPs for submittal to the Under: Secretary by April:30.

4. EMERGENCY READINESS ASSURANCE APPRAISALS AND ASSESSMENTS. Cognizant Secretarial Officers and Operations/Field Offices shall periodically review the abifity of DOE- and/or. DOE contractor-operated facilities to meet requirements of the Emergency Management System. Appraisals and assessments shall be based on specific standards and criteria, published by the Director of Emergency Management. Appraisal findings shall. be acknowledged by the appraised activity within 90 days of receipt of findings with a corresponding plan for correction. The appraising organization shall determine closure of all open or unresolved appraisal findings. Appraisals shall be scheduled, conducted, and reported in accordance with this Order.

a. DOE- and DOE contractor-operated facilities shall conduct an annual internal readiness assurance: assessment of their emergency management. programs. Assessment results shall be documented in the consolidated Operations/Field Office ERAP.

b. Each DOE Operations/Fié7d Office shall assess the energency management prograin at each site/facility under its supervision. Each site/facility shali be assessed at least once every 3 years. The Operations/Fjeid Office shall notify the Cognizant Secretarial Officer of its assessment schedule.

c. Cognizant Secretarial Officers shalt schedule and perform periodic readiness assurance appraisals of emergency management. activities.

d. Schedules for all assessments, appraisals, and follow-on activities shall be coordinated with the.Director of. Emergency Management to minimize impacts and maximize benefits. No more than one external assessment or appraisal, not including follow-on activities, should be scheduled per site per year. 


\section{CHAPTER XI \\ PROGRAY ADEIHISTRATION}

1. PERSONNEL REOUIREMENTS: Each Operations/Field Office Manager, and each manager/administrator of a DOE- or contractor-operated site/facility subject to this Order shalt designate an individual to administer emergency management. This individual shall develop and maintain the emergency plan; develop the Emergency Readiness Assurance: PI an and annual updates; develop and conduct training and exercise programs, coordinate assessment activities, develop related documentation, and coordinate emergency : resources.

2. CLASSIFICATION-REVIEW. If the relevant site/facility/activity is generating classified or Unclassified Controlled Nuclear. Information (UCNI), or is conducting operations that are classified or UCNI, then ali emergency preparedness documents, such as.plans; procedures, scenarios, and. assessments; shall be reviewed for classified and UCNI by an Authorized Derivative Classifier or UCNI reviewing official.

3. EHERGEHCY. PLALS. The emergency plan shall document the emergency management program and describe the provisions for response to an Operational Emergency.

4. EMERGENCY PLAN IMPLEMENTING PROCEDURES. Emergency RIan ImpTementing Procedures shall describe how emergency plans shall be implemented.

5. LESSONS LEARNED. The emergency management program-shall include a system to track and verify correction of findings or lessons learned from training, dril1s, exercises, and actual responses.

6. EXERGENCY OPERATING RECORDS PROTECTION PROGRAM. A program shall be established to ensure that vital records, regardless of media, essential to the continued functioning or reconstitution of an organization during and after an emergency, are available, per 36 CFR 1236. 


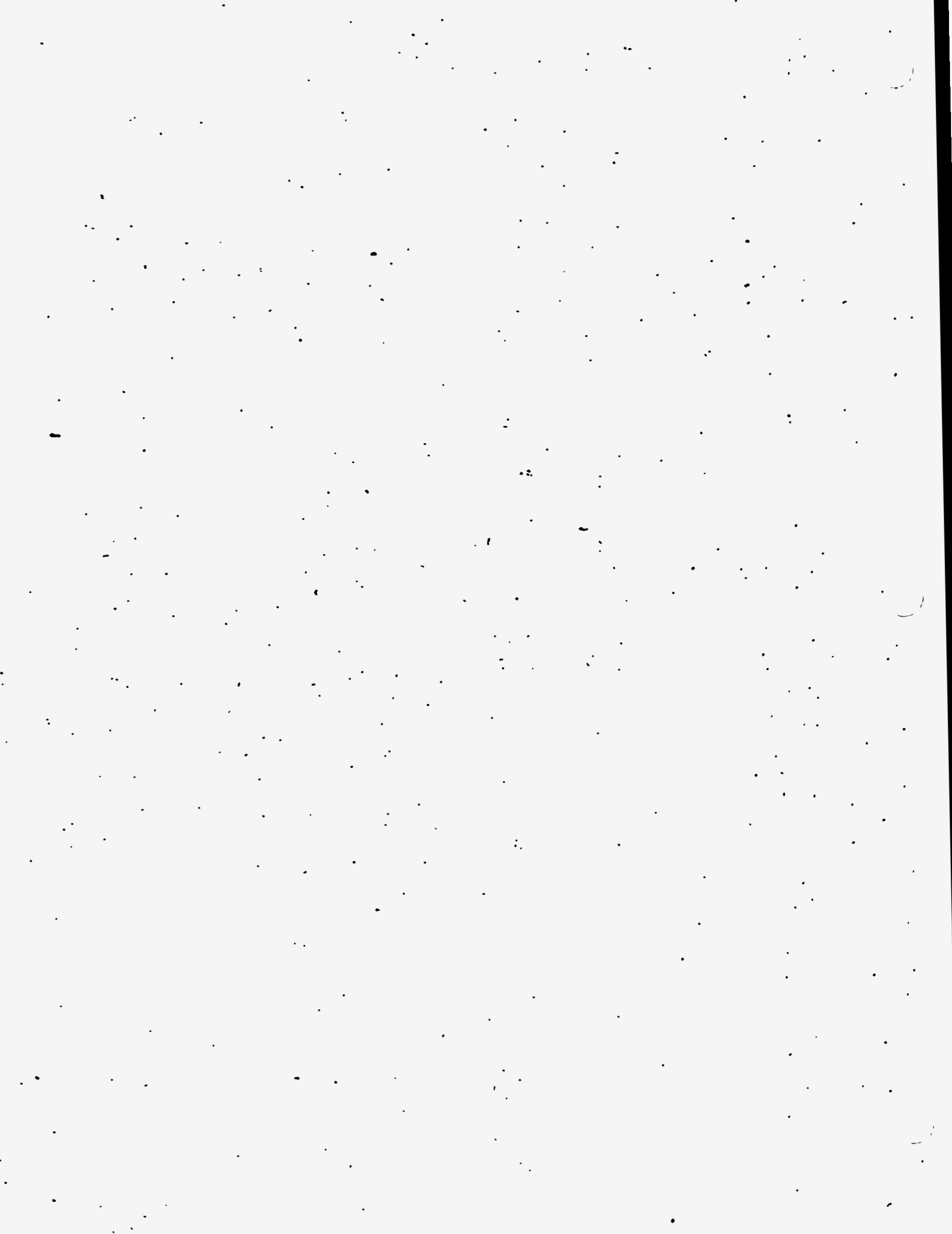




\section{CONTRACTOR REQUIREMENTS DOCUNERT COMPREHENSIVE EMERGENCY MANAGEHENT SYSTEH}

The contractor shall implement site/facility/activity-specific comprehensive emergency management program(s) based on a graded approach. The contractor shall comply with the following requirements.

1. Implement comprehensive emergency management. requirements, as set forth eisewhere in the contract, as they appiy to the site/facility/activity, commensurate with the hazards. present.

2. Conduct hazards surveys and, if warranted, hazards assessments for each stte/facility.

3. Establish an Operational Emergency Base Program that implements the requirements of applicable Federal, State, and local laws/regulations/ ordinances for fundamental worker: safety. programs, and expand upon this . Operational Emergency Base Program; if warranted, to implement additional emergency management activities at sites/facilities with significant quantities of hazardous materials (radiological and non-radiological).

4. Prepare and submit to the cognizant Operations/Field Office Manager. for approval: documentation to establish Emergency Planning Zones; Emergency Plans that.document comprehensive emergency management programs; and Emergency Readiness Assurance Plans.

5. Conduct an annual assessment of the emergency management program.

6. Establish and maintain a system to track and verify correction of findings or lessons learned from training, drills, exercises, and actual responses.

7. Designate an individual to be responsible for and administer emergency management functions for the organization.

8. Participate in the preparation of mutual assistance agreements with local, State; and-Tribal authorities, as requested by the Operations/Field: Office.

9. Ensure: immediate mitigative and corrective emergency response actions and appropriate protective actions and protective action recomendations to. minimize: the consequences of the emergency, protect worker and public health and safety, provide-security, and ensure the continuance of such actions unti7 the energency is terminated.

10. Ensure the proper-identification, categorization, notification, and-reporting of emergencies to DOE facility/site managers, Operations/Field Office Managers; and the Headquarters Emergency Operations Center in accordance with applicable DOE" policies and. requirements. 
11. Provide for investigation of emergency root causé(s) and corrective action(s) to prevent recurrence in accordance with Departmental requirements (é.g., see DOE 0225.1 and DOE 5480.19).

12. Integrate emergency public information planning with the development and maintenance of "the Emergency Plan.

13. Assist Operations/Field Office Managers; the Director of Emergency

- Hanagement; and the Assistant Secretary for Environment, Safety and Health in.. scheduling and conducting evaluations, appraisals, and assessments of the contractor!'s facilities.

14. Respond to ali external evaluation, appraisal, and assessment findings within 90 . days of receipt of findings.

15. Resoive all evaluation, appraisal, and assessment findings with the responsibie organization or request approval for an exemption to the requirements. 


\section{U.S. Department: of Energy}

Washington, D.C.

ORDER

SUBJECT: ENVIRONMENT., SAFETY, AND HEALTH REPORTING

DOE 0231.1

Approved: $09-30-95$

Review Date: 09-30-97

Chg 1: 10-26-95

1. OBJECTIVE. To ensure collection and reporting of information on environment, safety and health that is required by law or regulation to be collected, or that is essential for evaluating Department of Energy (DOE) operations and identifying opportunities for improvement needed for planning purposes within the DOE.

2. CANCELLATIONS. The Orders or paragraphs of Orders listed below are canceled. Cancellation of an Order or paragraphs of Orders does not, by itself, modify or otherwise affect any contractual obligation to comply with such an Order or paragraphs of Orders. Canceled Orders or paragraphs of Orders incorporated by reference into a contract shall remain in effect until the contract. is modified to delete the reference to the requirements in the canceled orders.

a. Paragraphs $2 b, 4 b$, and $4 c$ of Chapter II, and $2 d$ and $3 b$ of Chapter III of. - DOE 5400.1, GENERAL ENVIRONMENTAL 'PROTECTION PROGRAM, of 11-9-88.

b. Paragraphs $5 \mathrm{a}(2)$ and $5 \mathrm{a}(7)$ of DOE 5400.2A, ENVIRONMENTAL COMPLIANCE ISSUE COORDINATION, of 1-31-89.

c. Paragraph 1a(3) (a) of Chapter II of DOE 5400.5, RADIATION PROTECTION OF THE PUBLIC AND THE ENVIRONMENT, of 2-8-90.

d. Paragraphs $5 b(1)$ and $6 a(23)$ of DOE 5440.1E, NATIONAL ENVIRONMENTAL POLICY ACT COMPLIANCE PROGRAM, of 11-10-92.

e: Paragraph 9e of DOE 5480.3, SAFETY REQUIREMENTS FOR THE PACKAGING AND TRANSPORTATION OF HAZARDOUS MATERIALS, HAZARDOUS SUBSTANCES AND HAZARDOUS WASTES, of 7-9-85.

f. Paragraph 6a(4) of DOE 5480.26, TRENDING AND ANALYSIS OF OPERATIONS INFORMATION USING PERFORMANCE INDICATORS, of 1-15-93.

g. Paragraphs 2a, 2b, and $2 c$ of Chapter III of DOE 5483.1A, OCCUPATIONAL SAFETY AND HEALTH PROGRAM FOR DOE CONTRACTOR EMPLOYEES AT GOVERNMENTOWNED CONTRACTOR-OPERATED FACILITIES, of 6-22-83.

h. Paragraph le of Chapter II and Chapters III, IV, and V of DOE 5484.1, ENVIRONMENTAL PROTECTION, SAFETY, AND HEALTH PROTECTION INFORMATION REPORTING REQUIREMENTS; of 2-24-81.

i. Paragraphs $7 c(6), 7 c(7)(a), 7 c(8)(a)$, and $7 g(8)(f)$ of DOE $5630.12 A$, SAFEGUARDS AND SECURITY INSPECTION AND ASSESSMENT PROGRAM, of 6-23-92. Vertical Tine denotes change. 
j. Paragraph 9 of Chapter VI, DOE 5634.1B, FACILITY APPROVALS, SECURITY SURVEYS, AND NUCLEAR MATERIALS SURVEYS, Of 9-15-92.

\section{APPLICABILITY.}

a. DOE Elements. Except for the exclusions in paragraph $3 c$, below, this Order applies to all DOE elements.

b. Contractors. Except for exclusions in paragraph $3 c$, below, the Contractor Requirements Document (CRD), Attachment 1 , sets forth requirements to be applied to contractors awarded contracts for the operation and management of DOE-owned and - Teased facilities. Contractor compliance with the CRD will be required to the extent. set forth in the contract. Contractors shall be directed to continue to comply with the requirements of Orders canceled by this Order until their contracts are modified to delete the reference to the requirements of the canceled Orders or paragraphs of Orders.

c. Exclusions.

(1) Activities conducted under the authority of the Director, Naval Nuclear Propulsion Program, as described in Public Law 98-525, with the exception of reporting required by Title 29, Code of Regulation (CFR), 1960.

(2) Occurrence reporting activities covered in DOE 0 232.1, OCCURRENCE REPORTING AND PROCESSING OF OPERATIONS INFORMATION, Of 9-25-95.

4. REQUIREMENTS. The reports listed under Responsibilities and in the CRD shall be submitted in accordance with DOE M 231.1-1, ENVIRONMENT, SAFETY, AND HEALTH REPORTING MANUAL, of 9-30-95, which specifies in detail the reports that shall be filed, the persons or organizations responsibie for filing the reports, the recipients of the reports, the format in which the reports shall be prepared, and the time. schedules on which the reports shall be filed. The DOE M 231.1-1 is a mandatory part of this Order. Procedures; protocols, or other methods shall be developed on a site-wide or facility basis to meet the reporting requirements contained in this Order and DOE M 231:1-1.

\section{RESPONSIBILITIES.}

a. Heads of DOE Elements shall meet the reporting requirements in DOE M 231.1-1, Chapters II and III.

(1) Report work-related fatalities, injuries, and i17nesses occurring among DOE and contractor employees arising out of work performed at DOE-owned or -7eased facilities in accordance with DOE M 231.j-1, Chapter II, paragraph 2a. 
(For additional information regarding occupational safety and heaith. (OSH) programs, see DOE 0 440.1, WORKER PROTECTION MANAGEMENT FOR DOE FEDERAL AND CONTRACTOR EMPLOYEES; Of $9-30-95 ; 29$ CFR 1904;" and 29 (FR 1960.)

(2) Report work-related damage or loss of property and vehicles in accordance with DOE M 231.1-1, Chapter II, paragraph 2c. Estimated loss or damage to DOE property or other property amounting to $\$ 5,000$ or more, or estimated costs of $\$ 5,000$ or more for cleaning (including decontamination), renovating, replacing, or rehabilitating structures, equipment, or property. Estimated damage of $\$ 1,000$ or more that involves Government-owned, -rented, or -leased vehicles or privately owned vehicles operated while on official business, shall be considered a "recordable case" and shall be reported. Excluded are commercial rental motor vehicles and private motor vehicles used for short periods of time (1 to 14 days) by employees on official travel status, and on which mileage records are not kept. The effective date of the revised reporting threshold for property and vehicle damages in this paragraph is 1-1-96. Prior to that date, the thresholds for reporting property and vehicle damages are to remain at $\$ 1,000$ and $\$ 500$, respectively, in order to ensure a uniform reporting basis within each year.

(3) Report work-hours and vehicle usage in accordance with DOE M 231.1-1, Chapter II, paragraph 2f; include total quarterly work-hours and vehicle usage, on a calendar year basis, for use in normalizing DOE accident statistics.

(4) Report DOE annual estimated property valuation in accordance with DOE.M 231.1-1, Chapter II, paragraph 2g; include annual (on a calendar year basis) estimates of property valuation by organization for use in normalizing DOE accident statistics.

(5) Report interim exposure data reporting in accordance with DOE M 231.1-1, Chapter III, paragraphs 1 and 3 . (For additional information, see 10 CFR 835, "Occupational Radiation Protection.") Report work-related ionizing. radiation exposure data pertaining to an individual who. visits a DOE or DOE contractor site or facility to the Radiation Records Repository, to the individual's employer, and to that individual.

(6) Report annual exposure data in accordance with DOE M 231.1-1, Chapter III, paragraphs 2 and 3. (For additional information, see 10 CFR 835, "Occupational Radiation Protection.") DOE facility directors shall report ionizing radiation exposure data summaries to the Radiation Records Repository for each monitored person: 
(7) Submit radiological exposure reports to. individuals in accordance with DOE M 231.1-1, Chapter III, paragraph 4. (For additional information, see 10 CFR 835, "Occupational Radiation Protection.") Radiological exposure data pertaining to a visit to a DOE or DOE contractor site by an individual shall be provided as a report to that individual.

(8) Submit Annual Summary of Fire Damage in accordance with DOE M.231.1-1, Chapter II, paragraph 3.. (For additional information, see DDE 0 420.1, "FACILITY SAFETY, of 9-30-95. ") Submit an annual report of fire damage to the DOE fire protection authority having jurisdiction by $3-31$ of the following calendar year.

(9) Submit epidemiologic analyses -- Excess Injuries and IIInesses in accordance with DOE M 231.1-1, Chapter II, paragraph 4. Notify the Assistant Secretary for Environment, Safety and Health of suspected excesses of ilinesses or injuries that require epidemiologic analyses to determine if the excesses are work related.

- (10) Submit OSH information in support of epidemiological studies conducted by external organizations in accordance with DOE M 231.1-1, Chapter II, paragraph 5. Submit OSH. information, upon request, to Centers for Disease Control officials, state health officials, their contractors, and grantees conducting epidemiological studies.

\section{b. Cognizant Secretarial Officers.}

(1) National Environmental Policy Act Reporting In Accordance With DOE M 231.1-1. Chapter I. paragraph 2. (For additional information, see DOE 0 451:1, "NATIONAL ENVIRONMENTAL POLICY ACT COMPLIANCE PROGRAM, of 9-11-95.") Each Secretaria1 Officer shall, for matters under the office's purview:

(a) Report annualiy on the progress made in implementing, and the effectiveness of, any commitment for environmental impact mitigation that is essential to render the impact of a proposed action not significant or that is made in a record of decision; - and

(b) Prepare an annual National Environmental Policy Act planning summary.

(2) Safequards and Security Vulnerability Reporting in accordance with DOE: $M$ 231.1-1, Chapter IV. (For additional information, see DOE 5634.18, "FACILITY APPROVALS, SECURITY SURVEYS, AND NUCLEAR MATERIALS SURVEYS, of 9-15-92.") UpOn receipt of a draft inspection report containing a "marginal" or "unsatisfactory" rating or other finding of noncompliance 
with requirements or performance weakniess, the lead cognizant secretarial officer shall report on corrective actions to the Under Secretary.

c. Assistant Secretary for Environment, Safety and Health.

(1) Annual Report to the Secretary of Energy in accordance with DOE M 231.1-1, Chapter II, paragraph 1. Prepare a report on the status and adequacy of DOE and contractor performance of their occupational safety and health responsibilities.

(2) Periodic Summary of Accident Data in accordance with DOE M 231.1-1, Chapter II, paragraph 2h. Prepare a DOE-wide summary of accident data.

(3) Ionizing Radiation Exposure Information.

(a) Inform the cognizant Secretarial Officer when a Headquarters employee's occupational ionizing radiation exposure for a given period approaches $70 \%$ of an administrative or regulatory limit; and

(b) Approve the use of alternate media for submitting information to the Radiation Records Repository as required by this Order.

(4) DOE ES\&H Performance Indicator Report in accordance with DOE M 231.1-1, Chapter II, paragraph 6b. (For additional information, see DOE 0 210.1, "PERFORMANCE INDICATORS AND ANALYSIS OF OPERATIONS INFORMATION, of 9-27-95." ) Prepare a quarteriy DOE Summary Performance Indicator report.

d. Heads of Field Elements (Managers and Directors).

(1) National Environmental Policy Act Reporting in accordance with DOE M 231.1-1, Chapter 1, paragraph 2. (See DOE 0 451.1, "NATIONAL ENVIRONMENTAL POLICY ACT COMPLIANCE PROGRAM.") Heads of a Field Organization shall, for matters under their Offices' purview:

(a) Report annualiy on the progress made in implementing, and the effectiveness of, any commitment for environmental impact mitigation that is essential to render the impact of a proposed action not significant or that is made in a record of decision; and

(b) Prepare an annual National Environmental Policy Act planning summary. 
(2) Annual Site Environmental Reports in accordance with DOE M 231.1-1, Chapter I, paragraph 1. Field element managers and directors shall prepare, on an annual basis, a summary of environmental data so as to characterize site environmental management performance.

e. Assistant Secretary for Human Resources and Administration in accordance with DOE H 231.1-1, Chapter II, paragraph 2a. Reports required by this Order which relate to work-related injuries, ilinesses, property damage, vehicle damage; work-hours and vehicle usage involving DDE Headquarters employees are to be prepared and submitted by the Office of the Assistant Secretary for Human Resources and Administration.

6. REFERENCES. The following references describe additional sources of information that may assist in the implementation of this Order.

a. DOE 1324.5B, RECORDS MANAGEMENT PROGRAM, of 1-12-95, estabiishes the DOE records management policy and program for managing records.

b.. Tiitle 29 CFR 1904, "Recording and Reporting Occupational Injuries - and I17nesses," provides Occupation'al Safety and Health Administration standards for recording and reporting occupational injuries and illnesses.

c. Title 29 CFR 1960, "Basic Program Elements: for Federal Employee Occupational Safety and Health Programs and Related Matters," Subpart I, "Recordkeeping and Reporting Requirements," provides Occupational Safety and Health Standards for recording and reporting Federal employee occupational injuries. and illnesses.

d. DOE 5700.2D, COST ESTIMATING, ANALYSIS, AND. STANDARDIZATION, of 6-12-92; establishes policy and responsibilities for developing, reviewing, and preparing cost estimates; standardizing co'st estimating procedures; and improving cost estimating and analytical techniques, cost data bases, cost and economic escalation models; and cost estimating systems.

7. CONTACT. Office of Operating Experience Analysis and Feedback (EH-33), 301-903-8371.

BY ORDER OF THE SECRETARY OF ENERGY:

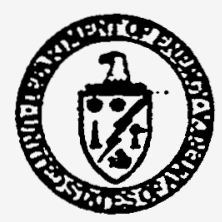

ARCHER L. DURHAM

Assistant Secretary for

Human Resources and Administration 
In the performance of this contract, the contractor is required to ensure that essential environment, safety and health information which is reliable and comprehensive is collected and made available efficiently to requesting organizations.

The reports listed below shall be filed in accordance with DOE $M$ 231.1-1, ENVIRONMENT, SAFETY, AND HEALTH REPORTING MANUAL, which specifies in detai? the reports that shall be filed, the persons or organizations responsible for filing the reports, the recipients of the reports, the format in which the reports shall be prepared, and the time schedules on which the reports shail be filed. DOE M 231.1-1, is a mandatory part of this Contractor Requirements Document. Procedures, protocols, or other methods shall be developed on a site-wide or facility basis to meet the reporting requirements contained in this Contractor Requirements Document and DOE M 231.1-1.

1. Hork-Related Fatalities, Injuries, and 171 nesses DOE and Contractor Employee Occupational Safety and Health (OSH) Programs in accordance with DOE 231.1-1, Chapter II, paragraph 2b. (For additiona] information see DOE 0 440.1, WORKER PROTECTION MANAGEMENT FOR DOE FEDERAL AND CONTRACTOR EMPLOYEES, of 9-30-95 and Title 29, Code of Federal Regulations (CFR), Part 1904.)

a. Report recordable occupational fatalities, injuries, and illnesses occurring among contractor employees arising out of work performed at DOE-Owned or -leased facilities in accordance with DOE M 231.1-1, Chapter II, paragraph 2b.

b. Report occupational fatalities, injuries, and illnesses occurring among subcontractors arising out of DOE work-related activities in accordance with DOE H 231.1-1, Chapter II, paragraph 2d..

2. Nork-Related Damage or Loss of Property and Vehicles in accordance with DOE M 231.1-1, Chapter II, paragraph 2c. Report estimated loss or damage to DOE property or other property amounting to 55,000 or more, or estimated costs of \$5,000 or more for cleaning (including decontamination), renovating, replacing, or rehabilitating structures, equipment, or property. Estimated damage of $\$ 1,000$ or more that involves Government-owned, -rented, or--leased vehicles or privately owned vehicles operated while on official business; shall be considered a "recordable case" and shall be reported. Excluded are commercial rental motor vehicies and private motor vehicles used for short periods of time ( 1 to 14 days) by employees on official travel status, and on which mi leage records are not kept. The effective date of the revised reporting threshold for property and vehicle damages in this paragraph is 1-1-96. Prior to that date, the thresholds for reporting property and vehicle damages are to remain at $\$ 1,000$ and $\$ 500$, respectively, to ensure a uniform reporting basis within each year. 
3. Hork-Hours and Vehicle Usage in accordance with DOE:M 231.1-1, Chapter II, paragraph 2f: Report quarteriy (on a calendar year basis) total work-hours and vehicle usage by organization. to provide data for normalizing DOE accident statistics.

4. DOE Annual Estimated Property Valuation in accordance with DOE $231.1-1$, Chapter II, paragraph 2g. Report annuai (on a calendar year basis) estimates of property valuation by organization to provide data for normalizing DOE accident statistics.

5. Interim_Exposure Data Reporting in accordance with DOE M 231.1-1, Chapter III, paragraphs 1 and 3 . (For additional information see 10 CFR 835, "Occupational Radiation Protection." ). Report work-related. ionizing radiation exposure data pertaining to an individual who visits a DOE or DOE contractor site or facility to the Radiation Records Repository, to the individual's employer, and to that individuat.

6. Annual Exposure Data Reporting in accordance with DOE M.231.1-1, Chapter III, paragraphs 2 and 3 . (For additional information see 10 CFR 835, "Occupational Radiation Protection. ") Report ionizing radiation exposure data summaries to the Radiation Records Repository for each monitored person.

7. Radiological Exposure Reports to Individuals in accordance with DOE M 231.1-1, Chapter III, paragraph 4. Radiological exposure data pertaining to a visit to a DOE or DOE contractor site by an individual shall be provided as a report to that individual.

8. Annual Summary of Fire Damage in accordance with DOE M 231.1-1, Chapter II, paragraph 3. (For more information see DOE 0.420.1, "FACILITY SAFETY, of 9-30-95.") Annually report fire damage to the DOE fire protection authority having jurisdiction by March 31, of the following calendar year.

9. Epidemiologic Analyses -- Excess Injuries and IIInesses in accordance with DOE M 231.1-1, Chapter II, paragraph 4. Notify the Assistant Secretary for Environment, Safety and Health, through their field office, of suspected excesses of ilinesses or injuries that require epidemiologic anaiyses to determine if the excesses are work related.

10. OSH Information in Support of Epidemiological Studies Conducted by. External Organizations in accordance with DOE M 231.1-1, Chapter II, paragraph 5. OSH information, upon request, shall be provided to Centers for Disease Control officials and state health officials and their contractors and grantees conducting epidemiological studies:

11. Quarterly Performance Indicator Data in accordance with DOE M 231.1-1, Chapter II, paragraph 6 . Report quarterly performance indicator data in support of the EH DOE Performance Indicator Program. (For additional information see DOE 0210.1 , "PERFORMANCE INDICATORS AND ANALYSIS OF OPERATIONS INFORMATION, Of 9-27-95.") 
Washington, D.C.

SUBJECT: OCCURRENCE REPORTING AND PROCESSING OF OPERATIONS INFORMATION

\section{ORDER}

DOE 0232.1

Approved: 09-25-95

Effective Date: 10-30-95

Review Date: 09-25-97

Chg 1: $10-26-95$

\footnotetext{
1. OBJECTIVES. It is Department of EnergY (DOE) policy to ensure that the Office of the Secretary and both DOE and DOE contractor line management are kept fully informed on a . timely basis of events that could adversely affect national security or the safeguards and security interests of DOE: the health and safety of the public or the workers: the environment; the intended purpose of DOE facilities; or the credibility of the Department. The following objectives are established in support of this policy.

a. To establish and maintain a system for reporting operations information related to DOE-owned or operated facilities and processing that information to.

- identify the root causes of Unusual, Off-Normal, and Emergency Occurrences and provide for appropriate corrective action.

b. To perform the following:
}

(1) TimeIy identification, categorization, notification, and reporting to DOE management of reportäble occurrences at DOE-owned or -operated facilities.

(2) Review-of reportable occurrences;-to: assess: the significance; root causes, generic implications, and the need for corrective actions.

(3) Timely evaluation and implementation of appropriate corrective actions.

(4) Dissemination of Occurrence-Reports to DOE.. operations and facilities to prevent similar occurrences.

(5) Maintenance of a central DOE system for. reporting, processing, and retrieving unclassified Occurrence Reports.

Vertical line denotes change. 
2. CANCELIATION. DOE 5000.3B, OCCURRENCE REPORTING AND PROCESSING OF OPERATIONS INFORMATION, of 1-19-93 is canceled. Cancellation of an Order does not, by itself, modify or otherwise affect any contractual obligation to comply with such an Order. Canceled.orders that are incorporated by reference in a contract shall remain in effect until the contract is modified to delete the reference to the requirements in the canceled orders.

3. APPLICABILITY. Except for the exclusions in paragraphs $3 a$, $b, c, d$, and $e$, this order applies to all DOE Elements and contractors operating, or operating on behalf of.DOE, one or more facilities (i.e., any equipment, structure, system. process, or activity that fulfills a specific purposel as provided by law and/or contract and as implemented by the appropriate contracting officer. A facility may be a Government-owned, Government-operated facility at a DOE site or a Government-owned, contractor-operated facility at a DOE site. In addition, facility operators are required to-report occurrences resulting from activities performed by subcontractors in support of facility operation. The following are excluded from this. Order:

a. Operations information for activities regulated by the Nuclear Regulatory Commission or a state under an agreement with the Nuclear Regulatory Commission.

b. Power Marketing Administrations' reporting of major electrical power outages, disturbances, and fuel shortages subject to the emergency power system reporting requirements prescribed in 10 CFR 205, 350 through 354," "Report of Major Electric Utility Systems
Emergencies."

c. The Naval Nuclear Propulsion Program.

d. Reporting required by other DOE orders for normal record-keeping purposes. e. Routine reporting as required by external regulatory.
agencies.

A Contractor Requirement Document is attached.

4. REOUIREMENTS.

DOE M 232.1-1, OCCURRENCE REPORTING AND PROCESSING OF OPERATIONS INFORMATION, is required to implement this Order.

a. Immediately following an occurrence; DOE-owned or operated facility staff and operators shall: 
(1) ensure that appropriate immediate response(s) are taken to stabilize or return the facility/operation to a safe condition; and

(2) identify and promptly notify the Facility Manager of abnormal events and conditions and record and archive appropriate information pertaining to such occurrences.

b. Departmental Element's and contractors responsible for DOE-owned or -operated facilities shall ensure a Facility Manager or Facility Manager Designee is available at all times to carry out the following requirements.

(1) Perform categorization of the event.

(a) If the event is categorized as an Emergency. in accordance with the DOE 5500 series Orders, then make the notification of the. Emergency as required in the DOE 5500 -series - Orders and prepare the written Occurrence. Reports in accordance with this order.

(b) If the event is not categorized as an Emergency, then categorize the event as an Unusual or off-Normal Occurrence as soon as practical but, in all cases, within 2 hours of identification.

(c) If the category is not clear or. the occurrence exceeds the threshold of more than one criteria, the occurrence shall be categorized at the higher level being. considered. As an example, discovery of a defective item, material, or service,. normally reportable as an off Normal Occurrence, that caused the reduction of safety margin below that: prescribed in the authorization basis, would be reported as an Unusual Occurrence.

(d) The occurrence category shall either be elevated, maintained, or lowered as information is made available.

(2) Notify the DOE Facility Representative and the HQ Emergency Operations Center (HQ EOC) of an Unusual occurrence as soon as practical but, in all cases, within 2 hours of categorization. 
DOE 0232.1

$9-25-95$

(a) If an Off-Normal Occurrence is upgraded to an Unusual Occurrence, the Facility Manager shall notify the HQ EOC that an existing occurrence has been upgraded and provide the HQ EOC with the Occurrence Report number. The HQ EOC will make any Iequired internal DOE HQ notifications.

(b) Follow-up notifications shall be made to DOE for any further degradation in the level of safety of the facility or other worsening conditions subsequent to the previous notification, including upgrading to an Emergency in accordance with DOE 5500 series Orders.

(3) Prepare and submit a Notification Report as: soon as practical but, in all cases, before the close of the next business day from the time of categorization (not to exceed 80 hours).

(4) Prepare and submit an Update Report when significant and new information is available or upon request of DOE.

(5) Document any changes in categorization in an Update Report and submit before the close of the next business day from the time of recategorization (not to exceed 80 hours).

(6) Prepare and submit a Final Report to the DOE Facility Representative when the root cause of the occurrence has been analyzed, corrective actions determined and scheduled, and lessons learned identified. Submit the.Final. Report as soon as possible, but no later than 45 calendar days after initial categorization.

(7) If the required analysis cannot be completed within 45 calendar days, submit an Update Report within the 45 days and include a detailed explanation of the delay and an estimated date for submittal of the Final Report.

(8) If the Final Report was rejected by either the Facility Representative or Program Manager, prepare and resubmit the revised Final Report within 21 calendar days of disapproval. 
. c. Departmental Elements and contractors at facilities shall do the following:

(1) Develop or revise implementing procedures for the Occurrence Reporting Program at their facility to ensure appropriate categorization, notification, reporting, and investigating of events and/or conditions.

(a) On the effective date of this order, all reporting requirements of this order shall be implemented except for the submittal and approval of the site implementing procedures.

(b) Implementation procedures shall be submitted for approval to the respective DOE secretarial office within 4 months after. approval of this Qrder.

(c) Implementation procedures submitted by the contractor or facility operator shall be considered automatically approved 2 months after submittal, if they are not deliberately approved or rejected by DOE prior to the automatic approval.

(d) Pending approval of new or modified implementing procedures, the procedures. approved and in effect as of the effective date of this Order may be used.

(2) Retain all supporting information pertaining to each Occurrence Report (e.g., graphs, analyses) in accordance with DOE $1324.5 B$, RECORDS MANAGEMENT PROGRAM.

(3) Collect and disseminate to their personnel the lessons learned from the facility's' respective occurrences and the operations information obtained from other similar DOE facilities.

d. The DOE Facility Representative or Designee shall be available at all times to do the following:

(1) Notify the appropriate head of the Field Element of reportable occurrences.

(2) Monitor the Facility Manager:s evaluation of the occurrence to ensure acceptability of root cause determinations, generic implications, and corrective action(s) implementation-and closeout. 
(3) Approve or reject the Final Report within 10 calendar days of receipt and forward to the Program Manager for approval.

(4) If the Final Report is not approved, return the report to the Facility Manager with a written explanation.

(5) Interact with the contractor and Field Element oversight organizations as necessary and inform and advise their respective management of their findings.

(6) Elevate any unresolved issues regarding actions or determinations on a reportable occurrence to the Program Manager for resolution and direction.

e. The DOE Program Manager or Designee shall do the

(1) Notify the cognizant Secretarial officer of all Unusual occurrences.

(2) Monitor the Facility Manager's and Facility Representative's evaluation of the occurrence to ensure acceptability of root cause determinations, generic implications, and corrective action(s) implementation and closeout.

(3) Review-and approve or reject the Final Report within 14 calendar days of receipt from the. Facility Representative.

(4) If the Final Report is not approved, return the report to the Facility Manager with a written explanation.

(5) Interact with the Facility Representative and HQ oversight organizations as necessary and inform and advise their respective management of their findings.

(6) Elevate any unresolved issues regarding actions or determinations on a reportable occurrence to the Secretarial officer and,. if necessary, the secretary for resolution and direction.

f. The DOE HQ Emergency Operations Center shall notify the Program Manager of all Unusual Occurrences. 
.. 9. The following guidelines and section 8-of the Occurrence Reporting Manual shall be used to develop criteria to categorize reportable occurrences.

(1) Emergencies. Emergencies are defined in the DOE 550.0 series of Orders. Emergency Occurrences are the most serious occurrences and require an increased alert status for on-site personnel and, in specified cases, for off-site authorities. The detailed initial notification requirements, definitions, criteria, and.classifications of emergencies and appropriate responses àre provided in the DOE 5500 series of Orders. Written Occurrence Reports shall be completed in accordance with this Order.

(2) Unusual Occurrences. An Unusual Occurrence is a non-emergency occurrence that exceeds the offNormal occurrence threshold criteria, is related. to safety, environment! health, security, or operations, and requires immediate notification to DOE. The types of occurrences that are to: be categorized as Unusual Occurrences are those that result in any of the following:

(a) Release of radioactive or hazardous materials above Ilmits established in Federal permits, Federal regulations, or DOE standards.

(b) Violation of safety, environmental, or health requirements defined in Federal permits, Federal regulations, or DOE standards.

(c) Significant internal or external threats to safety, environmental, or health protection, or to the ability of a facility to operate.

(d) Significant degradation in the operation, maintenance, or performance of safety class structures, systems, or components or of environmental, safety, security, or health conditions.

(e) Fatalities or significant injuries.

(f) Significant exposures to hazardous or radioactive materials.

(g) Off-site or on-site contamination.that does not meet the emergency:criteria-defined in 
the DOE 5500 series of Orders but is in excess of regulatory limits.

(h) Failure of environmental monitoring equipment necessary to demonstrate compliance.

(i) Failure of safety class structures, systems, or components reducing the capability below a minimum required safety function or resulting in significant delay or cost in operations.

(j) Actuation of emergency systems, except under approved testing.

(k) Reduction of the safety margin below that prescribed in the authorization basis of a facility or process (including violations and noncompliances of Technical safety Requirements, Operational Safety Requirements, Technical Specifications, or other authorization basis documents).

(1) Determination of an actual Unreviewed Safety Question which reveals a currently existing inadequacy in the approved authorization basis.

(m) Violation of DOE safety or environmental requirements, or the loss of control or release of radioactive material above allowable limits.

(n) Release of a hazardous substance or material that exceeds a reportable quantity and is not Federally permitted..

(0) Failure or significant- degradation of administrative controls which are required to ensure safety, security, environment, or health protection.

(p) Theft/diversion/intentional destruction of Government assets and the identification of significant criminal activities.

(q) A significant fire or explosion at a DOE facility or caused by DOE operations. 
(r) A potentially significant concern by the press or general population or possible damage to the credibility of the Department.

(8) A significant nuclear explosive occurrence at DOE-owned-or -operated facilities or during onsite or offsite nuclear explosive transportation. •

(3) Off-Normal Occurrences. Off-Normal Occurrences are abnormal or unplanned events or conditions that adversely affect, potentially affect, or are indicative of degradation in the safety, safeguards and security, environmental or health protection, performance or operation of a facility. The types of occurrences that are to be categorized as off-Normal Occurrences are those that result in any of the following:

(a) Release of radioactive or hazardous materials below limits established by Federal permits, Federal regulations or DOE: standards, but that must be reported in writing to state or local agencies in other. than routine periodic reports.

(b) Internal or external threats (including, but not Iimited to, safeguards and security) to safety, security, environmental or health protection, or the ability of a facility to operate.

(c) Degradation of environmental, safety, security, or health conditions:

(d) Serious personnel injury or significant lost." workdays.

(e) Personnel contamination, assimilation, or exposure.

(f) Off-site or on-site contamination of hazardous or radioactive materials in exçess. of administrative limits. but within regulatory limits.

(g) Degradation of environmental monitoring equipment necessary to demonstrate compliance.

(h) Violation of safety, environmental, or health administrative limits. 
(i) Operational procedural violations, including maintenance and administrative procedures, which have the potential to impact the safety, security, environmental or health performance or operation of a facility.

(j) Discovery of a condition that leads the Facility Manager to limit facility operations due to the identification of a potential degradation of the authorization basis of a facilfty or process.

(k) Discovery of a potential Unreviewed Safety. Question that could affect the present or future operation of the facility.

(1) Identification of actual or potential defective items, materials, or services, including defects : identified by subcontractors and suppliers, that could impose a substantial safety hazard.

(m) Unanticipated significant delay or cost in achieving programmatic objectives.

(n) Loss or damage to property caused by DOE operations or loss or damage to DOE property.

(o) Violation of a nuclear explosive standard or rule, or training related occurrences indicative of a hazard to a nuclear explosive.

5. RESPONSIBIIITIES.

a. Assistant Secretary for Environment, Safety and Health (EH-1).

(1) Develop, promulgate, and maintain policies to implement and sustain. an effective occurrence Reporting Program.

(2) Provide formal Departmental interpretation of the requirements of this order.

(3) Develop, promulgate, and maintain guidance. materials, and conduct workshops, as necessary, for implementing the requirements of this order. 
(4) Monitor reports relative to reporting activities at DOE facilities to assess implementation of this order to identify needed improvements.

(5) Monitor and audit implementation of this order related to the office of Environment, Safety and Health functional areas of responsibility.

b. Secretarial officers.

(1) Delegate responsibilities and authority for implementing this order, to include designation of Program Managers.

(2) Review and approve the Facility/site Implementation Procedure after coordination with the office of -Environment, Safety and Health.

(3) Establish agreements with Heads of Field Elements to ensure support to the DOE Facility Representative and Program Manager(s) in accordance with this order.

(4) Review Occurrence Reports and. identify circumstances that are indicative of deteriorating or poor program performance in their respective areas of authority.

(5) If deemed appropriate, delegate authority for approval of Final. "Off-Normal" Occurrence-Reports from the cognizant Program Manager to the cognizant DOE Facility Representative.

(6) If deemed necessary, formally request the Secretary of Energy to grant an exemption to the reporting requirements of this order., after obtaining concurrence from the office of Enviromment, Safety and Health. The secretarial Officer may grant temporary exemptions to the reporting requirements of this order, up to 1 year in duration. Prior to approval of the temporary exemption, the Office of Environment, Safety and Health should be notified.

c. Director, office of Emergency Management $(\mathrm{NN}-60)$. Ensure that the Emergency Operations Center is prepared to receive and record incoming initial - notifications of Unusual Occurrences and disseminate these reports to appropriate Headquarters organizations. 
.. d. Heads of Field Elements.

(1) Ensure that agreements are established with responsible secretarial officers on the working relationship between the Secretarial officer and the: Field Element for the purpose of carrying out. the requirements of this order.

(2) Assess the contractor's capability and performance in carrying out the requirements of this Order, in accordance with established agreements with the responsible secretarial officers.

(3) Provide technical support as necessary to DOE Facility Representatives in responding to any reportable occurrence, in accordance with established agreements with the responsible Secretarial officers. :

(4) Designate and direct DOE Facility Repregentatives and Designees to fulfill the responsibilities required by this order.

e. Program Managers (in addition to other requirements prescribed by this order).

(1) Review activities relating to reportable occurrences, including reporting and development of programs and procedures.

(2) Ensure that a system for prompt notification and categorization of reportable occurrences has. been established for their DOE programs and for facilities under their cognizance.

(3) Ensure that the Headquarters Emergency Operations Center is informed of how the Program Manager or Designees can be reached at all times.

(4) Ensure that lessons learned and generic or programmatic implications are: identified and elevated to the secretarial officer for appropriate action.

(5) Ensure that actions are taken to minimize or prevent recurrence.

(6) Review and assess reportable occurrence information from facilities under. their cognizance to assess significance, root cause, generic implications, and the-need. for corrective 
action, and to ensure that DOE and contractor staff involved in these operations perform the related functions.

(7) Ensure that Occurrence Reports and operations information from other organizations are disseminated to appropriate DOE and contractor activities within their cognizance, are reviewed for generic implications, and are used to improve operations.

(8) Ensure that Occurrence Reports are prepared and transmitted in accordance with DOE security requirements.

f. DOE Facility Representatives (in addition to other requirements prescribed in this order).

- (1) Ensure that facility personnel under their cognizance prepare and promulgate procedures for notification and reporting that are compatible with and serve the policies of this order.

(2) Actively monitor day-to-day operations and performance of facilities/activities under their cognizance.

(3) Ensure that lessons-learned and generic or programmatic implications are identified and elevated to the Head of the Field Element for appropriate action.

(4) Ensure that facility personnel act to minimize or prevent recurrence.

(5) Review and assess reportable occurrence information from facilities under their cognizance to assess significance, root causes. generic implications, and the need for corrective actions, and to ensure that contractor staff involved in these operations perform the related functions.

(6) Ensure that Occurrence Reports and operations information from other organizations are disseminated to appropriate contractor activities within their cognizance, are reviewed for generic implications, and are used to improve operations.

(7) Ensure that Occurrence Reports are prepared and transmitted in accordance-with. DOE securityrequirements. 
6.. CONTACT. The contact for this order is Eugenia Boyle, office of Nuclear and Facility Safety, at Internet address Eugenia.BoyleeHQ.DOE.GOV or (301) 903-3393.

BY ORDER OF THE SECRETARY OF ENERGY:

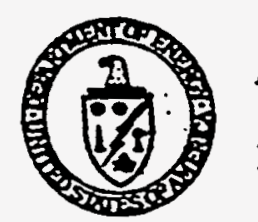

ARCHER I. DURHAM Assistant Secretary for Human Resources and Administration 


\section{CONTRACTOR REQUIREMENTS DOCUMENT}

\section{Occurrence Reporting and Processing of Operations Information}

In the performance of this contract, the contractor is required to establish an Occurrence Reporting Program for the timely identification, categorization, notification, and reporting of operations information related to DOE-owned or operated facilities and for the processing of that information to identify the root cause, provide for appropriate corrective actions, and prevent similar occurrences through the identification of good practices and lessons learned. The facility-specific Occurrence Reporting Program shall be developed in accordance with DOE $M$ 232.1-1, OCCURRENCE REPORTING AND PROCESSING OF OPERATIONS INFORMATION.

In support of this requirement, the contractor is required to develop or revise implementing procedures for DOE approval within 4 months after approval of DOE 0 232.1, OCCURRENCE REPORTING AND PROCESSING OF OPERATIONS INFORMATION, or the incorporation of this Contractor Requirements Document into the contract. Since all reporting requirements of this order are to be implemented on the effective date of DOE 0232.1 , procedures previously approved and in effect may be used pending approval of the new or modified implementing procedures. Implementation procedures submitted by the contractor or facility-operator shall be considered automatically approved 2 months after submittal, if they are not deliberately approved or rejected by DOE. 

US. Department of: Energy:

ORDER

Washington, D.C.

DOE 0360.1

5-31-95

SUBJECT: TRAINING

1. ORJECTIYES.

a. Assign responsibilities and provide requirements for establishing, implementing, documenting and evaluating training programs for Federal employees.

b. Commit to the continuing development of employees to ensure guality performance from a technicaliy competent, versatile, and diverse work force.

c. Establish the requirements for the training and qualification of technical etuployees: and managers whose position reguires then to. provide management direction or oversight that could impact the safe operation of a defense nuclear facility.

2. CANCELLATIOH. DOE 3410.1B, TRAINING, of 2-29-88.

3. APPLICABILITY.

a. : Applicability. This Order is applicable. to Department of Energy Federa employees. Clarification of the applicability of the spectfic requirements is included within the chapters.

b. Exemptions. If applicable, specific exemptions can be found in . each of the Ordar's chaptors.

c. Director; Naval Nuclear Propulsion Program wi17, in accordance with. the responsibilities and authorities assigned by Executive Order 12344, statutoriiy prescribed by 42 United States Code 7158, note, and to ensure consistency throughout the joint

Navy/Department of Energy organization of Naval Nuclear Propulsion

Program, implement and oversee all policy and practices pertaining to this Department of Energy Order for activities under the Director's cognizance.

\section{REOUIREAEISS.}

a. Specific reguirements are contained within the chapters of this Order as follows:

(1) Chapter I - Requirements for the Administration of Training

(2) Chapter II - Requirements for the Technical Qualification Program

(3) Chapter III - Requirements for the Conduct of Technical Training

(4) Chapter IV - Requirements for Academic Degree-Training

(5) Chapter V - Requirements for Retraining

oLstaibutran:

A11 DepartmentäT ETements
IWITLTER:BY:

Office of Professional and Tec: nical Training and Developmen 
b. The following documents shall be followed for the implementation of this order:

(1) 5 United States Code 4103 et. seq., which grants the authority to operate training programs.

(2) 5 Code -of Federal Regulations; Part 410 et. sea., which contains the Office of Personnel Management regulations on the conduct of training programs.

(3) Executive Order 11348, which provides training goals and practices.

(4) Executive Order 11478, which outlines provisions on equal opportunity in training programs.

\section{RESPOASIBILITIES.}

a. Assistant Secretary for Human Resources and Administration sha71:

(1) Estahlish Department. of Energy training policy and provide resources to ensure the estabi ishment and management of Department-wide. training and human resource development programs.

(2) Appoint a Technical Personnel Program Coordinator to . facilitate technical training, gualification, and: educational programs. for Federal and contract empioyees.

b. Cognizant Secretarial Officers and Heads of Field Elements shall:

(1) Ensure that individuat development plans, ammual training plans, and out-year training plans are developed and implernated.

(2) Provide sufficient resources for training programs to ensure the development of a technically competent, diverse work force.

(3) Provide content expertise support to ensure the adequacy and accuracy of training that relates to assigned area of responsibility.

(4) Implement training and qualification programs for personnel who provide management direction or oversight of contractor technical activities that could impact the safe operation of a defense nuclear facility, as indicated in Chapters II and. III of this Order.

(5) Implement performance appraisal requirements that reflect supervisory and employee accountability for training and quatification.

(6) Consistent with the criteria in Chapter I, determine whether to waive, in whole or in part, any right to recover nonsalary training expenses under a continued service agreement.

(7) Serve as the management sponsor for applicable functional area qualification standards as indicated in Chapter II. 
(8) Ensure that self-assessments of the effectiveness of training programs are conducted every 3 years.

c. Deputy Assistant Secretary for Human Resources shall provide guidance and assistance to the Cognizant Secretarial Officers and

- Reads of Field Organizations in the application of merit promotion principles and practices in the selection of employees for training and development programs, and the use of-other career enhancement initiatives such as upward mobility.

d. Director of Training and Human Resource Development shal1:

(1) Deveiop and issue Department standards, procedures and guidelines that relate to employee training, development and qualification activities.

(2) Coordinate the development, implementation and maintenance of the:Departhent's training and developaent..strategic. plan.

(3) Coordinate the developmient and revision of training and qualification programs for personnel who provide management direction or oversight of contractor technical activities. that could impact the safe operation of a defense nuclear faci7ity, as indjeated in chapters II and III of this order.

(4) Promote partnerships to achieve training and development goals through coliaborative efforts, joint financial management, and jointiy sponsored training activities.

(5) Promote the effective sharing and use of Department facilities, new learning technologies, and training. programs.

(6) Serve as the Departrent's liaison with other governient agencies. When neeessary, complete agreements with other. government agencies for the use of.training programs and facilities.

e. Training Managers appointed by Cognizant Secretarial Officers and Heads of Field ETements, as either a fuil time- or part time assignment, shail:-

(1) Promote and facilitate the use of a systems approach for qualification and training activities.

(2) Coordinate the development and administration of the annual training plans, out-year training plans and training budgets.

(3) Coordinate the implementation of training and qualification programs for personnel who provide management direction or oversight of contractor technical activities that could impact the safe operation of a defense nuclear facility; as indicated in chapters II and III of this order.

(4) Provide assistance to employees and supervisors to facilitate the development, review and implementation of individual development plans.

(5) Coordinate and develop local training policies and procedures, as applicable. 
f. Managers/Supervisors sha71:

(1) Hork with each staff member to achieve mutual understanding of job competencjes, job training, and career development opportunities and requirements.

(2) Document training and development activities in the individual development plan.

(3) Ensure that employees entering a new position have a new or revised individual development plan within 60 days, and that individual development plans for a 71 employees are reviewed and updated annualiy:

(4) Ensure implementation of individual development plan activities, approve individual training requests, establish pre-training expectations, and discuss with trainees how training will' be:applied:to"their: job:

(5) Ensure that on-the-job orientation and training is provided to employees new to the organization.

(6) Monitor and assess employee progress toward completion of assigned qualification activities, as applicable.

9. Enplovees shall:

(1) - Work with their immediate supervisors to identify training and development activities that foster immediate and longrange performance objectives, and coordinate with supervisors to document those activities in the individual. development plan.

(2) Successfully complete assigned training, development, colveatton; and qualffication activities and. conply with cont fnued service agreements.

(3) Provide objective feedback to supervisors and training personnel on the effectiveness and relevance of training. Provide training documentation to Training/Personnel office to maintain training and qualification records current.

6. ASSISTAMCE. Questions concerning this order may be referred to the Director, Office of Training and Human Resources Development, HR-2, Thomas W'. Evans, (202) 275-1717:

BY ORDER OF THE SECRETARY OF ENERGY:

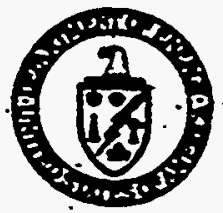

ARCHER L. DURHAY

Assistant Secretary for Human Resources and Administration 
5-31-95

TABLE OF CONTENTS

\section{CHAPTER I - ADNINISTRATION OF TRAINING}

Page

1. TRAINING PROGRAM COMPONENTS........................

a. Planning ...............................

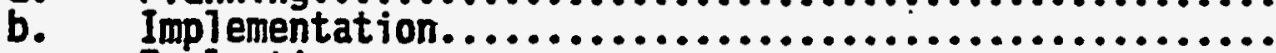

2. C. EvaINING LOGISTICS.

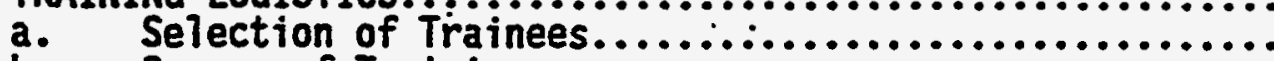

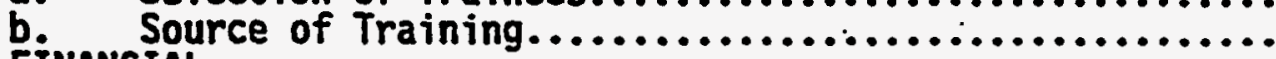

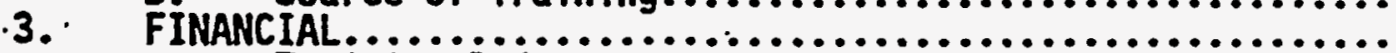

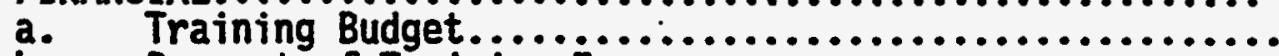

b. Payment of Training Expenses.......................

4. TRAINING REQUESTS. AND APPROUAL

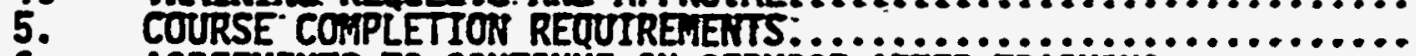

6. AGREEMENTS TO CONTINUE IN SERVICE AFTER TRAINING...........

. $a$. Establ ishing Continued Service Agreements.............

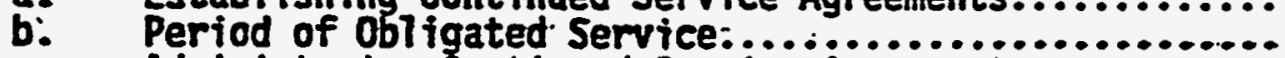

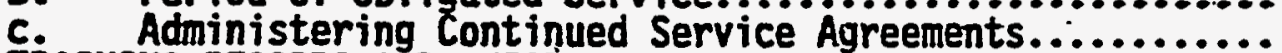

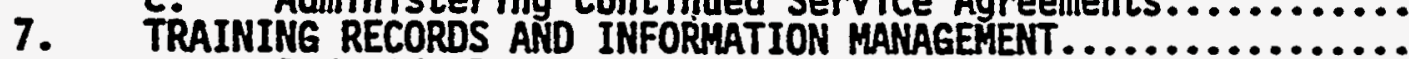

a. Individual Records..........................

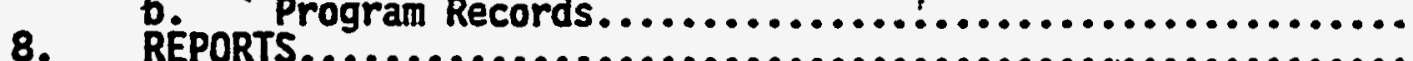

$I-1$

$1-1$

$\mathrm{I}-\mathrm{2}$

$I-2$

$I-3$

$\mathrm{I}-3$

$\mathrm{I}-3$

$\mathrm{I}-3$

I-3

$\mathrm{I}-3$

I-4

I-5:

I-5

I-5

I-6

I-6

$\mathrm{I}-8$

I-8

I-8

I-9

CHAPTER II - TECHIICAL QUALIFICATION PROGRAY.

1. APPLICABILITY.

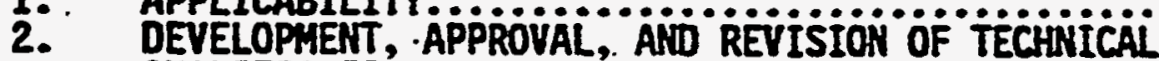

QUALIFICATION STANDARDS

a. Development of the Quai ification Standards.

b. The-Technical Excellence Executive Comittee............

c. Subject Matter Experts From Headquarters and Fieild Ë iements Subject Matter Experts From Headquarters and Field Elemen
Affected by the Technical Q Qualification Program........

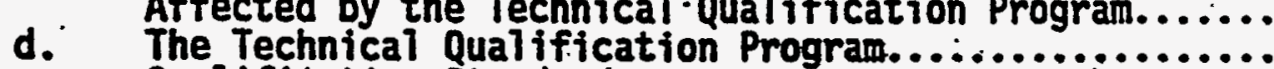

e. Qualification Standards.

3. IMPLEMENTATION OF THE QUALIFICATTION PRÖGRAM

a. Headquarters and Field Element Managers...................

b. Employees in the Technical Qual if ication Program.......

c. . Exemptions....

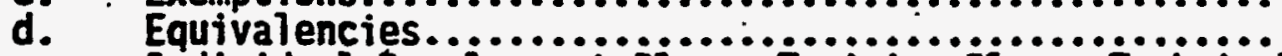

e. Individual Deveiopment pians, Training Pians, Technical

f. Qualification Records, or Related Documents.

. Technical Qual ification Program.....................

g. Personnel tho Complete Applicabie Qualification

Requirements.....................................

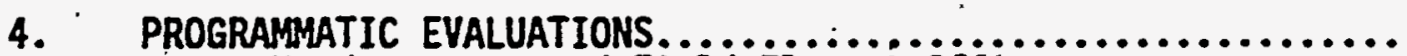

a. Headquarters and Fieid Eiement Offices.................

b. Assistant Secretary for Environment, Safety, and Health........................................

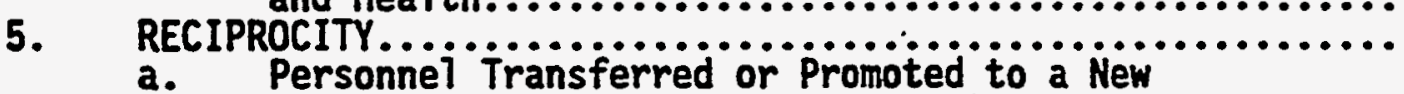
Assignment Within Their Functional Area... 
b. Personnel Transferred or Promoted to a New Assignment in a Different Functional Area.

6. RELATIONSHIP TO OTHER PERSONNEL ACTIVITIES............... II-6

a. New Hires, Transfers, or Promotions of Personnei...... II 6

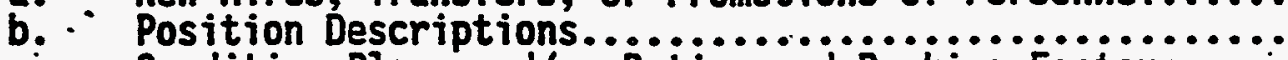

c. Crediting Plans and/or Rating and Ranking Factors.... Attachment ii - Tẹnnicai Quaiłiłication Program Compentency Exemption Form............

II -6

II -6

II -6

II -7

CHAPTER III - COMDUCT OF TECHIICAL TRAIHING.

1. APPLICABILITY.

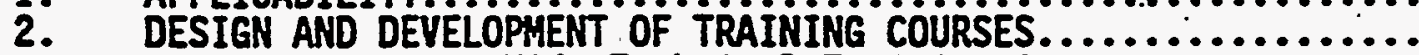
a... Department-Wide Technical. Training Courses..............

b. Office/Facility-Specific Téchnical Training

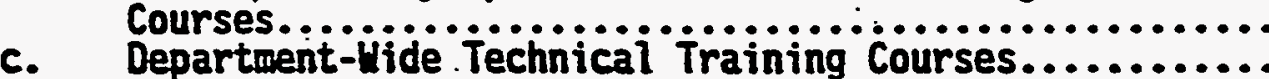

d. The Office of Training and Human Resources Development

e. Documentation....................................

' f. Development or Revision............................

3. IMPLEMENTATION OF TRAINING. a. Technical Instructor Quai ification................... b. Testing and Evaluation.............................

4. TRAINING COURSE AND PROGRAM EVALÜÄTiON.................... a. Training Course Evaluation........................... b. Prograw Self-Assessments..............................

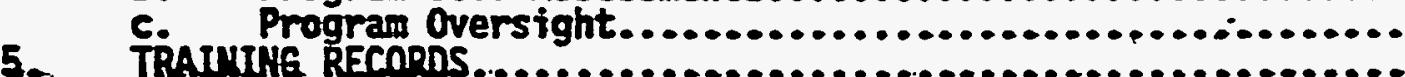
a. The Traintag Officer (o Equivaient) Within

Each Headquarters and Field Office.................. III -4

b. Training Providers................................ III -5

\section{CHAPTER' IV - ACADEIIC DEGREE TRAIHIHS}

1. APPLICABILITY. ............................

2. AUTHORIZATION Ö ACADËIC DËGRË TRÄHING $\ldots \ldots \ldots \ldots \ldots \ldots$

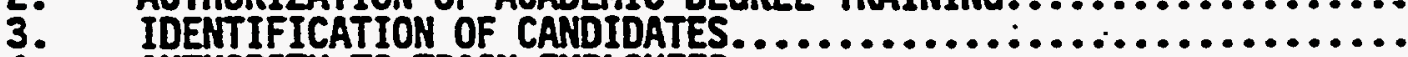

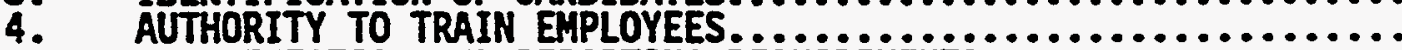

5. DOCUMENTATION AND REPORTING REQUIREMENTSO

IV-1

IV-1

IV -1

IV -2

IV-2

\section{CHAPTER.V - RETRAIHING}

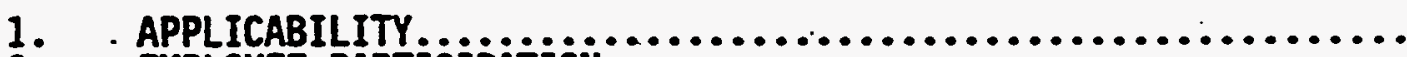

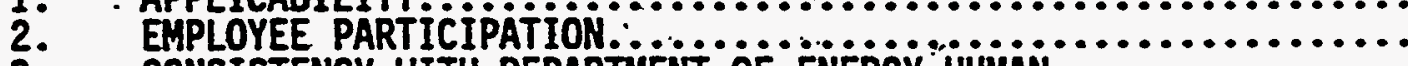
CONSISTENCY WITH DEPARTMENT OF ENERGY HUMAN RESOURCE MANAGEMENT POLICIES............................

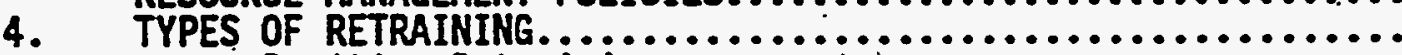

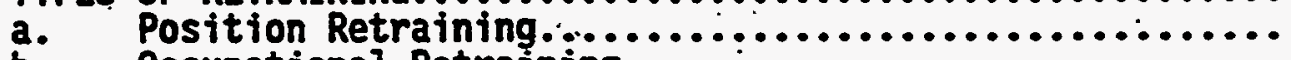
b. Occupational Retraining... 


\section{CHAPTER I}

\section{ADNINISTRATIOH OF TRAIHIHG}

\section{TRAINING PROGRAM COAPOAIENTS:}

a. Planning: The Department's strategic plan includes a description of the goals and strategies for developing and maintaining a competent work force. The implementation of such strategies. requires a planning process based on the following:

(1) Individual Development Plans.

(a) Individual development pịans are required within 60 days of an employee joining the Department or. transferring to a new position, and shall be reviewed and updated annuatiy.

(b) Individual development plans are not required for temporary employees and others from whow; by the. nature of their position, training and development would resuit in minimal benefit to the Department.

(c) Supervisors and manágers shall initiate and impiement individual development plans through discussions. with individual employees regarding job requirements and - the. competencies required to successfuity meet these requirements.

(d) The individual development plan shall provide a mechanism to estahl ish the employee's training, developinent; and qualffication needs based on the:

1 Department and organization goals, objectives, and mission.

2 Technical qualification standards for the position (if appicable).

3 Employee's personal and professional development goals.

(2) Ànnual Training Plan.

(a) Departmental Elements shall develop and maintain annual training plans. This plan is the management document for training and development activities for the current fiscal year, and shall be approved by the Head of the Departmental Element.

(b) Annual Training Plans shall:

1 be based in part upon the information contained in employee individual development.plans, technical qualification documents, or other. training plans. 
2 define objectives and set priorities for the organization's training program, identify the estimated number of employees to be trained, types and sources of training, resource requirements, and evaluation processes.

(c) The Office of Training and Human Resources Development shall estabi ish guidelines for the format and content of the plan.

(d) Organizations shall submit information from the approved annual training plans to the Office of Training.. and Human Resources Development as requested.

Out-Year Training Plan. A plan covering at least two additional years shall be included with the annual training plan and integrated with multi-year budget projections to. provide a best estimate of training requirements and resources. The out-year training plan does not require the same levei of detail. as the annual training plan.

b. Implementation. The major elements of employee training include orientation, general training, performance development and career development.

(1) Qrientation. Training that all employees receive uporrentry into the Department, or. into a new position in a different Departmental Element.

(2) General Training: Training that applies to employees within the Department of Energy or an organizational unit of the Dopartimant. This. way incluct areas swet as equal employment opportunity, ethics, - and general employee training for nuciear facilifties. Departmental management establishes general training requirements.

(3) Peirformance Development.. Training that supports the acquisition or improvement of work-related-competencies and skilis. These may be legally or position required and include administrative, technical, and managerial ski11s:

(4) Career Develonment. - Training and deveiopment activities that support career growth and help to achieve an optimal match of individual and Departmental needs.

c. Evaluation. Departmental: Elements shall perform self-assessments of training and development programs to determine how well they meet short and long range needs. These assessments shall be conducted every 3 years in accordance with local policy and procedures. Self-assessments shail address the following:

(1) The extent to which training programs are achieving the objectives stated in the annual training pians and other organizational plans and strategies. 
(2) The effectiveness of training in providing empioyees with skilis and knowledge that can be used in the work place.

(3) The effective and economic use of training resources.

2. IRATHIHG LOGISTICS.

a. Selection of Trainees.

(1) Merit promotion procedures shal1 be used when the training:

(a) is part of an authorized training agreement;

(b) is part of a program that inciudes promotions or reassignments to another occupational job series, when competition has not occurred at an earlier stage; or,

(c) is required before an employee may be considered for a promotion.

(2) The Secretary shall approve training for Presidential appointees, and the Office of Personnel Management shall approve training for the Secretary.

b. Source of Training.

(1) Individuals or organizations with a possible conflict of interest that would be detrimental to the training activities shall not be selected as a source of training.

(2) The Secretary shall concur in the selection of a training : source involving the White House, the Office of Managenent and Budget, or the Congress.

(3) The Assistant Secretary for Policy shall approve any training involving foreign travel.

3. EIHANCIAL.

a. Training Budget. Departmental Elements shall develop an annual training budget based on projected activities and cost estimates as reflected in the annual training plan.

b. Payment of Training Expenses.

(1) In determining whether to pay training expenses, priority shall be given to the objectives established in the annual training plan as follows:

(a) Training that is required by law or regulation;

(b) Performance deveTopment training; and

(c) Career management and development training. 
(2) Payment of the following expenses shall not be authorized as part of the cost associated with training:

(a) Premium pay for employees while in training; unless the employee normaliy receives premium pay or the payment of premium pay reduces the overall cost of the training.

(b) Fees required for an employee to take professional certification or license examinations. Fees for an examination preparatory course may be paid if the. course is provided as training.

(c) Costs or fees imposed by an educational institution for the sole purpose of granting a degree; unless it. is provided to relieve recruitment and retention. probiems, and al7 of the provisions of " 5 Code of " Federal Regulations 410 and Chapter IV of this Order are met.

(d) Membership fees that are not a condition of enrolling, or participating, in training:

(e) Retroactive approval of any training expense that requires a continuous service obligation.'

(3) Employees on training assignments shall be rejmbursed for travel in accordance with Federal travel regulations and Department policy.

\section{IRATHITIG REOUESTS AMD APPBOYYA.}

a. Requests to attend Department-sponsored training prograns of 8 or more hours duration shall be formaliy approved and authorized based on a review of the necessity of the training, availability . of funds, and current internal and external requirements.

Departmental Elements shalf estabilish approval and authorization. policies and/or procedures.

b. Data from the request shall be entered into the training information system and DOE Form 3410.4 generated in accordance with local requirements.

c. Employees approved for academic courses shall be required to register for credit if it is given. The Department shall not pay for employees to enrol1 in a course on an audit basis when credit is given for the course.

d. Empioyees shall be advised of the action taken on their-training requests prior to course registration dates. Employees enrolling in, or registering for, courses without the prior authorization of the authorizing official may be personally obligated for tuition and other course costs. 


\section{COURSE CONPLETIOH REOUIRENENTS.}

a. Employees shall, upon completion of training courses provided at Government expense, forward a copy of their grade notification and/or other evidence of satisfactory course completion, to the servicing training or personnel office for entry in their officiat training record or personnel folder.

b. Employees shall attend at least 80 percent of the program or course sessions and satisfactority complete course activities, in courses where grades or other scores indicating successfut completion of the courses are not given.

c. If an employee requests permission to withdraw. from a program or course, or if the supervisor finds it necessary to request the employee to.withdraw,..2. menorandum from the employee's immediate supervisor describing the circumstances of the withdrawat shat submitted to the servicing training or personnel offjce. Except in. a case where the supervisor has requested the employee withdraw for reasons benefiting the organization rather than the enployee, a determination shail be made by the authorizing official that repayment of any direct costs incurred is required by the employee. The employee shall be notified of the decision of the

- authorizing official.

d. Employees who do not successfully complete undergraduate or graduate courses (i.e., grade of " $C$ " for undergraduate courses and "B. for graduate courses) shal1 be required to pay the government for any tuition and/or related course costs incurred. Exceptions may be considered by the authorizing official upon receipt. of witten justification from the employee and their supervisar.

6. AGREEMEITS TO COITIMUE IH SERUICE AFTER TRAIHIHE.

a. Establishing Continued Service Agreements.

(1) A continued service agreement shall be required for each training activity which exceeds 160 hours. However, Cognizant Secretarial Officers and Heads of Field Elements . may require agreements to continue in service for other training instances or programs, if applied equitably to all individual participants.

(2) A continued service agreement shall not be required. for the: following:

(a) work assignments for which one of the objectives is to develop or assess employee competency levels;

(b) coaching, mentoring, on-the-job, or similar training;

(c) correspondence courses completed as part-time training; 
(d) training provided by manufacturers, suppliers, or contractors for the purpose of equipment or. operating systems installation, use or maintenance; and

(e) training performed under a performance improvement plan.

(3) Prior to registering for training, the employee shall sign the continued service agreement on the reverse side of the. first page of DOE Form 3410.4 , or the equivalent, indicating that they have read and understand the provisions of. the agreement. The original agreement shall be filed in the official Personnel file and a copy of the agreement shall be provided to the employee.

b. Period of Obligated Service.

(1) The continued service agreement obligates the employee to remain with the Department for the length of the instance of training plus a post-training perjod equal to three times the length of the training. The length of the training period equals the sum of fuil time: training days plus the part time training hours. An instance of training. may be a single training activity or, a group of concurrent activities with a common purpose, and/or obtained from the same source over a defined time period. Each instance. of:training requires a separate continued service agreement.

(2) When the Department pays some, or. all, of the additional expenses of training, but the employee receives no. salary for the training period, the period of obligation may be reduced to a period equal to the length of the training period.

c. Administering Continued Sérvice Aareements.

(1) Involuntary Separations. The agreement shall be canceled and right of recovery waived when the employee is separated involuntarily for reasons beyond his or her control, - and not because of misconduct or personal. del inquency during the training or the post-training obligated service period: For. purposes of the agreement, when an employee resigns under circumstances that show cleariy that the resignation is an election to resign rather than to undergo other separation procedures, (and there is a record of a preliminary: personnel action on file, e.g., reduction-in-force-notice), the resignation sha71 be considered an involuntary separation, provided that the reason for the separation is not.misconduct or personal del inquency, as indicated above.

(2) Orders to Military Service. Orders to report for military service (other than training duty) shall be sufficient reason for waiving the training agreement during the period of training; or obligated post-training service. The trainee is responsible for submitting proof (a copy of his or her orders with reporting endorsements) if he or she 
wishes to secure a waiver of the post-training. service obligation.

(3) Transfer to an International Organization. Separation from the Department for the purpose of accepting employment with an international organization, of which the United States is a member, should be considered grounds for waiving the right to recover, if such employment is deemed to be in the interest of the Department and the public.

Transfer to Another Federal Agency. When the Department receives a request for transfer from an employee subject to a continued service agreement, it shall notify. the gaining agency that the employee is still subject to a continued service agreement. If the Department determines that the training. received will be utilized. in the new position, the agreement is transferred to the gaining agency, and-the-gaining agency shall then assure that the agreement is fulfilled. If the Department determines that the training received will not be utilized in the new posit.ion,- it shalt. notify the employee in writing, before the effective date of the transfer, that it intends to recover the additional expenses.

(5) Liability in Yoluntary Separation. When an employee. voluntarily leaves Federal service during a period of obligated post-training service, he or she immediately becomes liable to the Government for repayment of the additional expenses, uniess otherwise stated in this Order.

(6). Hethod of colleation. Collection shall be made by withiofding the actuat anount of additionat expenses fruar any monies due the employee from the Department, or by other - procedures consistent with collection methods provided by. statute or regulations. The appropriate finance office shall collect the amount due.

(7) Amount of Additional Expenses to Repay. The Government's right of recovery with be enforced for a percentage of . additional-expenses proportionate to the percentage of the training agreement not completed, unless there is a waiver action.

(8) Request for Waiver.: Employees with obligated service who Teave the Department shali be:

(a) notified if the Department intends to seek recovery instead of transferring the obligation,

(b) advised by their supervisor of their right to request reconsideration of the amount to be recovered, or pursue a waiver of the Government's right to recover,

(c) advised to submit their requests in writing to the appropriate approving official through the servicing 
personnel office, before the effective date of separation from the Department,

(d) advised to state the grounds on which they believe the determination to reconsider, or waive recovery rights, should be based, and

(e) have the opportunity to respond to the Department's findings before the Department may recover training expenses.

(9) If any continued service agreement is violated and a waiver is not granted, a statement to that effect sha11 be placed and retained in the. employee's Official Personnel Folder until funds are recovered. This statement shall. confirm that. an unfuifililed.agreement. exists, specify the amount of the unexpired term of the agreement; and note the anoum of money due the government.

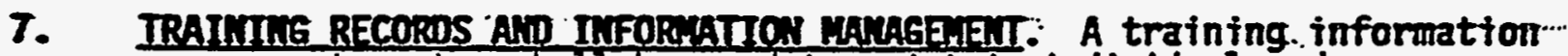
management system shall be used to maintain individual and program records, and produce reports. Training managers or their representatives are responsibie for accurate and complete data entries, training status updates and the review of records to ensure validity. The training information management system shall provide for:

a. Individual Records. Individual training records shall be reviewed by employees annuaily. All training records shall be merged vith the Official Personnel Folder when an employee leaves the agency. For each training instance of 8 hours or more, or for mandatory training, the record shall include:

(1) Titie and training objectives of the course;

(2) Source of the training;

(3) Length of course with start/end dates;

(4) Whether the empioyee satisfactorily completed training and an employee/supervisory evaluation (sections $H$ and $I$ of DOE Form 3410.4, or a substitute form);

(5) Expenses related to employee involvement in training, exclusive of employee salary cost;

(6) The period of time (if any) the employee is obligated to continue in service.

b. Program Records. When the Department pays for the devel opment of a training course, the following documentation shal] be required and maintained by the Departmental Element responsible for the training:

(1) Learning objectives, based upon course goals; 
DOE 0360.1
$5-31-95$

$I-9$ (and I-10)

(2) A detailed course outline indicating the content of the course and the instructional design;

(3) Master copies of all instructor and student materials; and

(4) Expenses of development.

8. REPORTS. Reports on training and development activities shall be provided upon the request of the Director. of Training and Human
Resources Development. 
-

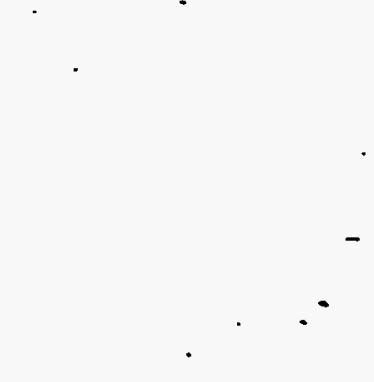

. $\therefore$

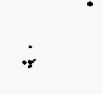

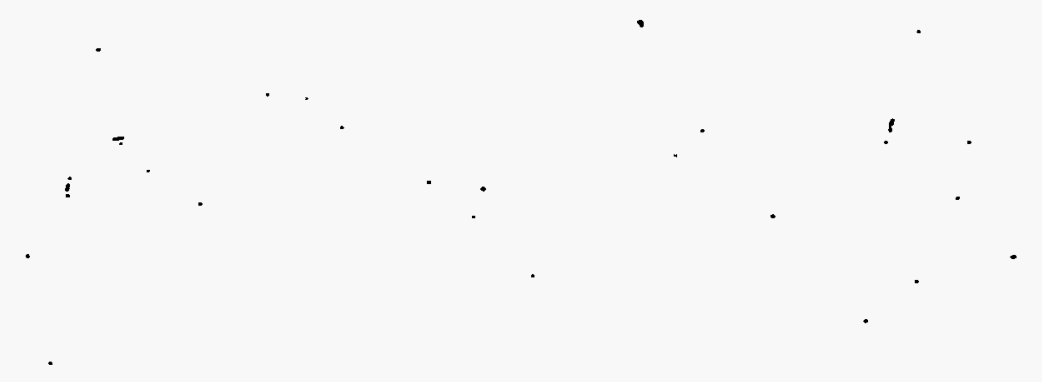

-

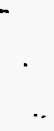

-
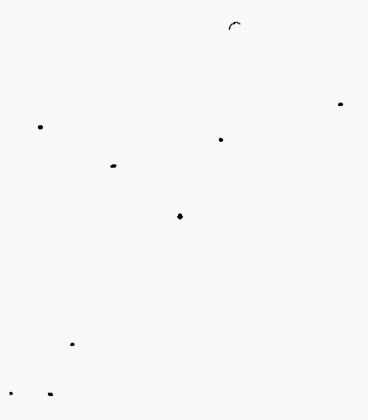


\section{CHAPTER II \\ IECHWICAL OUALIFICATIOH PROGRAY}

1. APPLICABILITY.

a. The Technical Qualification Program is the process used to. objectively determine that individuals performing activities related to the technical management, oversight or operation of defense nuclear facilities possess the necessary knowledge, skills and abilities to perform their specific duties and responsibilities.

b. The Technical Qualification Program applies to Department of Energy Federal technical employees in 800 and 1300 occupational saries, .. and others, whose position requires them to provide management direction. or oversight that-could impact the : safe:= operation of a defense nuclear. facility.

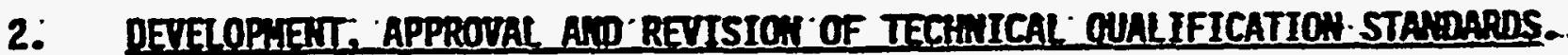

a. Development of the Oualification Standards shall be based upon functional areas of responsibility within the Department, with input.from affected Headquarters and Field Elements.

b. The Technical Excellence Executive Comnittee shall consist of heads of Departmental Elements from Headquarters and the Field. This Comittee shall:

(1) approve alt elenents of the Technical Qualification Progran that have cross-cutting, Department-wide implication; ..

(2). designate a managenient sponsor for each of the functional area qualification standards;

(a) The management sponsor sha77 be a senior manager from a Departmental Element, such as: Defense Programs or Environmental Management:

(b). The management sponsor shall concur with the technical adequacy and accuracy. of the qualification standard.

c. Subject Matter Experts From Headquarters and Field Elements Affected by the Technical Oualification Proaram shall participate in the development, revision, and/or review of the qualification standards applicabie to their organization.

d. The Technical Qualification Program shall be estabi ished. in a building block fashion as described below.

(1) The general technical base qualification standard shall be based upon core technical competencies for technical personnel in all of the functional areas, and shall include knowledge and skills that are based upon applicable industry practices and management discretion. 
(a) The Office of Training and Human Resources Deveiopment shall coordinate the development, maintenance and distribution of the general technical base qualification standard.

(b) The Technical Excellence Executive Committee shall approve the general technical base qualification standard for Department-wide application.

(2) Functional area qualification standards shajl build on the core competencies established in the general technical base qual ification standard and shall be based upon general position requirements and accepted industry practices associated with the functional area.

(a) Department-wide functional area qualification standards shalf be developed for each of the. functional areas.

(b) Functional area qualification standards shail contain the following information:

1 Duties and responsibilities associated with the functional area;

2 Background and experience in terms of preferred education and experience, this does not supersede requirements estabi ished by the office of Personnel Management;

3. Listing of the technical competencies associated with the functione? aroe. The colpetency statements define the-level of expected performance for an individua?. Supporting knowledge and/or skill statements shall be - provided-as guidance' to describe the intent of the competency statements;

$4 \quad$ Appijicable evaluation requirements for completing the qualification standard;

5 Continuing training and proficiency requirements.

(c) The Office of Training and Human Resources Development shal1 coordinate the development, maintenance and distribution of the functional area qualification standards.

(d) The Technical Excellence Executive Committee shall approve the functional area qualification standards for Department-wide application.

(3) Office/facility-specific qualification standards shall build upon the functional area qualification standards and be. 
based upon a functional analysis of requirements associated with the position.

(a) The affected Headquarters or Field Element office shal1 develop and maintain office/facility-specific qualification standards.

(b) The content and approval of these standards shall be determined by the affected Headquarters or Field Element office.

e. Qualification Standards shall be formally reviewed and updated. at least every 3 years.

3. IHPLEAERTATION OF THE QUALIFICATION PROGRAY.

a. Headquarters and FieTd Element Managers shaf7 :designate the:positions and/or individuals in their respective organizations required to participate. in. the. Technical Qual ification Program, and the functional area that appifes to them:"

b. Employees in the Technical Oualification Program shal1:

(1) satisfy the applicable competencies contained in the following qualification standards:

(a) the general technical base qual ification standard;

(b) the appropriate functional area qualification standard; and

(c) the office/factifty-speciffe qualffication standard applicable to their position.

(2) complete the program in accordance with the following sçhedule:

(a) : Incumbent employees shall complete the Technical Qualification Program within 3 years of the date of this order.

(b) New hires and personnel transferred or promoted into a new functional area shall complete the program within 18 months of their hire, transfer, or promotion date.

(c) Personnet transferred or promoted within their functional area shall complete office/facilityspecific requirements within 1 year of the transfer or promotion.

c. Exemptions may be necessary to excuse an individual from completing one or more of the competencies in Department-wide qualification standards. Exemptions shail be processed as
foliows: 
(1) Exemptions from individual competencies shall be justified and documented using the Technical Qual ification Progran Competency Exemption Form (Attachment A);

(2) Exemptions shall be requested by the individual's immediate supervisor, and approved one level above the immediate supervisor.

(3) Copies of approved exemptions shall be forwarded to the local training office for transmittal to the office of Training and Human Resources Development.

(4) The Office of Training and Human Resources Development shall track all exemptions for review by the management sponsor during the qualification standard review and update process.

d. Equivalencies may be granted to personnel that satisfÿ. competencies indicated in the qualification standards based upon previous education, training, certification, or experience. Equivalencies shali be processed as follows:

(1) Equivalencies for individual competencies shall be granted based only upon objective evidence that the individual satisfies the competency. '

(2) All equivalencies shall be documented and approved one level above the individual's iumediate supervisor.

(3) Formal documentation of equivalencies shall be included as part of the individual's training and qual ification record.

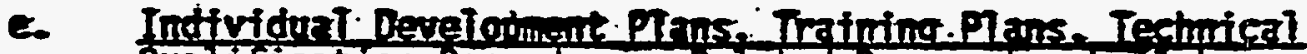
oualification Records, or Related Documents shall be updated to reflect the learning activities that an individual shall participate in to satisfy competencies.

f. Headquarters and Field Elements Affected by the Technical Qual ification Program shall develop written procedures to govern the implementation of the Program in accordance with the overali requirements of this order. These procedures shall describe, but not be Timited to:

(1) the process for identifying personnel and/or positions required to participate in the Technical Qual ification Program;

(2) the process and requirements for developing, approving, reviewing and maintaining office/facility-specific qualification standards;

(3) the process for evaluating employees against qualification standards and documenting the approval of exemptions and equivalencies for Department-wide competencies;

(4) the process and requirements for establishing and/or updating individual development plans, training plans, or. 
related training and qualification records to document the . Tearning activities that an individual shall accomplish to satisfy established competencies;

(5) the process for documenting the satisfactory completion of learning activities to satisfy established competencies; and,

(6). the process and requirements for maintaining training and. qualification related records.

g. Personnel Who Complete Applicabie Qual ification Requirements Shatl:

receive a Certificate of Completion signed by the applicable Headquarters.or Field Element Office. Hanager.

continue their professional development and maintain proficiency through participation in continuing training, education, job rotations, and related activities as defined in the qualification standards.

4. PROGRAVATIC EVALUATIOHS.

a. Headquarters and Field Element Offices shall conduct periodic self-assessments of the implementation of the Technical Qualification Program within their cognizant area of responsibility. These assessments may be included as part of the 3-year self-assessments required in Chapter I.

(1) Assessments shall ensure that appropriate personnel are identiffed to participate in the Progran that adbuante progress is being made; and, that the Program is being implemented effectively and efficiently.

(2) Assessments shall be scheduled, performed and documented in accordance with established office procedures.

b. Assistant Secretary for Environment, Safety and Heal th shall perform independent evaluations of the Technical Qualification Program.

5. RECIPROCITY.

a. Personnel Transferred or Promoted to a New Assignment With in Their Functional Areas shall complete the following:

(1) applicable competencies in the functional area qualification standards for which an exemption was granted at their previous assignment; and,

(2) the office/facility-specific qualification requirements at their new assignment.

b. Personnel Transferred or Promoted to a New Assignment in a Different Functional Area shall complete the following: 
(1) the new functional area qualification standard competencies; and,

(2) the office/facility-specific qualification requirements at $\therefore$ their new assignment.

6. RELATIOHSHIP TO OTHER PERSOMWEL ACTIVITIES. The Technical qual ification standards identify the preferred technical competencies of individuals filling selected positions and shall be considered under the following circumstances:

a. New Hires, Transfers, or Promotions of Personnel. - When filling a position that requires participation in the Technical Qualification Program, the technical competencies identified in the Technical qualification standards should be incorporated into the selection process. 2s..appropriate; -

b. Position Descriptions when being developed and/or revised, should reflect the technical competencies identified in the Technical qualification standards as appropriate;

c. Crediting Plans, andior Rating and Ranking Factors used to select the most qualified individual, should reflect the appropriate: standards.

7. RECORDS. A training and qualification records system shall be estabiished for each employee in the Technical Qualification Program. The following records shall be maintained in this system:

2. documentation of approved expiptions fram competencies,

b. documentation of approved equivalencies for competencies,

c. completed qualification cards, records, or other documents that document satisfactory achievement of competencies, and

d. technical qualification program certificates of completion. 
Hane:

Date:

Functional Area:

Comptency for Which Exemption is Requested (include number and wording):

Justification for Exemption:

Requested By:

Approved By:

Reviewed By:

\section{Imediate Supervisor}

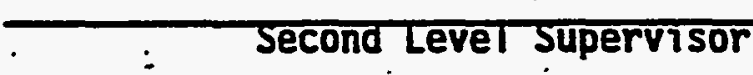

\section{Training. officer}

Date:

Date:

Date:
Ordginal tos

$\operatorname{cop} 2$ tos

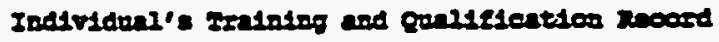

Inestradual

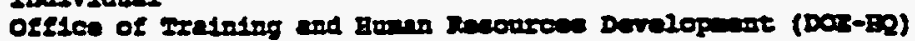





\section{CHAPTER III \\ COADICT OF TECHHICAL TRAINTHG}

1. APPLICABILITY.

a. These requirements are in addition to the requirements in chapter I of this Order. The requirements in this chapter shall apply to training that supports the Technical Qual ification Program described in Chapter II of this Order: The requirements contained in this chapter should also be considered for the training of Department of Energy employees at facilities or organizations not affected by the Technical Qualification Program.

b. - These requirements apply to new technical training design, development and implementation. activities that occur after the approvat date of this Order. Existing technical training:activities and programs shail meet the requirements of this. document within.18months of the approval. date of this Order, or prior to being used, whichever is fonger.

2. DESIEY AM DEVELOPET OF TRAIUIHG COURSES. technical training courses include alt classroom, laboratory, computer-based training, and individualized instruction activities that are designed to provide a structured and formal learning environment.

a. Department-Wide Technical Training Courses shall support the competencies documented in the general technical base qual ification standard and. the functional-area qualification standards.

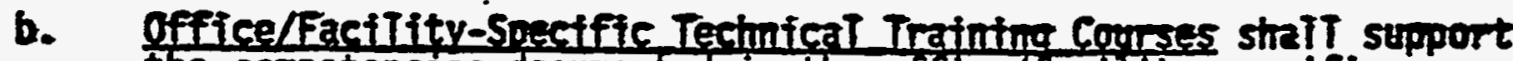
the competencies documented in.the office/facility-specific quat iffeation standards.

c. Department-Wide Technical Training Courses shali each have a Departmental office or Element designated as a course sponsor. course sponsors are responsible for the following:

(1) ensuring the technical adequacy and accuracy of the course;

(2) ensuring the instructional adequacy of the course;

(3) ensuring that the. course meets the requirements of -this Order; and,

(4) overseeing the development and/or revision of the course.

d. The Office of Training and Human Resources Deveiopment shall:

(1) maintain a database that indicates the competencies in the functional area qual ification standards that are covered by Department-wide technical training courses.

(2) approve course sponsors for Department-wide technical training courses. 
(3) maintain the Department of Energy course catalog. A11 approved Department-wide technical training courses shall be iisted in this catalog. The following information shali be included for each approved course:

(a) course title;

(b) course number;

(c) brief outline of the course content;

(d) terminal learning objective(s) or course goal(s);

(e) name of course sponsor (by organization);

(f) duration of the course;

(g) qualification standard competencies covered by the course.. .

e. Documentation shall be maintained for all technical training: courses, including:

(1) a Tesson plan or detailed course outline indicating the technical content and instructional design of the training. course;

(2) terminal learning objectives (or course goals) and enabling learning objectives, written in accordance. with Department of Energy Guideline, "Guide to Good Practice For Developing Learning Objectives";

(3) an examination question -bank, examination(s), or otherformal evaluation tools, used to determine-trainee mastery of the learning objectives; and,

(4) copies of all additional course materials such as student handouts, exercise guides, overhead transparencies, etc.

f. Development or Revision of Department-wide technical training courses shall be closely monitored by the course sponsor.

(1) Al1 new or revised Department-wide téchnical training courses shall be approved by the course sponsor prior to delivery. This approval shall consider the adequacy of both the technical content and the instructional methodology.

(2) The Office of Training and Human Resources Development sha71 concur with all Department-wide :technical training .courses for which they are not the course sponsor. 
- 5-3I-95

3. IMPLEMERTATIOH OF TRAIHIHG.

a. Technical Instructor Qualification.

(1) The training provider shall ensure that all classroom . instructors have the instructional and technical qualifications required to conduct technical training.

(2) Verification of the instructor's qualification shall be completed prior to conduct of the class.

(3) The training provider shall ensure that the documentation used to verify the instructional and technical qualifications of the instructor is maintained as part of the training documentation. This shall include, at a ninimb, ... copy . of the instructor!'s.resume.

(4) Supervisors and managers in Headquarters and Field Element offices shall ensure that personnel serving as instructors and/or evaluators for on-the-job training activities arecompetent to conduct the training.

b. Testing and Evaluation.

(1) Technical training courses that support the Technical Qual ification Program shall include a written examination or other documented formal evaluation to determine satisfactory achievement of the learning objectives by the participants. Hinimum acceptable criteria. for completing and documenting evaluations shall be estabilished by office policy or. procedure.

(2) Uritten examinations or other formal evaluation methods shali be based upon the course learning objectives. They shall be developed considering the guidance provided in Department of Energy guideinnes. "Guide: to Good Practices For. the Development of Test Items" and "Guide to Good Practices For the Design, Development, and Implementation of. Examinations."

(4) Examination results shall be kept confidential and only the individual, the individual's immediate supervisor, and the applicable Training/Personnel Office shall be notified of the results. Access to examination results by other - individuals requires the approval of the local Personnel Office Director.

(5) Individuals who do not satisfactorily complete a technical training course that supports a Technical qualification Program requirement shall receive remedial training and be given an opportunity to be reevaluated.

(6) Course sponsors and/or training providers shall maintain a controlled and secure training records system to ensure proper repository for written examinations, examination question banks; and other evaluation instruments." 
4. TRAIHING COURSE AND PROGRAY EVALUATIOH.

a. Iraining Course Evaluation.

(1) The Office of Training and Human Resources Development.sha11 maintain a trainee course evaluation form to be used for al1 Department-wide technical training courses.

(2) Training providers shall ensure that classroom training courses are evaluated by the trainees.

(3) Course sponsors shall review the course evaluation results to determine if any changes or revisions to the course are. required.

(4) The course sponsor shall coordinate with the training. provider to make changes or revisions. Changes or revisions to vendor provided training shail be requested in accordance with contract and procurement. regulations.

b. Program Self-Assessments.

(1) Headquarters and Field Element offices shall conduct. selfassessments of the design, development and implementation of technical training within their cognizant area of responsibility. These assessments may be included as part of the 3-year self-assessments required in Chapter I.

(a) Assessments. shall ensure that the training is technicaity adequate and accurate, meets the requirements of this order, and is being implemented effectivety and efficfently.

(b) Assessments shall be scheduled, performed and documented in accordance wịth estabi ished office procedures.

c. Program Oversight. The Assistant Secretary for Environment, Safety and Health (EH) shail perform independent evaluations of technical training that supports the Technical Qualification Program.

5. TRATHING RECORDS.

a. The Training Officer (or Equivalent) Within Each Headquarters and Field office shall maintain a centralized individual training and qualification records system for all employees within their organization.

(1) The centralized system shall ensure that a standard and consistent data base is available to support the needs of management, and ensure that records are availabie for employees, regardless if they transfer to another organization. 
(2) Individual training files shall contain the following information:

(a) copies of completed technical qual ification records, and Certificates of Completion;

(b) the resuits of written examinations or performance evaluations that document the completion of competencies in the Technical Qualification Program;

(c) Technical training courses completed, inciuding the dates of the course and the grade(s) for examinations;

(d) seminars, workshops, or other training activities that are not considered technical training: and

(e) documentation of completed on-the-job training and . mentoring activities.

b. Training Providers shalT ensure that post-training documentation is abtained upon completion of technical training courses.

(1) Post-training documentation shall include the following:

(a) examination results for technical training that supports the Technical Qualification Program;

(b) signed attendance sheet(s) for each day of the training;

(c) copy of the instructor's resume and other supporting documentation used to verify qualification of the instructor;

(d) copy of the course outline and learning objectives; and,

(e) copy(s) of training course evaluation results.

(2) The Office of Training and Human Resources Development shall maintain post-training documentation for Department-wide technical training.

(3) Headquarters and Field Element Offices shall maintain posttraining documentation for office/facility-specific technical t training. 



\section{CHAPTER IV}

\section{ACADEIIC DEGREE TRAIUIUG}

\section{APPLICABILITY.}

a. These requirements apply to Federal employees serving under a career or career conditional appointment, or other appointment

- that allows adequate opportunity for the employee to fulfill any obligation to continue in the service of the agency.

b. The provisions of this Chapter allow for the authorization of training, without regard to the constraints in the training law on "academic degree training", when the training is necessary to assist in the recruitment or retention of empioyees in occupations in which there are existing or. anticipated shortages of qual ified personnet.

C.. Exempitions. Employees occupying or seeking to qualify for appointment to Schedute $C$ positions and Presidential appointees are not eligible for academic degree training.

2. AUTHORIZATION OF ACADEIC DEGREE TRATHIHE.

a. Training may be authorized under this authority oniy when it is necessary to assist in the recruitment or retention of an empioyee in an occupation for which a shortage of qualified personnel exists or is anticipated. Shortage category determinations shall be made in accordance with 5 code of Federal Regulations 410.511 . (b) and (c).

b. At Hexiquarters, Ho Deputy Asststant Secretary for Henan Resources shaif make the determination that a recruitment and/or retention probiem exists that will result in a shortage of qualified personnel. For all other offices, this determination shait be made by the Head of the Departmental Element.

c. To remedy a retention problem; training must involve a course of study which is selected mainiy for its potential contribution to effective performance in that occupation.

d. Recruitment, retention and other problems related to the shortage of qualified personnel shall be evaluated by the Deputy Assistant Secretary for. Human Resources using the criteria set forth in 5 Code of Federal Reguiations 410.511 (d), (e) or (f).

3. IDEITIFICATIOA OF CANDIDATES. Recruitment methods and types of appointments. shall be based upon the specific recruitment. or retention problem and, therefore; will vary from situation to situation: However, the following conditions and options apply to all situations:

a. Any available appointment mechanism may be used as long as it allows a continued service agreement to be fulfilled.

b. Candidates may be selected from within or recruited from outside the Department. 
c. Recipients of academic degree training must be qual ified for the positions they. will occupy while being trained.

d. Academic degree training is allowable when the current position occupied, or a different targeted position is in the shortage category and all other.criteria are met.

4. AUTHORITY TO TRAIH EYPLOYEES. In exercising the academic degree training authority of this chapter, Heads of Departmental Elements sha11:

a. Give priority to relieving shortages in occupations which involve skills critical to the organization's mission.

b. . Give appropriate consideration to any special salary rate, student - Toan repayment, or other monetary inducement authorized by Taw al ready provided, or being provided, which contributes to the alleviation of the staffing problem in the occupation targeted by . the training:

5. DOCWNEMTATION AND REPORTIH'G REOUIREXEITS. Each servicing personnel office/training office shall have avaitable for review:

a.- A record of employees who are assigned to training under these provisions;

b. A record of any finding that a continuing shortage exists, along with evidence leading to that finding and a reassessment of that finding no later than 3 years after the. most recent determination;

c. Records required in $a$ and b above stail be retatned for 3 yeirs beyond completion of training or degree; and

d. The following information in the Official Personnel Folder of each. employee participating in such. training:

(1) The justification for the shortage determination, described in terms of occupational series, grade or grade range, geographic locality, and organizational assignnent;

(2) Kind of training, a description of the field of study, and nature of any degree pursued under the training; and,

(3) A written continued service agreement. 


\section{CHAPTER V}

\section{RETRAIHING}

1. APPLICABILITY.
a. This chapter is applicable to Department of Energy Federal employees.
b. Retraining programs are designed to provide new knowiedge, skills or competencies to employees because of knowledge or skilits obsolescence in current position(s) or to meet changing mission requirements.

2. EUPLOYEE PARTICIPATION. In occupational retraining, where an increase in:prometion potential nay result, employee participation is governed by. applicable merit staffing procedures. In alf retraining, participation shall a7so be consistent with:
a. the program's purpose, coverage, and atTocated resources;
b. the extent to which an individual's current skills, knowledge, and
experience are beneficial in learning new. functions;
c. the extent to which an individual is motivated to learn new- functions; and,.
d. ' the cost-effectiveness of retraining to. meet mission needs:

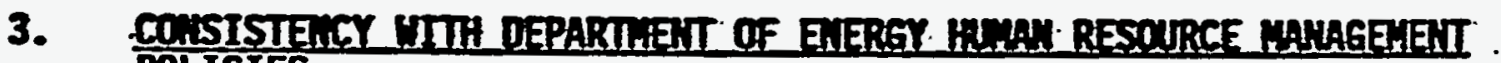 \\ POHICTES.}

a. Retraining programs shall be consistent with human resource management policies and practices. The following shail. be. considered when establishing a program:

(1) Waiver of qual ifications for initial placement;

2) Pay and grade retention;

3 Retreat to previous or equivalent position;

(4) Tenure status; and, .

(5) Accelerated promotion(s)

b. Retraining program managers shall ensure that work assignments involving the White House, the Executive Office of the President, the Congress, or foreign travel receive required special concurrences, and that a continued service agreement is completed by an employee before beginning a retraining program.

\section{TYPES OF REIRAIHIHG.}

a. Position Retraining shall be provided to implement changes in policy, objectives, processes, results, or other work activities or conditions in current or anticipated functions. Position retraining does not involve a promotion or a change in promotion potential or occupation. 
b. Occupational Retraining shall be provided as a result of a change
to a new occupation and may or may not affect promotion potential
Occupational retraining shall include al1 competencies needed to

b. Occupational Retraining shall be provided as a result of a change
to a new occupation and may or may not affect promotion potential.
Occupational retraining shall include al1 competencies needed to

b. Occupational Retraining shal1 be provided as a result of a change
to a new occupation and may or may not affect promotion potential
Occupational retraining shal1 include af 1 competencies needed to perform effectively in the new. occupation.

DOE 0360.1

5-31-95 
U.S. DEPARTMENT OF ENERGY DEPARTMENT-WIDE

- FUNCTIONAL AREA QUALIFICATION STANDARD

\section{FIRE PROTECTION \\ QUALIFICATION STANDARD}

Defense Nuclear Facilities Technical Personnel.

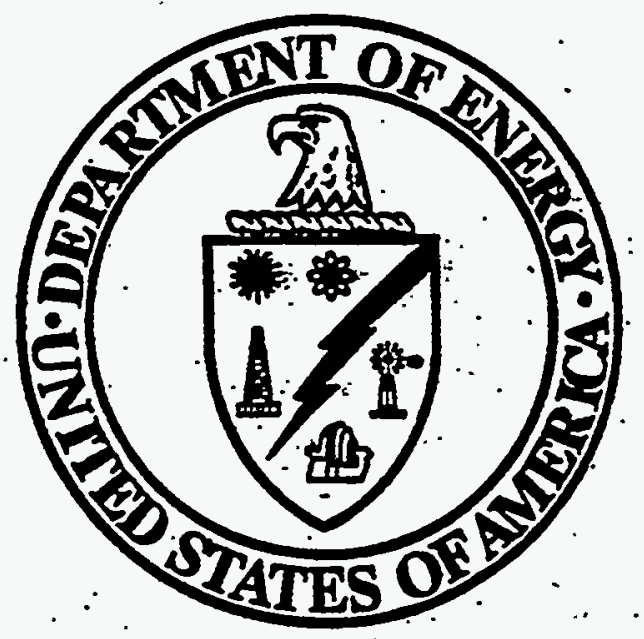

U.S. Department of Energy

Washington, D.C. 20585

Mạay 1995 


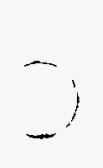




\section{Approval and Concurrerice}

The Assistant Secretary for Environment, Safety, and Health is the Management Sponsor for the Department-wide Environmental Restoration Functional Area Qualification Standard. The Management Sponsor is responsible for reviewing the Qualification Standard to ensure that the technical content is accurate and adequate for Department-wide application. The Management Sponsor, in coordination with the Human Resources organization, is also responsible for ensuring that the Qualification Standard is maintained current. Concurrence with this Qualification Standard by the Assistant Secretary for Environment, Safety, and Health is indicated by the signature below.

The Technical Personnel Program Coordinator (TPPC) is responsible for coordinating the consistent development and implementation of the Technical Qualification Program throughout the Department of Energy. Concurrence with this Qualification Standard by the Technical Personnel Program Coordinator is indicated by the signature below.

The Technical Exceilence Executive Committee (TEEC) consists of senior Department of Energy Managers. This Committee is responsible for reviewing and approving the Qualification Standard for Department-wide application. Approval of this Qualification Standard by the Techinical Exceilence Executive Committee is indicated by the signature below.

NOTE: The signatures below reflect concurrence and approval of this Qualification Standard for interim Implementation. Final concurrence and approval will occur in December 1995, pending comments received based upon implementation.

\section{CONCURRENCE:}
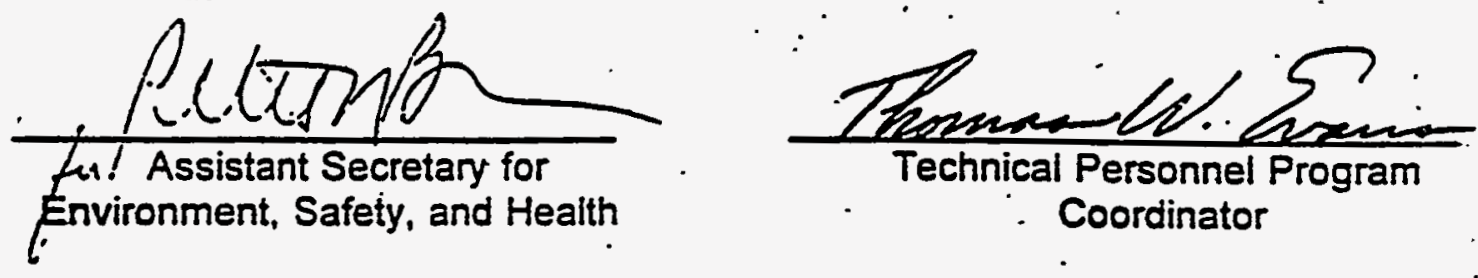

\section{APPROVAL:}

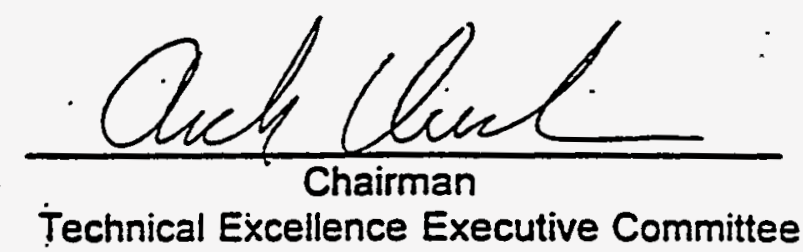




\section{CONTENTS}

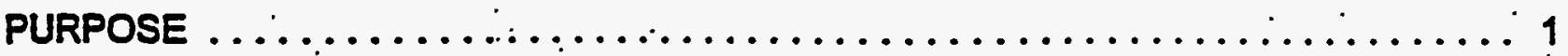

APPLICABILITY $\ldots \ldots \ldots \ldots \ldots \ldots \ldots \ldots \ldots \ldots \ldots \ldots \ldots \ldots \ldots \ldots \ldots \ldots, 1$

IMPLEMENTATION REQUIREMENTS $\ldots \ldots \ldots \ldots \ldots \ldots \ldots \ldots \ldots \ldots \ldots \ldots, 1$

DUTIES AND RESPONSIBILITIES $\ldots \ldots \ldots \ldots \ldots \ldots \ldots \ldots \ldots \ldots \ldots \ldots, 4$.

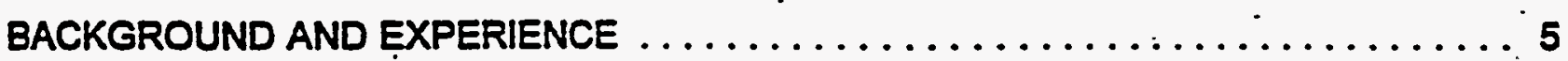

REQUIRED COMPETENCIES $\ldots \ldots \ldots \ldots \ldots \ldots \ldots \ldots \ldots \ldots \ldots \ldots \ldots \ldots, \mathbf{5}$

$1 \ldots \quad$ GENERAL TECHNICAL $\ldots \ldots \ldots \ldots \ldots \ldots \ldots \ldots \ldots \ldots \ldots \ldots \ldots \ldots \ldots$

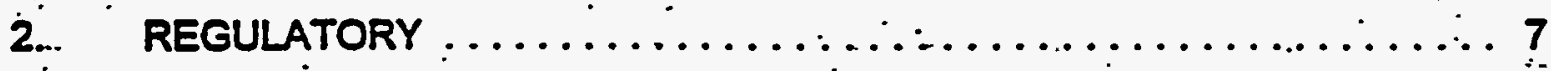

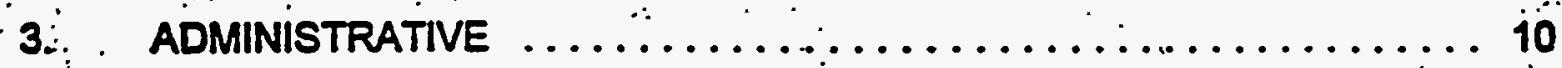

4. MANAGEMENT, ASSESSMENT, AND OVERSIGHT ............. 11

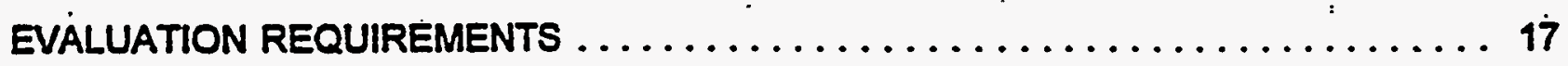

CONTINUING TRAINING AND PROFICIENCY REQUIREMENTS $\ldots \ldots \ldots \ldots \ldots, 17$. 



\section{U.S. DEPARTMENT OF ENERGY \\ FUNCTIONAL AREA QUALIFICATION STANDARD}

\section{FUNCTIONAL AREA}

\section{Fire Protection Engineer}

\section{PURPOSE}

The Technical Qualification Program is divided into three levels of technical competence and qualification. The General Technical Base Qualification Standard establishes the base technical competence required of all Department of Energy defense nuclear facility technical personnel. The Functional Area Qualification Standards build on the requirements of the General Technical Base Qualification Standard and establish Department-wide functional competence requirements in each of the identified functional areas. Officeffacility-specific qualification standards establish unique operational competency requirements at the Headquarters or Field element, site, or facility level.

The Fire Protection Engineering Functional Area Qualification Standard establishes common functional area competency requirements for all Department of Energy fire protection engineer technical personnel who provide management oversight or direction impacting the șaferoperation of.defense nuclear facilities. Satisfactory and documented completion of the competency requirements contained in this Standard ensures that technical employees possess the minimum requisite competence to fulfill their functional area duties and esponsibilities. Additionally, these competency requirements provide the functional foundation to assure successful completion of the appropriate Office/facility-speciric qualification standard.

\section{APPLICABILITY}

This Standard applies to all Department of Energy Fire Protection Engineers technical: personnel who provide management direction or oversight impacting the safe operation of defense nuclear facilities. Personnel designated by Headquarters or Field element line management as participants in the Technical Qualification Program are required to meet the : requirements of this Standard as defined in Department of Energy (DOE) Order 3410.

\section{IMPLEMENTATION REQUIREMENTS}

The competencies contained in the Standard are divided into the following four categories:

1. General Technical.

2. Regulatory

3. Administrative

4. Management, Assessment, and Oversight 
. 
F.ach of the categories is defined by one or more competency statements indicated by bold r.nt. The competency statements define the expected knowledge and/or skill that an individual must possess, and are requirements. Each of the competency statements is further explained by a listing of supporting knowiedge and/or skill statements. The supporting knowledge.and/or skill statements are not requirements and do not necessarily have to be fulfilled to meet the intent of the competency.

The competencies identify a familiarity level, working.level, or expert level of knowledge; or they require the individual to demonstrate the ability to perform a task or activity. These levels are defined as follows:

Familiarity level is defined as basic knowledge of or exposure to the subject or process adequate to discuss the subject or process with individuals of greater knowiedge.

Working level is defined as the knowiedge required to monitor and assess operations/activities, to apply standards of acceptable performance, and to reference appropriate materials and/or expert advice as required to ensure the safety of Departmental activities.

Expert level is defined as a comprehensive, intensive knowledge of the subject or process sufficient.to provide advice in the absence of procedural guidance.

$\because$ Domonstrate the ability is defined as the actual performance of a task or activity in accordance with policy, procedures, guidelines, and/or accepted industry or Department practices.

Headquarters and Field elements shall establish a program and process to ensure that all defense nuclear facility technical personnel required to participate in the Technical Qualification Program meet the competency requirements contained in this Standard. Documentation of the completion of the requirements of this.Standard shall be included in the employee's training and qualification record.

In select cases, it may be necessary to exempt an individual from completing one or more of the competencies in this Functional Area Qualification Standard. Exemptions from individual competencies shall be justified and documented in accordance with DOE Order 3410.

Exemptions shall be requested by the individual's immediate supervisor, and approved one level above the individual's immediate supervisor.

Equivalencies may be granted for individual competencies based upon an objective evaluation of the employee's prior education, experience, and/or training. Documentation of equivalencies shall indicate how the competency requirements have been met. The supporting knowiedge and/or skill statements may be considered when evaluating anindividual's ability with respect to each competency requirement. 
-raining shall be provided to employees in the Technical Qualification Program who do not . ieet the competencies contained in the qualification standard. Departmental training will be based upon supporting knowledge and/or skill statements similar to the ones listed for each. of the competency statements. Headquarters and Field elements should use the supporting knowledge and/or.skill statements as a basis for evaluating the content of any training courses used to provide individuals with the requisite knowledge and/or skill required to meet the qualification standard competency statements. 


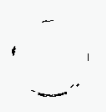




\section{DUTIES AND RESPONSIBILITIES}

The following are duties and responsibilities normally expected of defense nuclear facility technical personnel assigned to the fire protection functional area:

A. Serve as a subject matter expert in the area of fire protection.

B. Review fire hazard analyses, assessment, and safety documentation for compliance with appropriate requirements.

C. Evaluate the participation of fire emergeñcy response organizations in emergency response exercises; monitor personnel training. and qualification, and equipment readiness to respond to fires, accidents, medical emergencies, hazardous material incidents, rescue and other emergencies.

D. Review adequacy of contractor fire protection programs to ensure compliance with applicable codes, standards, guides, regulations, Departmental Orders, and accepted practices.

E. Participate in accident and incident investigations as required.

F. Interpret fire protection requirements and make recommendations to Department management, facility representatives, contractor management, and line organizations.

G. Represent the site/facility and/or the Department at fire protection meetings, professional conferences, and technical standards committees.

H. Provide oversight of site fire protection programs and their implementation.

1. Evaluate adequacy of facility design in accordance with fire protection criteria and. recommend changes to facility design and/or fire protection criteria..

J. Review and evaluate requests for exemptions and equivalencies.

K. Participate in the development of contract requests, budget impacts, and planning for future fire protection activities.

L. Maintain proficiency in fire protection engineering concepts and practices.

M. Participate in special assignments and perform assessments related to fire protection.

Additional duties and responsibilities specific to the site, the facility, operational activities, and/or involved organizations shall be contained in the facility specific qualification standard(s). 


\section{RACKGROUND AND EXPERIENCE.}

The U. S. Office of Personnel Management's Qualification Standards Handbook establishes minimum education, training, experience, or other relevant requirements applicable to a particular occupational series/grade level, as well as alternatives to meeting specified requirements. The Fire Protection Engineer position is classified by the Office of Personnel Management as Occupational Series 804.

DOE Order 5480.7A requires that each Department Cognizant Secretarial Office and each Operations Office have available one or more "qualified Fire Protection Engineers" to accomplish the specific objectives outlined in the Order. A "qualified Fire Protection Engineer". is defined in the Order as follows:

Qualified Fire Protection Engineer: A graduate of an accredited engineering curriculum and having completed not less than four years of engineering practice; three of which shall have been in responsible charge of diverse fire protection engineering work. If not such a graduate, a qualified engineer shall, either: demonstrate a knowledge of the principles of engineering-and have completed not less than six years engineering practice, three of which shall have been in responsible charge of diverse fire protection engineering projects; be a registered professional engineer in fire protection; or meet the requirements for a Grade 11 or higher Fire Protection Engineer as defined by the Office of Personnel Management:

\section{REQUIRED COMPETENCIES}

The competencies contained in this Standard are distinct from those competencies contained in the General Technical Base Qualification Standard. All Fire Protection Engineers must complete the competency requirements of the General Technical Base Qualification Standard prior to, or in parallel with, the completion of the competency requirements contained in this Standard. Each of the competency statements defines the level of expected knowledge and or skill that an individual must possess to meet the intent. of this Standard: The supporting knowledge and/or skill statements further describes the intent of the competency statements. 

Deparment-Wide Fire Protection Qualification Standard

1. General technical

See "Required Background".

$\operatorname{Rev} 0$

Page 6

May 1995 


\section{?. REGULATORY}

NOTE: 1: When Department of Energy (DOE) directives are referenced in the qualification standard, the most recent revision should be used.

2.1. Fire protection personnel shall demonstrate an expert level knowledge of Department of Energy (DOE) Order 5480.7A, Fire Protection.

\section{Supporting Knowledge and/or. Skills}

a. Describe the purpose and content of the Order.

b. Explain the applicability of the Order.

c.. State the objectives of the Order.

d. Identify the additional fire protection related codes, standards, and regulations which contain minimum mandatory fire protection implementation criteria for Department Fire Protection Programs.

e.. Define the following terms and identify when the use of each process is appropriate in accordance with the Order: '

$\therefore$ Equivalency

- Exemption

f.:- Identify the requirements for an individual to be considered a. "Qualified Fire Protection Engineer".

g. Explain the responsibilities of each of the following with respect to the implementation of the requirements of the Order:

- Cognizant Secretarial Officers.

- Assistant Secretary for Environment, Safety, and Health

- Director of Nuclear Safety

- Assistant Secretary for Nuclear Energy

- Director of Administration and Management

- Heads of Field Organizations

- Heads of Headquarters Elements

- Contractor Organizations

h. Identify the basic requirements which must be met by a Department of Energy Fire Protection Program as described in Section 9 of the Order.

i. Describe the role of Department Fire protection personnel with respect to implementation of this Order. 



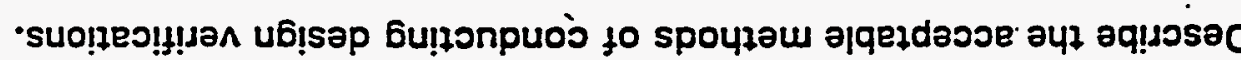
$\cdot \theta$ -suomeo!y!don

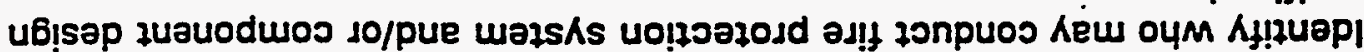

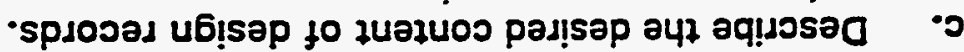

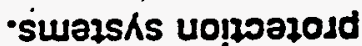

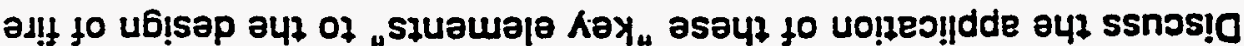

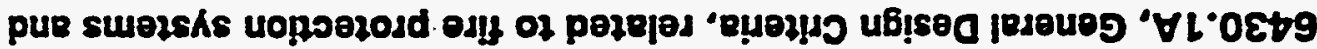

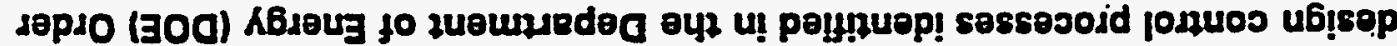

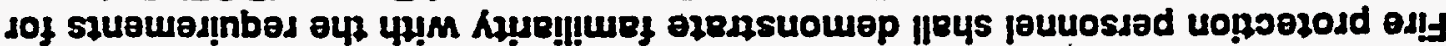

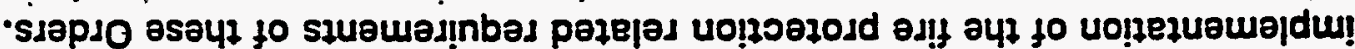

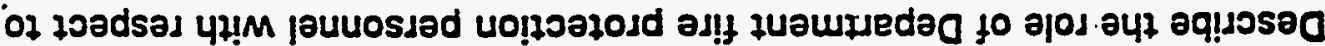

-sıapıo әsaúz to uo!̣ezuəwajdu!

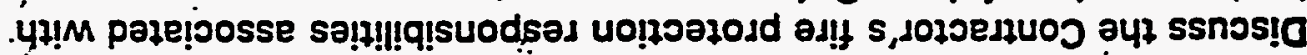
-uo!̣oalojd ad!l

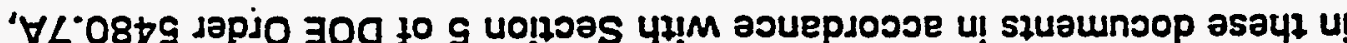

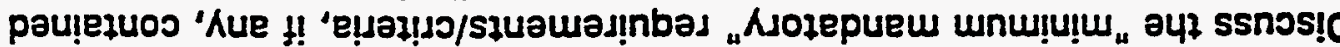

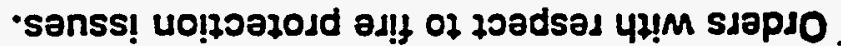

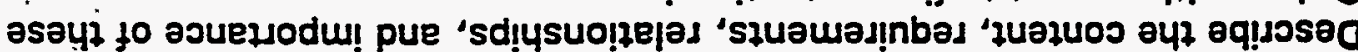

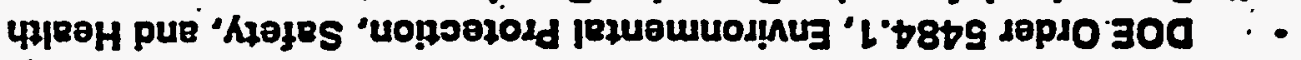

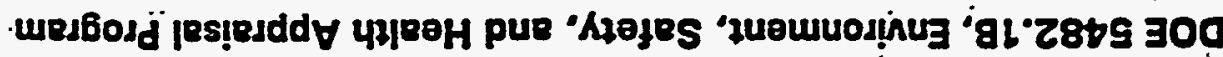
spiepuers uonoorord

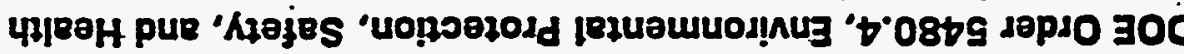
:spiopums

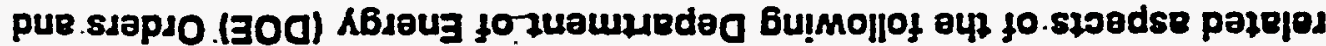

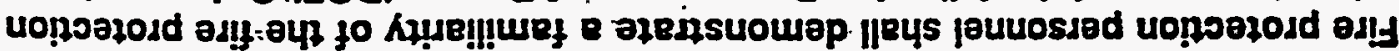


f. Describe the conditions to be considered when testing to verify or validate design features. 



\section{3. . ADMINISTRATTVE}

3.1 Fire protection personnel shall demonstrate a familiarity level knowledge of the requirements and methods to maintain communications with Headquarters, field elements, and other regulatory agencies.

\section{Supporting Knowledge and/or Skills}

a. Describe the Department's organization and discuss the Department's procedures for communicating between Headquarters and Field Elements.

$\therefore \because \cdots \cdots$

b. Describe the Department's procedures and policy for. communicating with state and local organizations, the Occupational Safety and Health Administration (OSHA), and other regulatory agencies.

3.2 Fire protection personnel shall demonstrate a working level knowledge of the record-keeping and reporting requirements specified by industry standards and. Department Orders.

Supporting Knowledge and/or Skills.

a.z: Discuss the Department's record-keeping and reporting requirements for fire protection programs.

b. - Given a copy of the Annual Summary of Department of Energy Fire Protection Programs, discuss the contents and its application within the Department.

c. Given a copy of the Fire Protection Resource Manual, discuss the contents and its application within the Department. 


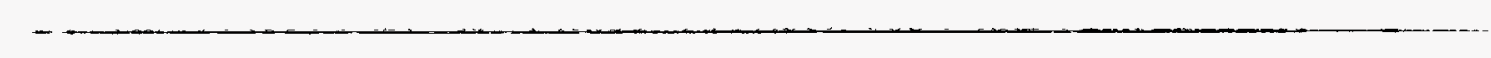

. 
- Hazard recognition

- Work controls

b. Discuss the importance of management commitment and the criteria used to evaluate this commitment to the following:

$\therefore$ Deficiency resolution

$\therefore \quad$ Self-assessment

- ' Issues management

Conduct of Operations

Trending and Analysis

$\therefore$ : Preventive maintenance

$\therefore$ Resource allocation (dollars, personnel, equipment)

c. Review a quality assurance program related to the fire protection organization and activities. Analyze the program for the following:

..... Independent verification

- Control of transient combustibles

- Personnel training

-... Documentation

Quality Assurance Implementation Plán

4.6. Fire protection personnel shall demonstrate a working level knowledge of emergencycy response operations. including personnel training and qualification. equipment, and facilities.

\section{Supporting Knowledge and/or Skills}

a. Discuss the relationships between, and importance of, the following as related to emergency response operations:

- Alarms and/or Monitoring

- Central Alarm Station (design)

- Dispatching

- Communication equipment and methods

- Interface with other organizations

b. Discuss fire protection concerns associated with providing emergency response operation activities. for the following:

- $\quad$ Confined space entry
- $\quad$ Hazardous material
- $\quad$ Fire fighting
- $\quad$ Smoke removal
- Occupant evacuation
- $\quad$.
- Ruter removal





\section{-. Transportation accidents \\ - Rescue}

C. Discuss the fire protection and emergency response concerns associated with the staffing and readiness of. personnel including:

- Evaluation of staffing levels

-. Mutual Aid Response Agreements

- Health and physical fitness

Central alarm station staffing

d. Explain the importance of emergency exercise evaluation and discuss the criteria used in conducting an evaluation of the following with respect to emergency response readiness:

Emergency drills

Equipment

Training

- ' Qualifications.

- Safety documentation

- Occupational safety and heaith

4.7 Fire protection personnel shall demonstrate the ability to assess emergency response operations including personnel training and qualification, equipment, and facilities.

\section{Supporting Knowledge and/or Skills}

a. Evaluate an emergency plan and explain the importance of pre-planning activities and emergency plan implementation exercises and drills.

b. Evaluate the emergency response operations equipment in accordance with procedure/code requirements.

c. Assess response times for emergency personnel and equipment with respect to emergency response operations.

d. Observe and evaluate emergency response equipment and facility maintenance.

e. Observe and evaluate emergency response personnel training and drills.

f. Observe and evaluate the emergency response operations associated with the following:

Fire emergency

Medical emergency

Hazardous material emergency 
$\therefore$ 
b. Given data from an assessment, analyze the results to determine compliance or noncompliance with the requirements.

c. Given the results from an analysis of compliance or noncompliance, document the results and communicate the results to contractor and/or Department line management.

4.17 Fire protection personnel shall demonstrate the ability. to independently assess contractor and/or Federal employee compliance with the requirements contained in the following Department of Energy (DOE) Orders with respect to fire protection issues:

$\therefore$ :

$\therefore$ DOE Order 5480.4, Environmental Protection, Safety, and Health

\section{Protection Standards}

- DOE 5482.1B, Environment, Safety, and Healtḥ Appraisal Program

\section{Sypoorting Knowledge and/or Skills}

a. Assess contractor and/or Department work activities associated with fire protection in accordance with the responsibilities and requirements of the above Orders.

b:- Given data from an assessment, analyze the results to determine compliance or noncompliance with the requirements.

c. Given the results from an analysis of compliance or noncompliance, document the results and communicate the results to contractor and/or Department line management. 

3. Training in areas added to the Fire Protection Functional Area Qualification Standard since initial qualification.

4. At a minimum, the continuing training and proficiency activities of fire protection personnel should include the following each year:

- Site/facility/position-specific topics such as changes to the facility, significant facility events

- Industry events lincluding both Department of Energy and applicable commercial : ievents)

-. Lessons learned

5. Fire protection personnel must be actively engaged in responsible fire protection related activities each year to maintain their qualification. 


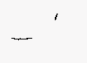


DRTE:

AEPLYTO

SEP 291988

ATTH OF:

- EH-321

SUBUET:

NFPA 1500 Implementation Plan.

TO:

John J. Schinixle, Director, Safety Programs Diyision, AL

Roger A. Hayes, Director, Operational a Environmental Sarety Division, CH

$\checkmark$ William D. Jensen, Director, Operational Safety Dirision, ID

Shed R. Elitiott, Director, Office of Safety \& Health, NY

Devid Howard, Director, Safety. \& Environmental Control Division, OR

- Ron Gerton, Director, Environment, Safety \& Health, RL

Janes T. Davis, Director, Enyironment, Safety \& Qiality Assurance, SAiv

Don N. Eridges, Director, Saiety Diyision, SR

The drat of the subject document was circulated for conment per Mr. Barber's Mey 20, Ises, memiranduin. The comments haye been incorporates and the reyision is atteched for your iniormation.

The NFPA 1500 Standard is considered applicable to those organizations trained and orcanized to perform structural firefighting at DOE facilities. It does not epply to incipient fireifighting, fire yarden programs, or personne] who may provide special support during a fire, such as mechanics or eleciricians who are not expected to be inyolved in firefighting. The standard site safjity frograms will coritinue to apply to these peopie.

Wo guidance is contained for Section 8 of NFP\& 1500. The Diractor of DOE medical programs is expected to issue such quidance in the future. Until then, each departinent should endeayor to provide as much of a program as is consistent with current site practices.

A Fire Protection Resource Menual is being developed. This document will be included with the manual, when issued.

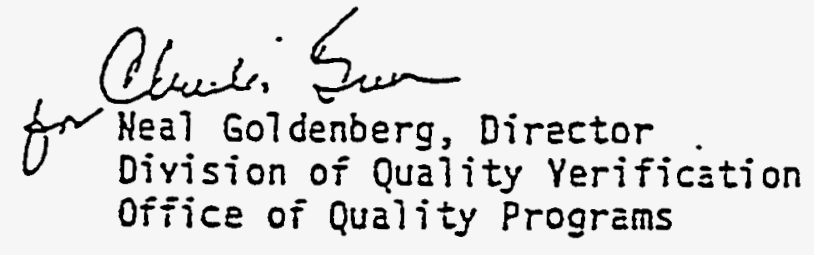

Attachment

Draft NFPA 1500

Implementation plan 
STANDRRDS INTERPRETATIOH/IHPLEHENTATIO!I

(INTERP.4)

STAKBARD:

HFPA 1500: Standard on Fire Department Decupational Safety and Health Program - Is87 Edition.

DOE IMPLEMENTATION:

Section 1-3.1. The implementation date of this standard is the date of this issuance. Exceptions are noted in other items.

Section 2-1.I. The documents required by this section need not be consolidated into a single document. In particular, Policy, Organization, and functional stetements should be ayallable for audit and up to dete. Training documents may consist of manuals, fiims, and other materials preparad by others and merely referenced in a training plan, or in functionel siEiEnEnis.

Section 2-3. Where the fire depertient, or other firefighting organization, is part of a larger organization that provides the requisite "rasesrch, development, implementation, and eniorcement, of an OS\&H program," the fire department program needs may be included within the la program.

Section 2-4. A. Saíty 0ificer shall be designated for each organization. Where safeiy services, monitoring, training, etc., are proyidad by another on-site organization, or the parant organization, the person designated as the Safety oficer shall be responsibie for coordinating the services required by the department.

Responsibility for safaty at the first-response level shall be incorporated in the department's emergency proceduras manual.

The fire department Safety officer can be anyone in the organization who can show up on the scene, not necessarily with the first response, but must be someone other than the incident comander as the safety officer is intended to be an independent yoice, advising the incident comnander.

Sestion 2-5. The OS\&H Committee may include representatives from other organizations when the department is part of a larger organization or at a site where safety services are provided by others. The required safety meetings may be joint meetings with others if the department's safety needs are amenable to joint meetings.

Section 2-6. The records required in this Section may be maintzined by a parent or service organization as long as they are auditable and are available to the department. 
Section 2-6.2. The departinent shall haye a procedure for reflecting possible exposures in the incident files and individual medical records.

Section 3-1.4. The requirement for training and education is considerer to require that ail firefighters must. be trained in the hazards to be encountered at the scene of an incident before they can participate in active operations reguiring such training.

Section 3-1.5. The individuals proyiding.the training and education need not be nembers of the fire department, but they should be knowledgeable in the araz of instruction as it relates to the fire seryice.

Section 3-1.6. Training officer qualifications may be met by either compliance with the stated IFPA 1041, or by obtaining locel or state certification.

Section 3-3.2. All personnel assigned to structural firefighting positions shall receive trairing adequats to meet the firefighter I qualification of KAFPA 1001 .

Se:tion 3-3.3. Trainirg progiems for drivers/operators shall be issigned to raet the intent of the referenced stenderd. It is linderstood th some licensing requirenents will yary by states and/or type of equipnent.

Section 3-3.4. All specialized training prograns, i.e., fire officer, driyer/operator, airport firefighter, shall be deyeloped and implemented within each organization. This shall be so accomplished as to meet the intent of the appropriate NFPR Staindard.

Seztion 3-4. Training in fire ground operations shall be based on accredited systens, such as those provided by the International fira Service Training association manuals, official state training manuals, etc.

Section 3-5. Because of the specialized operations and hazards pecuitia to most DOE sites, these "special hazards" training requirements are of prime importance. Training should include not only the nature of the hazards, but familiarization with the protective systems employed, the monitoring and alarm systens peculiar to the operation, and the support services provided by other parts of the site organization in monitoring or ajleviating an emergency situation.

Section 4-2.1. Drivers of fire department yehicles shall receive special training in the operation of the vehicle and must be certified and/or licensed, as appropriate, or as required by the State to operate fire department vehicles.

Section 4-2.4. An exception to the requirement is the rear attendant $c$ an ambulance when actively attending to a patient. This exception shall stand until such time as acceptable safety restraints are available for the rear ambulance attendant. 
Section 4-3.1. An exemption may be granted for some site-specific yehicles, such as golf cart-type rehicles used within building to deliver supplies and equipment and automatically restricted in maximum speed. However, any such exemptions must be reviexed and approved by the Safety officer and documented in the department files.

All present and future acquisitions of used apparatus shall be brought up to the minimum standards for safety seating requirements.

Section 4-5.4. For ladders, see the Interpretation Wote on MFPA 1932 . (Al) test conditions are required except that the annual test requirement may be changed to not less than eyery fiva years. All other conditions noted as requiring the test are unchange(j).

Section 5-1.1. A.s a clarification, all equipment must be available and donned before the individual indulges in any eyolutions requiring protective clothing use. It is not necessary for each menber of a departnent or brigada to have a full set oi all protective clothing as long as supplies for the enticipices nesses $\varepsilon a n$ be delivered to the point of use in adequat: quantities and sizas for anticipated needs and without incurring undue deliy in the emergency response.

All new equipment needed to fulfill the requirements of this section shall be procured by the end of FY 1990.

Section 5-2.7. The fire resistance of work station uniforms should be considered in app?ying this Section. Where firefighting is provided by personnel who have other primary jobs, such as in most fire brigades, the provisions of NFPA 1975 need not be applied to their work clothing. However, eny exceptions to the requirement should be raviered by the Safety oficer and exception documented in the department records. Training needs and turnout gear provisions should take into account the clothing nomally worn by responders.

Section 5-3.4.2. SCEA cylinders need not be emptied quarterly if not. required by the manuiacturer/supplier.

Section 5-4.1. Personal Alert Safety Systems (PASS) need be proyided only for people involved in interior firefighting or hazardous responses. 
Section 5-5.3. Life safsty ropes used for rescue shall be preyiously unused and shall be thoroughly examined upon completion of rescue in accordance with the nanufacturer's recomnendations. Ropes used for rescue shall remain in the custody of the-original purchasing engine company or fire department. Records shall be kept, documenting the use, inspection, and inspector, inmediately. after each use and prior to any future use. The date and officer in charge will also be indicated on the records. All ropes leaving the custody of the fire department must be destroyed, or otherwise preyented from being reused in life safety operations. Any indication of wear or shock loading: will be justification to destroy said rope. Life safety ropes shall be completely dry and ciean prior to restring for use as. Iife safety lines.

Section 5-8.I and Section 5-8.2. Change "shall" to "should." In vies of the limited number of responses and shorter travel distances at DOE facilities, as compared to operations by municipal fire. departinents, and the Appendix discussions on these sections, the mandatory continuous use of hearing protection is not required. Howeyer, the Safety Coordinator should ensure that a hearing protection pregran is in place tirat is compatible with site-wide programs.

Section 6-1. Some of the requirements pertairing to emergency operations may be covered by a parent organizztion or be provided by other on-site orgazizations at DOE facilities. Healti physics, for example, may provide the basic personnel required by Seztion 6-1.7 for radiological emergencies. All of the elements of Chapter $\epsilon$, hoveyer, should be in place in the overall site plan. All energency plans should clearly identify the incident commander for each typa of emergency.

Section 6-2. The minimun response requiring interiur firefighting or other operations requiring the entrance of SCBA-equipped people shall be 5 persons. then less personnel are available, interior operations shall not be attempted.

Section 6-3.2. Clarification. The requirenent for personnel "standing by" does not mean the required people cannot be periorming some other function, but they must be able to suspend what trey are doing to provide the immediate rescue efforts.

- Section 6-3. The "standing by" requirement for qualified life support personne? may be relaxed if, in the Chief's opinion, "qualified personnel are readily availabie and are dedicated to the site. (At a small site, it should not be necessary for medical/ambulance personnel to respond on eyery inciderit). 
Section 8. A number of the requirements of Chapter 8 are currently planned for DOE-adoption, such-as a Health Data Base (Section 8-1) and Rehabilitation (Section 8-6), and Physical Fitness Program (Section 8-2). Ir addition, a number of federal, state. and local requirements are being impose of are under devejopment that pertain to the subjects in Chapter 8. As an interim requirement, all DOE departments shall identify any discrepancies frc the Chapter 8 requirements (and referenced NFPA 1001 Standard) needed to attain complete compliance with the Chapter.

HOTE: The resource needs shall be provided to the DOE Health Protectioi Director as planning input. Regardless of what future programs may be required, each organization should endeayor to bring current prograns into compliance with the proyisions of Chapter 8. Pending the development of the final criteria, a dedicatad effort should be made by each department to develop a physical fitness maintenance program.

IMPACT:

These implementations recognize the portions of the Standerd that refer to services and functions proyided at many DoE sites by other organizations than tie fire depariment. Ey ellowing for their incorporation into the fire department programs, the duplication of effort and added expenses are. eliminated.

Also, by recognizing the special conditions applicable to some $D O E$ operations, the intent of the Standard can be achieved without all of $t$ conditions applicable to an independent municipal fire department.

Since the Standard is new, there will be an added expense to those departments not currentiy in compliance. Howeyer, the added benefits of establishing a thorough and recognized safety progran outweigh the initial costs. 


\section{memorandum}

AEPLY TO

DAR: NOV 071991

ATTN OF: $E H-31.3$

SUAJECT: Guidance on Performance of Fire Hazards Analyses

TO:

\section{Distribution}

The purpose of this memorandum is to provide interim guidance on the development of fire hazards analyses (FHA) for Department of Energy (DOE) facilities pending the development and issuance of a DOE standard. While FHA's are currentiy required for new facilities by DOE Order 6430.1A and are being performed for nuclear facilities, no comprehensive Departmental guidance on their scope and technical content currently exists. Reliance on fire protection guidelines developed by the Nuclear Regulatory Commission for the commercial nuclear power industry is not considered appropriate for all DOE facilities because of the unique and varied nature of these facilities compared to a commercial nuclear powerplant.

The guidance is provided in the attachment to this memorandum. It is general in nature and represents a minimally acceptable level of effort. It is intended to be utilized by qualified fire protection engineers.

Interpretations of these guidelines for nuclear facilities, where needed, will be provided by the Office of Nuclear Safety Policy and Standards $(N E-70)$. For nonnuclear facilities, the Office of Safety and Quality Assurance (EH-30) will be the interpretive authority. Where generic issues overlap, EH-30 will develop the interpretation with the concurrence of NE70 .

Questions regarding this memorandum should be directed to $\mathrm{Mr}$. Dennis Kubicki on FTS 233-4794.
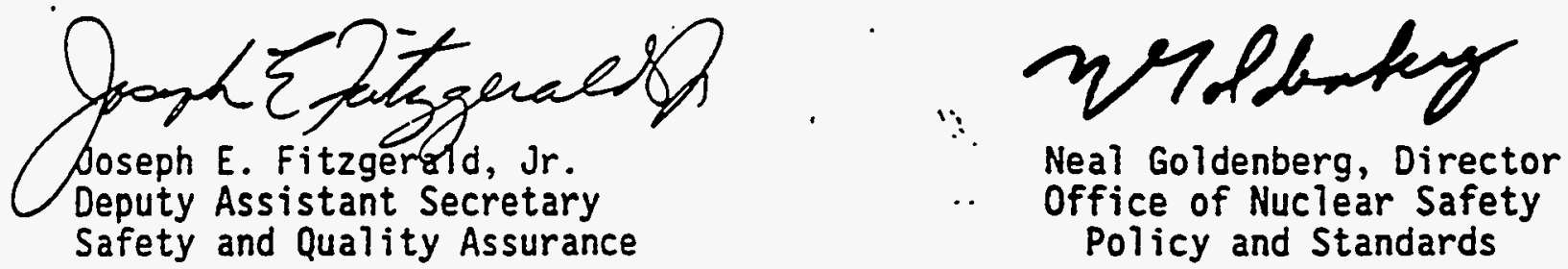

Attachment

cc w/attachment:

P. Ziemer, EH-1

W. Young, NE-1 


\section{Guidance on the Performance of Fire. Hazards Analyses}

The purpose of a fire hazards analysis (FHA) is to comprehensively and qualitatively assess the risk from fire within individual fire areas in a Department of Energy (DOE) facility so as to ascertain whether the objectives stated in Paragraph 4 of DOE Order 5480.7, "Fire Protection," are met. This must include an assessment of the risk from fire and related perils (direct flame impingement, hot gases, smoke migration, fire fighting water damage, etc.) in relation to existing or proposed fire safety features to assure that the facility can be safely controlled and stabilized during and after a fire. To the extent that this analysis completely addresses the following issues, an FHA will satisfy the requirements for a "Fire Protection Safe Shutdown Analysis." The level of detail necessary is directly related to the complexity of the facility and the potential risk to the public and facility operators.

An FHA which addresses all relevant fire safety issues shall be performed for all new facilities as directed by DOE Order 6430.1A; for all nuclear facilities, or as directed by the DOE Program Secretarial Officer or delegated authority.

A preliminary FHA shall be performed for new facilities early in the design phase to assure an acceptable level of protection as the design is evolving. It shall be updated when significant changes. occur within an individual fire area.

An FHA shall be performed under the direction of a fire protection engineer, with support from systems, electrical, and mechanical engineers, as well as operations staff, as needed.

An FHA shall contain, but not be limited to, a conservative assessment of the following fire safety issues:
(a) Description of construction
(b) Fire protection features
(c) Description of fire hazards
(d) Protection of essential safety class systems
(e) Life safety considerations
(f) Critical process equipment
(g) High value property
(h) Damage potential: Maximum Credible Fire Loss (MCFL) and Maximum Possible Fire Loss (MPFL)
(i) Fire Department/Brigade response
(j) Recovery potential
(1) Potential for a toxic, biological and/or radiation incident due to a fire
(im) Emergency planning
(n) Security and Safeguards considerations related to fire protection
(o) Natural hazards (earthquake, flood, wind) impact on fire safety
(p) Exposure fire potential 
The FHA shall assume that an automatic fire protection system will malfunction. If redundant automatic fire protection systems are provided in the area, only the system which causes the most vulnerable condition is assumed to fail. Passive fire protection features, such as blank fire-rated walls or continuous fire-rated cable wraps, are assumed to remain viable.

The focus of the FHA shall be the individual fire areas which comprise the facility. A fire area is defined as a location bounded by fire rated construction, having a minimum fire resistance rating of 2 hours, with openings protected by equivalently rated fire doors, dampers or penetration seals. The boundaries of exterior fire areas (yard areas) shall be as determined by the Program Secretarial Officer or delegated authority. Where a facility is not subdivided by fire-rated construction, the fire area shall be defined by the exterior walls and roof of the facility.

An essential element of an acceptable FHA is an inventory of all safety class systems within the fire area that are susceptible to fire damage. This includes those primary and supporting mechanical and electrical systems which must function effectively during and after a fire event to assure safety, including safe shutdown where applicable. For example, loss of the building ventilation system in a fire (due to damage to power cables) may result in an ambient air temperature rise which may cause the failure of sensitive electrical safety class components, such as relays. Such safety class systems may include, but are not limited to, process monitoring instrumentation, instrument air, the facility hydraulic system, and emergency lighting system.

All credible fire-related failure modes of safety class systems (Class $A$ systems as defined in DOE 5000.3A) shall be considered. For example, it is insufficient to assume that fire will merely cause the loss of function of safety class equipment when power cables to that equipment is within the fire area. It is also necessary to consider the potential for spurious signals which may cause the maloperation of such equipment. Similarly, fire induced electrical faults may trip upstream electrical disconnect devices in such a way as to render inoperable other safety class systems that may not even be located within the fire area. In addition, the effects of combustion products, manual fire fighting efforts, and the activation of automatic fire suppression systems must be assessed.

Fire propagation and the potential for fire-induced radiological dispersal through the facility air distribution system must be considered. These effects must be considered for the normal operating mode of the air distribution system as we 17 as alternate modes, such as shutdown, that may result from the fire.

An acceptable tool that may be used in the deveiopment of an FHA is a fire model, as applied by qualified fire protection engineers. However, the use of such models is predicated on their being conservative and validated. As of this date, DOE has not sanctioned to use of any one model for use in an FHA. However, efforts are currently underway to further develop FIRAC toward this end. DOE acceptance of individual models found acceptable by 
the Nuclear Regulatory Commission for the commercial nuclear power industry will be considered on a case by case basis until a DOE Fire Model is approved.

Alternately, an assumption can be made that all potentially vulnerable systems will be damaged within the fire area. Acceptable exceptions to this assumption are water-filled steel pipes, tanks, and similar components of superior structural integrity with welded fittings and adequate pressure relief.

The quantity and associated hazards of flammable and combustible materials that can be expected to be found within the fire area shall be factored into the analyses. Consideration should also be given to the presence of transient combustibles associated with storage and maintenance activities. Averaging combustible loading as a means to characterize the fire severity is not considered an acceptabie technique.

FHA's for high bay locations shall consider the effects of smoke/hot gas stratification that may occur at some intermediate point below the roof or ceiling. Similariy, the effect of smoke movement through doors and dampers held open by fusible links needs to be addressed.

The fire hazards analysis shall be documented, including all assumptions, and shall be referenced in the facility SAR. 
proposed action will not brve a significarit effect on the quality of the human enviroment. Accortiongly, the Commission has determined not to prepare an enviromental impact statement for the proposed schedular exemption.

For further detalls with reapect to this action, see the liceases's application for amendment dated June 24,1982 which is available for public inspection at the Commission's Public Document Room. Gelman Building 2120 L Street. NW. Washington, DC 2055 and at the local public document roam at the Branford Price Millar Library, Portland State .Univernity, 934 SW. Harrison Street. ' P.O. Box 1151, Portland. Oreson 92207.

Dated at Rockvilte Meryiand this sd day of Augusil 1982

For The Nuclear Regulatory Comisurae.
Thoodoce R. Quny,

Director, Project Directorete V. Division of Rocctor Projoct LIIIV/Y. Office of Nevilear Reactor Regubtion

[FR Doc. 82-18990 Fled 8-7-82; 645 8س]

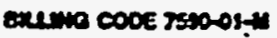

\section{Applleation for a Lfeense to Export a Utilization Factity}

Pursuant to 10 CFR 110.70(b) “public notice of recelpt of an application". please take notice that the Nuclear Regulatory Commission has received the following application for an export license A Copy of the application is on file in the Nuclear Regulatory Commission's Public Document Room located at $2120 \mathrm{~L}$ Street, NW. Washington, DC.
A requeat for a bearing or petition for leave to intervese may be filed within 30 days after publication of this notice in the Fodaral Register. Any requeat for hearing or pettion for leave to intervese shall be served by the requestor or petitioner upon the applicant the Office of the General Counsel U.S. Nuclear Regulatory Commission. Washington. DC 20555; the Secretary. U.S. Nuclear Regulatory Commissiont and the Executive Secretary, U.S. Department of State, Washington. DC 20520.

In its review of the epplication for a license to export a utilization facility as defined in 109 CFR part 110 and noticed herein, the Commission does not evaluate the health, safety or environmental effects in the recipient nation of the facility to be exparted. The information concerning this application follows.

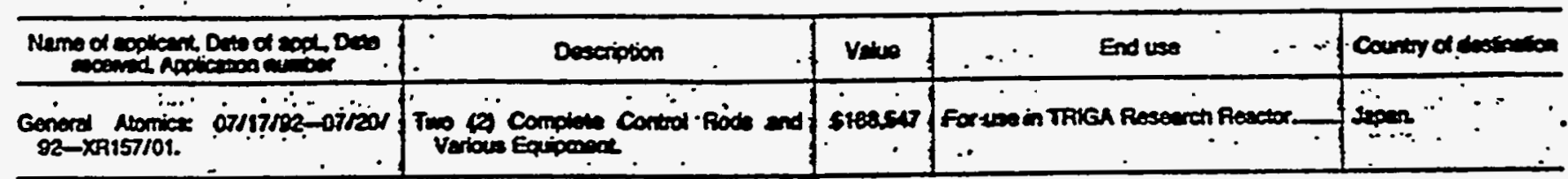

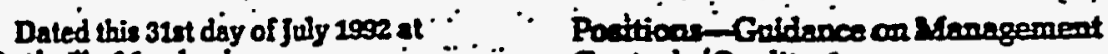
Rockvithe Merjand.

For the Nucien Reatlitory Commiscion.

Rowild D. Hiauber,... $: \therefore$

Ascistont Director for Exparte Sicurity, and Safety Cooperation Office of intermational

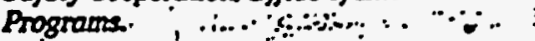

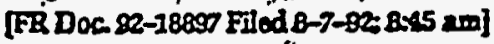

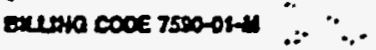

Guldence on Fre Protection for Fuet Cycle Factlties

AGENCY: Nuclear Reguiatory

Commission (NRC). ..

Acriout Guldance to applicants and. licensees for prepariog ticeose applicents and conductiog operetions.

summam: This sotice provides guidance on fire protection for fuel cycle facilities in the form of a Technical Position. The Technical Position will be administered by the Fuel Cycle Safety Branch. Division of Industrial and Medical Nuclear Safety, Office of Nuclear Material Safety and Safegand.

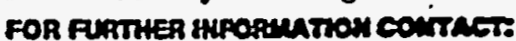
Amar Dalta, Eud Cycle Safety Branch. Division of Industrivi and Medical Nuclear Sufety, Office of Nuclear Material Sofety and Safegard. Washington, DC 20555. (302) 504-2538.

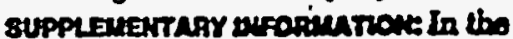
Foderal Rogistar (54 ER 11500-08) doted March 21. 1889, the NRC mullished for comment four Branch Techolcal Coctrola/Oratity Aswrence. Requirementer for Opation Chemieal Sufety, and Fire Proliection for Fut :Cycle Racilitien After.concideratica of the commeots received wid the . experience geined in woing these Tectonicel Pesitions the NIRC hes decided to revise and reisture the Tecturical Position on Pive Peotection for Fued Cycte Faclitien. It is the NRC's - intent that this revised Tectonical ·. Poction wouid serve as a sounce of Information for applicants and licensees on the features of equipment. facilitien. and procedures that can be ased to provide reasonable assurance of fire safety for fuel cycle facilitien. It would provide guidance for implementing fire protection programs at these facilities that would be acceptable to the NRC staff as having the elements necessary to protect beaith and minimize danger to life or property. If would thus also provide information to the staff in revlewing applicetions and inspection facilities.

The information contained berein reflects the NRC staff's vieur. conceroing good industry practice. However, the provisions of this Technical Position do not constitute requirements. Other approaches to the selection of equipmeot design of facilities, and operational procedures are acceptable. provided that they grant equal or higher levele of protection of health and axfety.
Tectroical Position on Fire Protactice for Fod : Cydif Frciltities.

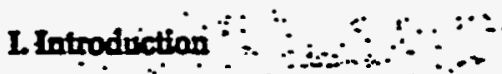

To be apporised by the Aitcic ans: applicatios for a license to popeess and-.. use licensed materials at a fuel csale facility most provide informition -. .. . . . showing that the applicant's proposed equipment, facilities, and prococimes are adequate to protect heatth and riminiose danger to life or property. in the anes of fire protection, the staff has in the part generally accepted compliance with local beilding codes aod proof of insurance es fificient information for approvel of license applications In addition, ad boc meswes have been taken in response to the staffs inspection firdings relating to specific facilities. However, following an accident at a uranium becostuodde production facility. the NRC zmdertook a major review of the operntional enfety of fuel cycie Eacilities Both the recomenerdations of the Matrorials Safety Regulation Review Stody Croup." appointed by the NRC and an independent staff sction to sasers operationd rafety at each of 12 mujer fuel cyate facilities licensed by the NRC. led the staff to the finding that fire protection is owe of the mont important safots cosicerers.

This finding cospled with the experience of the applicams and the staff in their reppective roles of $\therefore$. operition and regulation of find cocle 

facilities, led to the formulation of this Technical Position (TP), which is intended to provide guidance to applicants and staff in the area of fuel cycle facility fire protection. This TP provides recommendations and guidelines for implementing acceptable fire protection programs at fuel cycle facilities and has elements that are intended to ensure protection of health and minimize danger to life and property. The guidance should not. however, be considered mandatory, and nothing should preclude a licensee from adopting a program that is prudent and employs other techriques of fire protection that meet or exceed these guidelines.

\section{Discussion}

\section{Fire Protection Concept}

The concept of fire protection presented by this TP consists of measures that will achieve a balance among the followings....

- Prevention of fires.

- Detection of fires and

- Containment and suppression of

fires. A discussion of these three levels of

\section{fire protection followge... $\therefore$ :}

a. Fire Prevention. Fire preventiơn measures at a fuel cycle facility should start with the desigm of the bitilings: structures, systems, componientis and processea involved in the storage,: : handling, and processing of the :.: used in the processes. The processes: should be designed and phyaically laid out 80 as to minimize the possibility of overheating overpressurization. leakage, and the confluence of:.. combustibles and igmition sources except where required by the process. Even with the most well-deaigmed $\cdot$; facility, prevention of fires depends to a great extent on following good: $\therefore . . . . \div .$. housekeeping practices and operating personnel scrupulously following safety instructions.

b. Fire Detection: The best fire prevention measures may occasionally fail, in which case an effective fire detection system would detect the occurrence of fire and activate alarm systems 80 that measures for. containment and suppression of the fire and personnel evacuation may start prompty. The type and location of the detectors would depend on the type of herard. The installation of a fire.. detection and alarm system is especially impartant where personnel presence is infrequent and the fire hazard is - moderate or high. : $\because \ldots::: ! ! ! d:$

c. Containimerit and Suppression of. Fire: Containment of fire in its aree of origin and prevention of its spread to new areas and new combustibles is one of the first steps to be taken upon detection of a fire. This is achieved by activating systems such as barriers. ventilation dampers, exhaust fans, and drainage pumps to prevent migration of gases, hot combustion products, and flammable liquids to new areas. Fire suppression activities should start at the same time as. barrier systems are activated. The media employed in the suppression and the means of their delivery to the fire source and to heated areas and substances depend on the plent area and the processes and equipment protected. The concerns for nuclear criticality safety, chemical safety, and the danger to personnel from non-life-supporting extingrishing media, such as carton dioxide, should all be . taken into accourt in planning a fire .. suppression system.

\section{Fire Hazard Anafysis}

A number of fuiel cycle facilities already in operation may not hayie all of the deaiga and construction features considered desirable for fire protection: Forisuch facilities; it is prudent to:

perform systematic fire hasaird analyses:3 of their.operations. Snch analyïes could, be.expected either to reveal fire protection:weaknesses:orto confirm the ? adequacy of the protection measures Where weaknesses are indicated; they: may be corrected by a judicious. - :combination of facility modification and : additional fire protection measures. Also, the licenised activities, processes, or buildings of operating facilities may . from time to time be modified.

Whenever this heppens, the fire hazard analyses should be updated. Qtherwise. these shonld be reviewed and updated : at regular intervals of time. : .:- ... III. Position $\cdots+\ldots \cdot \cdots$

1. Fire Protection Program $: \therefore \therefore \therefore \therefore$

The licensee should establish and : implement a Fire Protection Program. The program should reflect a

commitment to perform tasks to ensure that the equipment and facilities are maintained in proper condition to prevent fires from occurring, maintain awareness of fire safety procedures among the employees and ensure compliance with those procedures, and maintain a readiness, if a fire does -. occur, to implement emergency. : procedures to suppress it and mitigate the consequences. ..... . $\because . . .$.

The program would be expected to include an appropriate set of the following components:"

a. Eatabliahment of a Fire Safety Review Committee and a definition of its duties, frequency of meetings. frequency of plant audits, and responsibilities for-reporting and recordkeepins (A plant safety committee may function as the Fire Safety Review Committee.]

b. Initiation of a Fire Hazard Analysis of the facility and its periodic updating.

c. Maintenance of the facility and equipment in proper condition to prevent fires from occurring.

d. Review and control of modifications of the facility or processes to minimize fire hazard.

e. Review and control of hazardous operations, such as welding and rorchx cutting, and any nonrotutine use of flammable or combustible materials.

f. Routine inspection, testing, and maintenance of all fire protection equipment.

8. Training of all employees in basic fire safety and of a selected group to respond to fire energencies. (The latter grouip may be part of the ptant emergency response teäm]

h. Reporfing and investigation of fireincidents $\because-\because \because \because$ a $\because \cdots$

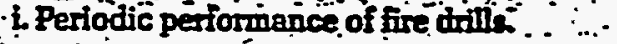
Rules for good honsekepping with a : view to minimizing fire dangegr 2 Administrotrie Contrals 21 Ppogram Management $: \quad: \because$

The licensè should ensure adequate manigement and supervisory attention to fire protection. The overall : management of an adequate program. would be expected to be under the .direction and control of a serior level individual, who should be given the $\because$ authority arid staff assistance to implement measures relating to fire protection throwhout the facility. Actual implementation of the day-to-day tanks of the program ahould be supervised by an individual having sufficient qualifications and practical experience in fire protection.

\section{Plant Audits}

Plant audits of fire protection should be performed at two levels as follows:

a. Monthly audits (walk-downs) to detect and correct departures from good housekeeping practices or operating procedures that may impact fire safety:

b. Annual audits by the Fire Safety Review Committee. inctuding.plant walkdowns, to review proper " functioning of the Fire Protection Program and generally the overall fire safety of the facility. 



\section{Building Construation}

\subsection{Construction Standard}

Type I construction, as classified by VFPA 220 . Types of Bullding Jonstruction, is considered adequately :iresafe for the process buildings of the Incility. (The National Fire Protection Association (NFPA) documents cited in the text are listed in the reference section in the order of their NFPA numben.) This standard specifies that the structural members of the buildings, including walls, columns, beams, floors: and roof 8 , are io be constructed of upproved noncombustible or limited combustible materials and have pecified minimum fire resistance ratingr. If nomprocess areas are housed in the same or adjoining buildings, the ontire building complex should be the squivalent of a Type I construction.

\section{Fire Areas}

To confine fire inits area of origin and prevent its spicead, areas ocintainiting processes or materiahs invoiving fire hazards should be separated by structural barriers into fire oreas. In particular, solvent extraction areas. boiler rooms, incinerators, warchouses. control rooms, switchgear rooms, computer rooms, maintesance strops. fire pump areas; and office arees stoold be aeparate fire areas.

Structural barriers, including walls, floors, cellings and roofs, that bound fire areas shơild tiavie eppropriate fire resistance ratings. Boundaries of such fire areas may coincide with zones the facllity is divided into, based, where such zoning exists. on radiotoxicity of the materials handled therein.

Openings in the barriers that are joundaries of the fire areas should have tevices, such as fire doors and fire 3tops, installed in them. Such devices should have at least the same fire resistance ratings as the barriers in which they are installed.

\subsection{Exposure Fire Risk}

When a process building is close to other buildings or installations with flammable, combuctible, or reactive liquid or gas storage, the risk of exposure fires originating in those inctallotions to the process building concerned should be evaluated.nnd appropriate protection menaures sbould. be taken. NFPA BOA. Protection of . Buildings from Exterior Fire Exposures. provides guidance on protection from such expasures. NFPA 30, Flammable and Combuntible Liquids Code lists minimum separation distances from tank storages.

\subsection{Persoconel Egress}

The building design should provide for safe means of egress for personnel in the event of a fire emergency. Egress routes should be clearly marked. NFPA 101. Safety to Life from Fire in Bulldings and Structures, provides guidance on egress design and protection of egress routes.

\subsection{Sonoke Vents}

If the building has undivided floor areas that are not provided with means of automatic fire suppression and are. lange enough that hose streams directed from outside may not reach all parts of the areas, mitigating features, such as smoke yents and curtain boards, should be provided. NFPA 204M, Smoke and Heat Venting, may be consulted.

\subsection{Hidden Spaces}

Concealed spaces should be devold of combrustibles as far as practicable. Suspeinded ceilings and their supports, insulation for pipes and ducts, and sound-attenuating materials hould be". noncombustible All crack or openings in floors leading to inscceseible under: floor spaces should be sealed.

\subsection{Iightning Protection}

Provisions should be made far protecting the facility from lightining : damage Guidance for the installotion of such protection is provided by NFPA 78, Lightring Protection Code: 38 Drainage Provisions

Floor drains, sized to remove $\because$ anticipated quantities of fire-fighting wrater, should be provided in process areas. Drainage from areas containing hazardous chemicals or rndioactive. materials should be collected in sumps for sampling and treatment before release to the environment.

\section{Electric installatinga} $\therefore$

All electrical wiring and installations shouid be made, used, and maintained in accordance with industry standards, such as NFPA 70. National Electrical Code, and other standards that apply to special situations, such as NFPA TOE. Electric Safety Requirements for Employee Work-places: NEPA 79. Electrical Standard for Industrial Machinery: and NFPA 75, Electrical Computer/Data Processing Equipment.

\section{Yentilation System}

\subsection{Ventllation Systein Desitz}

The ventilation aytein thida be desigaed to isolate affected areas dering fire accidents and to provide chnomets for exhursting firo producter throngh fitters if meceserry, to outriale the plant. NFPA Standand OaA Air Conditionions :- and Ventilating Sycteme, may bo consulted on rentilation design for fire protection.

\section{IIPPA Filters}

When a yentilation system is required to prevent the release of radioactive material to the atmosphere, all materials of construction for the system should be noncombustible. HEPA filters should conform with industry standards, such as Underwriters Laboratories Standard UL 588 (also designated ANST B 132.1), High Efficiency Alr Filtration Units.

\subsection{Barrier Penetrations}

Whenever the rentilation duct rystem penetrates a fre-rated benter. a fire damper. having a fire reststance rating at least equal to that required of the berrier. shovid be installed in the drict. Guidance will be found in UL 555 . Standard for Fire Bawpers and Celting Dampers.

4.4 Antomtic Chosing

All fine dooss fire dianperiond ceiling dampers should clase automatically, and ahouid rematin closed, upon operation of a furible link or other treat-uctualed device : - ? 45 Feating Fnomaces

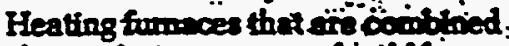

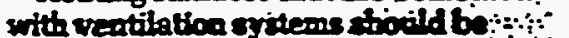

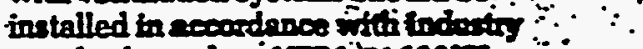

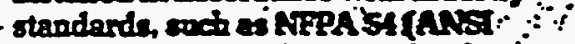

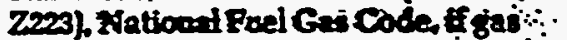
fired, or NFPA 31 , Oil Burniag $\because \because \because$. Equipment, if oil fired Guidance for the Installation of electrical duct.henter: will be found in NFPA 70, National Eroctrieni Code

\section{Process Fire Safely. : . :}

51 Some Chemicais and Their Fire Hazand

The process chemicail Iisted below are those that are used in builk quantities in ficl cycle facilities and also are fire harards.

\subsubsection{Nitric Acid}

Nitric acid is itself noncombertible. but under certain conditions, it iftrates cellulosic and other organic matedals. making them enity ignitble. A nftrit acid spill the constitutes a fire heard. in addition to being a corrosion and toxicity hazand.

\subsection{Sulfirác Adt}

In additioeto tis corrovion sind. toxicity brond this chenien bind ibe . pacperty of al worbing wrater frops. organic materials acoompaniad by

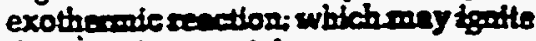
the orgate montedele. . 


\subsubsection{Anhydrous Ammonia}

One of the uses of this chemical is as a source material for the production of hydrogen for use in reduction processes. It is a flemmable gas, which is stored and pumped in the liquified state, and undergoes dissociation into hydrogen and nitrogen in a high-temperature dissociator at about $1650^{\circ} \mathrm{F}$. Anhydrous ammonia is flammable and presents, if ignited in a confined space, an explosion hazard. It also presents a toxicity hazard.

\subsubsection{Hydrogen}

Hydrogen has a high burning velocity and also a wide flammable range in mixtures with air. A small bydrogen name, as at a leak from a pipe, is bluigh and almost invisible. The hazards of fire and explosion are high in the event of a leak from any equipment that contains or uses hydrogen. Additionally, there is the hazard of explosion in vessels and fumaces were explosive mixtures of hydrogen and an oxidizer may. form inadvertently. :

5.1.5 Fluorine. $\because \ldots, \therefore \ldots$ $\cdots:$

Fhorine is one of the most reactive - elements known. Apart from its being highly corrosive and toxic it reacts violently with hydrogen and many $\ldots .:$. organic materials and causes fires even

- though it is itself nonflammabte.: $:$. . . - Fuorine may also canse explosion in conlact with metallic powders and water vapor.

\section{2. - Processes Involving Use of Flammable Liquids aud Gases}

521 Processes involving solvents or other chemical substances, that may be classified as Ilammable liquids according to NEPA 324: Classification of Flammable and Combustible Liquids:. should be isolated from each other and from the remainder of the facility by locating them either in separate buildings or in spaces enclosed by barriers having a minimum fire resistance rating of 1 hour.

522 All electric motors, switchgears, lighting, and other electrical installations in these process areas should be of the explosive-proof type NFPA 70, National Electrical Code. provides guidance.

523 No open llame should be permitted in these areas: Construction or maintenance workinvolving torchcutting or welding may be permitted only when the process is shut down the inventory of flammable and combustible materials is at a minimum, and safety measurea, such as fire watches are implemented: NFPA 51B. Fire Prevention. in the Use of Cutting and Welding. provides guidance.

5.24 The process areas should be provided with automatic fire detection and automatic explosion prevention/ suppression systems. NFPA 69 .

Explosion Prevention Systems, provides guidance on desigm, selection, and installation of such systems.

5.25 Ovens or furnaces that use hydrogen as atmosphere and have a hydrogen burner (and usually also have a natural ges pilot burner) should have flame-supervision system. Such a system should activate $a$ visual and/or an audible alarm and should shut off the hydrogen supply upon loss of flame. NFPA 86C, Industrial Fumaces Using a Special Processing A tmosphere. provides guidance.

5.26 Where a process involving a Ilammable liquid or gas must be in thesame fire area as an ignition source. such as an open flame, one or more analyzers should be installed: strategically to monitor the flammable: or combustible vapor or gas!. concentration in the air. Itie áfialyziers: should activate both visible and audible: alarms whenever the vapor or example 10 percent of the lowier nammable limit: Simultainépiusty, ignition and heat soinces in the area should be turned off aútómatically 5.3 - Fire Hazaind in the Handring of Uràiüm Oxides

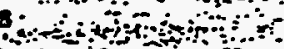

Uramium oxdde powder, usually. following a calcining or a blending process and sometimes when heated by process machinery, may undergio: spontaneous exothermic chemical reaction Such "unstabilized" powider is known to have ignited combustible components of transfer pessages and . mechanical handling inachiinery, sưch as: vinyl pipes, flexible neoprene boots andparts of valves, and nylon.parts of conveyors. Such components should be made of noncombustible materials. as far as practicable, or of materials having sufficiently high ignition temperatures. and resistance to heat-degradation.

\subsection{Machining Operations of Combustible Metals}

5.4.1 Metals, such as uranium. magnesium, titenium, and zirconium. and their alloys, are known to be combustible; especially when in a finely divided form. Machining operations in the facilities should, therefore; be .: evaluated for the potentiel for. $\cdot 2 \cdots . . . \cdots$ combustible dust cloud formation and combustible scrap and swarf : accumulation from operations, such as .. sawing ginding machining, and ... - abrasive cutting.:Fire protection.: ... . measures for all of these metals are similar. NFPA 480, NFPA 481, and NFPA 482 Standards for the Production. Processing. Handling and Storage of Magnesium, Titanium, and Zirconium. respectively, provideguidance.

5.42 -No open flames should be permitted in the areas where machining operations of combustible metals are performed. If maintenance operations. such as welding, are to be performed in the vicinity, machining operations should be halted and metal scraps should be removed. -......

5.3 Machining operations : $\because \cdots$ producing fine particles of combustible metals should be performed in enclosures with a dust collection system in operation. The dust-laden air should be ducted to a dust collector and. If required. a HIXPA Ellter for removal of . radioactive particles. The collection hood and duct leading to the Iilter should be designed to minimize. deposition of the fines and to facilitate. cleaning A liquid precipitation separatoris the preferred type of dist : collector:

5.4.4-Each dust-produch miachine. should bi equiped with ts ory dust : separafor unit as far as practicable $=$

$55^{\circ}$ Scrap and surarf generatéd by. inchining opentions and accumplated : :-" In the immediate area, and ount apd : dludge collected in the dust geparatorsand ducts ahouid be removed os ofien as necessary, but at least ouce a-day

5is--Extinguishing agetits suitable for the particularmetal fire, as wiell as suitablé scoops or appliciators for the pupose, should be readily available to the operator performing the inachining:

\section{5 - Incinerators}

5.5 .1 Incinerators should be $\because$ separated from the remainder of the facility by fire banriers.having a . '. . minimum 1-hour fire resistance rating.

5.52 . If the incineratoris to burn radioactive-contaminated waste, its exhaust should be ducted to a sampling and filtration system before releasing it to the environment. The exhaust may be ducted also to the facility off-grass system. Such ducts should be designed to minimize deposition of particulate effluent and to facilitate cleaning.

5.5.3 Depending on the temperature of the exhaust a cooling water spray or passage.through a liquid precipitation separator may be needed for both. cooling and dust separation.....-

5.6 Boilèrs and Boiler-Fürïaces.". : - .

5.1 . Bollers for the supply of steam for process operations and boiler- furnaces should be separated from the remainder of the facility by. fire barsiers 
that have a minimum 1-hour fire resistance sating.

5.8.2 The construction and operation of the boller-furnaces should comply vith industry standards, such as the relevant standards in the NFPA 85 series, depending on the type of furnace and the fuel used.

5.6.3. The fuel storage tanks should be separated from the furnece area by sire barriers that have a minimum 1-hour ire resistance rating. The fuel lines should be laid out to minimize the possibility of damage and should be clearly marked.

\subsection{Stationary Combustion Engines}

5.7.1 Stationary combustion engines. if located In part of a structure housing fuel cycle processes, should be in enclosures that have a fire resistance rating of at least 1 hour.

5.72 Rooms housing stationary combustion engines 'should be of ' noncombustible construction or. if combustible materials are used, should be protected by automatic fire suppression systems $\therefore \therefore^{\circ} \cdot \therefore$.

5.7.3 - Process-generated dust or flammable vapors shovid be limited in the room when the engine is operating.

5.7.4. Fuel storage tanks, except for: day tanks, should be locited outside the room and should be constructed in accordance with industry atandards: such'as NFPA 30, Flammable and. Combustible Liquids Code. Guidance on the construction and capacities of. unenclosed day tanks will be found in NFPA 37. Stationary Combustion Engines and Gas Turbines.

53.5. The engine exhaust system should be designed to prevent fgnition of any combustible material by contact with the hot metal surfaces or by leaking exhaust gases or sparks:

5.7.8 The stationary combustion engine room should be ventilated effectively to minimize accumulation of combustible vapor and the possibility of explosion. NFPA 37 provides guidance.

5.8 Storage and Handling of Flammable and Combustible Liquids and Gases

58.1 The construction installation. operation. and maintenance of combustible liquid storage and the related loading and dispensing systems should comply with industry standards. such as NFPA 30, Flammable and Combustible Liquids Code.

5.8 .2 Indoor storage of nammable and combustible liquids may be permitted in limited quantities in approved closed containers for day use und maintenance work or for diesel. engine operation. Appropriate portable fire extinguishers should be on hand at such tocations.

58.3 Steel supports of aboveground storage tanks should be protected from exposure fires, if dictated by the proximity of other flammable or combustible liquid atorage tanks. location in a common diked area, or proximity of a tank-truck loading and unloading area.

5.84. In addition to normal operating vents, some aboveground storage tanks may require emergency relief venting.

NFPA 30 provides guidance on this matter.

5.8.5 The construction, installation. operation, and maintenance of bulk gas (including liquified gas) storage and the related loading and dispensing systems should comply with good industry practice, such as NFPA 50, Bulk Oxygen Systems at Consumer Sites: NFPA 50B. Liquified Hydrogen Systems at Consumer Sites; and NFPA 54, National Fuel Gas Code.

\subsection{Hot Cells: :}

591. The construction materials for hot cells should be noncombustible. The internal surface coatings should be nowicombustible or limited combustible. 592 . The liquid-filler windows : should contain a noncombustible. miedium: Iydraulic fluids in the masterslave manipulators should be $:-1$. nonilammable...... $\therefore$.

593 Where process materials and equipment present a fire hazard, the quantities of combustible materials and the sources of ignition should be" $\because$ maintained at the absolute minimum. If llammable gases or vapors may. be : present in explosive proportions. an. ". inert atmosphere should be provided when operating the hot cell.

5:9.4 If combustible materials are used in a hot cell. extinguishing agents that are compatible with the materials handled should be provided within the hot cell together with their delivery systems. Nuclear criticality concerns should be considered in selecting. extingulshing media.

5.95 Filters for the exhaust air from a hot cell should be of noncombustible construction.

59.6 Further guidance for hot cell fire protection is provided in NFPA 801. Facilities Handling Radioactive Materials.

\subsection{Glove.Boxes ..}

5.10.1 The construction materials for glove boxes may be of the limited.. combustible type if only noncoimbustible process materials are.used within them. Otherwise, except for the gloves, the. glove box should be of noncombustible construction.
5.10 .2 If combustible materiais are used or if there is the possibility of an explosive mixture forming within the glove box. the relevant guidance provided for hot cells should also apply to glove boxes.

5.10.3 If a number of glove boxes are operated in series, fire dampers should be provided at intervals to impede propagetion of fire.

\subsection{Laboratories}

The fire protection methods of laboratories handling radioactive materiais are similar to those of chemical laboratories. Guidance is provided in NFPA 45. Fire Protection for Laboratories Usting Chemicals.

\section{Fire Detection and Alarm Systems.}

\subsection{Automatic Fire Detectors}

Automatic fire detectors of appropriate types should be installed in all areas with substantial combustibles that are infrequently visited or occupied only part of the 24-hour day, unless such. areas are covered by automatic fire suppression systems.

B2: Vapor and Gas Detectore $\therefore$

-Automatic tlammable vapơ and gàs $: \because$. . ... defectors ohound be installed in areas. where there is a potential for leakage of tlammable liquids or gases. $\therefore . \cdots: \because \because$ 6. Audible and Visible Alarms . . . . . .

Automatic fire detectors and . flammable vapor or gas detectors should actuate audible and visible alarms in the area of origin of the alarm. as irell as at a central monitoring station that is constantly supervised Actuation of any fire suppression system such as flow through a sprinkler system, should also actuate visible and audible alarms. The central monitoring stations should have continuous.information on the status and functioning of the fire detection systems, combustible vapor/gas defection systems, and automatic fire suppression systems, including a zone indication of the origin of an alarm. These systems should comply with industry standards. such as NFPA T2G. Installation. Maintenance, and Use of Notification Appliances for Protective Signaling Systems; and NFPA 72E. Automatic Fire Detectars...

6.4 Manual Fire Alarms ${ }^{*} \cdot .$. : ...... . .

Manual fire alarm actuators (pullboxes) or telephones should be available at strategic locations, for example, nearexits from the various facility areas. 


$$
\text { - }
$$


with assistance from offsite fire departments where such assistance is available, NFPA 600, Private Fire Brigades, should be used for guidance.

11.2 Training

All members of the Fire Emergency Response Team should receive training adequate to perform their duties of responding to a fire emergency in the tacility. NFPA 600 provides guidance on Iraining and the frequency of refresher i essions and drills.

\section{V. References}

\section{iTs. Nucloor Regulatory Commission} Documents.

1. Foderal Register (51FR45122). Report of the Materials Safety Regulation Review Study Group. December 17. 1988.

2. Results of Operational Safety Assessments at the Major Fuel Cycle Facilities: Memorandum from Hugh $L$ Thompson J $\mathrm{r}_{\mathrm{n}}$ Director. Office of Nuclear Material Safety and Safeguards. to. Victor Stello. Ifin Executive Director for Operations, U.S. Nuclear Regulatory . Commission July 1. 1987.

3. NUREC 0800 , Standard Revieiw Plan 85.2. Guldelines for Fire Protection for . - Nuclear Power Planta, Revision 2. July 1882.

$\therefore$ - Federal Regieté, Vol 54, No. 53, - Gridance on Management Controls/ :Quality Assiurance, Requirements for Operation, Chemical Safety, and Fire Protection for Fuel Cycle Facilities, March 1889.

\section{Nationä Fine Protectiọn Association Documents}

\section{NEPA 10-1990, Portable Fire}

Extinguishers. 6. NFPA 11-1988, Low Expansion

Foam and Combined Agent Systems. 7:NFPA 11A-1988, Medium- and

High-Expansion Foam Systems. 8. NFPA 22-1889. Carbon Dioxide

Extinguishing Syatems.

8. NFPA 12A-1989. Halon 1301 Fire

Extinguighing Agent Systems.

10. NFPA.12B-1990, Halon 1211 Fire

Extinguishing Systems:

11. NFPA 13-1989, Installation of Sprinkler Systems.

-12. NFPA 14-1990. Installation of

Standpipe and Hose Systems.

13. NFPA 15-1990. Water Spray Fixed

Systems for Fire Protection.

14. NFPA 16-1991. Deluge Foam-Water

Sprinkier and Foam-Water Spray

Systems.

15. NFPA 20-1990, Installation of

Centrifugal Fire Pumpz.

10. NFPA 24-1987. Private Fire Service

Mains and Their Appurtenances.

27. NFPA 30-1890, Flammable and

- Combustible Liquids Code.
18. NFPA 31-1987, Oil Buming

Equipment.

19:'NEPA 37-1990. Stationary

Combustion Engines and Gas Turbines.

20. NFPA 45-1888. Fire Protection for

Laboratories Using Chemicals.

21. NFPA 50-1990, Bulk Oxygen

Systems at Consumer Sites.

22. NEPA 50B-1989. Liquified

Hydrogen Systems at Consumer Sites.

23. NFPA 51B-1989. Fire Prevention in

Use of Cutting and Welding Processes.

24. NFPA 54-1888, ANSI Z223.1-1988.

National Fuel Gas Code.

25. NFPA 69-1988, Explosion

Prevention Systems.

26. NFPA 70-1990. Netional Electrical

Code.

27. NFPA TOE-1988. Electrical Safety

Requirements for Employee Workplaces.

28 NFPA 72G-1989. The Installation.

Maintenance and Use of Notification

Appliances. for Protective Signaling .

Syztems.

29. NFPA. 72E-1990, Automatic Fire

Delectors.

32. NFPA 75-1989. Electronic

Computer/Data Processing Egdipment.

32 NFPA 77-1988, Recommended:

Practice on Static Electricity... . : $\therefore$ : : •

32. NFPA 78-1889; Lightining

Protection Code: àtria

33. NFPA $79-1987$, Industrial $\because \therefore$

Machinëry. $\because \because \because \because \therefore, \because \because \because \because:$

-3L NFPA 80-1990, Fire Doors and

Windows.

35. NFPA 80A-1987. Protection of

Buildings from Exterior Fire Exposures.

36. NFPA 85D-1989, Prevention of

Purnace Explosions in Fuel Oil-Fired

Multiple Burner Boiler-Furnaces.

37. NFEA 86C-1987. Industrial

Furnaces Using a Special Processing

Atmosphere.

38. NFPA 90A-1989, Air Conditioning

and Ventilating Systems.

39. NIFA 90B-1989, The Installation of.

Warm Air Heating and Air Conditioning.

Systems.

40. NFPA 101-1891. Safety to tife from

Fire in Buildings and Structures.

42. NFPA 204M-1991. Smoke and Heat

Venting.

42 NFPA 220-1985. Types of Building

Construction.

43. NFPA 251-1990. Fire Tests of

Building Construction and Materials.

44. NFPA 321-1991. Classification of

Flammable and Combustible Llquids.

45. NFPA 600-1888, Private Fire

Brigades.

46. NFPA 801-1991. Facilities.

Handling Radioactive Materials.

47. NFPA 803-1988, Recommended

Fire Protection Practices for Light

Water-Cooled Nuclear Reactors.

\section{Other Documents}

48. American National Standards Institute (ANSI) N665-1985. Facilities for Fabricating Fuel for Light Water Reactors (LWR)-Fire Protection. 49. ANSI/ASHRAE.15. Safety Code for Mechanical Refrigeration.

50. American Society for-Testing . Materials (ASTM) E-84. Surface Buming Characteristics of Building Materials (1976).

51. ASTM E-119. Fire Test of Building Construction and Materials (1976).

52 Factory Mutual System Approval

Guide-Equipment, Materials, Services

for Conservation of Property.

53. National Fire Protection

Association. Fire Protection Handbook.

54. Underwriters Laboratóries (UL)

555. Standard.for Fire Dampers and

Ceiling Dampers.

55. UL 588 (ANSI B 132.1). Hrigh"

Efficiency Air Fultration Units. . .

56. UL Building Materials Directory. ..

Dated at Rociville. Margiend, this 2oth day of Joly 1982

For the Nuclear Regulatory Commisaion

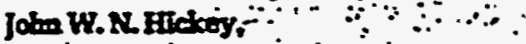

Chief. Fuet Civie Sofety Bianchi Division of -Induistrial and Medical Nuclear Safelfy:-

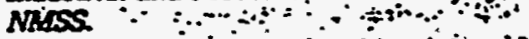

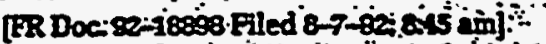

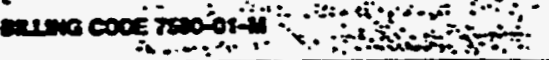

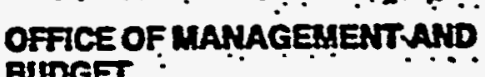
BUDEET.

Guidetines and Discount Rates for Benefit-Cost Analyals of Federal Progrems .

Dated: july 23. 1992

Acatcr: Office of Management and Budgef, Executive Office of the :-. President.

Acrion Notice. of proposed revision and expansion of OMB Gircuilar No. A-O4.

suanamr: Notice is hereby given that the Office of Management and Budget (OMB) proposes to revise Circulai $A-94$ The revised Circular includes expanded guidance for the-conduct of benefit-cost and costeffectiveness analyais. It also includes guidelines for lease-purahase anaiysis that were formeriy provided in OMB Circular A-104. which has been rescinded $A$ draft of the revised. Circular is available on request from the Ofifice of Management and Budget.

Circular A-94 was last revised in 1972. At that time the Circular specified a 10 percent real discount rate for use in most benefit-cost and cost-effectiveness andyces: An exception was subsequently provided, in Circular A- 


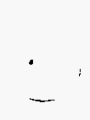

.

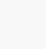

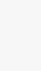




\section{ATTACHMENT TO NUCLEAR CRITICALITY SAFETY GUIDE \\ FOR FIRE PROTECTION PROFESSIONALS \\ IN DOE NUCLEAR FACILTIES \\ Rev. B, June 30, 1994}

Typographaphical corrections were noted to this document following its publication. Please make the following pen and ink changes to the document:

Page 5, para 2, line 1. Change "will" to "with".

Page 10, July 24, 1994. Change location from "Wough" to "Wood".

Page 18, last paragraph, line 1. Change 3.2.3 to 4.2.3.

Page 28, last paragraph. Change "Appendix B" to "Appendix C".

Page 33, penultimate paragraph. Delete extra bracket before 7.

Page 36, 6th paragraph, line 2. Change section 3.0 to 4.0 .

Page 44. Delete incomplete sentence at bottom.

'Page 45, paragraph 4, 8th line. Delete "d" on used.

Page 48, 1st paragraph, line 3. Change 7.3 to 8.3.

Page 49, end of 2nd paragraph. Change 7-2 to 8-2.

July 15,1996 
. 


\section{NUCLEAR CRITICALITY SAFETY GUIDE FOR FIRE PROTECTION PROFESSIONALS IN DOE NUCLEAR FACILITIES}

Prepared for the U.S. Department of Energy

Defense Programs

Environmental Management

Prepared by: Wayne D. Holmes, PE, MSFPE

Branch Manager

HSB Professional Loss Control

Thomas P. McLaughlin, Ph.D

Group Leader - Nuclear Criticality Safety

Los Alamos National Laboratory

Rev B

June 30,1994 
- 


\section{NUCLEAR CRITICALITY SAFETY GUIDE \\ FOR FIRE PROTECTION PROFESSIONALS \\ IN DOE NUCLEAR FACILITIES}

\section{TABLE OF CONTENTS}

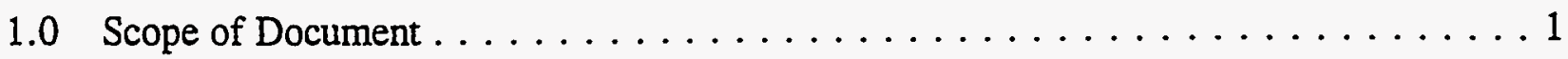

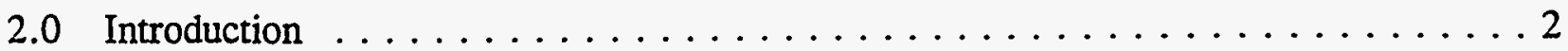

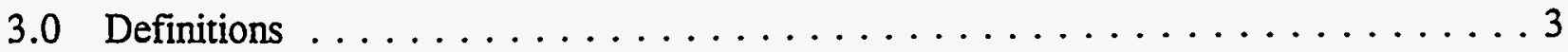

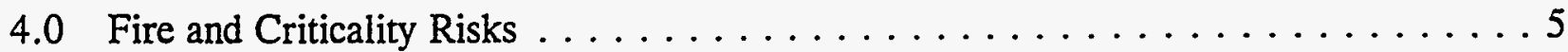

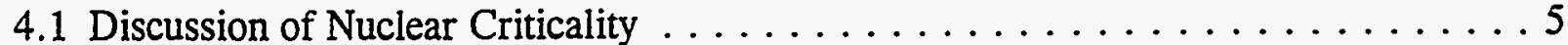

4.1.1 Definition and Description of Criticality Peril $\ldots \ldots \ldots \ldots \ldots \ldots$

4.1.2 History - Examples of Past Criticality Events . . . . . . . . . . 9

4.1 .3 Frequency of Criticality Accidents $\ldots \ldots \ldots \ldots \ldots \ldots \ldots \ldots \ldots \ldots$

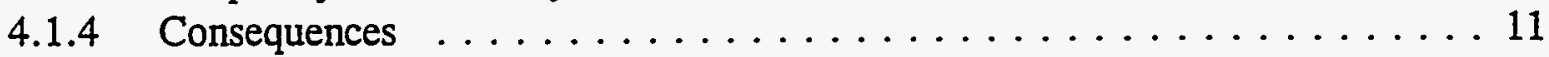

4.2 Discussion of Fire Peril . . . . . . . . . . . . . . . 13

4.2.1 Discussion of industrial/commercial Fire Problem $\ldots \ldots \ldots \ldots 13$

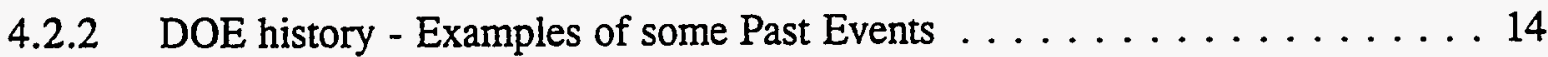

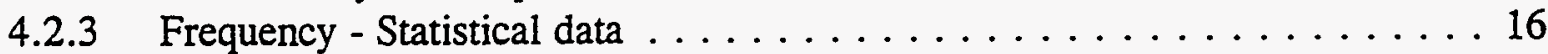

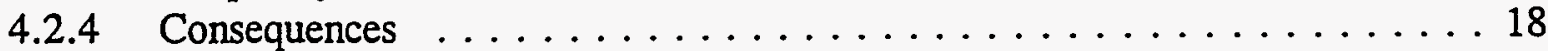

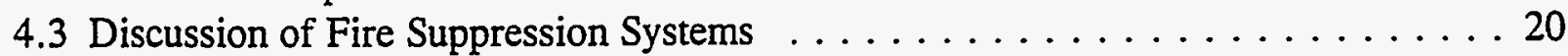

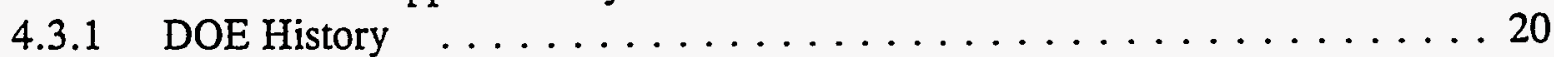

4.3.2 Statistical Data on Sprinkler Systems . . . . . . . . . . . . 20

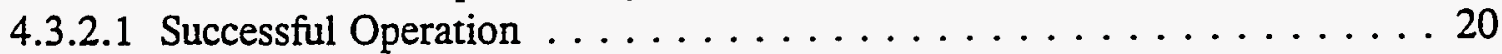

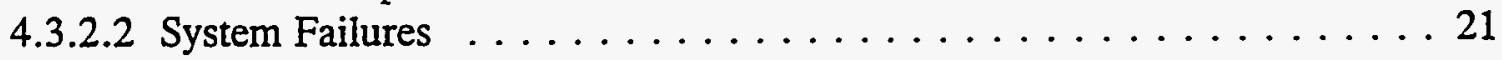

4.3.2.3 Non-fire Water System Failures . . . . . . . . . . . . . 24

4.3.3 Consequences of Fire Suppression System Actuations . . . . . . . . . 25

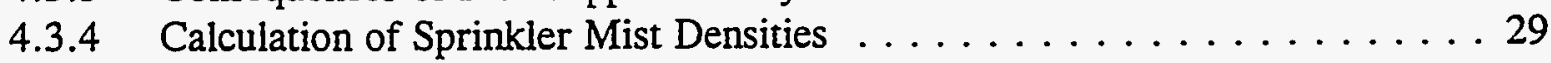

4.4 Discussion of "Risk" . . . . . . . . . . . . . . . . . . 30

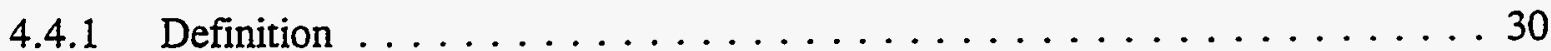

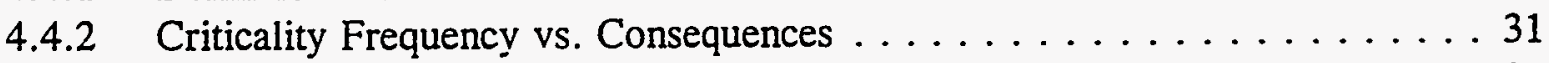

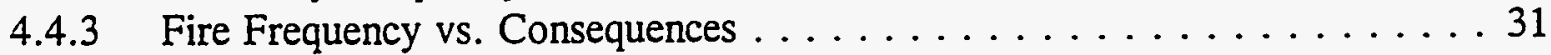

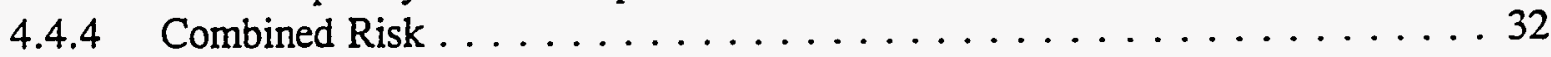

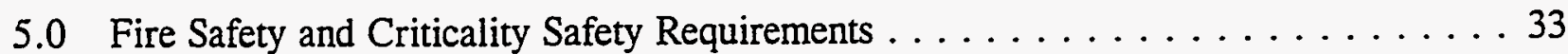

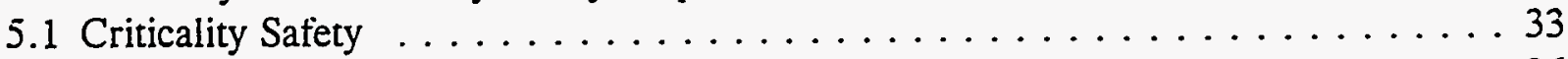

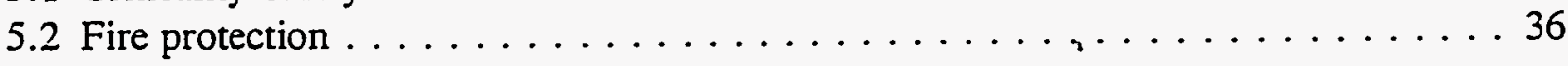

6.0 Nuclear Criticality Consequences of Non-suppression of Fires . . . . . . . . 42

7.0 Guidelines for Evaluation and Design of New or

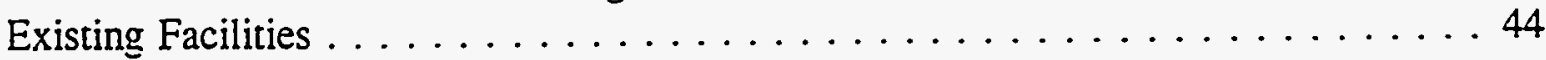




\section{Table of Contents (Cont'd.)}

8.0 Guidelines for Fire Protection Response for Facilities

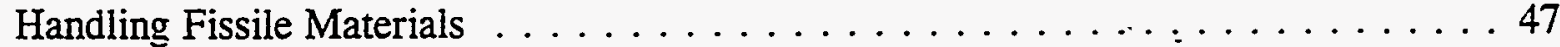

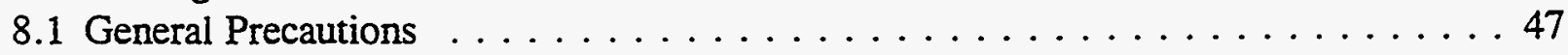

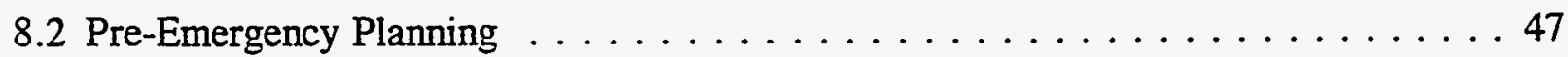

8.3 Fire-Fighting Classification of Fissile Areas $\ldots \ldots \ldots \ldots \ldots \ldots \ldots \ldots$

Appendix A - Summary of Criticality Accidents in Process Operations

Appendix B - References

Appendix C - Single Parameter Limits

Appendix D - Logic Diagram for Evaluating Fire Protection Where Fissile Materials are

Present 


\section{NUCLEAR CRITICALITY SAFETY GUIDE FOR FIRE PROTECTION PROFESSIONALS IN DOE NUCLEAR FACILITIES}

\subsection{SCOPE OF DOCUMENT}

This guide is intended to provide information for use by fire protection professionals in the application of reasonable methods of fire protection in those facilities where there is a potential for nuclear criticality. This guide may also be used by nuclear criticality specialists, risk analysts, and other safety professionals with interest in selecting alternate means of fire protection to balance the risks associated with facility fire and with nuclear criticality.

It is intended that this guide be applied to facilities which process, handle, or store fissile materials. Such facilities and operations may include, for example. reactor fuel operations, uranium enrichment operations, plutonium or uranium solvent extraction operations, Pu or HE recovery operations, and other similar operations. Fissile isotopes included in the scope of this guide are limited to ${ }^{233} \mathrm{U},{ }^{235} \mathrm{U}$, and ${ }^{239} \mathrm{Pu}$ as addressed by ANSI/ANS 8.1.

Operations involving intentional creation of chain reactions such as critical experiments or reactor operations are considered to be beyond the scope of this guide. However, other parts of these facilities are covered and some of the concepts included in this guide may be applicable. directly or indirectly, to such operations. Fissionable isotopes, such as neptunium, americium. curium. and other plutonium isotopes, are also beyond the scope of this guide. 


\subsection{INTRODUCTION}

Misunderstandings and miscommunications have often led to situations in which fire protection systems and activities have been viewed as reducing criticality safety. Similariy, the need to prevent criticality incidents has, in some cases, had an adverse impact on fire safety. This Guide will review and analyze historical data to show that:

1. Fire is a significant threat to DOE facilities

2. Fire protection systems, in particular sprinkler systems and standpipe systems, are needed to minimize the fire exposure.

3. The need to limit sprinkler protection usually resuits from failure to achieve criticality safety by preferred means.

4. Lack of sprinkler and standpipe systems results in larger fires requiring manual firefighting activities that discharge considerably more water in a more damaging form than sprinklers. 


\subsection{DEFINITIONS}

critical - fulfilling the condition that a medium capable of sustaining a nuclear fission chain reaction has an effective multiplication factor, $k_{\text {eff }}$, equal to unity. (DOE STDXXXX-93, Draft B, Nuclear Criticality Safety Guide for DOE Nonreactor Nuclear Facilities)

criticality - the condition of being critical. (DOE STD-XXXX-93, Draft B. Nuclear Criticality Safety Guide for DOE Nonreactor Nuclear Facilities)

criticality accident - The release of energy as the result of accidentally producing a selfsustaining or divergent neutron chain reaction. (ANSI/ANS 8.1)

double-contingency principle - a precept that requires designs to incorporate sufficient factors of safety to require at least two unlikely, independent. and concurrent changes in process conditions before a critically accident is possible. Protection is provided by either:

1. the control of two independent process parameters (which is the preferred approach, if practical) or

2. a system of multiple (at least two) controls on a single parameter.

In all cases, a single failure will not result in the potential for a criticality accident.

effective multiplication factor $\left(k_{\mathrm{cff}}\right)$ - The ratio of the total number of neutrons produced during a time interval (excluding neutrons produced by sources whose strengths are not a function of fission rate) to the total number of neutrons lost by absorption and leakage during the same interval. (ANSI/ANS 8.1)

fissile isotope - a nuclide capable of undergoing fission by interaction with slow neutrons.

fissionable isotope - any nuclide capable of undergoing fission by any process.

fission - the division of a heavy nucleus into two or more parts with masses of equal order of magnitude. usually accompanied by emission of neutrons. gamma radiations and. rarely, small charged nuclear fragments. (DOE STD-XXXX-93. Draft B, Nuclear Criticality Safety Guide for DOE Nonreactor Nuclear Facilities) 
. Vuclear Criticality Safety Guide For Fire Protection Professionals

In DOE Nuclear Facilities Draft B. June 30, 1994

risk - the quantitative or qualitative expression of possible loss that considers both the probability the hazard will cause harm and the consequences of that event. (DOE STDXXXX-93. Draft B, Nuclear Criticality Safety Guide for DOE Nonreactor Nuclear Facilities) 


\subsection{FIRE AND CRITICALITY RISKS}

Striving to achieve an optimum level of overall safety, the safety professional in any safety discipline must reach a balance among what may appear. at times, to be conflicting safety goals. The safety professional must consider the relative risk of various hazards and the alternatives in arriving at a reasonably safe solution.

According to H. C. Paxton in Critical Control in Operations will Fissile Materials, "Safety is an acceptable balance of risk against benefit; it is meaningless as a concept isolated from other goals." In his text, Nuclear Criticality Safety: Theory and Practice, Ronald Knief further elaborates, "Nuclear safety in fuel cycle facilities encompasses both criticality safety and radiation protection activities. General industrial safety and fire protection are also important adjuncts to overall facility safety. Each safety discipline tends to focus initially on the plant operations themselves, but then must interact effectively with the other safety activities."

The goal of this guide is to provide information to allow effective interaction between the - fire protection and nuclear criticality safety disciplines. With effective interaction, an acceptable balance of the fire and nuclear critically risks may be achieved. To provide some perspective on the relative risks of nuclear criticality and fires, the following sections discuss some of the hazards and risks associated with these perils.

\subsection{Discussion of Nuclear Criticality}

\subsubsection{Definition and description of criticality peril}

In order to effectively assess the relative safety risks of nuclear criticality and fire, it is important that the fire protection professional have a sound, basic understanding of nuclear criticality. The fire protection professional must clearly understand what a nuclear criticality is and what it is not.

A nuclear fission takes place when a heavy nucleus captures a neutron. becomes unstable, and splits or fissions into two or more smaller nuclei. The fission results in multiple "daughter" isotopes, release of energy in the form of gamma radiation, and the release of high energy neutrons. The average number of neutrons emitted per fission is energy dependent. Fissions occur naturally and somewhat regularly in many fissionable materials. 
The key difference between naturally occurring, non-critical fissions and critical fission incidents is the rate of neutron/nucleus interactions. In noncritical situations, the rate of leakage of neutrons is sufficiently high to preclude interaction of neutrons and fissile nuclei in a self-sustaining chain reaction. In a critical situation, the number of neutron/nucleus fission interactions is of sufficient numbers to sustain the fission process.

Thermal fission of ${ }^{235} \mathrm{U}$, for example, produces an average of 2.43 neutrons per fission. If more than 1.43 neutrons are lost from the system due to neutron leakage, or non-fission interactions with other nuclei, less than one neutron will be available to sustain the fission chain reaction. In such a situation, the system will remain sub-critical.

For fission to take place in tissile material. not only must there be a sufficient number of neutrons available for interaction with fissile nuclei. the neutrons must be at low enough energy or speed to interact with the nuclei. The neutrons must be slowed or thermalized to a low enough energy to interact with the fissile nuclei to result in fission.

A material which slows neutrons is known as a neutron moderator. Hydrogen is a very effective neutron moderator. Water, with its high hydrogen content, is a good moderator of neutrons.

Leakage of neutrons from a fissile material helps to prevent the continuation of the fission process within the material. Reflection of neutrons leaking from fissile materials back into the system will promote the fission process. Water molecules, which also "bounce" neutrons. tend to reflect escaping neutróns back into the system.

One index of criticality is given by the neutron multiplication factor. $\mathrm{k}$. The neutron multiplication factor is defined as the ratio of the number of neutrons in one generation (i.e.. period of time) to the number of neutrons in the justprevious generation.

$$
k=\frac{\begin{array}{c}
\text { number of neutrons } \\
\text { in one generation }
\end{array}}{\begin{array}{c}
\text { number of neutrons in } \\
\text { the } j u s t-\text { previous generation }
\end{array}}
$$


Since not all neutrons produced are available to interact within the system due to leakage of neutrons from the system, it is useful to have a measure of the neutrons which are available for fission in the system. This measure is known as the effective neutron multiplication factor, $\boldsymbol{k}_{\mathrm{efr}}$. The effective neutron multiplication factor is defined as the ratio of the neutron production rate to the neutron loss rate.

$$
k_{e f f}=\frac{\text { neutron production rate }}{\text { neutron loss rate }}
$$

When the neutron production rate and the loss rate exactly balance. $k_{\text {cff }}$ equals one, the fission is self-sustaining, and the system is critical. If neutron production rate is less than the neutron loss rate in the previous generation. $k_{\text {eff }}$ is less than one, and the system is subcritical. If the neutron production rate is greater than the leakage rate, $k_{\text {eff }}$ is greater than one, and the system is supercritical.

$$
\begin{array}{ll}
k_{\text {eff }}<1 & \text { subcritical } \\
k_{\text {eff }}=1 & \text { critical } \\
k_{\text {eff }}>1 & \text { supercritical }
\end{array}
$$

A nuclear criticality generally initiates as a rapid, short duration event. Typically, there is a "blue flash", a rapid release of neutrons and gamma rays, and release of fission products. Following a sharp spike of energy release during the initial excursion, accidental nuclear criticalities tend to be selflimiting and immediately shutdown the reaction. In aqueous solutions this is due to localized heating of the liquid which reduces the density of the moderator and the production of hydrogen and oxygen bubbles which produce voids which further reduces the moderator density. In some cases. a transient condition may be created, in which subsequent criticality events continue periodically over a period of time. The subsequent criticalities. following the initial spike. tend to be lesser magnitude than the initial spike.

In order for there to be a danger of a criticality to occur. there must be a fissile material present. For the purposes of this guide. this includes specific isotopes of uranium and plutonium. $\left({ }^{233} \mathrm{U},{ }^{235} \mathrm{U},{ }^{239} \mathrm{Pu}\right)$ There must be sufficient mass of 
of the fissile material present. In addition, the material must be in density sufficient for its volume to optimize the leakage of neutrons. Material shape is important in determining neutron leakage rate. Spherical shapes optimize the volume to surface areas thus minimizing neutron leakage. As mentioned previously, a water moderator and reflector of neutrons enhances the fission process. Factors influencing the potential for criticality are illustrated in Figure No. 1.

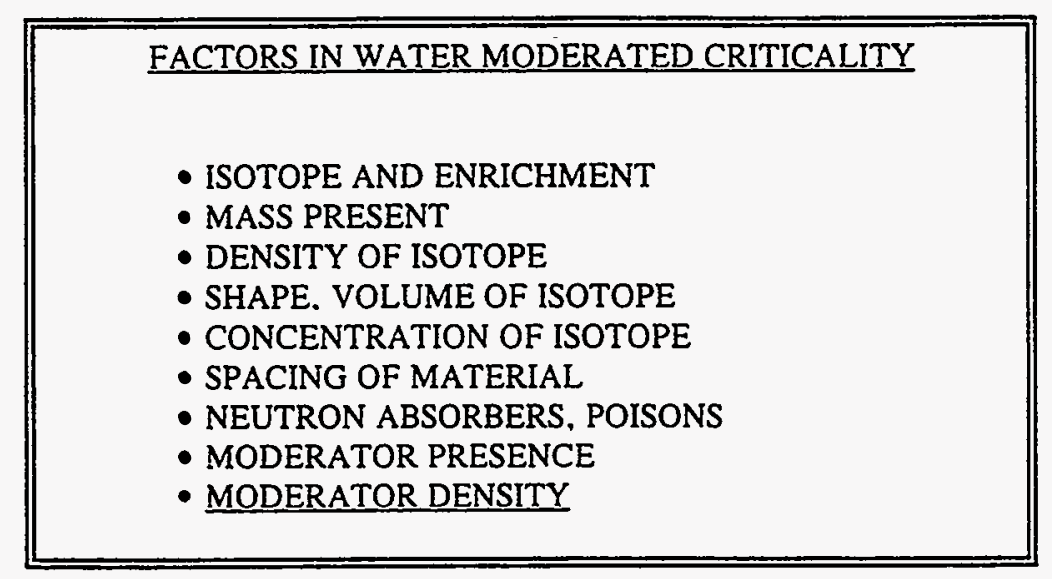

Figure 1

In his report, Criticality Control in Operations with Fissile Material, Paxton illustrates this concept:

"...Let us illustrate the various influences on criticality by limiting our attention to two common materials, enriched uranium and water. To start. we consider a critical sphere of $U(93)$ metal at normal density. The diameter of this sphere is about 6.9 in., corresponding to a volume of 2.8 liters and a total mass of about 52 $\mathrm{kg}$. If the same quantity of material is formed into a slab or an elongated cylinder, distances through which neutrons must scatter to reach a surface are decreased (the surface-to-volume ratio increases), so the chance that a neutron may escape from the material is increased. In other words. leakage is increased at the expense of fission and capture. so that the new shapes are subcritical. Returning to the sphere. if the size is maintained but the density of $U(93)$ is decreased, neutrons pass through less matter on their way to the surface. the chance of leakage is increased. and the new sphere is subcritical. Likewise, a decrease in ${ }^{235} \mathrm{U}$ enrichment at constant size and density decreases the chance of fission relative to leakage and capture, so that the sphere is again subcritical. 
Now, several different influences of water on our U(93) sphere will become apparent. If the sphere is immersed in water, some neutrons that would otherwise escape from the surface are scattered back into the fissile material, leakage is reduced. and the sphere is supercritical. Actually, the critical diameter of the uranium sphere drops to $5.3 \mathrm{in}$. (corresponding to 1.3 liters or $-24.5 \mathrm{~kg}$ of uranium). Of course, this neutron-return effect is by no means limited to water. Any material that surrounds fissile sphere will act similarly as a neutron "reflector."..."

It is important that the fire protection professional understand that, although the accidental criticality includes a rapid release of energy, it is not a nuclear explosion in the same sense as a nuclear weapon detonation. None of the criticality accidents which have occurred in process operations has resulted in any significant property damage and few resulted in any significant contamination. The limited consequences of criticality accidents is further discussed in Section 4.1.4 of this guide.

\subsubsection{History - Examples of Past Criticality Accidents}

According to Statton and Smith ${ }^{1}$. since the beginning of the nuclear industry, there have been only eight reported criticality events in process operations in the free world. Others have occurred in reactors and critical assemblies. A discussion of the process operations criticality incidents is included in this guide to provide background on those events to provide insight into the causẹ and consequences of some criticality incidents.

These eight accidents are summarized in Table No. 1 and are further discussed in Appendix.

:Stratton. W.R., and Smith. D.R.. A Review of Criticality Accidents, DOE/NCT-04, Lawrence Livermore National Laboratory. March. 1989. 


\begin{tabular}{|c|c|c|c|c|c|c|c|}
\hline \multicolumn{8}{|c|}{ CRITICALITY ACCIDENTS IN PROCESS OPERATIONS } \\
\hline DATE & I.OCATION & MATERIAI. & GEOMETRY & CAUSE & J:ISSIONS & DAMAGE & $\begin{array}{l}\text { MAXIMUM } \\
\text { PERSON } \\
\text { DOSE OR } \\
\text { EXPOSURE }\end{array}$ \\
\hline June 26.1958 & $\begin{array}{l}\text { X.12 Plant } \\
\text { Oax R1dgo, } \mathrm{Nk}\end{array}$ & $2.5 \mathrm{~kg}$ '”o n1tzato & 55-gal. drum & $\begin{array}{l}\text { rater added to } \\
\text { uranyl ontrato } \\
\text { solution }\end{array}$ & $1 \times 10^{11}$ & nono & $161 \mathrm{rem}$ \\
\hline Decembor 30, 1958 & $\begin{array}{l}\text { LASL } \\
\text { LOS Alamos, NM }\end{array}$ & $\begin{array}{l}3.27 \mathrm{~kg} \text { Pu } \mathrm{ln} \text { two. } \\
\text { phaso ayatem }\end{array}$ & $\begin{array}{l}250 \text { gal. } \\
\text { cylindrical tank }\end{array}$ & $\begin{array}{l}\text { st1rring chango } \\
\text { geometry }\end{array}$ & $1.5 \times 10^{11}$ & noino & $12,000 \mathrm{rem}$ \\
\hline October 26,2959 & $\begin{array}{l}\text { Icpp } \\
\text { Idabo }\end{array}$ & $\begin{array}{l}34.5 \mathrm{~kg} \text { mu } 1 \mathrm{n} 800 \\
\text { 1. water }\end{array}$ & $\begin{array}{l}\text { sooo gal. } \\
\text { cylindrical tank }\end{array}$ & $\begin{array}{l}\text { aolution } \\
\text { inadvortentiy } \\
\text { odphoned }\end{array}$ & $4 \times 10^{11}$ & none & $50 \mathrm{R}$ \\
\hline Jabuary 25, 1961 & $\underset{\text { IAdaho }}{\text { ICPP }}$ & $\begin{array}{l}\text { a } \mathbf{~ k g} \text { ' 'U } \\
\text { woter }\end{array}$ & $\begin{array}{l}2 \text { et diametor } \\
\text { cy } 11 \mathrm{l} \text {.der }\end{array}$ & $\begin{array}{l}\text { solution moved to } \\
\text { unsafo geonetry }\end{array}$ & $6 \times 10^{11}$ & none & $<200 \mathrm{mx}$ \\
\hline Apr11 7, 1962 & $\begin{array}{l}\text { Racuplex } \\
\text { Plait } \\
\text { Baaford. WA }\end{array}$ & $1.55 \mathrm{~kg} \mathrm{Pu}$ & 28 lach cylinder & $\begin{array}{l}\text { solution transfer } \\
\text { to large tank }\end{array}$ & $8 \times 201$ & none & $220 \mathrm{rem}$ \\
\hline July 24, 1964 & $\begin{array}{l}\text { United Nuclear } \\
\text { Coxp. } \\
\text { Hough River } \\
\text { Junction, RI }\end{array}$ & $2.64 \mathrm{~kg} \cdots \mathrm{v}$ & 18 lnch cylinder & $\begin{array}{l}\text { solution pourod } \\
\text { into unsafo tank }\end{array}$ & $1.3 \times 10^{11}$ & none & $10,000 \mathrm{R}$ \\
\hline August 24, 1970 & $\begin{array}{l}\text { BMPL Pu Plant } \\
\text { Hindscalo, gagland }\end{array}$ & $2.15 \mathrm{~kg} \mathrm{Pu}$ & cylinder & $\begin{array}{l}\text { Pu in trapped } \\
\text { solvent }\end{array}$ & $2 \times 10^{n 1}$ & none & 2 rads \\
\hline October 17,1978 & $\underset{\text { ICPP }}{\text { ICPO }}$ & $\begin{array}{l}20.5 \mathrm{~kg} U(89) \\
9.3 \mathrm{~kg} \times \mathrm{Ug}\end{array}$ & $\begin{array}{l}\text { cylindrical scrub } \\
\text { columa }\end{array}$ & $\begin{array}{l}\text { Mo strlpped tron } \\
\text { solvent }\end{array}$ & $3 \times 20^{11}$ & none & none \\
\hline
\end{tabular}

TABLE NO. 1 


\subsubsection{Frequency of Criticality Accidents}

In the fifty year history of the nuclear industry in the free world there have been only eight criticality accidents reported in processing operations. (See Figure No. 2) During the period from June, 1958 through July, 1964. the average frequency of criticality accidents was approximately one accident every 12 months. Since 1964, there have been only two reported criticality accidents and there have been none since 1978. While there is little statistical significance due to the small number of incidents, there has been an average frequency of criticality accidents of 0.16 criticality accidents per year (one accident every 6.25 years) for all fissile material processing operations over the fifty year history.

\subsubsection{Consequences}

The consequences of a criticality are a function of several factors. Some of those factors include whether the operation is hands-on or in a shielded facility, the magnitude of the excursion, the position of personnel at the time of the excursion, and emergency action which are taken in response to the incident.

There are some common characteristics of the consequences of the criticality accidents which have occurred. None of the incidents have resulted in any significant damage to process equipment or facilities. At most. the damage has been limited to clean-up of solutions in facilities designed for decontamination. 
Vuclear Criticality Safety Guide For Fire Protection Professionals In DOE Nuclear Facilities Draft B. June 30, 1994

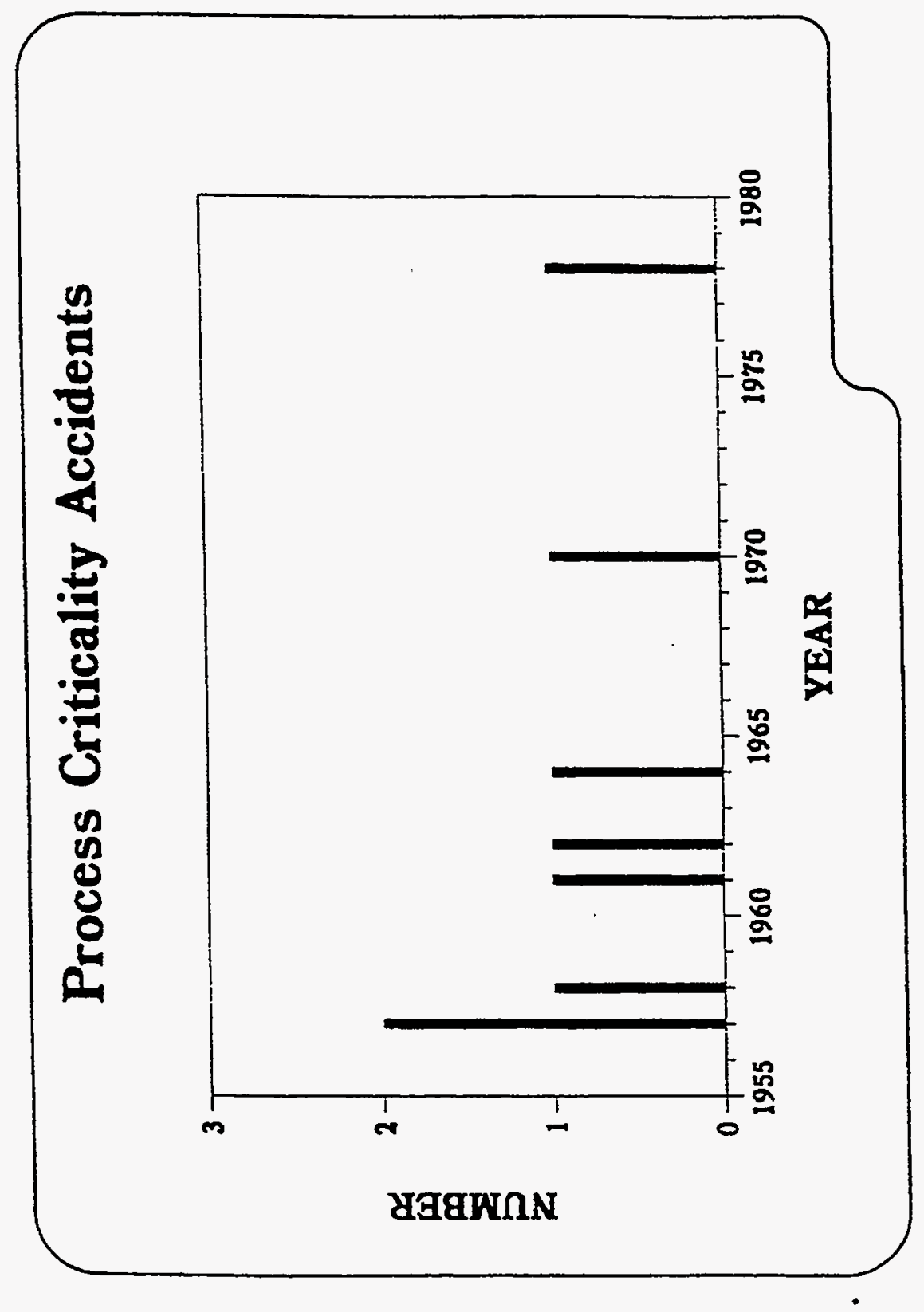

Figure No. 2 
A result of criticalities is the release of fission products and fission product radioactivity. In each of the cases the property damage consequences of fission product release has been negligible. There has been no significant contamination of facilities due to fission product release and environmental releases have been minimal. The magnitude of nuclear contamination due to dispersal and loss of confinement of special nuclear material has far exceeded the contamination due to fission products of the criticality.

Any accidental loss of human life is tragic. Every reasonable means must be taken to avoid accidental loss of life. Considering the number of fissile processes which have been conducted over the past fifty years, the fact that only two lives have been lost due to accidental nuclear criticalities in process operations is a testament to the care exercised in protecting nuclear facilities against accidents.

Beyond the two fatalities. the health and safety impact of criticality accidents on personnel has been very low. Due to distance, shielding, or the duration of the . exposure. the non-lethal radiation dose received by other personnel present at the time of criticality accidents have had no lasting effect on their health.

\subsection{Discussion of Fire Peril}

\subsubsection{Discussion of Industrial/Commercial Fire Problem}

Fire has a major impact on the U.S. economy and the safety of citizens. According to National Fire Protection Association statistics, there were 4,730 non-fire fighter deaths and 28.700 non-fire fighter injuries due to fires in the U.S. in 1992. Property damage due to fires in the U. S. in 1992 were estimated to amount to $\$ 8.295$ billion. Over $20 \%$ of the property damage by fires in the U. S. in 1992 was sustained in industrial, commercial, and special use properties. In 1992. ten catastrophic multi-death fires in non-residential structures (including industrial, commercial, and assembly occupancies) claimed 52 lives. DOEowned. contractor-operated facilities include a wide variety of types of occupancies. For the most part, occupancies which would be covered by this guide could be generally classified as industrial/commercial properties.

Fortunately, DOE has enjoyed a much more favorable fire history than other industrial/commercial groupings both in frequency and severity due to the "improved risk" level of fire protection provided at most DOE facilities. However, the DOE is not exempt from experiencing significant fires. 
Vuclear Criticality Safety Guide For

Fire Protection Professionals

In DOE Nuclear Facilities

Draft B, June 30, 1994

Some examples follow.

\title{
4.2.2 DOE History - Examples of Some Past Events
}

\author{
Rocky Flats Fire, Bldg. No. 776-777 \\ Mav 11, 1969
}

The most notable event, from a fire damage, potential personnel hazard, and potential nuclear criticality hazard. was the Rocky Flats fire of 1969. This fire is believed to have initiated in a lidless can containing plutonium in a glovebox and quickly spread to other combustible materials in the glovebox. The fire department received alarms from heat detectors in the facility at 2:27 pm.

Responding promptly, the fire department encountered dense smoke and congested conditions which hampered their ability to locate the fire and effectively direct fire fighting efforts. Because of a concern for potential nuclear criticalities, the use of water for fire-fighting had been prohibited except as a last resort. For this reason, automatic sprinkler protection had not been installed in this particular facility, although the new plutonium production facility, which was under construction at the time of the fire, was being provided with automatic sprinklers. Initial fire attack was made with carbon dioxide extinguishers but they were ineffective.

Fueled by plutonium and 600 tons of combustible shielding, and fanned by the uninterrupted ventilation system. the fire continued. unabated. Plastic glovebox windows burned out. The smoke plugged some filters which allowed the normal airflow to reverse direction. Plutonium oxide was released into the room.

Despite precautions against the use of water to fight fires in piutonium tacriities due to the concern for potential nuclear criticality. the fire chief. weighing the relative risks, made the command decision to use water less than ten minutes after the fire alarm was received. The fire department used fire water hose streams throughout the duration of the fire fighting effort. The fire. which spread extensively through the glovebox lines. was brought under control by $6: 40 \mathrm{pm}$. over four hours after the initial alarm.

Despite the extensive use of water delivered by fire hoses. and substantial quantities of fissile plutonium. no nuclear criticalities occurred. There were no lost-time injuries from the fire due to the fire-fighting efforts. Since the fire occurred on a Sunday, there were few people in the facility. Damage to the building and equipment was extensive. The fire was reported to have consumed nearly six tons of combustible material in addition to the combustion of 
plutonium. In addition to smoke and heat damage, the facility was heavily contaminated by plutonium. Plutonium was also tracked out of the building by fire fighters. There was detectable ground contamination but no evidence of plutonium contamination beyond the plant boundaries. The initial facility restoration cost was estimated to be $\$ 45$ million. Of that cost, about $\$ 26$ million is attributed to fire damage, clean-up, and Pu recovery.

Paducah Gaseous Diffusion Plant Fires November 11, 1956 and December 13,1962

Sprinkler protection was not provided in the gaseous diffusion buildings due to the lack of combustible contents and. what was believed a the time to be. noncombustible construction. On November 11. 1956, an intense. but localized. fire was initiated by a compressor gas seal leak. This fire subsequently ignited the combustible, built-up roofing system and spread throughout the building. As a result. the entire 67,000 sq. $\mathrm{ft}$. of the roof was destroyed. The total loss was $\$ 2,100,000$ : the fourth largest loss from all causes which had been suffered by the Atomic Energy Commission. One fire-fighter was seriously injured.

As a result of this major fire, full automatic sprinkler protection was provided for all gaseous diffusion buildings at three sites. Sprinklers were effective in limiting the loss due to an explosion which later occurred at the Paducah plant.

On December 13. 1962, an explosion occurred in a process cell at the Paducah plant. The automatic sprinkler systems. which are not designed to protect against explosions. responded to the energy released by the explosion and the hot steam which was generated. by the opening of 2341 sprinkler heads. The sprinklers controlled the fire such that only a single hose line was necessary to effect extinguishment. The explosion caused damage totaling $\$ 2,900.000$. It has been estimated that the loss would have been on the order of $\$ 160.000 .000$ if sprinklers had not been provided to prevent the propagation of an ensuing fire.

\section{Metallic Plutonium Fire}

In his book. Living with Radiation: Problems of a Nuclear Age for the Lavman. Vol. 2. Fire Service Problems, F. C. Brannigan. a former AEC fire protection engineer. described a "Small Metallic Plutonium Fire Leads to Major Property Damage Loss." A small amount of pyrophoric plutonium was reported to have spontaneously ignited in a dry box. A watchman discovered the fire which involved the plutonium, combustible parts of the dry box, and rubber gloves. Fire 
fighting was delayed because of the plutonium which was known to be processed in the facility. Carbon dioxide extinguishers were used without effect. Despite the uncertainty of the potential nuclear criticality effects, water spray was eventually applied to the fire and the fire was controlled.

Brannigan concluded that the significance of the incident was two-fold:

"The dry box fire discussed above had two serious consequences: (1) It allowed escape and dissemination of considerable plutonium contamination throughout the immediate area; (2) it also burned through the combustible CWS filter at the dry box permitting flames and some unburned combustible gases to pass through ventilating ductwork to the large main bank of filters which were of combustible type."

He also commented on the relative risks associated with such installations and the appropriate balance of precautions and protection which should be provided:

"It is quite probable the provisions of one or two automatic sprinklers within the dry box involved in the fire would have permitted earlier fire detection, much earlier establishment of fire control. and limited fire and contamination damage to immediate surroundings. The provision of automatic sprinklers admittedly may introduce new risk of contamination spread in water runoff and, in the case of fissionable materials, and danger of inducing an accidental criticality incident. The incident provides tangible evidence to support the belief that failure to provide automatic fire detection and control measure for radiological risks will in general result in a level of personal injury and property damage risks exceed that which would exist if automatic fire detection and control devices were used."

\subsubsection{Frequency - Statistical data}

Overall. the Department of Energy has enjoyed a favorable fire protection history. However. fires, including large loss fires, have not been infrequent events on DOE facilities. Former DOE Fire Protection Manager. Walter W. Maybee, collected. analyzed. and published information on fire frequency and severity in DOE/EP-0052. Automatic Sprinkler System Performance and Reliability in United States Department of Energy Facilities. 1952-1980. In his data base. Maybee included 633 fire protection-related incidents in DOE and predessor agency facilities. The data base did not include fires which resulted in "no loss" or property damage losses less than $\$ 1.000$. which are not required to be reported 
to DOE headquarters.

Maybee reported that. on average, the DOE experiences twenty-six fires which exceed $\$ 1,000$ in property in its facilities each year. He also analyzed the frequency and severity of DOE facility fires using extreme value projects and other statistical tools to project the recurrence period of fire losses. Graphical representation of Maybee's projections are included in this guide as Figures No.

3.

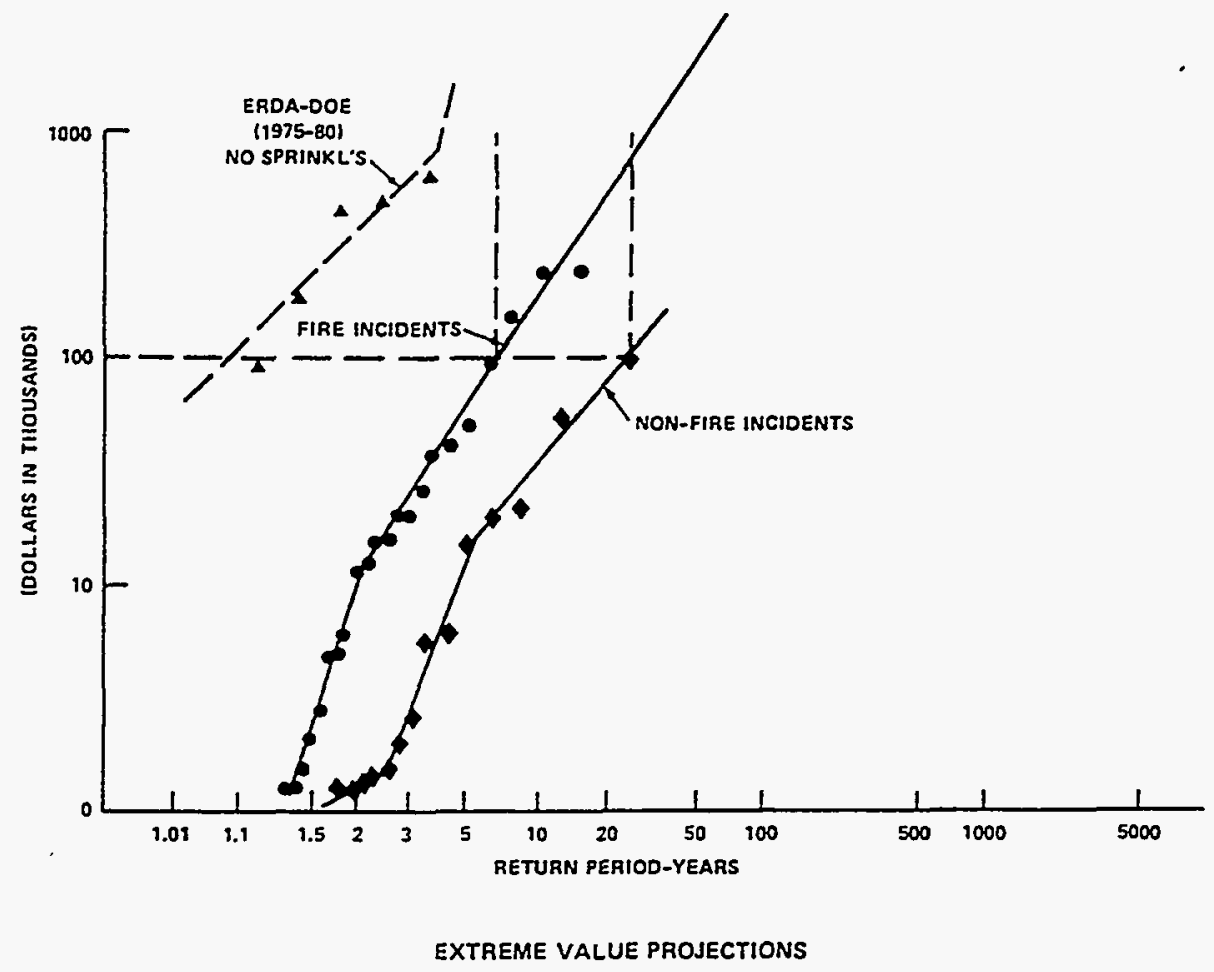

Note: Fire incidents include all property damage losses resulting from fires. Nisn-fire incidents are those property damage loss resultung from perils other than tire.

Figure No. 3 
Based on Maybee's extreme value projections, it is revealed that the projected frequency of fires exceeding $\$ 100.000$ value in DOE facilities is about $1.4 \times 10^{-1}$ per year or about once every seven years. For fire losses exceeding $\$ 1$ million, the projected frequency rate is about $3.3 \times 10^{-2}$ per year or about once every 30 years. Significant fires are not only credible events in DOE facilities, their recurrence rates are relatively high in risk assessment terms for moderate and high consequence events.

In addition to resulting in property damage, fires in DOE facilities result in personal injuries and deaths. In the same document. Maybee reports that there have been 20 fire deaths reported in DOE and predecessor organizations during the period from 1943 to 1980 . Thus. on average, there are 0.54 fire deaths per year. Historically, fire deaths occur slightly more frequently than one death every two years at DOE facilities

\subsubsection{Consequences}

From the above discussions, the consequences of fires, both historical and potential, should be clear. Fires endanger personnel, result in property damage and impaired operations, result in uncontrolled contamination. and. without quick and properly designed suppression, may result in accidental criticalities.

Personnel injuries are discussed in Section 3.2.3. of this guide. The frequency and magnitude of property damage losses due to fire are also discussed in previous sections of this guide. Figure No. 4 displays a summary of information on the cumulative impact of fires during the period 1952 through 1980. These subjects need not be further elaborated upon in this section. 


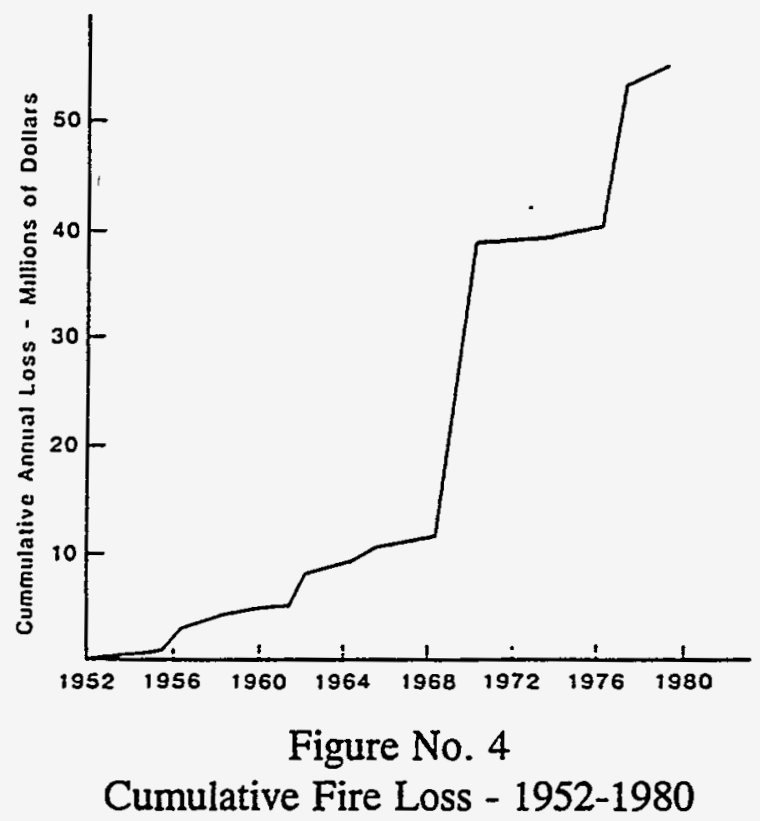

Fires may also constitute a design basis accident. Fires are likely to be a cause of spread of nuclear contamination. Fires can result in the breach of confinement enclosures due to burn-through or failure of gloves, viewing panels, or other primary barriers. Fires can also seriously impact the performance of active ventilation systems design to preclude release of radioactive materials.

Smoke and large soot particles associated with the burning of hydrocarbons may quickly clog filter media. Such clogging of filters, and subsequent overpressurization of the filters. can and has resulted in breaching of filters and release of radioactive contamination.

Ventilation systems designed for confinement control can handle air-flows and pressure transients under normal conditions and limited range of abnormal conditions. Hot, expanding gases resulting from energy released during fires. as well as the production of large quantities of smoke and volatiles from the fire, concurrent with impairment of the ventilation system due to fire products. can result in pressurization of the confined volume and unanticipated and uncontrolled flow reversals.

Air-borne contamination is difficult to control. The ability to control 
contamination can be significantly impacted by a fire and the potential to effect control seriously diminished if early fire intervention is not provided.

Fires may also result in accidental criticalities. Some examples of fire consequences which may lead to criticality accidents are discussed in Section 6.0 of this guide.

\subsection{Discussion of Fire Suppression Systems}

\subsubsection{DOE History}

The history of performance of automatic sprinkler systems in government-owned nuclear facilities is well documented. The previously cited Maybee report documents the performance of sprinklers. which are the principle fire protection system used to protect nuclear facilities since the founding of the Atomic Energy Commission in 1947. The data collected and analyzed in that report include nearly 600 fire protection-related incidents and over 100 fires. The performance of automatic sprinkler systems, as documented by Maybee, an summarized blow, has been outstanding.

\subsubsection{Statistical Data on Sprinkler Systems}

\subsubsection{Successful Operation}

The Maybee report confirms that automatic sprinkler systems have been extremely successful in controlling fire losses in government nuclear facilities. The data demonstrate that automatic sprinkler systems are more than $98 \%$ effective in controlling or extinguishing fires. Contrary to some popularly held beliefs fostered by and misrepresented by the Motion picture and television industries. most fires do not result in the operation of large numbers of sprinkler heads and do not result in massive releases of water. About onethird of all fires occurring in sprinklered, government nuclear facilities were completely extinguished by the operation of a single sprinkler head. Greater than $92 \%$ of all fires were controlled or extinguished by the operation of six or fewer sprinkler heads.

Furthermore. there has been no loss of life due to fire in sprinklered, government nuclear facilities.

The magnitude of property damage losses from tire in a sprinklered building is 
Nuclear Criticality Safety Guide For

Fire Protection Professionals

In DOE Nuclear Facilities

Draft B, June 30, 1994

about one-fifth of the losses in unsprinklered buildings. This fact is particularly significant in light of the fact that it is the facilities which have a high loss potential which are provided with automatic sprinkler protection.

\subsubsection{System Failures}

The Maybee study reported only two cases where an installed sprinkler system did not control or extinguish fires. One involved a dust collector for which the sprinkler system control valve had been shut due to cold weather and in which pyrophoric dusts spontaneously ignited. The second involved a massive failure of a large electrical transformer which broke a 3-inch sprinkler main which prevented the systems from controlling the ensuing fire.

The fact that automatic sprinkler systems are not prone to frequent inadvertent actuations has been supported by studies by the National Fire Protection Association, the Center for Fire Safety Studies at Worcester Polytechnic Institute, the Electric Power Research Institute, and the U.S. Department of Energy.

The previously cited Maybee report also addresses reliability and presents a high degree of statistical significance. The investigation included over 4200 sprinkler systems. In terms of operating history, it included 30.000 systemyears or 4.7 million sprinkler head-years of experience. The data analysis included both the effectiveness of sprinkler operations to control fires and the reliability of sprinkler systems to remain functional without inadvertent operation.

Among other topics, the Maybee report addressed "failure" or leakage of closed-head sprinklers. Established by the vast data base. it was concluded that the probability of a sprinkler head failing due to leakage from all causes is $2.2 \times 10^{-6}$ per year. In risk assessment terms this represents an extremely low frequency event.

To put this in perspective. many risk analysts consider events with a probability of occurrence of $1 \times 10^{-6}$ per year or less as "incredible" and need not be addressed in quantitative risk assessments. On this basis. the likelihood of an individual sprinkler head leaking is considered to be barely credible.

A similar study was conducted by Mr. Edward A. Sawyer at the Center for Fire Safety Studies at the Worcester Polytechnic Institute. Mr. Sawyer's 
Master of Science Thesis was Failure Analysis of Inadvertent Operations of Fire Protection Systems Including Design Recommendations. Sawyer's study included 556 inadvertent actuations of fire protection systems as reported by the U.S. DOE, the Institute for Nuclear Power Operators, the U.S. Nuclear Regulatory Commission. and through personal communications with fire protection professionals in the nuclear power industry. Sawyer's investigation included all causal affects including adverse environmental conditions. Based on his study, Sawyer concluded that the probability of inadvertent opening of a fusible element of a sprinkler head is $1.2 \times 10^{-6}$ per year. This reported probability is the same order of magnitude as cited in the DOE report.

A third major study was conducted on behalf of the Electric Power Research Institute. This report was published in 1985 as EPRI NP-4144, Turbine Generator Fire Protection by Sprinkler Systems. Among its many conclusions regarding sprinkler system reliability, the EPRI report concluded that the probability of fusible link operated sprinkler head failing in the open position is $9.8 \times 10^{-6}$ per year. Independently. this study found the probability of sprinkler head leakage to be of the same order of magnitude as the other two studies.

Inadvertent operation of closed-head sprinkler systems do occur, but the frequency of such occurrences can be predicted on a finite frequency. Data support the fact that the probability of a single. closed-head failing and discharging water in the absence of a fire is so low as to be practically incredible.

While the statistical reliability of a wet-pipe sprinkler system is exceptionally high, the reliability of a sprinkler system to preclude inadvertent discharge of water can be further enhanced by the provision of a pre-action sprinkler system. Pre-action systems are designed primarily to protect properties where there is a serious danger of water damage in the unusual event that water may be inadvertently be released due to sprinkler head or piping failures. In the pre-action system. closed-head sprinklers are used and a control valve holds back water from the sprinkler piping. It requires the independent operation of a sprinkler head or pipe failure -AND- accuation of a separate fire detection system to open the control valve before water will be discharged. The resultant combined probability, i.e.. the probability of a pre-action sprinkler system inadvertently discharging water. is $1.08 \times 10^{-8}$ per year. (See Figure No. 5.) 


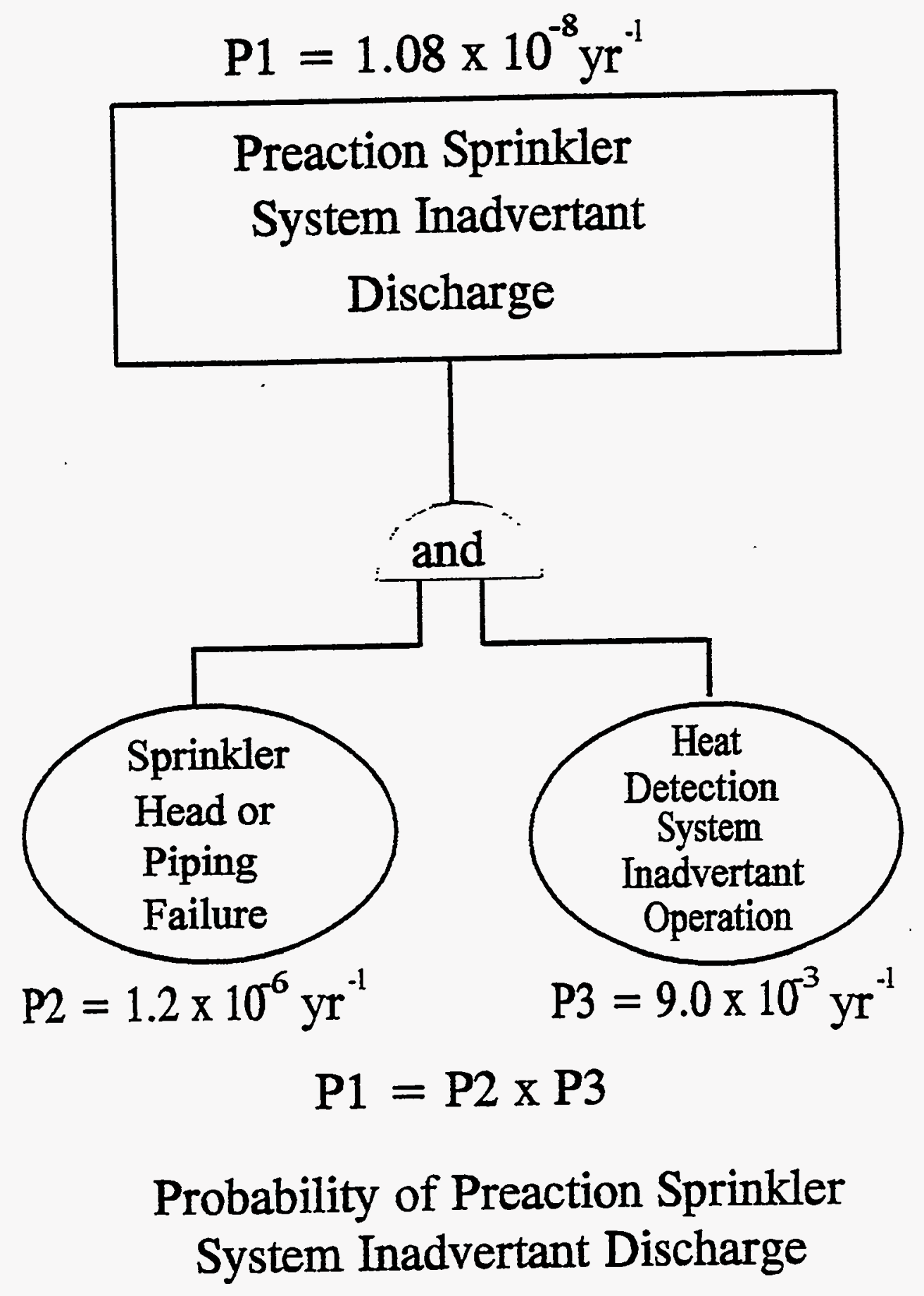

FIGURE NO. 5 
The EPRI study presents similar data for a pre-action system. That report states that the combined probability of inadvertent pre-action valve actuation due to spurious operation of a heat detector and a fusible sprinkler head failing in the open position is less than $10^{-8}$ per year. Both the Sawyer and EPRI studies conclude that the generic probability of a pre-action system failing in such a manner as to result in discharge of water under non-fire conditions is far below the accepted criteria for credibility. The drawback. however. of a pre-action system is that sprinklers, detectors, and control valves must all function properly to control a fire. reducing the probability of success. Therefore pre-action should be used only where water damage is an overwhelming concern.

\subsubsection{Non-fire Water System Failures}

The Maybee study also addressed "water damage" incidents due to sprinkler systems as compared to damage due to failures of other, non-fire protection, water systems. The study evaluated sprinkler system water damage incidents and non-fire protection water system damage incidents reported in the DOE during the period 1970-1980. The data show that, the number of non-fire protection water damage incidents exceeds the number of sprinkler system water damage incidents by a factor greater than 1.5. Furthermore, the average water damage loss reported for non-fire water system incidents was more than four times that of sprinkler system water damage incident. Only two of the sprinkler water damage losses exceeded $\$ 10,000$, whereas six non-fire system losses exceeded $\$ 10,000$. Not only do non-fire water system leakage incidents occur at a higher frequency than fire protection leakage incidents. the magnitude of the impact of non-fire water system leakage incidents is much greater.

There may be a number of factors which result in the much higher reliability for sprinkler systems. Among them are:

1. Automatic sprinkler systems are almost universally designed as engineered systems. Nearly all sprinkler systems are designed by cognizant professional engineers or certified technicians in accordance with stringent NFPA standards. Many other plumbing systems are not designed and installed under the same level of engineering and design . attention. 
Vuclear Criticality Safety Guide For

Fire Protection Professionals

In DOE Nuclear Facilities

Draft B, June 30, 1994

2. Sprinkler system components are required to be listed or approved by nationally recognized testing laboratories. This help to assure high quality and reliability of components. For example, UL 199 Standard for Automatic Sprinkler Heads requires that sprinkler head specimen be tested for not only for performance in response to fires but also for reliability to prevent inadvertent operation. Among the supplemental tests required by UL 199 are 875 psi hydrostatic tests, 30-day cycle water hammer tests, $1500 \%$ overload strength test for the heat responsive element, cold soldering tests, and operating temperature tests. Few, if any, standard plumbing fixtures are so rigorously tested and qualified.

3. The NFPA has rigorous standards for inspection and test of sprinkler systems. New installations are inspected and tested at a minimum of $200 \mathrm{psi}$ for two hours with no allowable leakage. All sprinkler systems are required to be inspected and functionally tested at least quarterly. Non-fire protection water systems are not tested and inspected as vigorously as fire protection systems.

4. Sprinkler systems are usually provided with continuous supervision. If an abnormal condition occurs, such as the flow of water, an immediate signal is sent to a constantly attended location and emergency personnel dispatch to take appropriate action, reducing the potential for severe damage.

\subsubsection{Consequences Of Fire Suppression System Actuations}

The consequences of water discharge on the potential for nuclear criticality are much the same regardless of whether the water is from fire protection or non-fire protection sources. As cited in the previous section of this guide, the quantity of accidental discharge from non-fire water systems is generally much greater than that for fire water systems. Two factors control the quantity of water discharge in the unlikely event of an inadvertent actuation of a sprinkler head:

1. For closed-head sprinkler systems, when one sprinkler head actuates. all other sprinkler heads do not actuate simultaneously. While this fact is obvious to the fire protection professional, it is not obvious, and may need to be explained, to persons not familiar with sprinkler systems. Thanks to Hollywood and television. it is a very widely held belief that in the event of a fire or other actuating influence, all sprinkler heads discharge simultaneously, as in the case 
of an open head deluge system. This contributes to the unfounded fear of "flooding" with huge quantities of water from closed-head sprinkler systems.

2. Sprinkler heads actually limit the rate of flow from sprinkler systems. The carefully calibrated orifice of sprinkler heads provides at throttle on water flow. While fire protection professionals are cognizant of this factor in designing systems for minimum discharge rates. this factor needs to be expressed in terms of maximum discharge rates with respect to flooding concerns.

For example: A single, 1/2-inch nominal sprinkler head may be connected to a water supply system with a static pressure of 140 psi and with a fire pump rated at 2000 gallons per minute and a churn pressure of $100 \mathrm{psi}$. Someone not familiar with fire protection systems may be concerned that the sprinkler head will discharge up to $2000 \mathrm{gpm}$. This is obviously not the case. Due to the throttling by the orifice. a sprinkler head on such a system could never discharge at a rate greater than about $66 \mathrm{gpm}$.

The potential consequences water discharge on nuclear criticality are likely to be the same regardless of whether the water comes from non-fire protection systems or from fire protection systems and regardless of whether a fire protection system water discharge is due to accidental release of water or due to discharge in response to an actial fire. Factors which influence the effects of water discharge on fissile materials in amounts and forms for which water may affect the neutron multiplication factor include the depth of water accumulation, the film thickness of water which may be achieved. the size of water droplets. and the density of water mist.

For open floor areas, it is very unlikely that water discharged from fire protection systems would accumulate to a depth which would result in an accidental criticality in combination with the release of fissile solutions. The estimated critical. infinite slab thickness of homogeneous, water-moderated solutions of ${ }^{235} \mathrm{U}$ is greater than $4 \mathrm{~cm}$. (over 1-1/2 inches). The estimated critical. infinite slab thickness of homogeneous. water-moderated solutions of $\mathrm{Pu}$ is greater than $5 \mathrm{~cm}$. (over 2 inches).

Thicknesses less than these will not result in criticalities. These allowable slab thicknesses assume a homogeneous solution of the fissile material throughout the liquid. It is unlikely, even assuming release of the tissile material into the water. that homogeneity would be achieved. Fire protection water would likely reduce 
the concentration of fissile nitrate solutions. thus lowering the density of the fissile material. The result would be that an even thicker slab thickness would be required prior to any accidental criticality occurring.

The above applies to fissile solutions. The same, and greater magnitudes of water reflector thickness apply to fissile metals. For example, empirical data ${ }^{2}$ indicate a sphere of up to $5.79 \mathrm{~kg}$ of metallic Plutonium with $5.2 \mathrm{wt} \%{ }^{240} \mathrm{Pu}$ can be immersed in greater than $30 \mathrm{~cm}$. (11.8 in.) of water without exceeding critical limits.

As a non-viscous liquid, water does not naturally accumulate to depths approaching these limits. In the absence of a source of confinement, water will not collect to depths which would adversely impact the potential for a nuclear criticality. Where artificial water confinement systems are provided. the depth, area, and volume can be adjusted and optimized to accommodate criticality and other limits. Where sumps, drains, or other localized water accumulation points exist where both water and fissile materials may commingle, the size of the sump may be adjusted to not exceed critical dimensions or a neutron poison such as borosilicate glass rachig ring may be provided to prevent criticality.

For a criticality to occur in a layer of water, it would be necessary that the water be at a depth greater than the infinite slab thickness, that the fissile material in an amount and density be released into the water, and that the fissile material be homogeneously distributed in solution. This combination of events (water discharge plus slab thickness exceeded plus fissile material release plus homogeneous solution), while possible. is unlikely.

Water may also accumulate as a film on vertical surfaces. Low adhesion and low viscosity of water result in very thin water film thicknesses being developed. Fire protection research into the ability of water discharged from automatic sprinkler systems to provide a coating over surfaces has been performed by the Factory Mutual Research Corporation. Factory Mutual reported that the maximum film thickness achieved in the research, discharging plain water at a rate of 0.50 gallons per minute, per square foot. was approximately $0.55 \mathrm{~mm}$. This water thickness is considered to be negligible.

Individual water droplets discharged from automatic sprinkler systems are also of

2Paxton. H.C.. and Pruvost. N.L.. Critical Dimensions of Systems Containing ${ }^{235} \mathrm{U}$. ${ }^{239} \mathrm{Pu}$, and ${ }^{233} \mathrm{U}, \mathrm{LA}-10860-\mathrm{MS}$. Los Alamos National Laboratory. 1987. 
definable nominal size. The deflector on standard-spray, automatic sprinkler heads is designed for efficient distribution of water droplets for fire fighting purposes. Factory Mutual Research Corporation as measured sprinkler drop sizes and has found that the median drop size for $1 / 2$ inch sprinklers discharging at 30 psi is $0.86 \mathrm{~mm}$. Further, Factory Mutual has demonstrated that the median drop size for $1 / 2$ inch sprinklers varies inversely with the one-third power of the pressure. Thus. median drop sizes can by calculated by the expression:

$$
d_{m}=(0.86)\left(30 / P_{0}\right)^{1 / 3}
$$

Where:

$$
\begin{aligned}
& \mathrm{d}_{\mathrm{m}}=\text { median drop size }(\mathrm{mm}) \\
& \mathrm{P}_{0}=\text { operating pressure.(psi) }
\end{aligned}
$$

It is not these small, individual drop which have much influence on moderation and reflection of neutrons but rather it is the integrated effect of the water mist. Standard calculational methods allow nuclear criticality safety specialists to calculate the effects of water mist densities on the potential for nuclear criticality. For most fissile material configurations, the density of the water mist has an insignificant effect on the neutron multiplication factor. For some arrays, particularly arrays of low-enriched uranium, light-water reactor fuel assemblies, low density water moderation may be of some interest. For those situations, the maximum water mist density which may be created by the discharge of a sprinkler system may be calculated by a fire protection engineer knowledgeable in hydraulics and sprinkler operating principles. This information can be shared with the nuclear criticality safety specialist to assure that safe margins are established in the event of discharge of water from sprinkler systems.

Various generic studies of sprinkler system mist densities for fissile arrays have been published and are listed in the references in Appendix B of this guide. There is general agreement in the literature that the maximum density of a water mist created by sprinkler systems is not likely to exceed an order of magnitude of $10^{-3}$ $\mathrm{g} / \mathrm{cm}^{3}$. This density is generally too low to affect most fissile arrays. 
Nuclear Criticality Safety Guide For

Fire Protection Professionals

In DOE Nuclear Facilities

Draft B, June 30, 1994

\subsubsection{Calculation of Sprinkler Mist Densities}

It is possible to estimate actual sprinkler mist densities which may be achieved in a particular area but specific variables must be addressed. The available water supply will affect the pressure at which the sprinkler head operates as well as the total volume of water which may be discharged. The water supply may vary from a few hundred gallons per minute at 50 psi for a gravity water system to several thousand gallons per minute at over 100 psi for a highly protected industrial facility. The piping arrangement, including the size and length of piping and fittings, may be important in determining hydraulic losses. Room size and height may affect sprinkler spray distribution. The sprinkler head type will influence the discharge rate. The sprinkler spacing will determine the amount of overiap of spray patterns. All of the above factors may need to be evaluated in determining the anticipated sprinkler density.

In order to simplify calculations, it may be necessary to make certain assumptions. In each case, the assumptions result in errors on the conservative side, that is, the calculated mist densities will be higher than those anticipated under actual conditions.

A simplifying assumption which might be made is that there is no hydraulic pressure loss due to friction loss in the piping. Losses in piping will result in lower pressures and thus result in lower discharge rates. Neglecting piping losses results in calculated discharge densities which will be higher than actual. If deemed necessary, more realistic discharge rates can be estimated using friction loss formulas for pipe losses. Fire protection engineers routinely include such calculations in determining sprinkler discharge rates.

Most fires are controlled by the operation of two sprinkler heads. or less. Single head sprinkler operation results in the highest per head discharge rate. However, in the worst case, it should be assumed that multiple heads operate. This results in overlapping of discharge patterns and in localized, higher density regions. Depending upon sprinkler spacing, as many as four to six spray patterns may overlap.

Fall times for droplets within the sprinkler mist can be estimated as a function of drop size, or more fundamentally as a function of the water pressure. and sprinkler height. Experimental terminal velocities for drops in air vary from $4.054 \mathrm{~m} / \mathrm{s}$ for $1 \mathrm{~mm}$ droplets to $9.296 \mathrm{~m} / \mathrm{s}$ for $5 \mathrm{~mm}$ droplets. 
With the proper input data and assumptions, further calculations are not complex. Water discharge rates are proportional to the square root of the water pressure. The volume through which the discharge occurs can be approximated by that of a paraboloid defined by the discharge area and height of the sprinkler head. The volume rate of discharge of water from the sprinkler head distributed throughout the voiume enclosed by the discharge pattern indicates the water/air density which is present due to sprinkler discharge. The resultant density must be further adjusted for overlap of discharge patterns from individual sprinkler heads.

While calculations may be relatively straightforward, they do require careful consideration of the significant input variables as well as knowledgeable application of reasonable assumptions. With this in mind. it is recommended that evaluation of anticipated sprinkler mist densities in air be performed by experienced fire protection engineers knowledgeable in sprinkler system hydraulics and water discharge dynamics.

\subsection{Discussion of "Risk"}

\subsubsection{Definition}

In a quantitative sense. risk is a function of the probability of loss or injury to people and property and the magnitude of the consequences of the loss or injury. Risk may be expressed as the product of the frequency and magnitude of undesirable consequences:

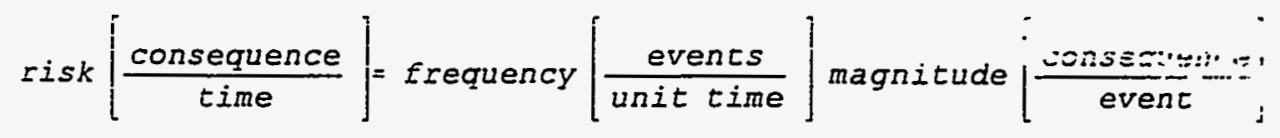

In nuclear risk assessment usage, there is general acceptance that risks which occur with a frequency less than $10^{-6}$ events per year are considered to be. "incredible" and need not be further addressed. regardless of their consequence. This is not intended to infer that such events will not happen. but rather is intended to suggest a risk acceptance level where it is not deemed economically prudent to pursue further risk reduction.

In dealing with quantitative risk expressions. the fire protection protessional and the nuclear criticality specialist need to be aware of the subtle differences in the expression of risk as described in the paragraph above. The conventional wisdom 
Nuclear Criticality Safety Guide For

Fire Protection Professionals

In DOE Nuclear Facilities

Draft B, June 30. 1994

of the general population is that sprinkler systems leak and accidentally discharge water under conditions other than fire. Given the very large population of automatic sprinkler systems installed in the U.S., this is a very true observation. However, on an individual fire protection system installation basis, the probability of a sprinkler system discharging is so extremely low, as cited in Section 4.3.2.2 of this guide, as to be approaching the incredible.

\subsubsection{Criticality Frequency vs. Consequences}

As reported in Section 4.1.3 of this report, the overall frequency of criticality accidents in processing facilities is low, with a mean occurrence frequency of one event per 6.25 years. The consequences of criticality accidents has been very low. Section 4.1 .4 of this guide discusses the consequences of nuclear criticalities. Direct property damage and nuclear contamination resulting from accidental criticalities has been minimal. There has been no reported off-site contamination from accidental criticalities, thus the health of the general population has not been adversely affected by these accidents. There have been two fatalities as a direct result of radiation exposures from process criticality accidents. Beyond the two fatalities, other workers health has not been significantly impacted by these events.

Every effort should be made to avoid a criticality accident. However, it must be kept in mind that the frequency of accidental criticalities is low and the consequence of accidental criticalities is very low. The resultant overall risk of criticality events is very low.

\subsubsection{Fire Frequency vs. Consequences}

Section 4.2 .3 of this guide addressed the frequency of significant fires in the DOE. Fires are high frequency events with an average of 26 significant fires reported annually. Many others are controlled or extinguished before reaching significant size. Large loss fires, those resulting in property damage in excess of $\$ 100,000$, have a frequency of recurrence of $1.4 \times 10^{-1}$ events per year and catastrophic fires, those resulting in damage in excess of $\$ 1$ million, have a projected frequency of recurrence of $3.3 \times 10^{-2}$ per year. Fires have. historically, had significant impact. Fires contribute to the spread of nuclear contamination and may contribute to the likelihood of an accidental nuclear criticality.

Fires are high frequency and high consequence events. The combined effect is that fire is high risk peril. 


\subsubsection{Combined Risk}

Although critical experiments are beyond the scope of this guide. a criticality incident and a fire which occurred in a Hanford Works facility in 1951 provides an interesting perspective. On November 16, 1951, a critical experiment was being conducted with $1.15 \mathrm{~kg}$ of plutonium in the form of plutonium nitrate in a 20 inch diameter, unreflected aluminum sphere. As a result of over-withdrawal of the control rod, a criticality of $8 \times 10^{16}$ fissions occurred prior to reinsertion of the cadmium rod by the scram circuit. As a result of the criticality, there were no personal injuries and no significant property damage, although there was some contamination due to leakage of the plutonium nitrate solution. The facility had been nearly decontaminated within a few days when a fire occurred involving nitric acid soaked rags in the facility. Although the criticality did not damage the facility, the fire resulted in abandonment of the building.

Both the fire safety and nuclear criticality safety disciplines share a common external perception. Both disciplines are perceived as constraining productivity. All safety disciplines need to weigh the needs to provide a safe working environment against the operational needs of the DOE missions. They also need to weigh the relative weights of the safety risks presented by various hazards, including those which exist outside of their primary areas of responsibility.

In generic sense, the facts presented in the preseding two sections indicate that the fire risk far exceeds the risk of accidental nuclear criticality. It must be recognized, however, that this generic conclusion cannot be arbitrarily applied to individual facilities. Each facility handling fissile material must have specific evaluations of the fire and criticality risks presented in order to assess the relative risk of each peril so that intelligent protection decisions can be made. Section 7.0 of this guide presents a methodology for assessing fire and criticality risks as a decision tool in determining an appropriate level of fire protection to be provided in facilities handling fissile materiais. 
Nuclear Criticality Safety Guide For

Fire Protection Professionals

In DOE Nuclear Facilities

Draft B. June 30, 1994

\subsection{FIRE SAFETY AND CRITICALITY SAFETY REOUIREMENTS}

\subsection{Criticality Safety}

The DOE provides requirement and guidance on nuclear criticality safety in DOE Orders. referenced national consensus standards, and DOE guides. DOE Orders 5480.4 .5480 .24 , and 6430.1 each address some aspects of nuclear criticality safety.

DOE 5480.4, 5-15-84, Environmental Protection. Safety and Health Protection Standards, establishes the ES\&H standards applicable to DOE operations. Attachment 2 to that Order establishes standards which are mandatory as policy requirements. ANSI N16.1-197.5, "Safety Standards for Operation with Fissionable Materials Outside Reactors" is designated as a mandatory standard. (Note. ANSI N16.1 was redesignated as ANSI/ANS 8.1 in 1983 and reaffirmed as ANSI/ANS 8.1 in 1988.) Attachment 3 to DOE 5480.4 includes referenced standards as good practice to be followed in DOE racilities. ANSI/ANS 8.7-1975, "Guide for Nuclear Criticality Safety in the Storage of Fissile Materials."

Up until the adoption of DOE 5480.24, Nuclear Criticality Safety, in 1992, the ANSI/ANS standards provided the only stand-alone requirements for nuclear criticality safety. On February 17,1993. DOE Office of Nuclear Safety Policy and Standards furnished Interpretive Guidance for DOE Order 5480.24. Together, DOE 5480.24 and the Interpretive Guidance must be consulted for current DOE policy on nuclear criticality safety. There is nothing in this fire protection guide which conflicts with DOE 5480.24 and the interpretive guidance on that order. Some significant aspects of the Order and guidance are included in this fire protection guide.

Contractors are required to comply with the mandatory criteria contained in the ANS 8. standards. (Section 7.)

The "double-contingency principle" in ANSI/ANS 8.1 4.2.2 has been modified to be a mandatory requirement, not a recommendation. (7.a.(2)(a) It requires:

Process designs shall incorporate sufficient factors of safety to require at least two unlikely, independent, and concurrent changes in process conditions before a criticality accident is possible. Protection shall be provided by either (a) the control of two independent process parameters (which is the preferred approach. if practical) or (b) a system of multiple (at least two) controls on a single parameter. 
In all cases, no single failure shall result in the potential for a criticality accident. The basis for selecting either approach shall be fully documented.

This principle is exceptionally important from the fire protection/criticality safety risk evaluation standpoint. Under such a principle, discharge of fire protection water. byitself, should not result in a condition which would create an unsafe condition from a criticality standpoint. Under this principle, it would require that some other parameter be also changed prior to a potentially unsafe condition occurring. For example. in addition to the discharge of water. there would have to be a concurrent change such as the release of fissile material from its container. or a concurrent breach of a fissile material container allowing in-flow of water, or a change in shape, concentration or density of fissile material. or other similar change.

Further, where a pre-action sprinkler system is provided, it would, by definition, meet the requirements for double-contingency failures. Under non-fire conditions, a pre-action system will not release water unless the piping system is breached and an independent actuation of the heat detection system occurs.

The "geometry control" recommendation of ANSI/ANS 8.1, 4.2.3, is also modified by 5480.24 (7.a.(2)(b) to be a mandatory requirement:

"As a first priority, reliance shall be placed on equipment design in which dimensions of the contained fissionable material and spacing between equipment are limited by passive engineering controls. Where geometry control is not feasible. the preferred order of controls is other passive engineering controls. active engineering controls, and administrative controls. . . The basis for not selecting geometry control shall be fully documented."

This requirement also has significant implications of fire protection/nuclear criticality safe evaluations. It is required that, where practical, fissile systems rely on geometry control, not moderation control, to achieve criticality safety.. In such as system. the system remains critically safe under all conditions of moderation. including all conditions resulting from the application of water during fire fighting activities. An exception to the use of geometry control must be fully documented.

Section $7 . c$ of 5480.24 requires that contractors provide fully documented. detailed criticality safety analyses for fissile operations. Some of the pertinent items required to be included in the document analysis are summarized below:

1. A description. using appropriate sketches or drawing, of equipment and facilities 
in which the hazard of criticality exists. This information may be useful to the fire protection engineer in developing an effectual fire hazard analysis and in providing assistance to the criticality safety specialist. It may also be useful to fire emergency response personnel in establishing pre-emergency plans for fire response.

2. A statement of the chemical an physical form of fissionable material and degrees of moderation. This information may also be useful to the fire protection professional in cooperating with the criticality safety specialist in an integrated approach to fire and criticality safety.

3. A statement of the maximum quantities of fissionable material. Useful information for use in the screening methods outlined in Section 7.0 if this fire protection guide.

4. An analysis of criticality incident scenarios and their impact on health and safety of the workers and/or public. This information is useful in evaluating relative health and safety risks due to criticality and other hazards.

5. An description of the safety control parameter which are intended to prevent criticality resulting from events such as: accumulation of fissionable material in scrap or waste, lathe turnings, crucible slag, sumps, filters. etc. Also inciuded shall be the description of the technical practices used to prevent exceeding the safety control parameters. This is specifically the type of information which can be used to perform an integrated fire protection/nuclear criticality safety evaluation of a fissile facility.

DOE 5480.24 and Interpretive Guide introduces, indirectly, the issue of the credibility of fires and fire fighting activities resulting in a nuclear criticality. The interpretive guide interprets "criticality accident" as meaning "credible criticaiity accident." The possibility that fire protection activities might, under some unlikely conditions, result in a criticality accident. should not be interpreted as justification to preclude the provision of fire protection. There must be demonstrated that there is some logical. and credible, mechanism for fire protection or fire fighting to result in a criticality and that the resulting consequences outweigh the consequences of failure to provide adequate fire protection.

In addressing the need for criticality alarm systems. Section 7.b(1) of 5480.24 establishes a credibility threshold for criticality accidents as a probability of not greater than $10^{-6}$ events per year. The same credibility criterion could also be applied to fire 
protection system-induced criticality accidents. As discussed elsewhere in this fire protection guide, the probability of an inadvertent water discharge from a fire protection system also resulting in an accidental nuclear criticality has a probability of occurrence which will often fall below this credibility threshold.

Section 7.f of DOE 5480.24 specifically addresses "Guidelines for Fire Fighting." It is interesting that the Order does not address other specific design basis accidents which might result in criticality accidents. In the area of fire fighting, the Order requires:

"Contractors shall establish guidelines for permitting fire fighting water or other moderating materials used to suppress fires within or adjacent to moderation controlled areas. These guidelines shall be based on comparisons of risk and consequences of accidental criticality with the risks and consequences of postulated fires for the respective area(s). (emphasis added) The basis for the guidelines shall be fully documented in a DOE approved Safety Analysis."

This paragraph recognizes that, despite the requirement for first priority reliance on geometry control, there may be areas where moderation control is practiced as the controlling parameter to prevent criticality. For those particular areas, special guidelines must be prepared by the $\mathrm{M} \& \mathrm{O}$ contractor which permit the used of water for fire fighting. Prohibiting the use of water to fire fires is not a recognized option. As written in this order, areas where moderation is not a controlled factor, guidelines for the use of water for fire fighting is not specifically required.

The key issue raised is that the "risk and consequence" of accidental criticality and postulated fire must be compared. Section 3.0 of this guide provides some historical data which may be of use. This may be done qualitatively or quantitatively but is required by the order. This approach is further discussed in Section 7.0 of this fire protection guide.

DOE 6430.1A, General Design Criteria, also addressed nuclear criticality safety. Portions of DOE $6430.1 \mathrm{~A}$ applicable to both nuclear criticality safety and fire protection are addressed below under "Fire Protection".

\subsection{Fire Protection}

DOE Order 5480.7A. Fire Protection, and DOE 6430.1A. General Design Criteria, both address factors associated with overall fire protection of DOE facilities.

DOE 5480.7A. the primary DOE Order addressing fire protection. addresses nuclear 
criticality. In Section 9.b(1) where it states, "Fire Protection systems shall be designed such that their actuation will not damage safety class systems or cause a criticality accident." It mandates that automatic fire suppression systems be provided to protect all new structures exceeding $5,000 \mathrm{sq}$. $\mathrm{ft}$. and all structures having a maximum possible fire loss exceeding $\$ 1$ million. Sprinkler protection is also mandatory where required by the Life Safety Code, NFPA 101.

DOE 6430.1A, General Design Criteria, addresses fire protection by sprinklers and nuclear criticality safety in two areas. Section 1300 and 1530 . Applicable sections of DOE 6430.1A. are quoted below, in bold type. Following each section quoted is a discussion of the requirement.

\section{0-4 NUCLEAR CRITICALITY SAFETY}

"An assessment of a design shall be made as early as practical to determine if the potential for nuclear criticality exists. When such potential exists, the design of nuclear criticality control provisions, including equipment and procedures, shall meet, as a minimum, the requirements of DOE $\mathbf{5 4 8 0 . 5}$ and the ANS 8 series on Nuclear Criticality Safety."

An important principal contained in both of these mandated documents is the doublecontingency principle. The principle calls for controls that assure that no single mishap - regardless of its probability of occurrence - can lead to an accidental criticality. That is, it requires that two unlikely, independent, and concurrent changes in process conditions occur before and accidental nuclear criticality is possible. This is an important principle to be recognized where pre-action sprinkler systems are provided. Since the pre-action sprinkler piping system is independent of the fire detection system and failure of both the independent mechanical and electrical systems must occur prior to release of water due to system failure. accidental water leakage from a pre-action system would, in itself, be considered a double-contingency failure as defined in the standards.

"Nuclear criticality safety shall be achieved by exercising control over both the quantity and distribution of all fissile materials and other materials capable of sustaining a chain reaction, and over the quantities, distributions, and nuclear properties of all other materials with which the fissile materials and other materials capable of sustaining chain reaction are associated. Design considerations for establishing such controls shall be mass, density, geometry, moderation, reflection, enrichment. interaction, material types, and nuclear poison." 
This paragraph allows considation of the neutron moderation and reflection effects of sprinkler water in the design for achieving criticality safety.

"The design shall ensure that material shall not be displaced or allowed to accumulate to form a critical mass in the event of a an internal or external accident. The design shall emphasize geometrically favorable compartments or spacing to minimize reliance on administrative control, and shall prevent the unsafe accumulation of moderator or reflection materials (e.g., water from a fire sprinkler system)..."

Displacement caused by fire (e.g., structural failure) or by manual firefighting must not result in a critical arrangement of fissile materials. Displacement by fire suppression systems is unlikely.

Sprinkler water droplets discharged from a standard upright sprinkler head possess very little momentum to cause movement of materials. Experimental terminal velocities for sprinkler droplets in air have been measured by the Factory Mutual Research Corporation to be $4.054 \mathrm{~m} / \mathrm{s}$ for $1 \mathrm{~mm}$ droplets. The small mass and low velocity of sprinkler droplets result in little energy to be transferred to impacted materials to cause movement. Water spray nozzles may exert higher impact forces which may need to be considered and can be calculated or experimentally measured.

The emphasis of this paragraph is to assure safe geometry. This geometry must be maintained under all credible accident conditions which should include a design basis fire. The effect of fire in changing fissile material geometry may present a much higher safety risk that of any fire suppression activity.

The potential for accumulation of water is covered in a subsequent paragraph of this section of the Order and discussed below.

"Process designs shall incorporate sufficient factors of safety so that at least two unlikely and independent concurrent changes must occur in process conditions before a criticality accident is possible."

This is a re-statement of the double-contingency principle which provides added emphasis to the importance of this principle 
"Structures, systems, and components that provide nuclear criticality safety shall be designed as safety class systems and be capable of performing their criticality safety functions during and following design basis accidents and events."

One Design Basis Accident is the Design Basis Fire. When analyzing criticality safety, the most severe fire must be postulated, assuming fire suppression system failure unless the suppression system is a safety class system to assure that criticality safety is maintained.

"Nuclear criticality safety shall be controlled, in decreasing order, by geometric spacing, density and/or mass limitation, fixed neutron absorber, soluble neutron absorber, and administrative control."

It should be noted that control of moderator (e.g., sprinkler water) is not one of the factors required to be controlled for criticality safety.

"Locations where a potential critical mass could occur in the event of accidental flooding by water from fire protection systems shall be protected by geometrically favorable curbed areas or collection systems."

This paragraph does specifically allows for the use of water fire protection systems and requires other means of control be used to assure criticality safety.

"Where frequency estimates for a specific operation at a specific location shows the frequency of a criticality accident to exceed $10^{-6}$ per year, the combination of shield design and facility layout shall minimize radiation doses to adjacent work stations and exit routes."

This paragraph introduces the concept of relative risk by establishing a limiting frequency of occurrence of event of $10^{-6}$ per year. As cited in Section 4.3.2.2 of this guide, published data indicate that it is not credible to anticipate that the introduction of water moderator due to sprinkler head leakage will contribute to a criticality accident at a frequency greater than the limit established in this paragraph. 


\section{FIRE PROTECTION}

\section{0-2.3.2 Criterion I}

"Whenever the maximum possible fire loss exceeds $\$ 1$ million, automatic fire suppression systems shall be provided."

Without exception. automatic fire suppression must be provided where the maximum possible fire loss within a single fire area exceeds $\$ 1$ million. ANSI/NFPA 801, Fire Protection Practice for Facilities Handling Radioactive Materials, states, "Automatic sprinkler protection provides the best means for controlling fires involving combustible occupancies and should be provided unless it can be shown that their operation will definitely create a situation more hazardous than that brought about by uncontrolled fire."

\section{SPECIAL FACILITIES}

\section{0-99.0 Nonreactor Nuclear Facilities - General}

"Fire suppression systems shall not: (1) prevent a facility from achieving and maintaining a safe shutdown condition, (2) prevent the mitigation of DBA consequences, or (3) cause an inadvertent nuclear criticality."

This paragraph introduces the concept of a potential conflict between fire safety and criticality safety. However. this paragraph does not state that sprinkler systems shall not be used where the potential for an accidental nuclear criticality exists, but rather implies that the fire suppression system and the fissile material arrangement and criticality control scheme must be compatible. Section 1530-2.3.2 has previously established the mandatory requirement for automatic fire suppression and Section 1300-4 mandates that criticality control be maintained under credible accident conditions by geometry and mass control, neutron absorbers, and administrative controls. The criticality controls, as required, must be integrated to function in concert with the appropriate. required fire suppression system.

"When the use of water sprinkler coverage is precluded because of nuclear criticality or other hazards, nonaqueous extinguishing systems (i.e., inert gas, carbon dioxide, high expansion foam, or halogenated organics) shall be used." 
If, after careful and knowledgeable study, it is determined that the fire hazard cannot be reasonably eliminated and criticality control cannot be established with the introduction of low-density moderation due to sprinkler discharge, then some other form of automatic fire suppression should be provided. It should be noted that fire fighting foam is not a non-aqueous material as stated in the Order and that both foam and "halogenated organics" contain hydrogen which will thermalize neutrons. The relative density of hydrogen atoms in foams and halons is much lower than that of "plain" water, thus the moderating and reflecting power of foams and halons is less.

"Automatic water sprinkler coverage shall be provided throughout the facility except in areas where nuclear criticality or other hazards specifically preclude its use or where Halon systems are required to reduce water damage."

This paragraph establishes that water sprinkler systems provide the most appropriate form of fire protection for general area usage. The determination of whether the presence of fissile material precludes the use of sprinklers is discussed in a previous paragraph. 


\subsection{NUCLEAR CRITICALITY CONSEQUENCES OF NON-SUPPRESSION OF FIRES}

In some cases, it has been postulated that the perceived risk of accidental nuclear criticality so far out-weighs the risk or consequences of a fire that effective fire suppression activities must be prohibited. The somewhat simplistic solution proffered is "let it burn", sometimes without due recognition of the increased risk presented by such a resolution.

Clearly, the "let it burn" rationalization will, in many instances result in a much greater property damage loss than would occur if prudent fire intervention methods were employed. It also increases the risk of direct and indirect personal injury due fire and fire products.

As discussed in Section 4.4.4 of this guide, the potential for loss of confinement and spread of nuclear contamination is increased by uncontrolled fires. This will lead to increased risk of injury and harm to on-site workers and the off-site population.

Moreover, the decision not to suppress fires in facilities containing fissile material will not necessarily preserve the criticality safety "status quo" which is desired. Uncontrolled fires may increase the risk of accidental criticalities. The risk of nuclear criticalities due to fires as a design bases accident may not have been fully analyzed.

Fires are likely to effect several levels of nuclear criticality safety "defense-in-depth." Common-mode failures due to fires may compromise "double-contingency" systems from a single fire event. For example:

1. Fires may result in loss of concentration control.

Heat from fires may cause evaporation of diluents thus resulting in higher concentration of fissile materials in solution.

In solvent extraction operations, the fire may consume combustible solvents, with resultant increase in fissile content.

2. Fires may result in loss of geometry control.

In closed systems. heating from exposure fires may result in high internal pressures causing geometry distortions or rupture. 
High temperatures for fires exposing of borated polyethylene or CPVC vessels containing fissile solutions may result in softening of the plastic causing geometry distortions.

Fissile materials in "bird-cages" or in light metal racks may be easily distorted by high temperature fire exposures of relatively short duration.

3. Fires may result in loss of spacing control

Light racks or shelving units may be distorted due to fire exposure resulting in spacing limit violations.

Arrays may collapse under fire exposure.

4. Fires may result in loss of fixed neutron absorber.

Fire may destroy borated PE materials needed for neutron absorption.

5. Fires may result in unplanned transport of fissile material into unfavorable geometry.

Fire exposure may result in leakage of solutions across valves into unsafe vessels.

Fire exposure may result in rupture and release of solutions from safe vessels to unfavorable surrounding areas.

6. Fires may result in increases in neutron moderation.

Process and sanitary pipes and system components are likely to fail and release their contents either from the heat of an unmitigated fire or from the collapse of structural components.

7. Fires eventually have to be extinguished by the fire department. The uncontrolled discharge of water from hose streams is much more likely to cause a criticality accident than is the controlled discharge from a fixed suppression system. 


\subsection{GUIDELINES FOR EVALUATION AND DESIGN OF NEW OR EXISTING FACILITIES}

Each facility handling fissile material must have specific evaluations of the fire and criticality risks presented in order to assess the relative risk of each peril so that intelligent protection decisions can be made on alternative means of protection. This section of the guide presents a methodology for assessing fire and criticality risks as a decision tool in determining an appropriate level of fire protection to be provided in facilities handling fissile materials.

Appendix D of this guide presents a suggested logic diagram to be used in evaluating fire protection where fissile materials are present. It presents a step-by-step logic process in evaluating the overall need for fixed fire protection. the impact of fires or fire suppression systems on nuclear criticality safety. and assessment of the relative risk presented by the fire protection and nuclear criticality perils. It presents a rational approach in decision analysis to determine appropriate levels of fire protection to be provided in a balanced context with the nuclear criticality hazard.

The first step in the evaluation process is conducted by the fire protection professional, without any necessary input from the nuclear criticality safety specialist. In this step, the need for fixed, automatic fire suppression for the facility is determined in accordance with the requirements of DOE 5480.7A. If fixed fire suppression is determined to be unnecessary, the evaluation process is terminated.

If automatic suppression system(s) are required, the fire protection professional should determine if the hazard is best protected by automatic sprinklers. If non-aqueous fire protection systems are determined to be more appropriate, the evaluation process suggested by this decision management system is terminated.

If it is determined that automatic sprinkler protection or other aqueous suppression system should be provided for the fire hazard present, then further evaluation is needed. The next several steps of the decision process are best performed by the nuclear criticality specialist.

The first step of this portion of the evaluation is to determine whether the total mass of fissile material in the area exceeds the critical mass necessary to result in criticality. If it is not likely that a critical mass will be present, then fire protection by any reasonable means may be safely provided and no further evaluation is required.

In the next step, it is determined whether the operations with fissile materials are being 
Nuclear Criticality Safety Guide For

Fire Protection Professionals

In DOE Nuclear Facilities

Draft B. June 30, 1994

In the next step, it is determined whether the operations with fissile materials are being performed by complying with the single-parameter safety limits established by ANSI/ANS 8.1 and summarized in Appendix $C$ of this guide. If the single-parameter limits are effectively implemented, any additional moderation due to fire suppression activities will not result in risk of nuclear criticality. Any form of fire protection may be provided without further criticality conflict.

It is at this point that joint evaluation by both the fire protection professional and the nuclear criticality specialist is required. Throughout the remainder of the decision process, it is important that both discipline cooperatively assess the situation presented by the fissile material process. Because of the specialty aspects of each of the disciplines, it is not desirable that either of the disciplines should attempt to complete the decisionmaking process without full and complete input for the other discipline specialist.

If it is determined by the criticality safety specialist that geometry control is to be employed to assure criticality safety, it is necessary to determine whether a credible fire can result in a change of fissile geometry in the facility. This fire consequence analysis should be conducted by a fire protection professional cognizant in fire effects evaluations. If it is determined that fire-induced geometry changes may be criticality unfavorable, automatic fire suppression should be provided.

In this case, where automatic sprinkler protection is determined to be warranted to protect against accidental criticalities due to fires, a joint evaluation of the effects of sprinkler water on criticality potential should be performed by both the fire protection professional and the nuclear criticality specialist. First it should be determined if criticality safety can be assured (i.e. double contingency) without regard to moderation control. Using standard and accepted nuclear criticality calculational techniques, the nuclear criticality specialist can determined the influence of partial moderation by sprinkler mists on effective neutron multiplication factors. The fire protection professional can used hydraulic calculations and sprinkler characteristics to determine the rate of maximum possible water application and mist density rates. Together, they can evaluate the credibility and consequences associated with fire protection water discharge.

If it is determined that water mists which will adversely affect criticality safety are not credible, then the credibility of flooding scenarios which will adversely affect nuclear criticality safety must be jointly evaluated. This evaluation must include the credibility and effects of flooding of primary material confinements such as cans, flooding of secondary confinements such as gloveboxes, and flooding of floor surfaces and sumps. 
If, based on this logical progression of evaluation, it is determined that criticality accidents are not credible due to water, then automatic sprinkler protection should be provided. If the criticality risk is determined to exceed the fire risk, based on sound evaluation techniques, then automatic sprinkler protection should not be provided. The fire protection professional should explore alternative means for fire risk reduction such that both criticality safety and fire safety goals are achieved. 


\subsection{GUIDELINES FOR FIRE PROTECTION RESPONSE FOR FACILITIES HANDLING FISSILE MATERIALS}

\subsection{General Precautions}

In a fissile materials area, the fire fighter should try to minimize any changes in equipment and surroundings to prevent geometry changes which may be unfavorable from a criticality standpoint. The potential for geometry changes can be reduced by using low water pressures, using spray nozzles in the full-spray position, and by minimizing the excessive use of prying tools. Re-entry should be made only with permission of the director of the emergency operation and the responsible radiation protection officer. While SCBA limits will tend to limit periods of potential exposure, other, more stringent limits may be set by the radiation protection officer.

Just as one should maintain a safe distance from any potential radiation source, fire fighters should attempt to provide separation between themselves and fissile materials in the event of an accidental criticality. In general, personnel which are located $15 \mathrm{ft}$. or more from a nuclear criticality are likely to be outside of the range where a lethal radiation flux would be created in the event of criticality accident. During any fire hose evolutions, the fire fighter is likely to be more than $15 \mathrm{ft}$. from any fissile material at which the hose stream is directed. However, the fire fighter must also be aware of the locations of any other fissile materials in the room, such as at the back and side of the fire fighter. in order to maintain as safe distance from any co-located fissile material. If a criticality should occur, the duration of exposure will effect the dose. If a criticality alarm should activate during fire fighting operations, the fire fighter should immediately evacuate the area in order to reduce potential radiation exposure.

\subsection{Pre-Emergency Planning}

The precautions discussed above are best implemented by an effective pre-emergency plan. Pre-emergency fire response plans should be developed for all facilities. It is important that for facilities storing or handling fissile materials specifically address the criticality aspects of fire suppression activities in the area.

It is beneficial to know before the time of an emergency in which areas fissile materials are located which may be subject to accidental criticalities. Responding emergency personnel should know the specific location where fissile materials may be specifically encountered within the facility. The form of fissile material and criticality control measures should be identified. Limitations. if any, on fire fighting activities should be 
Vuclear Criticality Safety Guide For

Fire Protection Professionals

In DOE Nuclear Facilities

Draft B, June 30, 1994

identified.

It may be advantageous in reducing the risk in responding to fires in fissile material areas, to have previously identified and categorized the special fire suppression and nuclear criticality aspects of the facility, prior to any emergency. In Section 7.3 of this guide, a suggested guide for classification of fissile areas for fire fighting is presented.

\subsection{Fire Fighting Classification of Fissile Areas}

Section 8.1 of this guide discusses some general approaches to risks associated with fire fighting in nuclear facilities, and in particular facilities containing fissile materials. It is recognized that each fissile area is unique and may have special fire fighting characteristics. In some facilities. there may be no need for fire fighting limitations due to the presence of fissile materials. In others, the nuclear criticality controls may be so delicately balanced that all fire fighting must be carefully restricted. It is strongly advised that each facility be evaluated by both fire protection professionals and nuclear criticality specialists to determine the levels and methods of fire suppression activities may be used. Section 7.0 of this guide provides a logic structure which may be used in that type of evaluation.

Based on the combined evaluation of the fire protection and criticality specialists, facilities may be classified by their relative propensity to result in an accidental criticality due to fire suppression activities. A suggested classification system is presented in Table No. 8-1.

TABLE 8-1

RECOMMENDED FIRE FIGHTING CATEGORIES

FOR FACILITIES HANDLING FISSILE MATERIALS

\begin{tabular}{|c|l|}
\hline \hline CATEGORY & \multicolumn{1}{|c|}{ FACILITY CRITICALITY CHARACTERISTICS } \\
\hline A & No likelihood of criticality if water is used for fire fighting. Quantity of fissile material is too small. \\
\hline B & $\begin{array}{l}\text { Minimal likelihood of criticality if water is used for fire fighting. Total fissile mass in area exceeds critical mass but } \\
\text { materials are distributed or in dilute solutions such that accidental criticality is extremely unlikely. Geometry. } \\
\text { volume. or concentration control. }\end{array}$ \\
\hline C & $\begin{array}{l}\text { Under reasonabiy foreseeable conditions. the addition of water could cause criticality. Credible conditions } \\
\text { anticipated during fire fighting could result in re-arrangement of material which. in the presence of water in the form } \\
\text { provided by fire fighting. might result in criticality. Geometry, volume. or concentration control. }\end{array}$ \\
\hline D & $\begin{array}{l}\text { Fissile materials present under moderation control to prevent criticality. Addition of water would likely result in } \\
\text { accidental criticality. }\end{array}$ \\
\hline
\end{tabular}


In this classification system. facilities are categorized from Class $A$ to Class $D$ Fissile Fire Fighting Classification. In Class A facilities, there is no danger of accidental criticality even though there are fissile materials present. In Class $D$ facilities, moderation controls on criticality prohibit the use of water in all forms. Class B and Class $C$ facilities have intermediate criticality risks, as identified in the figure.

Once so classified, the allowable fire suppression activities can be identified which can be associated with each classification. The generally acceptable fire fighting response for each classification illustrated in Table No. 7-2

TABLE NO. 8-2

FIRE FIGHTING RESPONSE TO FISSILE AREA CATEGORIES

\begin{tabular}{|c|l|}
\hline CATEGORY & \multicolumn{1}{|c|}{ FIRE FIGHTING RESPONSE } \\
\hline A & No restrictions on the use of water for fire fighting. \\
\hline B & $\begin{array}{l}\text { Use of water for fire fighting permissible but quantities and pressures should be minimized. Care should be } \\
\text { exercised to prevent re-arrangement of equipment and materials. }\end{array}$ \\
\hline C & Use of water should be limited to pre-planned use \\
& as a last resort to prevent a more severe consequence \\
\hline D & $\begin{array}{l}\text { Water shouid not be used. Alternate. non-aqueous fire suppression agents. only. may be safety used. Dry chemical. } \\
\text { dry powders. carbon dioxide. and halon extinguisters are acceptable. }\end{array}$ \\
\hline
\end{tabular}


$$
\text { - }
$$

.

, 
APPENDIX A

SUMMARY OF CRITICALITY ACCIDENTS IN PROCESS OPERATIONS 


\section{SUMMARY OF CRITICALITY ACCIDENTS IN PROCESS OPERATIONS}

For background purposes, some criticality accidents are briefly discussed below.

Y-12 Plant

Oak Ridge, TN

June 16, 1958

Process piping was being flushed with water which was collected in a 55 gallon drum. Due to an improper valve line-up, a quantity of enriched uranium solution was accidentaily transferred into the drum. As additional water was added to the drum, the solution became critical. A succession of bursts produced $1.2 \times 10^{18}$ fissions over a three minute period. The event continued for about 20 minutes as continued flow of water reduced the concentration of the solution to a sub-critical state. One person, within about six feet of the drum, received a non-lethal dose of $461 \mathrm{rem}$. Seven others received lesser doses. There was no property damage and no contamination. The plant was returned to operation in three days.

\section{Los Alamos Scientific Laboratory \\ Los Alamos, NM \\ DECEMBER 30,1958}

Residual plutonium in raffinate and nitric acid wash solutions from four safe vessels were transferred into a 38 inch diameter. 225 gallon tank. Within this tank there existed an eight inch thick organic layer containing $3.27 \mathrm{~kg}$ of plutonium floating on an aqueous solution containing $60 \mathrm{~g}$ of plutonium. When a stirrer in the tank was turned on, the action caused thickening of the organic layer to create a super-critical system. The excursion corisisted of a single spike producing $1.5 \times 10^{17}$ fissions. An operator who was looking directly into the tank at the time of accident receive a dose of 12,000 rem and died 36 hours later. Two others received does of 134 and 53 rem. The was no significant damage, although the shock of the event displaced the tank support by $3 / 8$ inch. There was no contamination.

Idaho Chemical Processing Plant National Reactor Testing Station October 16, 1959

This operation involved recovery of fissile material from spent reactor fuel in shielded facilities. During air-sparging of a uranyl nitrate solution containing $34 \mathrm{~kg}$ of U(93) in safe tanks. about 200 liters of the solution (containing $170 \mathrm{~g} \mathrm{U} / \mathrm{l}$ ) was transferred to a $9 \mathrm{ft}$. diameter, 5000 gallon tank containing about $600 \mathrm{l}$ of water. The resulting criticality produced an initial spike of $10^{17}$ followed by lower power oscillations over a 20 minute period. During this period nearly half of the water was boiled off. Because of the shielding, none of the operators received significant gamma or neutron doses. Release of fission products resulted to beta exposures of $50 \mathrm{R}$ and $32 \mathrm{R}$ to two persons during the subsequent plant evacuation. There was no equipment damage. 


\section{Idaho Chemical Processing Plant National Reactor Testing Station January 25, 1961}

A uranyl nitrate solution ( $200 \mathrm{~g} \mathrm{U}(93) /$ liter) was contained in a 5 inch diameter pipe within a shielded facility. In an attempt to clear some plugged lines, air was introduced into the system. The bubble of air forced about 401 of the solution into a 24 inch section which was normally above the solution level. The solution in this unsafe geometry resuited in a criticality with a single spike of $6 \times 10^{17}$ fissions. Because of the shielding, personnel exposures were less than $100 \mathrm{mr}$. There was no damage to the facility.

\section{Recuplex Plant \\ Hanford, WA \\ April 7, 1962}

Following an overflow of a plutonium solution, transfer of the solution was made from a sump to an 18 inch diameter transfer tank. About 46 liters of solution containing 1400 to $1500 \mathrm{~g}$ of plutonium was transferred to the tank of unsafe dimension. The resultant accidental criticality continued for 37 hours with a total yield of $8.2 \times 10^{17}$ fissions. The excursion was terminated by the boiling off of about $6 \mathrm{l}$ of water and settling of plutonium bearing organic. One person who was about 5 to 6 feet from the tank at the time of the initial excursion received a dose of $110 \mathrm{rem}$. Two others received lesser doses. There was no damage or contamination.

\section{United Nuclear Corporation \\ Wood River Junction, RI \\ July 24, 1964}

Concentrated $\left(240 \mathrm{~g}{ }^{235} \mathrm{U} / \mathrm{l}\right)$ uranium contaminated trichloroethane was stored in 5 inch diameter polyethylene bottles identical to bottles containing very low concentration trichloroethane. A bottle thought to contain low concentration solution, but actually containing a high concentration of uranium, was poured into an 18 inch diameter sodium carbonate make-up tank. When the solution was agitated by an electric stirrer, the system went critical. The resultant excursion of $1 \times 10^{17}$ fissions splashed about one-fifth of the solution to the floor and result in lethal exposure of 10,000 rad to an adjacent operator who died 49 hours later.

An hour and a half later. two men entered the area to drain the tank. When they turned off the stirrer, the change in geometry resulted in a second excursion of $10^{16}$ fissions. The two men received doses of 60 and 100 rads. Physical damage to the facility from the two incidents was limited to clean-up of the solution. 
BNFL Pu Plant

Windscale, England

August 24, 1970

This incident involved a solvent extraction operation for scrap recover of plutonium.

Following the transfer of $300 \mathrm{~g}$ of plutonium in solution, a small excursion ( $10^{15}$ fissions) of brief duration ( $<10 \mathrm{~s}$ ) occurred. About $39 \mathrm{l}$ of solution containing $2.15 \mathrm{~kg}$ of plutonium had been previously trapped in the system. One person received an exposure of 2 rads while another was exposed to one rad.

Idaho Chemical Processing Plant National Reactor Testing Station Octoher 17, 1970

This incident occurred in a shieided cell containing a solvent extraction process for the reprocessing of spent fuel. A change in concentration in a scrubbing column resulted in $2.7 \times 10^{18}$ fissions over a half hour period. There was no significant personnel exposure and to damage to process equipment. 
APPENDIX B

REFERENCES 


\section{REFERENCES}

\section{A. DOE Orders}

1. General Design Criteria, DOE 6430.1A. U.S. DOE, Washington. DC. 4-6-89.

2. Environmental Protection. Safety, and Health Protection standards, DOE 5480.4, U.S. DOE. Washington. DC, 5-15-84.

3. "Fire Protection", DOE 5480.7A. U.S. DOE, Washington, DC.

4. "Nuclear Criticality Safety", DOE 5480.24, U.S. DOE. Washington, DC. 8-12-92.

\section{B. Other DOE Documents}

1. "Criticality Safety Moderator Hazards". Safety Notice, No. 91-1. Office of Nuclear Safety, U.S. DOE. Washington. DC. September. 1991.

2. "Discharge of Fire Water Into a Critical Mass Lab", Safety Notice, No. 92-51, Office of Nuclear Safety, U.S. DOE, Washington, DC, October, 1992.

3. "Accumulation of Fissionable Material in Exhaust Ventilation Systems", Bulletin, No. 90-3, Environmental Safety and Health. U. S. DOE, Washington. DC, August, 1990.

4. "New Study Documents Reliability of Automatic Sprinkler Systems", Bulletin, No. 5, Environmental Safety and Heaith. U. S. DOE, Washington. DC. September. 1992.

5. "Interpretive Guidance for DOE Order 5480.24, 'Nuclear Criticality Safety", Office of Nuclear Energy, U. S. DOE, Washington. DC, 2-17-93.

6. "Criticality Safety Program Guide for DOE Nonreactor Nuclear Facilities". Draft DOE Standard. Draft 8, April 12, 1993.

7. "Lessons Learned from Investigation of a Minor Incident at a Small Plutonium Laboratory", Serious Accidents, Issue No. 265. USAEC, Division of Operational Safety, Washington, DC. May 27, 1966.

8. "Could Sprinkler Protection Have Reduced this $\$ 200.000$ Radiochemistry Building Fire Loss?", Serious Accidents, Issue No. 175. USAEC, Division of Operational Safety, Washington. DC, April 5. 1961.

\section{ANSI/ANS Standards}

1. Nuclear Criticality in Operations with Fissionable Material Outside Reactors, ANSI/ANS-8.1-1988, American Nuclear Society, LaGrange Park. IL. 1988. 
2. Nuclear Criticality Control of Special Actinide Elements, ANSI/ANS-8.15-1981. American Nuclear Society, LaGrange Park. IL. 1981.

3. Guide for Nuclear Criticality Safety in the Storage of Fissile Materials, ANSI/ANS8.7-1975, American Nuclear Society, LaGrange Park, IL. 1975.

\section{Other Publications}

1. Alcorn, F. M., "Criticality Evaluation of Low-Density Moderation in PWR Fuel Storage", Transactions of the American Nuclear Society, V.27, LaGrange, IL. 1977.

2. Anon., "Fatal Radiation Accidents Reported, 1945-1987", IAEA Bulletin, 4/1988, International Atomic Energy Agency, Vienna, Austria, 1988.

3. Blyckert, W. A., Carter, R. D., and Ridgeway, K. R., Redefined Criticality Risk Categories for Fire Fighting, ARH-2468 Rev., Atlantic Richfield Hanford Company, Richland. WA, April 10, 1972.

4. Brannigan. F.C. and Miles, G.S., Living with Radiation: Problems of a Nuclear Age for the Layman. Vol. 2. Fire Service Problems, USAEC, Washington, DC. 1960.

5. Dean, R. K.. Comparison of Gel and Water as Suppressors of Radiant Ignition on Vertical Surfaces, Factory Mutual Research Corporation, Norwood, MA. 1972.

6. Foster, A.R., and Wright, R.L., Basic Nuclear Engineering, Alalyn \& Bacon, Inc., Boston. MA, 1977.

7. Hall, D.T., and Clayton, T.C., Turbine Generator Fire Protection by Sprinkler System, EPRI NP-4144, Electric Power Research Institute, Palo alto, CA, July, 1985.

8. Handley, G. R., "Effect of Water Sprinklers on Array Criticality Safety Analyses". Transactions of the American Nuclear Society, V.13, LaGrange, IL, 1970.

9. Handley, G. R., "Some Effects of Water Sprinklers on Array Criticality Safety Analyses", Nuclear Technology, V. 13, 1972.

10. Henley, E.J., and Kumamoto. H., Reliability Engineering and Risk Assessment, PrenticeHall, Inc. Englewood Cliffs, NJ. 1981.

11. Holmes. W. D.. "Fire Protection by Sprinklers Where Fissile Materials Are Present". Proceeding of the International Symposium on Fire Protection and Fire Fighting in Nuclear Installations, International Atomic Energy Agency, Vienna, Austria. 1989.

12. Holmes. W. D., Maximum Moderator Density in Air From Automatic Sprinklers Installed in Assembly Room. Bldg. No. 17, American Nuclear Insurers. West Hartford. CT., 1981. (unpublished) 
13. Knief. R.A.. Nuclear Criticality Safety Theory and Practice, American Nuclear Society, LaGrange Park, IL, 1986.

14. Maybee. W.W., "Review of Fire Protection in Nuclear Facilities of the Atomic Energy Commission, 1947-1975", Nuclear Safety, Vol. 20. No. 3, May-June, 1979.

15. Maybee, W. W., "Review of Fire Protection int the Nuclear Facilities of the Atomic Energy commission, 1947-1975", Nuclear Safety, Vol. 20, No. 3, June, 1979.

16. Maybee, W. W., "Sprinkler Performance Update", SFPE Bulletin, May/June, 1988, Society of Fire Protection Engineers. Boston, MA, 1988.

17. McCaughey, D.A., and Bidinger. G.H.. "Film Effects of Fire Sprinklers on Low Enriched Uranium Storage Arrays", Transactions of the American Nuclear Society, 1988 Annual Meeting, LaGrange, IL, 1988.

18. McLaughlin. T.P., "Applications of PRA in Nuclear Criticality Safety", LA-UR-92-1892, Los Alamos National Laboratory, Los Alamos, NM.

19. McLaughlin, T.P., "Process Criticality Accident Likelihoods. Consequences, and Emergency Planning", Nuclear Energy, Vol. 31, No. 2, April, 1992.

20. Patterson, David E., "The Rocky Flats Fire", Fire Journal, National Fire Protection Association. Quincy, MA, January, 1970.

21. Paxton, H. C., Criticality Control in Operation with Fissile Material, Los Alamos scientific Laboratory, Los Alamos. NM, 1972.

22. Paxton. H.C., and Pruvost. N.L. Critical Dimensions of Systems Containing ${ }^{235} \mathrm{U}_{\text {, }}{ }^{239} \mathrm{Pu}$, and ${ }^{233} \mathrm{U} .$, LA-10860-MS, Los Alamos National Laboratory, Los Alamos, NM. 1987.

23. Sawyer, E. A., Failure Analysis of Inadvertent Operations of Fire Protection Systems Including Design Recommendations, Master of Science Thesis. Worcester Polytechnic Institute, Worcester, MA, 1986.

24. Stratton, W. R., A Review of Criticality Accidents. Los Alamos Scientific Laboratory, Los Alamos, NM. 1967

25. Thomlinson, R.E.. Nuclear Safety Guidance in the Use of Water to Fight Fires in CPD Facilities, HW-82254, GE Hanford Atomic Products Operations, Richland. WA, May 15. 1964.

26. Williams, C.A., Principles of Risk Management and Insurance, Vol. 1. American Institute for Property and Liability Underwriters. Malvern. PA. 1981. 
27. Woodruff. Nathan H.. "Use of Water to Fight Fires in Areas Presenting Criticality Risks.". USDOE Office of Operational Safety, Washington. DC. July 23. 1964.

28. Yates, K. R., Denning, R. S., and Jung, R. G., "Rationale for Sprinkler Operation in High Assay Gaseous Diffusion Cascade". Transactions of the American Nuclear Society, V.39, LaGrange, IL, 1981.

29. You, H. Z., Sprinkler Droplet Size Measurements, Part II. An Investigation of the Spray Patterns of /selected Commercial Sprinklers with the FMRC PMS Droplet Measuring System, Technical Report J.I. OGC1E7.RA. Factory Mutual research Corporation. Norwood, MA, 1983.

30. You, H. Z, An Estimation of Water Volume Fraction Provided by Automatic Sprinklers in the Assembly Room of Building No. 17. Windsor Facility, Combustion Engineering, Technical Report No. S21438.93, Factory Mutual Research Corporation, Norwood, MA, 1981. 


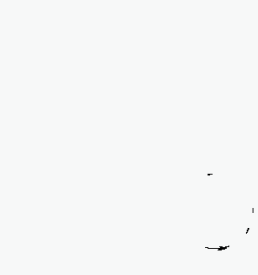




\section{APPENDIX C}

\section{SINGLE PARAMETER LIMITS}


TABLE 1

SINGLE-PARAMETER LIMITS FOR UNIFORM AQUEOUS SOLUTIONS OF FISSILE NUCLIDES

\begin{tabular}{|c|c|c|c|c|c|}
\hline \multirow[t]{2}{*}{ Parameter } & \multicolumn{5}{|c|}{ Subcritical Limit for Fissile Solute } \\
\hline & ${ }^{233} \mathrm{UO}_{2} \mathrm{~F}_{2}$ & ${ }^{233} \mathrm{UO}_{2}\left(\mathrm{NO}_{3}\right)_{2}$ & ${ }^{235} \mathrm{UO}_{2} \mathrm{~F}_{2}$ & ${ }^{235} \mathrm{UO}_{2}\left(\mathrm{NO}_{3}\right)_{2}$ & ${ }^{239} \mathrm{Pu}\left(\mathrm{NO}_{3}\right)_{4}$ \\
\hline $\begin{array}{l}\text { Mass of fissile } \\
\text { nuclide, } \mathrm{kg}\end{array}$ & 0.54 & 0.55 & 0.76 & 0.78 & 0.48 \\
\hline $\begin{array}{l}\text { Diameter of } \\
\text { cylinder of } \\
\text { solution, } \mathrm{cm}\end{array}$ & 10.5 & 11.7 & 13.7 & 14.4 & 15.4 \\
\hline $\begin{array}{l}\text { Thickness of } \\
\text { slab of } \\
\text { solution. cm }\end{array}$ & 2.5 & 3.1 & 4.4 & 4.9 & 5.5 \\
\hline $\begin{array}{l}\text { Volume of } \\
\text { solution, } 1\end{array}$ & 2.8 & 3.6 & 5.5 & 6.2 & 7.3 \\
\hline $\begin{array}{l}\text { Concentration } \\
\text { of fissile } \\
\text { nuclide, } g / 1\end{array}$ & 10.8 & 10.8 & 11.6 & 11.6 & 7.3 \\
\hline
\end{tabular}

TABLE 2

SINGLE-PARAMETER LIMITS FOR METAL UNITS

\begin{tabular}{||l|c|c|c||}
\hline \multirow{2}{*}{ Parameter } & \multicolumn{3}{|c|}{ Subcritical Limit for } \\
\cline { 2 - 4 } & ${ }^{233} \mathrm{U}$ & ${ }^{235} \mathrm{U}$ & ${ }^{239} \mathrm{PU}$ \\
\hline $\begin{array}{l}\text { Mass of fissile } \\
\text { nuclide, kg }\end{array}$ & 6.0 & 20.1 & 5.0 \\
\hline $\begin{array}{l}\text { Cylinder } \\
\text { diameter, cm }\end{array}$ & 4.5 & 7.3 & 4.4 \\
\hline $\begin{array}{l}\text { Slab } \\
\text { thickness, cm }\end{array}$ & 0.38 & 1.3 & 0.65 \\
\hline $\begin{array}{l}\text { Uranium } \\
\text { enrichment. } \\
\text { wt\% }{ }^{235} \mathrm{U}\end{array}$ &.-- & 5.0 &.-- \\
\hline $\begin{array}{l}\text { Maximum } \\
\text { density for } \\
\text { which mass } \\
\text { and dimension } \\
\text { limits are } \\
\text { valid. g/cm }\end{array}$ & 18.65 & 18.81 & 19.82 \\
\hline
\end{tabular}


Table 3

Single-Parameter Limits for Oxides Containing No More Than 1.5\% Water By Weight at Full Density

\begin{tabular}{|c|c|c|c|c|c|c|c|}
\hline Parameter & ${ }^{233} \mathrm{UO} 2$ & ${ }^{233} \mathrm{U} 308$ & ${ }^{233} \mathrm{UO3}$ & ${ }^{235} \mathrm{UO2}$ & ${ }^{235} \mathrm{U} 308$ & ${ }^{235} \mathrm{UO3}$ & ${ }^{239} \mathrm{PuO2}$ \\
\hline Mass of fissile nuclide, $\mathbf{k g}$ & 10.1 & 13.4 & 15.2 & 32.3 & 44.0 & 51.2 & 10.2 \\
\hline Mass of oxide, (1) $\mathrm{kg}$ & 11.7 & 16.0 & 18.7 & 37.2 & 52.8 & 62.6 & 11.5 \\
\hline Cylinder diameter, $\mathrm{cm}$ & 7.2 & 9.0 & 9.9 & 11.6 & 14.6 & 16.2 & 7.2 \\
\hline Slab thickness, $\mathrm{cm}$ & 0.8 & 1.1 & 1.3 & 2.9 & 4.0 & 4.6 & 1.4 \\
\hline \multirow{2}{*}{$\begin{array}{l}\text { Maximum bulk density }{ }^{(0)} \text { for } \\
\text { which liunits area valid, } \mathrm{g} / \mathrm{cm}^{3}\end{array}$} & 9.38 & 7.36 & 6.56 & 9.44 & 7.41 & 6.60 & 9.92 \\
\hline & $1-0.085(1.5-w)$ & $1-0.065(1.5-w)$ & $1-0.056(1.5-w)$ & $1-0.086(1-5 w)$ & $1-0.065(1.5-w)$ & $1-0.057(1.5-w)$ & $1-0.09(1.5-w)$ \\
\hline
\end{tabular}

(i) These values include the mass of any associated moisture up to the limiting value of $1.5 \%$ by weight.

(B) $w$ represents the quantity of water, in wi\%, in the oxide.

Table 4

Single-Parameter Limits for Oxides Containing No More Than $1.5 \%$ Water By Weight at No More Than Half Density ${ }^{(2)}$

\begin{tabular}{|c|c|c|c|c|c|c|c|}
\hline Parameter & ${ }^{233} \mathrm{UO2[2]}$ & ${ }^{233} \mathrm{U} 308\{2\}$ & ${ }^{233} \mathrm{UO3}[2]$ & ${ }^{235} \mathrm{UO2[3]}$ & ${ }^{235} \mathrm{U} 308[3]$ & ${ }^{235} \mathrm{UO3}[3]$ & ${ }^{239} \mathrm{PuO2}[4]$ \\
\hline $\begin{array}{l}\text { Mass of fissile } \\
\text { nuclide, } \mathbf{k g}\end{array}$ & 23.4 & 30.5 & 34.7 & 88 & 122 & 142 & 27 \\
\hline $\begin{array}{l}\text { Mass of oxide, } \\
\text { (1) } \mathrm{kg}\end{array}$ & 27.0 & 36.6 & 42.4 & 102 & 146 & 174 & 30 \\
\hline $\begin{array}{l}\text { Cylinder } \\
\text { diameter, cm }\end{array}$ & 11.9 & 14.8 & 16.3 & 20.4 & 26.0 & 28.8 & 12.6 \\
\hline $\begin{array}{l}\text { Slab thickness, } \\
\mathrm{cm}\end{array}$ & 1.6 & 2.2 & 2.6 & 5.8 & 8.0 & 9.3. & 2.8 \\
\hline
\end{tabular}

(a) These are half the maximum bulk densities of Table 3 .

(B) These values include the mass of any associated noisture up to the limiting value of $1.5 \%$ by weight. 


\begin{abstract}
APPENDIX D
SUGGESTED LOGIC DIAGRAM FOR

EVALUATING FIRE PROTECTION

WHERE FISSILE MATERIALS ARE PRESENT
\end{abstract}




\section{Suggested Logic Diagram for Evaluating Fire Protection Where Fissile Materials are Present}
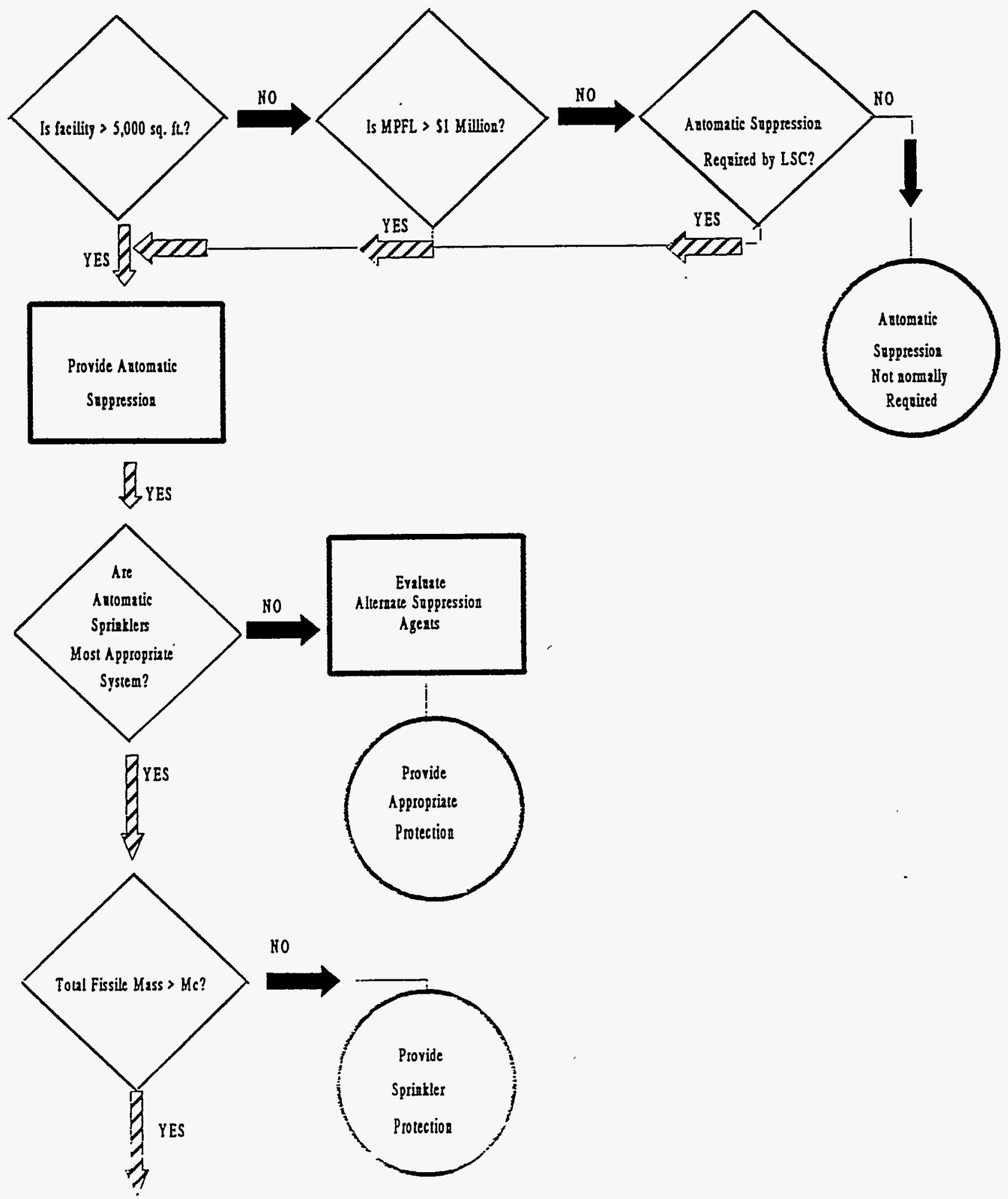

(Continued on Page 2) 


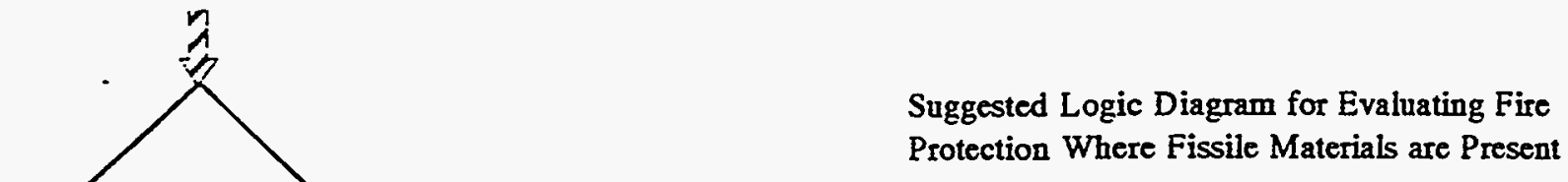

Single Panmeter

NO

Page -2-
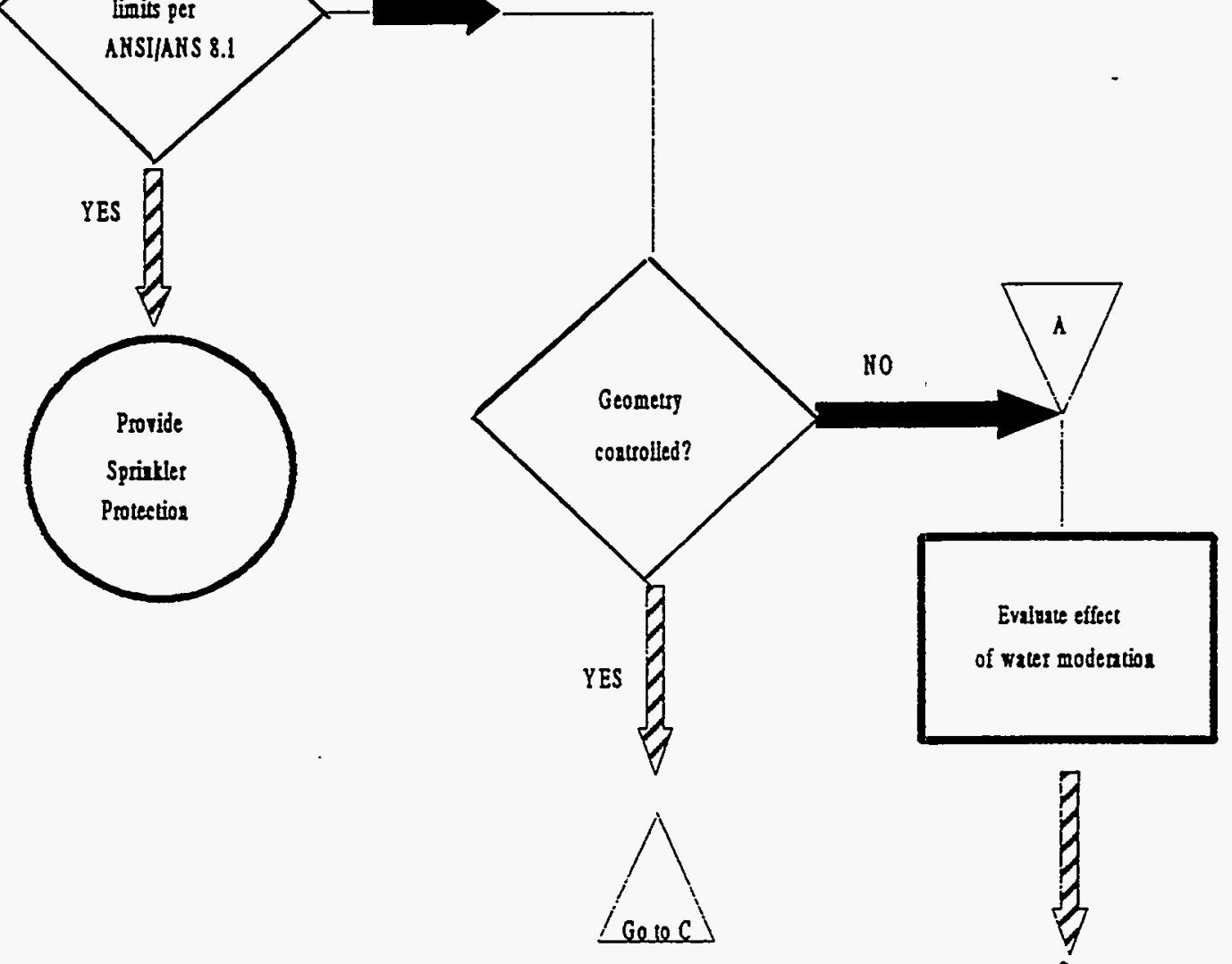

Can Fire Protection

water sesult is

criticality sader

any conditions?

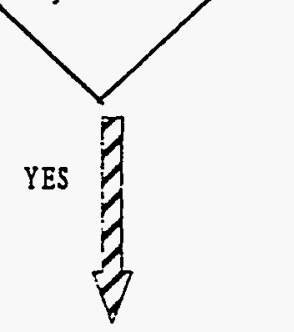

HO

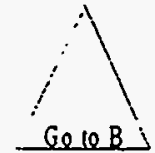

KO

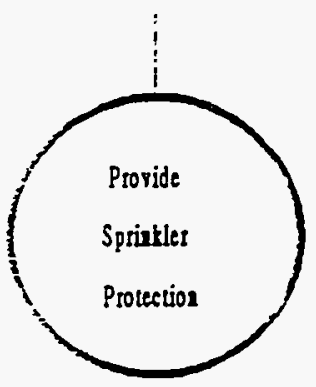




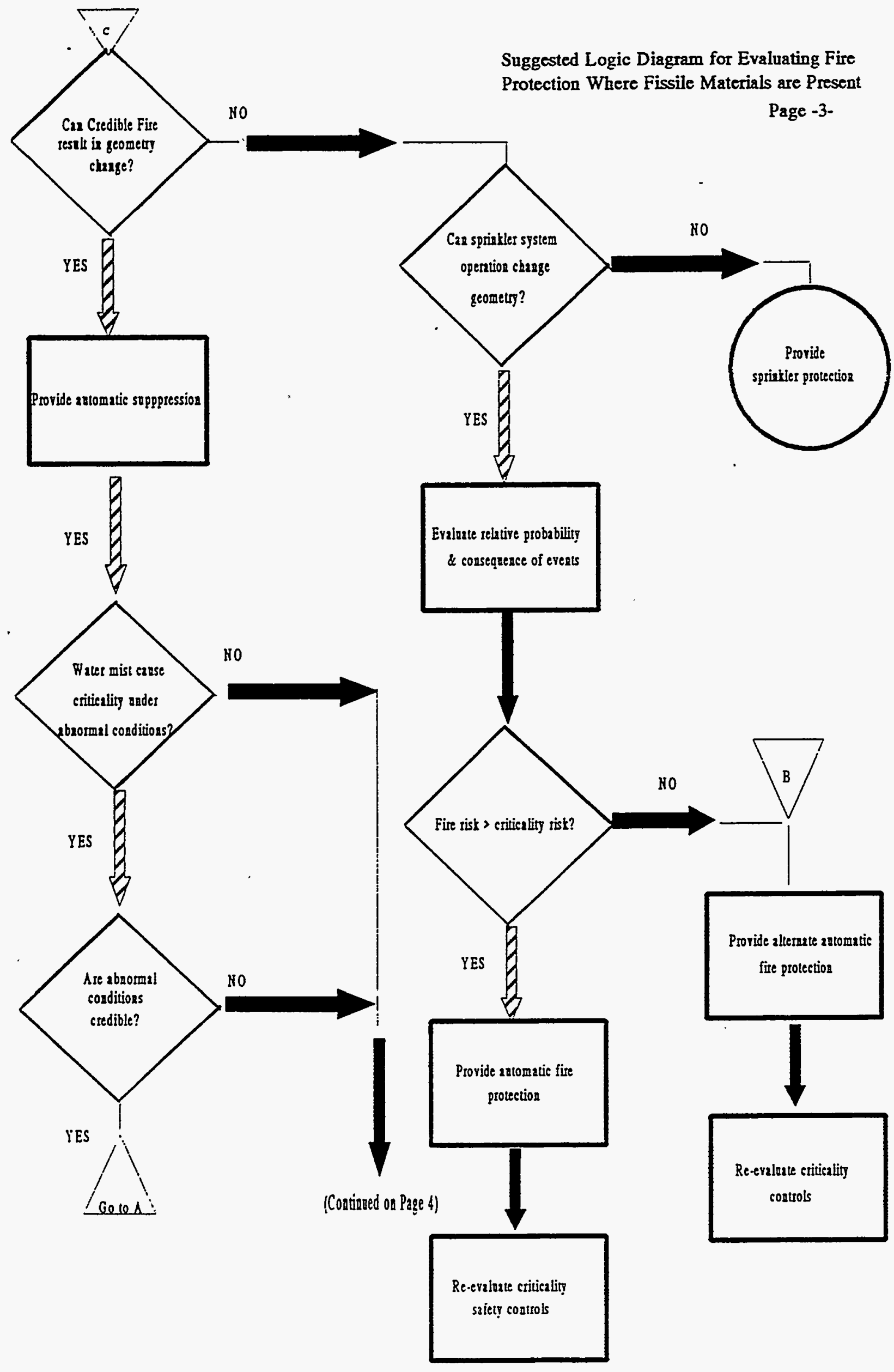




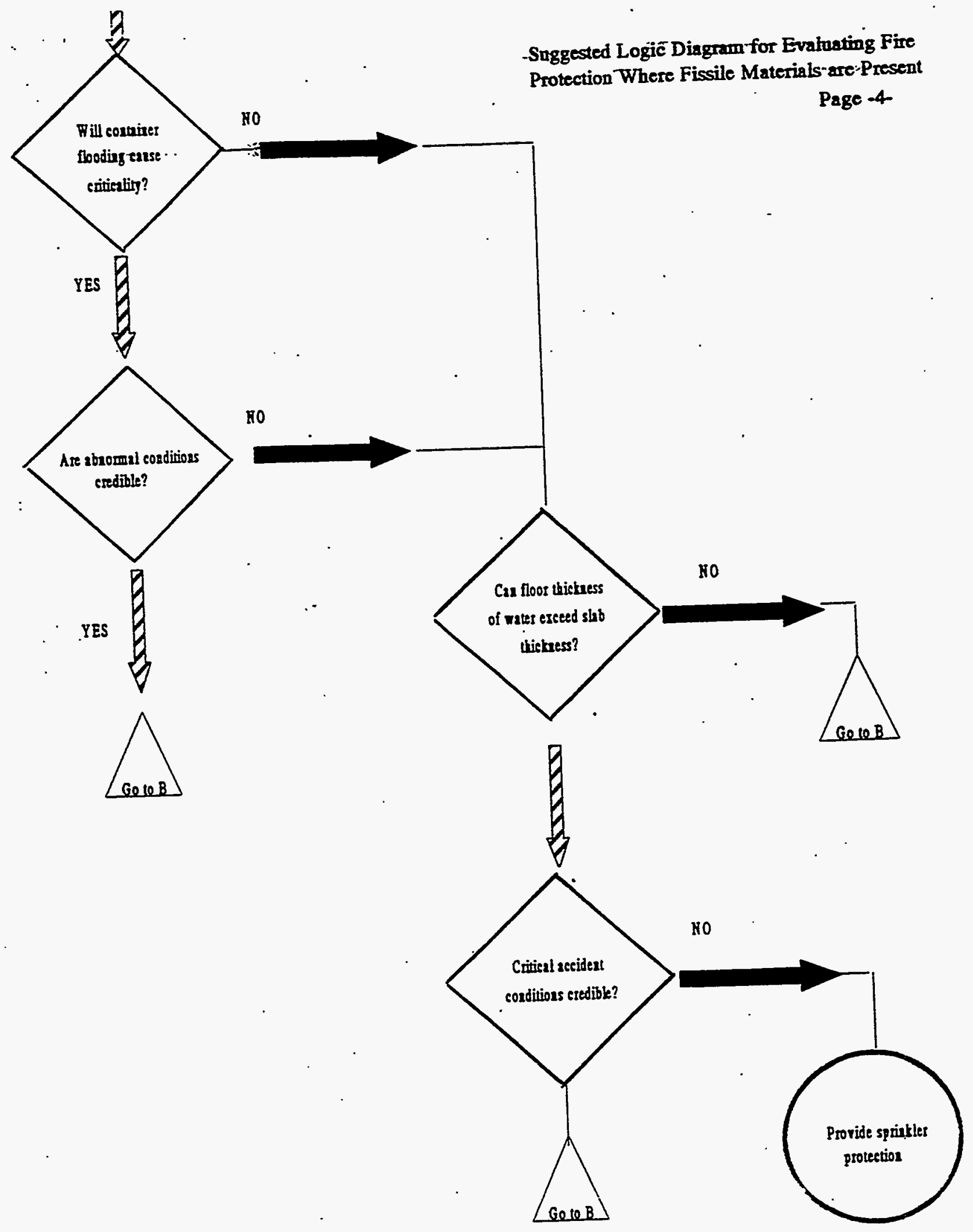


SORT: 6055.6

DOCI: DODI 6055.6

DATE : 19941215

TITL: DODI 6055.6 DOD Fire and Emergency Serviçes Program, December 15, 1994, USD (AT\&T)

Refs: (a) DOD Instruction 6055.6, "Department of Defense Fire Protection Program, " August 1, 1988, (hereby canceled)

(b) DOD Directive 1000.3, "Safety and Health Policy for the Department of Defense, "March 29, 1979

(c) DOD Instruction 6055.7, "Mishap Investigation, Reporting and Recordkeeping," April 10, 1989

(d) MII-HDBK 10083, "Fire Protection for Façilities Engineering, Design, and Construction," January.15, 1994

(e) through $(q)$, see enclosure 1

A. REISSUANCE AND. PURPOSE

This Instruction:

1.' Reissues reference (a) to update policy and criteria for the allocation, assignment, operation, and administration of DoD fire departments and related fire prevention functions, including emergency response, under reference (b)

2. Establishes the DOD Fire and Emergency Services Quality Working Group.

3.. Authorizes the publication of Guides, Handbooks, and Manuals to provide specific information on DoD fire fighter qualifications, fire and emergency services programs, and fire incident reporting.

\section{B. APPLICABILITY}

This Instruction applies to the Office of the Secretary of Defense (OSD), the Military Departments, and those Defense Agencies having responsibility for maintaining organized fire and emergency services (hereafter referred to collectively as "the DoD Components"). The term "Military Services" as used herein, refers to the Army, the Navy, the Air Force, and the Marine Corps.

C. POIICY

It is DoD policy that:

1. The DOD Components shall establish.and maintain an installation 

fire fighting, fire prevention, and emergency services program (hereafter referred to as "the fire and emergency services program") as an element of the overall DoD accident prevention program prescribed in DoD. Directive 1000.3 (reference (b)).

2.. All DoD Components that occupy General Services Administration (GSA) managed buildings are concurrently responsible with GSA for developing and maintaining sound fire prevention programs.

\section{RESPONSIBILITIES}

1. The Deputy Under Secretary of Defense (Environmental Security), shall:

a. Oversee the implementation of this Instruction and represent the Secretary of Defense on both internal and interagency matters on the fire and emergency services program.

b. . Provide criteria, guidance, and instructions to incorporate fire fighting, fire prevention, and emergency response elements in appropriate DOD program and budget documents.

c. Establish, as an integral element of the Defense Environmental Security Council (DESC) and related Board and Committee structure, the DoD Fire and Emergency Services Quality Working Group (comprised of members from OSD, the Military Services, and the Defense Logistics Agency)

2. The Heads of the DOD Components having responsibility. for maintaining organized fire, and emergency services shall establish and maintain programs that conform to the requirements and procedures specified in this Instruction. Particular emphasis shall be placed on fire prevention education as a means to enhance the total fire and emergency services effort and other fire prevention techniques to eliminate the causes of fires and to prevent death, injuries, and property damage if fire occurs.

3. The Secretary of the Navy shall maintain the DoD Fire Incident Reporting system as prescribed in DOD Instruction 6055.7 (reference c), in an automated management information system format, for collecting and analyzing fire incident data and fire department response information.

4. The Secretary of the Air Force shall administer a DoD Fire Fighter Certification system for all DoD Components, and shall provide basic structural fire fighting, aircraft rescue fire fighting, and technical training for all DOD Components (except for specialized and local training as provided herein). 
$\therefore$ 
Additionally, a DoD Physical Fitness Program shall be developed and provided to all DOD Components.

\section{E: PROCEDURES}

1. The DOD Fire and Emergency Services Quality Working Group shall:

a. Meet at the call of the Chair to share information, discuss issues, and recommend policies to the DESC related to fire prevention, fire suppression, training, fire apparatus, fire equipment, fire. administration, emergency. medical response, and hazardous materials emergency response: The Chair of the Quality Working Group will rotate annually among. The Military Services and the DIA members.

b. Serve as the technical advisor to the DESC for the DOD Fire and Emergency Services Program, the Fire Incident Reporting System, the Fire Fighter Certification System, and the Fire Fighter Physical Fitness Program.

c. Draft and revise, as required, the DoD strategic Plan for Fire and Emergency Services.

d. Develop meaningful metrics to evaluate the success of the DoD fire and emergency services program.

2. The DOD Components' fire and emergency services programs shall include the elements described in Enclosure 2.

\section{F. INEORMATION REQUIREMENTS}

The fire incident reporting requirements prescribed herein, including the establishment of the Department of the Navy as the central DoD report file, are assigned Report Control symbol DD-ACQ (AR) 1765.

\section{G. EFFECTIVE DATE AND IMPIEMENTATION}

1. This Instruction is effective immediately. Detailed implementing instructions are only necessary to provide for any DoD Component-unique fire and emergency services situations. If used, they shall provide for inter-DOD Component fire department consolidation actions and staffing adjustments.

2. DoD Components must satisfy their bargaining obligations with unions under U.S.C. Chapter. 71 prior to implementing any changes generated by this Instruction. The Instruction does not supersede any existing collective bargaining agreement until the agreement expires and the bargaining obligation is fulfilled. 
- ' 
3. Forward one copy of implementing documents to the Under Secretary of Defense Acquisition and Technology within 120 days.

Paul G. Kaminski

Enclosures - 7

1. References

2. Program Elements

3. DoD Minimum Airfield Rescue Eire Fighting Vehicle Allowances

4. Maximum Response Times for Structural Fire Pumpers

5. Staffing Requirements for Management and Administrative Fire Service Positions

6: Staffing Requirements for Fire Prevention Positions

7. Staffing Requirements for Positions Required to Staff Fire Apparatus

\section{REEERENCES, continue}

(e) National Fire Protection Association (NEPA), "National Fire Codes"

(f) DoD Instruction 6055.1, "DOD Occupational Safety and Health

Programs," October 26, 1984

(g) Fire Administration Authorization Act of 1992, Public Law 102-522

(h) Title 29 Code of Federal Regulations, Part (120), "Hazardous Waste Operations and Emergency Response," March 6; 1989

(i) DoD Directive 1402.4, "Entry Age For Selected Firefighter and Law Enforcement officer Positions," December 29, 1988

(j) DoD Instruction 1010.13, "Smoke-Free Workplace," March 7, 1994

(k) DoD Instruction 4000.19, "Interservice, Interdepartmental, and Interagency Support," April 15, 1992

(I) Part 1856 of Title 42, United States Code

(m) Section 2210 of Title 15, United States Code

(n) DoD Instruction-7230.7, "User Charges," January 29, 1985

(0) DoD Instruction 4100.33, "Commercial Activities Program Procedures," September 9, 198,5

(p) Section 2465 of Title 10 , United States Code

(q) Section 2907 of Title 10, United States Code

NOTE: Available from the National Fire Protection Association, Batterymarch Park, Box. 1901, Quincy, Massachusetts 02269-9101 END NOTE:

DOD FIRE AND EMERGENCY PROGRAM ELEMENTS

1. Fire Prevention

a. Engineering and Plans. The plans for all military construction projects, facility modernization, rehabilitation programs, or self-help projects shall be reviewed for concurrence with MIL-HDBK-1008B (reference 

(d)), by qualified personnel to ensure that they meet the life safety and fire prevention criteria promulgated by the DoD Components and the National Fire Codes, reference (e).

b. Fire Risk Management Surveys. Qualified personnel shall conduct fire risk management surveys of facilities. Hazardous conditions shall be reported as specified in DOD Instruction 6055.1 (reference (f)) and promptly corrected or incorporated into the DoD installations hazard abatement plan.

c. Survey Frequency. The frequency of local fire risk surveys shall be determined according to the building or area occupancy hazard, known fire loading, and mission criticality.

d. Smoke .Detectors. Smoke detection systems shali be installed in buildings where safety to life is of principal concern, in accordance with MIL-HDBK-1008B (reference (d)). This includes all buildings used for sleeping purposes. Additionally, programs shall be established to:

(1) Require the instaliation of smoke detectors as a prerequisite for assignment to mobile home space on DoD property..

(2) Include mobile homes on DoD installations in the smoke detector inspection schedule for family housing units.

(3) Require the installation and maintenance of smoke detectors in all Government-leased housing.

e. Residential Sprinkler systems. Provide residential sprinkler systems in accordance with Fire Administration Authorization Act of 1992, Pub. I. 102-522, reference (g.).

f. Public Fire Education Promotion. Public Fire Education Programs shall be developed to inform and motivate DoD personnel, and dependents of DoD personnel, who reside or work on DoD installations or in Governmentleased.facilities, as to their individual responsibilities in fire prevention. Fire prevention and/or safety materials, including nominal value incentive and educational items, are an authorized expenditure of funds in promoting fire prevention and safety as an integral part of the Public Eire Education-Program.

2: Fire Incident Investigation and Reporting. Investigations and reporting shall be in accordance with the requirements of DoD Instruction 6055.7. (reference (c)).

3. Fire Protection Standards. DoD fire protection standards consist of the relevant standards promulgated by the Department of Labor - 

Occupational Safety and Health Administration (OSHA), the National Fire Protection Association (National Fire Codes), national building codes, and other-fire safety criteria published by the Department of Defense and other Federal Agencies.

4. Emergency Response. Fire departments shall be prepared, by virtue of appropriate training, to respond (both on-and-off the installation) to emergencies involving DoD facilities, structures, aircraft, transportation equipment, hazardous materials, and both natural and man-made disasters. Procedures shall be implemented in accordance with nationally recognized standards and integrated emergency management systems to prevent loss of life, injury, and property damage; to maintain security; and to minimize public inconvenience.

a. 'Structural Fire Response. Ensure that fire flow requirements are met on the initial response of primary fire apparatus to an announced structural fire. Use a fire protection classification system for determining the structural fire protection requirements that distinguishes between individual activities, based on their strategic importance and mission criticality.

b. Hazardous Materials Response. Establish integrated regional hazardous materials emergency response policies to avoid duplication of. . resources. Hazardous materials emergency response shall meet the requirements of OSHA 29 CER 1910.120 (reference.(h)).

c. Aircraft Rescue Fire Fighting (ARFF) Response. Ensure that fire flow requirements are met on the initial response of ARFF apparatus to an announced aircraft emergency. Response to aircraft emergencies shall also include structural fire suppression forces to provide additional rescue and fire suppression personnel to establish agent resupply.

\section{d. Disaster Preparedness Plans. Establish and maintain Disaster}

Rlanning Programs for response to natural and man-made disasters, and ensure that operational procedures are developed for sustained emergency operations. All DOD installations having. fire departments, and other DOD installations having either 10 or möre persons as residential occupants or a constructed facility value of more than $\$ 1,000,000$, shall have a designated "Base/Installation Emergency Preparedness officer," who, in addition to any other duties, shall maintain the Disaster Preparedness Plan. Such plans shall be coordinated with disaster preparedness plans of all local jurisdictions of civil government; e.g., city, county, fire district, that adjoin the installation and such plans shall be tested or exercised at least once in each fiscal year. The format of such disaster plans, and scope of their testing or exercises, shall be determined by the Head of each DoD Component. Fire department disaster plans shall be integrated and coordinated with installation Disaster preparedness Plans. 
e. Emergency Medical Response. Where fire departments provide emergency medical response, establish and maintain emergency medical response programs that are staffed with appropriately certified emergency medical personnel and equipment.

5. Fire Suppression, Hazardous Material, and Rescue Vehicles. The DOD Components with fire departments shall plan, program, and budget for fire and rescue vehicles, based on the standard criteria in paragraphs 5.a. through $\mathrm{f}$. , below:

a. Pumpers. The standard requirement for pumpers is based on response time criteria (enclosure 4). and the estimated fire flow requirement established for each installation in accordance with MIL-HDBK-1008B (reference (d)).

(1) Installations (including multiple activities serviced by a consolidated fire department) should be divided into fire demand zones (FDZ) (small areas that represent a single demand for fire services). Demand within any given EDZ is based on required fire flow and response time criteria.

(2) The number of full-time fire fighter personnel and units of mobile equipment needed at any single installation to meet the standards in this Instruction shall depend on the extent to which equivalent fire fighting forces are available from outside șources. Instaliations shall include outside fire companies in determining compliance with these standards when those companies compare favorably with DoD standards in staffing and equipment and can meet the prescribed response-time criteria.

(3) The number of staffed pumpers required is determined on the basis of 750 gallons per minute (GPM), regardless of the actual pump capacity of the pumpers on hand, and is calculated by dividing two-thirds of the estimated fire flow by 750 .

b. Aerial Ladders, Brush Trucks, Hazardous Materials, Emergency Response Vehicles, and other Specialized Apparatus. The DoD Components shall determine the requirements for such specialized apparatus for each applicable installation.

c. Aircraft Rescue Fire Fighting (ARFF) Vehicles. The criteria for aircraft rescue fire fighting apparatus are in enclosure 3.

d. Administrative Command and support Vehicles. Criteria for administrative, command, and support vehicles shall be established by the DOD Components.

e. Structural and ARFF Vehicle Availability. The DOD Components shali establish mandatory maintenance programs to ensure availability of 

structural and ARFF vehicles. Such programs shall include a priority maintenance and repair system, stocks of required spare parts, scheduled. inspections, and discrepancy reporting systems.

f. Reserve Apparatus. When there is an operational and training. need, the DoD Components shall equip and maintain reserve apparatus. During emergencies, reserve apparatus may be placed in service and staffed by recalled off-duty fire fighters. Reserve apparatus àre obtained by retaining apparatus that becomes excess through normal replacement programs. New equipment shall not be acquired to meet authorized reserve apparatus needs. The DoD Components shall not operate or staff reserve apparatus as in-service units, except when used as a replacement for a vehicle that is out of service, or during major disasters. The maximum allowances for reserve.structural and/or aircraft rescue fire fighting apparatus are as follows:

(1) For 1-4 in service and staffed engine and/or ARFF companies, one reserve pumper and/or AREF unit is authorized.

(2) For 5-9 in service and staffed engine and/or AREF companies, two reserve pumper/ARFE units are authorized. ,

(3) For 10 or more in service and staffed engine and/or ARFF companies, three reserve units are authorized.

(4) Reserve units are allowed for aerial ladders, resupply vehicles, or other special category units as approved by the DoD Components.

(5) Additional consideration shall be given to large consolidated fire departments having unique reserve vehicle requirements.

\section{Standardization of Apparatus}

a. Structural fire apparatus shall be constructed to comply with the" provisions of NFPA 1901, Standard for Automotive Fire Apparatus (reference (e)): Structural fire pumpers shall be standardized at a minimum 750 GPM pumping capacity.

b. ARFE vehicles shall be constructed to comply with the provisions of NFPA 414, Standard for Aircraft Rescue and Fire Fighting Vehicles (reference (e)). AREF vehicles shall be standardized in the following water capacities in gallons: $1,000,1,500,2,500$, and 3,000. The 1,000-galion AREF vehicles assigned to rapid deployment forces shall be transportable by military airlift (C-130, C-17, and C-141).

c. Where required, rescue vehicles shall have off-pavement performance capability and shall be capable of carrying all required personnel and equipment. 
d. Aircraft rescue fire fighting twin agent units shall be capable of . carrying two of the following agents: AFFF, dry chemical, or halon.

\section{7: Response Times}

a. Structural Apparatus. Response times for structural fire pumpers are specified in enclosure 4. (Maximum response times do not apply to specialized fire apparatus, aerial ladders, and hazardous materials emergency response vehicles.).

b. AREF Apparatus. ARFE vehicles shall be capable of responding to any incident on the runways or overruns within 1 . minute after pre-positioning for an announced emergency, and to any incident on the runways or overruns within 3 minutes for an unannounced emergency. Response times apply to the first arriving vehicle in either situation.

8. Staffing. Staff installation fire departments at not less than the minimum levels established herein. Airfield fire departments or ARFF shall be staffed to provide flight Iine protection 24 hours per day, even if the air control tower is closed for flight operations. Maximum positions may be exceeded at remote installations when approved by the DOD Component. Entry age of fire fighter personnel shall be in accordance with DoD Directive 1402.4 (reference (i)).

a: Management and Administrative Fire Service Positions. Required staffing for management and administrative fire service positions is in enclosure 5 .

b. Fire Prevention Positions. Required staffing for fire prevention positions is in enclosure 6.

c. Fire Fighter Positions. Structural and aircraft fire suppression and rescue sérvices shall be equipped and personnel assigned shall be cross-trained to be mutually supporting. Required staffing for these positions is in enclosure 7. The DoD Components shall consider both civilian and military fire fighters to fill required positions:

\section{d. Fire Alarm Communications Center Personnel}

(1) All installations shall maintain around-the-clock capability to conduct essential fire emergency communications. Communications equipment operators shall be trained in the proper use of communications equipment including telephone, radio, and other electrical or electronic alarm signal receiving systems. Also, operators shall be trained for dispatching fire apparatus, and requesting medical, police, or other fire department assistance as necessary. Dedicated GS-392 or equivalent communications specialists are required. (Bilingual capability is required at overseas locations.) 

(2) The DOD Components may approve exceptions for smaller installations and remote sites where dedicated communications specialists are not economically feasible. The transferring of the fire alarm receiving and communications functions to a non-related function or the requesting of another party, such as military police or engineering personnel, to report to the fire station to operate the alarm and communications equipment is not a viable alternative and will not be considered as an exception. Installations may request exceptions based on one of the following:

(a) Where the installation alarm and communications function can be consolidated with an established continuously manned Emergency Communications Center for all emergency services (fire, police, ARFF, medical, explosive ordnance disposal, etc.), communications personnel employed at the consolidated communications center shall be trained in fire department communications procedures. (Bilingual capability is required at overseas locations.)

(b) Where fire fighters can be assigned on a rotational basis to operate the alarm receiving and communications equipment, fire fighters shall be properly trained in fire alarm communications. Alarm room staffing shall be in addition to the requirement for a fully staffed structural and ARFF response. (Bilingual capability is required at overseas Iocations.)

(c) Where fire suppression is provided by other than DoD fire departments, fire alarm commuications shall be consolidated with other continuously staffed functions such as military police or security. Communications personnel employed at the consolidated facility shall be trained in fire department communications procedures. (Bilingual capability is required at overseas locations.)

(d) Where the fire department can be dispatched and the communications function is managed as part of a municipal automatic aid program.

9. Personnel Physical and Medical Requirements. The DoD Components' medical surveillance programs shall include the pre-employment medical and physical criteria for fire protection personnel of NFPA 1500, "Standard on Fire Department occupational Safety and Health Program" (reference (e)). DOD Fire protection personnel shall receive an annual physical examination as specified in NFPA 1582, "Standard on Medical Requirements for Fire Fighters" (reference (e)).

10. Personnel Training and Physical Fitness Programs

a. Training. Training programs shall conform to the DoD Fire Fighter Certification system requirements, patterned after the National Fire Codes 
xestares 
(reference $(e))$.

(1) DoD Eire Protection School. The Department of the Air Force shall accomodate the training requirements of the other DoD Components. The Air Force Fire Protection school is designated as the certral DoD Fire Protection school. s.r. $4 x$

(2) National and State Fire Academies. The DoD Components shall use the National Fire Academy and State agencies for specialized, advanced, and executive-level training, including the use of courses handed-off in the Train-the-Trainer P.rogram.

(3) Live-Fire Training. Live-fire training areas that meet local environmental standards shall, be developed by each applicable DoD Component at appropriate locations to provide realistic proficiency training at a. reasonable cost. Thorough consideration shall be given to creating regional training facilities for closely located DoD installations and for cooperative arrangements with aivil sector fire departments and off-base live-fire training.

(4) First Responder. Programs shall be estiablished to train all Dod and contract fire fighters (continental United states only) to, at least, the U.S. Department of Transportation and OSHA 29 CFR 1910.120g first responder level.

(5) On the Job Training. Training shall be provided and documented for all personnel assigned fire and emergency services duties through an on-the-job training program, in conformance with the objectives outlined in the DOD Fire Fighter Certification system.

b. Physical Fitness. All DoD fire and emergency services personnel shall participate in a physical fitness exercise program designed to maximize job performance. DoD fire protection personnel shall be a special emphasis target group for the DoD Component's anti-smoking education program, required by DoD Instruction 1010.15 (reference (j)).

c. DoD Eire Eighter Certification system (FFCS). All DoD military, GS-081 civilian, and contract fire fighters will participate in the certification system. The FFCS is a condition of employment for GS-081 civilian fire fighters.

11. Personal Protective Equipment. Prohibit the acquisition and use of any personal protective clothing and equipment used for structural and aircraft fire fighting, rescue, and hazardous materials emergency operations that are not in compliance with appropriate NFPA standards (reference (e)). Develop and enforce standards for firefighters to ensure that hair and beard styles do not interfere with safety or the proper fit 

of personal protective equipment.

a. Equipment shall be procured and maintained in accordance with the requirements of current National Fire Code standards and DoD Instruction 6055.1 (references (e) and (f)), and other appropriate requirements. Commercial off-the-shelf equipment will be.purchased rather than developing a unique military specification.

b. All DOD fire protection personnel shall be issued personal protective equipment commensurate with their assigned tasks.

c. All personnel engaged in confirmed fire fighting and hazardous materials operations shall use self-contained breathing apparatus and all components of a fire fighting and/or hazardous materials: protective ensemble.

12. Fire Department Uniforms. All personnel shall avoid wearing any clothing that is unsafe due to poor thermal stability or poor flame resistant characteristics of the fabrics. The DoD Components may establish policies for the use of clothing which consists of 1008 natural fibers or blends that are principally natural fibers.

13. Consolidation of Fire Departments. To minimize the impact of personnel costs and to eliminate duplicate fire protection, the DoD Components shall continue the ongoing efforts to consolidate fire departments. (See DoD Instruction 4000.19, reference (k)).

\section{Mutual Aid}

a. The DoD Components, under Chapter.15A of 42 U.S.C. (reference (1)), are encouraged to enter into reciprocal agreements with local fire protection agencies for mutual fire fighting and emergency response assistance. If practical and agreeable to the local fire protection agency involved, a portion of the required fire protection for the DoD installation may be provided for under the mutual aid agreement. The DoD Components shall. not increase staffing or equipment above DoD requirements solely to provide mutual aid to local fire protection agencies.

b. Each agreement entered into under paragraph E.14.a., '(above) shall conform to 15 U.S.C. 2210 (reference (m)), which provides for compensation to municipalities for direct costs and losses sustained while fighting fire on Federal property. Each agreement shall provide the terms for reimbursement of each party for all or any part of the costs incurred in furnishing fire protection or emergency response to the other party. (See DOD Instruction 7230.7 , reference (n).)

c. In the absence of any agreement installation commander are 
authorized to render emergency assistance to preserve life and property in the vicinity of the DoD installation, when, in their opinion, such assistance is in. the best interest of the United States. (See reference $(\dot{\mathrm{n}}) \cdot$ )

d. In connection with mutual aid fire fighting or emergency response assistance agreements, any service performed by DoD personnel, civilian or military, shall constitute service rendered in the line-of-duty.

e: The performance of such service by any other individual shall not constitute such individual as an officer or employee of the United states.

f. Develop plans and procedures to provide fire suppression and emergency response services for nearby Federal Agency facilities, in the event normal municipal fire suppression and emergency response services are inhibited. (See DoD Instruction 4000.19, reference (k)).

15. Contracting Fire Protection. When contract protection services are required according to the criteria in DOD Instruction 4100.33 (reference (0)), statements of work shall be-performance oriented. Funds shall not be obligated or expended for entering into a contract. for the performance of fire fighting functions at any military installation or facility (10 U.S.C. 2465, reference (p)). However, the DoD Components may contract with local governments for the provision of fire protection services at military installations to be closed under the Base Closures Act, 10 U.S.C. 2907, reference (q).

16. Fire Brigades. On DoD installations where an organized, dedicated fire department is not justified and external assistance is not readily available, fire brigades shall be organized and provided appropriate equipment and training. The installation commander shall publish a written policy statement that includes the brigade's. functions and work place. Personnel expected to do interior structural fire fighting shall be physically capable and trained to perform the required tasks. Fire fighting equipment shall be operationally satisfactory.

17. Program Management and Evaluation

a. Fire and emergency services program operational readiness inspections shall be conducted at intervals established by the DoD Component.

b. The DoD Components shall periodically evaluate the target buildings used for establishing fire flow rates at each installation to determine where annual pumper operating and salary costs can be economically offset by the one-time expenditure for installing sprinklers. 

A. Permanently assigned aircraft having. less than 1,000-gallon fuel capacity and all helicopters.

B. Permanently assigned aircraft less than 75 feet in length; or carrying ordnance.

c. Permanently assigned aircraft less than 100 feet in length or carrying ordnance.

D. Permanently assigned aircraft less than 175 feet in length; ordance, high value, on hazardous cargo.

E. Permanently assigned aircraft greater than 175 feet in length; ordnance; hazardous or high-value cargo.
To be determined by

DoD Component
$2 w / 2,000$ gallon total capacity

3w/3,000-gallon total capacity

3w/9,000-gallon total capacity total capacity

NOTE. These ininimum allowances do not include specialized ARFF vehicle requirements for airfields, such as Twin Agent Units, rescue vehicles, rapid intervention vehicles.

MAXIMUM RESPONSE TIMES FOR STRUCTURAI FIRE PUMPERS NOTE: Rumpers may be located to serve several or all areas if situated. within the response time. Some areas may be served entirely by pumpers from other areas within the prescribed response times. END NOTE:

DESCRIPTION . . - RESPONSE TIME (Minutes)

NOTE: DOD Components may increase response times when adequate fixed fire protection systems are provided. END NOTE:

1ST 508 REMAINING 508

1. Shops and Industrial Buildings

2. Hangars

3. Warehouses

4. Technical Facilities

5. Hospitals

6. Ship Berthing

7. Administrative 
8. Exchange and Commissary

9. Recreation and Assembly

10. Dining Halls

11. Bachelor Office Quarters,

Bachelor Enlisted Quarters, .

Dormitories

12. Multifamily Dwellings

13. Single and Duplex Dwellings

14. Trailer Courts

15. Isolated or scattered Buildings

STAEFING REQUIREMENTS FOR MANAGEMENT AND ADMINISTRATIVE FIRE SERVICE POSITIONS
18

18

18

20

POSITIONS

NUMBERS OF FIRE COMPANIES

NOTE: Eigures reflect only those personnel necessary to meet fire suppression needs (staffed fire apparatus) and do not consider personnel required for fire prevention, fire alarm communications, management and administration, and personnel assigned for maintenance of fixed fire protection systems. END NOTE:

$$
12345 \text { or more }
$$

\section{Fire Chief}

$$
1 \quad 1 \quad 1 \quad 1 \quad 1 .
$$

2. Deputy Eire Chief
11.

NOTE: Deputy Fire Chief. Position may be authorized by DoD Component. END NOTE:

3. Assistant Fire Chief (Shift Supervisor)

$$
2 \quad 2 \quad 2 \quad 2
$$

4. Assistant Fire Chief (Training)

$1 \cdot 1 \quad 1$

NOTE: Assistant Fire Chief (Training). Position may be authorized by DOD Component. END NOTE:

5. Assistant Fire.Chief (Fire Prevention). Where four or more fire prevention personnel are required, an assistant fire chief (fire prevention) is authorized.

6. District/Battalion Chief (Supervisory Fire Fighter). Additional supervisors may be required due to the overall size and large geographic service areas at large or consolidated installations, where the physical dispersion of fire department stations makes it unmanageable for one shift supervisor to provide immediate direction of day-to-day operations. 
NOTE: Total square footage of buildings (excluding family housing); continuously used outside storage areas (continuous movement of equipment and/or supplies to and from the storage site), ships and waterfront facilities: END NOTE:

NOTE: These baseline staffing figures may be increased or decreased depending on the DOD Component' assessment of the hazardous nature of the matrerial stored or operations conducted amount of fire of fighter crew-type inspections conducted on low-hazard occupancies, the mission criticality of the equipment and operations, predominant construction features, utilization of fire prevention personnel for public fire education and review of construction plans; and other local factors bearing on the demand for full-time fire prevention personnel. END NOTE:

$251-750$

$751-1,500$

$1,501-2,500$

$2,501-5,000$

$5,001-8,500$

$8,501-12,500$

$12,501-17,500$
1.

2

3

4

5 .

6

7

17,501 and above

NOTE: The number of fire Prevention perșonnel for areas in excess of $17,500,000$ square feet shall be determined on a case-by-case basis by the Dod Component.

\section{STAEFING REQUIIREMENTS FOR FIRE APPARATUS}

FIRE, APPARATUS IDENTIEIERS

POSITIONS PER

VEHICLE REQUIRED

1. AREF Fire Fighting Apparatus 3 NOTE: AREF fire fighting apparatus with manual turrets require four positions per vehicle. END NOTE: 


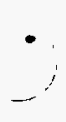


4. AREF Twinned Agent Fire Fighting Apparatus

5. Structural Pumpers $\approx \quad: \quad \cdot \quad 4$

6. Aerial Ladders

7. Structurai Rescue Apparatus

8. Hazardous Materials Apparatus

9. Structural. Tanker and/or Resupply Apparatus 1

10. Brush Fire Apparatus

NOTE: Brush truck, brush/structural, or MACI truck shall be considered synonymous. However, when the primary response is structural, four positions may authorized by the DoD.Component. At installations with severe wildfire risk, two positions per brush fire truck may be authorized by the DOD Component. END NOTE: 



\title{
nemorandum
}

DATE:

\author{
MAR 07 1995:
}

REPLY TO

ATTN OF:

Occupational Safety and Health Policy:Kubicki:3-4794

SUBJECT: IMPLEMENTATION OF NFPA STANDARD 25

TO:

\section{Distribution}

The purpose of this memorandum is to provide guidance on the implementation of National Fire Protection Association (NFPA) Standard 25, "Standard for the Inspection, Testing, and Maintenance of Water-Based Fire Protection Systems." This Standard has been in effect since it's promulgation in 1992 and has been applicable to the Department of Energy (DOE) through the requirements del ineated in DOE 5480.4, "Environmental Protection, Safety and Hea7th Protection Standards," and 5480.7A; "Fire Protection."

The subject guidelines, which are included as Attachment 1, were developed by the DOE Fire Safety Committee based on requests for assistance from both $D O E$ and contractor fire protection representatives and maintenance organizations. This guidance was perceived to be needed to reduce unnecessary costs associated with inspection, testing and maintenance of fire protection systems and to facilitate the application of the Standard to the unique circumstances which characterize the Department.

Neither this memorandum nor the attached guidelines impose new requirements on the Department or it's contractors. In fact, the guidance in some instances reflects a relaxation of existing requirements from those delineated in the NFPA Standard. To the extent that this was done, the DOE Fire Safety Committee considered the implications and concluded that implementation of the revised criteria would maintain an acceptable level of safety.

Nothing in these guidelines prevents the development of alternate approaches that will achieve a comparable level of fire protection. These approaches can be implemented based on an "Equivalency" determination as defined by DOE $5480.7 \mathrm{~A}$.

If you have any questions, please contact me on 301-903-4794.

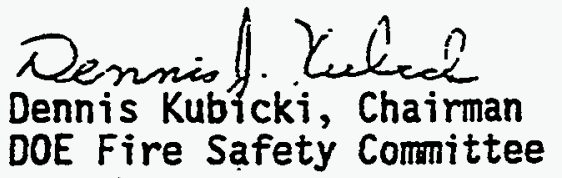

Attachment 


\section{DISTRIBUTION}

Chuck Ramsey, EH

Bill Boyce, EM

Matt Cole, ER

Carl Caves, NE

Bill Froh, DP

Dennis Kirson, AL

David Boy 11, SR

Jim Hutton, OR

Dario Luna, NV

Patrick Smith, ID

Mike Saar, $\mathrm{CH}$

Craig Christenson, RL

Don Kelly, OK

Peter Lee, RF

Nadine Giimore, $\mathrm{OH}$

Deri Harper, Fernaid

Terry Dembrowski, WAPA

David Heitz, Hound

Gordon Veerman, ANL-East

Bud Bucci, Hanford

Bruce Campbe17, Rocky Flats

Bill Brown, Y-12

Halter Maybee, LANL

Virginja Hoitzclaw, Sandia Livermore

John Sharry, LLNL

Norm Hess, Savannah River

Ken Phillips, EG\&G Idaho

Dave Barreres, Yucca Mountain Project 
IMPLEMENTATION OF NATIONAL FIRE PROTECTION ASSOCIATION STANDARD 25, "INSPECTION, TESTING, AND MAINTENANCE OF WATER-BASED FIRE PROTECTION SYSTEMS" AT DEPARTMENT OF ENERGY EACILITIES 
TABLE OF CONTENTS

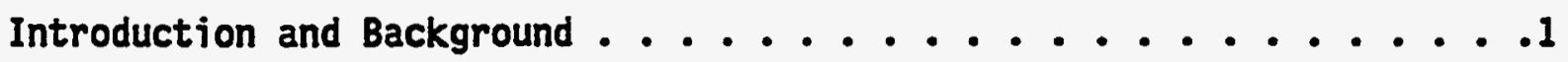

General Discussion of Maintenance

of Fire Protection Systems. . . . . . . . . . . . . . 2

Method. . . . . . . . . . . . . . . . . . . .

Subcomittee PhiTosophy ..................... . .

DOE Maintenance Management Order,

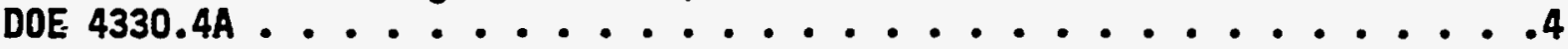

Nuclear Facilities. . . . . . . . . . . . . . . . . 4

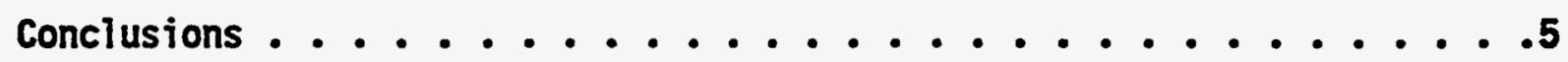

Specific Subcomittee Recommendations . . . . . . . . . . . . 5

Recommended Frequencies Matrix. . . . . . . . . . . . . 6 


\section{Introduction and Background}

The Department of Energy (DOE), by its choice, complies with the National Fire Protection Association (NFPA) standards, including NFPA 25 on Inspection, Testing, and Maintenance of Hater-Based Fire Suppression Systems. The NFPA issued its Standard 25 on February 10, 1992. This document gathered all the inspection, testing, and maintenance requirements for these systems into one standard; previousiy they were contained in the various design standards for water-based fire suppression systems. The frequencies of many maintenance requirements were increased in the new NFPA 25, and there were many required procedures added.

Prior to the development of and unrelated to NFPA 25, the DOE Richland Operations Office decided to study its maintenance and fire protection system failure rate data to see if there was justification to reduce its costs by not conforming with the NFPA frequencies. A committee of fire protection professionais there found such justification for the Hanford Site, and decided to request that frequencies be reduced for maintenance of 14 specific fire protection systems. They submitted an exemption request to the DOE Office of Environmental Management, which ultimateTy approved and forwarded it to the DOE Office of Environment, Safety, and Health. The Office of Environment, Safety, and Health approved that request.

The DOE Fire Safety Committee, aware of Richland's action, decided to form some subcommittees at its December 1992 meeting to study some specific problems. One of these was a Programmatic Issues Subcommittee, which was first charged with developing DOE-wide guidance on implementing NFPA 25, based on the Richland exemption request and a Draft Hanford Site Compliance with NFPA 25 Plan. This is the report of that Subcommittee's work.

A request for a determination of equivalency to NFPA 25 was also submitted by Martin Marietta Energy Systems, Inc. (MMES), to the Oak Ridge Operations Office and to the Office of Environment, Safety, and Health. That request was approved, contingent upon MMES complying with the recommendations of the Programmatic Issues Subcommittee. The Subcommittee examined the MMES proposal in detail, including many instances where differing maintenance frequencies that had been previously recommended existed, and determined appropriate frequencies for maintenance of fire protection systems.

There is a general lack of available data on how previous and existing fire suppression system maintenance requirements were estab7ished. Several literature searches and discussions with technical experts in this area failed to reveal definitive research in this area. Failure rate data were obtained from several DOE sites, and some comparisons were made on the effects of changing testing frequencies in particular to see what failure rates would subsequently result. For the case where this was done the failure rates were actualiy worse at the site with the more frequent testing. In some cases, the best answers the Subcommittee was able to justify were that professionai judgement and experience, as used by the NFPA committees in establishing the existing maintenance requirements, had to be used when establishing our own requirements. 


\section{General Discussion of Maintenance of Fire Protection Systems}

The establishment of maintenance requirements, including the specific maintenance actions needed and the frequencies at which they must be performed, is not an exact science. The goal is to balance the amount of maintenance to maximize system life or reliability against the cost of the maintenance. Theoreticaliy, more frequent maintenance leads to longer life and higher reliability. It also leads to increased costs. Optimization of maintenance frequency might be achieved by performing maintenance at the point where the graphs of frequency of maintenance and system reliability intersect. Some manufacturers do parametric studies of their products or systems to determine the optimum maintenance requirements, but that has not been done for fire protection systems.

Un7ike many "systems," there is little "maintenance" which is done to fire suppression systems, on a routine basis, to increase their performance or prolong their useful life. There is no periodic cleaning done to enhance performance, no lubrication, no planned replacement of parts on a periodic basis, and no measurement of system performance to predict future maintenance needs. Maintenance of fire protection systems consists largely of periodic testing of components, either singly or in a full system test, to verify operation, and periodic inspection to verify system integrity. Fire protection systems are examined visualiy to ensure that there are no gross misconfigurations or degradation problems which would prevent performance, and that system components are operable, e.g. nozzles and sprinkler heads are not blocked.

There are exceptions. The more "exotic" systems, such as foam-water systems, require chemical testing of the foam. These systems have substantially more moving parts than most fire suppression systems that do require more of what might be considered "maintenance" than do more common fire suppressien systems. Additionally, internal combustion engines which drive generators or fire pumps also have more classical maintenance requirements such as periodic replacement of lubricating oils.

The benefit from fire suppression systems maintenance as it is done now is that critical system components which have failed or are near failure are not allowed to remain in that state for long periods of time. Increasing the frequency of maintenance would lessen the time that a component was allowed to remain in a failed state without the knowledge of the systems operators. The study which was done at Hanford documented very low rates of failure of components in large populations of specific maintenance procedures performed. Hanford is continuing to take data to determine if their decreased maintenance frequencies are causing increases in faijure rates.

In considering which specific frequencies to recommend for testing of certain components, the Subcommittee tended not to make extreme changes in the Tength of component operational testing that might significantly increase the timie in which failed components remain in service, however. 


\section{Method}

The Subcommittee met in a face-to-face setting at the Annual DOE/Contractor Fire Protection meeting in Augusta, Georgia, in March of 1993 and the Annua meeting in Albuquerque, New Mexico, in May, 1994. It met numerous other times by teleconference. The Subcommittee discussed each point of the proposed Draft Hanford Site Compliance With NFPA $25 \mathrm{plan}$, and the current7y-approved Oak Ridge maintenance schedule. The issue of the validity of transferring the Hanford or Oak Ridge recommendations generically to all DOE sites was discussed at length. Many hesitations to adopt the existing proposals were based on such questions of validity of the rationale used to justify those proposals as it would be applied to places with differing security and environmental conditions. The question of application of the Subcommittee recommendations to fire suppression systems in nuclear facilities was discussed.

Several literature searches were done. The collection of the Fire Research Information Services at the National Institute of Standards and Technology was searched for research on maintenance and fire protection systems. The DOE Headquarters!' Library performed a literature search on the key words "fire protection system" and "maintenance." And the NFPA Library performed a search to try to correlate fire protection systems, maintenance, and system reliability. These efforts turned up little work done on maintenance, and essentially no work done to identify correlation between maintenance of fire protection systems and their reliability.

The Subcommittee's recommendations on maintenance frequencies are included in this report in tabular form, with justifications and footnotes included. The specific deliberations of the Subcommittee are included in its minutes, attached as an appendix to this report. Where appropriate, references are provided.

\section{Subcommittee Philosophy}

The Subcommittee used the Draft Hanford Site Compliance Hith NFPA 25 and the Oak Ridge fire protection maintenance $p$ Tan to consider changes to NFPA 25 requirements. The Hanford plan was developed by engineers at the Hanford site in consideration of their failure experience and environmental conditions. The effort put into developing the Hanford plan was very comprehensive, and the Subcommittee did not desire to duplicate it. Likewise, the Oak Ridge frequencies have been used for upwards of 20 years, with acceptable failure rates being experienced. Where there was any question that the basis for the a recommendation may not be generaliy applicable to DOE sites, the Subcommittee opted to stick with the NFPA 25 frequency.

Many of the maintenance frequencies were not changed, but were caveated with a note for a DOE site to make its own judgement to use the NFPA requirement or to request relief through DOE. These were left that way because of the uncertainties of external environmental influences upon structural integrity of systems and influences upon the performance of some parts, such as strainers. Engineers at DOE sites, which believe that they have justification for changing these maintenance frequencies, should examine the basis for the Hanford changes in maintenance; the intent of the NFPA 25 standard; the 
specific performance requirements of their systems; and the specific environmental conditions encountered and their effects on system integrity and performance. Situations thought to justify less frequent maintenance must be referred to the DOE Operations Office through appropriate channels for consideration of an Equivalency as defined by the DOE Fire Protection Order, DOE 5480.7A.

The Subcommittee did not attempt to rigorously define the term "failure." A failure was considered as the specific piece of equipment being inspected or tested not meeting the inspection or test criteria.

\section{DOE Maintenance Management Order, 4330.4A}

This DOE Order currentiy governs the maintenance of DOE facilities. It requires that DOE contractors develop Maintenance Implementation PIans addressing certain specified elements of good maintenance programs and practices. The determination of maintenance procedures and frequencies for nuclear facilities is based on regulatory and code requirements; vendor recommendations; experience at this facility and other facilities; engineering judgement; cost/benefit analysis; available manpower; minimizing personnel radiation exposure using ALARA principles; function, ease of replacement, and demonstrated reliability of the equipment or system; optimizing the equipment or system availability during unit operating conditions; and operating history. (XX - Chapter II, para. 5.3.3) These are the same principles that the Subcommittee used in its deliberations. The Subcommittee believes that its work is compatible with the requirements of this Order.

\section{Nuclear Facilities}

Maintenance at DOE nuclear facilities wi?l soon be governed by 10 CFR 830 Part 340. The original draft of this regulation was published in the December 9, 1991, edition of the Federal Register. The major point of this regulation is that a Maintenance and Implementation Plan will be required for nuclear facilities, and that plan will be approved by DOE. The M\&IP will contain specifics on which systems in the nuclear facility are covered, what maintenance will be done on those systems, and when that maintenance will be done, among other things. Any deviations from NFPA 25 or other nationally recognized consensus standards for maintenance of systems in nuclear facilities will have to be listed in the Implementation Plan for this nuclear safety rule, to be approved by the Cognizant Secretarial Officer or designee. These deviations will have to be carefully scrutinized and justified. The avenue to do this is clearly through the development and approval of the M\&IP. 


\section{Conclusions}

The Subcommittee reminds all readers of this document that the NFPA 25 requirements are minimum requirements which should not be changed without solid technical rationale. The Subcommittee believes that the rationale used in the development of the maintenance frequencies in this document was sound. This document constitutes a fully DOE-approved equivalent means of complying with the NFPA 25 standard.

\section{Specific Subcommittee Recommendations}

The following table lists those specific maintenance, test, or inspection activities from NFPA 25 which the Subcommittee changed or thought that a DOE site might be able to justify change based on their specific environmental circumstances. The Subcommittee recommends that contractors perform trend analysis of failures of their fire protection systems so that a sufficient database will exist in the future to justify equivalencies. 


\section{Recommended Frequencies Matrix}

Note: Only in those instances where a change from NFPA 25 was made; a potentially-justified change was indicated; or a conscientious decision was made to continue with the NFPA 25 frequency, are shown in these tables. The frequencies specified in NFPA 25 should be followed for Category I nuclear facilities or facilities specifically open to the general public, i.e., museums and public auditoriums.

\begin{tabular}{|c|c|c|c|}
\hline Item & $\begin{array}{l}\text { NFPA } 25 \\
\text { Reference }\end{array}$ & $\begin{array}{l}\text { NFPA } 25 \\
\text { Frequency }\end{array}$ & Recommended Frequency and Justification \\
\hline \multicolumn{4}{|c|}{$\begin{array}{l}\text { Chapter 2, Sprinkler } \\
\text { Systems }\end{array}$} \\
\hline $\begin{array}{l}\text { Sprinkter head, } \\
\text { Inspection }\end{array}$ & $2-2.1 .1$ & Annually & $\begin{array}{l}\text { At same frequency as facility assessment is required, } \\
\text { not to exceed three years. } \\
\text { This is understood to be on the basis of a floor-level } \\
\text { visual examination of a representative sample. } \\
\text { These passive components are not prone to failure under } \\
\text { normal conditions. It is unlikely that a visual } \\
\text { inspection would reveal a condition which would cause } \\
\text { failure of a sprinkler head. If systems are exposed to } \\
\text { severe environments, this frequency should be re- } \\
\text { examined }\end{array}$ \\
\hline
\end{tabular}




\begin{tabular}{|c|c|c|c|}
\hline Item & $\begin{array}{l}\text { NFPA } 25 \\
\text { Reference } \\
\end{array}$ & $\begin{array}{l}\text { NFPA } 25 \\
\text { Frequency }\end{array}$ & Recommended Frequency and Justification \\
\hline $\begin{array}{l}\text { Alarm Device, } \\
\text { Inspections }\end{array}$ & $2-2.6$ & Monthly & $\begin{array}{l}\text { Quarterly, } \\
\text { Same as NFPA } 72 \\
\text { NFPA } 72 \text { allows a quarterly visual inspection of the } \\
\text { alarm initiating device. If it is acceptable to inspect } \\
\text { the electrical portion quarterly, then it should be } \\
\text { acceptable to inspect, to the extent possible, the } \\
\text { mechanical part quarterly also. }\end{array}$ \\
\hline $\begin{array}{l}\text { Hydraulic nameplate } \\
\text { on sprinkler } \\
\text { systems, Inspection }\end{array}$ & $2-2.7$ & Quarterly & $\begin{array}{l}\text { At same frequency as facility assessment is required, } \\
\text { not to exceed three years. } \\
\text { DOE contractors generally maintain a system of drawings } \\
\text { which would permit retrieval of the needed information. } \\
\text { There is little chance of tampering with or removal of } \\
\text { a hydraul ic nameplate in a DOE facility also. } \\
\text { See footnote AA. }\end{array}$ \\
\hline $\begin{array}{l}\text { Waterflow alarms, } \\
\text { Test }\end{array}$ & $2-3.3$ & Quarterly & $\begin{array}{l}\text { Quarterly, } \\
\text { Unless a site justifies a less frequent activity based } \\
\text { on their failure rates and obtains an approved DOE } \\
\text { equivalency to NFPA } 25 . .\end{array}$ \\
\hline $\begin{array}{l}\text { Gauges, } \\
\text { Test }\end{array}$ & $2-3.2$ & 5 years & $\begin{array}{l}\text { Note gauge condition during inspection or test, test or } \\
\text { replace if abnormality noted. }\end{array}$ \\
\hline $\begin{array}{l}\text { Sprinkler System } \\
\text { Piping, Inspection }\end{array}$ & $2-2.3$ & Annually & $\begin{array}{l}\text { At same frequency as facility assessment is required, } \\
\text { not to exceed three years. }\end{array}$ \\
\hline $\begin{array}{l}\text { Water motor gong, } \\
\text { Test }\end{array}$ & $2-3.3$ & Quarterly & $\begin{array}{l}\text { Quarterly, } \\
\text { Unless a site justifies a less frequent activity based } \\
\text { on their failure rates and obtains an approved DOE } \\
\text { equivalency to NFPA } 25 \text {. }\end{array}$ \\
\hline
\end{tabular}




\begin{tabular}{|c|c|c|c|}
\hline Item & $\begin{array}{l}\text { NFPA } 25 \\
\text { Reference } \\
\end{array}$ & $\begin{array}{l}\text { MFPA } 25 \\
\text { Frequency }\end{array}$ & Recommended Frequency and Justification \\
\hline $\begin{array}{l}\text { Compressor, } \\
\text { Maintenance }\end{array}$ & $2-4.2 .1$ & $\begin{array}{l}\text { Per } \\
\text { manufacturer }\end{array}$ & $\begin{array}{l}\text { Annually } \\
\text { Some manufacturers do not provide specific frequencies } \\
\text { for maintenance. Annually was believed to be a } \\
\text { reasonable frequency for these devices based on no } \\
\text { known failures presented to the Subcommittee. }\end{array}$ \\
\hline \multicolumn{4}{|c|}{$\begin{array}{l}\text { Chapter 3, Standpipe } \\
\text { and Hose Systems }\end{array}$} \\
\hline $\begin{array}{l}\text { Hose Cabinets, } \\
\text { Inspection }\end{array}$ & 3.1 & Monthly & $\begin{array}{l}\text { At same frequency as facility assessment is required, } \\
\text { not to exceed three years. } \\
\text { There were no known failures of standpipe systems, } \\
\text { attributable to the condition of a hose cabinet, } \\
\text { discussed in subcommittee del iberations. The failure } \\
\text { of a cabinet would not lead to automatic failure of the } \\
\text { system. Because of these factors, an annual inspection } \\
\text { was recommended. }\end{array}$ \\
\hline $\begin{array}{l}\text { Alarm Devices, } \\
\text { Test }\end{array}$ & 3.1 & Quarterly & $\begin{array}{l}\text { Quarterly, } \\
\text { Unless a site justifies a less frequent activity based } \\
\text { on their failure rates and obtains an approved DOE } \\
\text { equivalency to NFPA 25. }\end{array}$ \\
\hline $\begin{array}{l}\text { Hose Nozzles, } \\
\text { Inspection }\end{array}$ & $\begin{array}{l}\text { Table } 3-1, \\
\text { refers } \\
\text { user to } \\
\text { NFPA } 1962 \\
\text { - where } \\
\text { para. 4- } \\
1.2 \\
\text { applies } \\
\end{array}$ & $\begin{array}{l}\text { Annually by } \\
\text { NFPA } 1962 \text {, } \\
\text { Monthiy by } \\
\text { para. } 3-2.1 \text { of } \\
\text { NFPA } 25\end{array}$ & $\begin{array}{l}\text { At same frequency as facility assessment is required, } \\
\text { not to exceed three years. } \\
\text { Nozzles are rugged devices, not prone to frequent } \\
\text { failure. }\end{array}$ \\
\hline
\end{tabular}




\begin{tabular}{|c|c|c|c|}
\hline Item & $\begin{array}{l}\text { NFPA } 25 \\
\text { Reference } \\
\end{array}$ & $\begin{array}{l}\text { MFPA } 25 \\
\text { Frequency }\end{array}$ & Recommended Frequency and Justification \\
\hline $\begin{array}{l}\text { Hose Nozzles, } \\
\text { Test }\end{array}$ & $\begin{array}{l}\text { Table 3-1, } \\
\text { para. 3- } \\
2.1\end{array}$ & Monthly & $\begin{array}{l}\text { As determined to be needed, if a visual inspection } \\
\text { reveals abnormalities, or after any-nozzle maintenance. } \\
\text { Nozzles are rugged devices. }\end{array}$ \\
\hline $\begin{array}{l}\text { Hose storage rack, } \\
\text { Inspection }\end{array}$ & $\begin{array}{l}\text { Table 3-1, } \\
\text { refers } \\
\text { user to } \\
\text { NFPA 1962, } \\
\text { which says } \\
\text { nothing }\end{array}$ & $\begin{array}{l}\text { Month7y, per } \\
\text { NFPA 25 } \\
\text { general } \\
\text { paragraph } \\
3-2.1\end{array}$ & $\begin{array}{l}\text { At same frequency as facility assessment is required, } \\
\text { not to exceed three years. } \\
\text { These are rugged devices, not subject to failures which } \\
\text { are so subtle and sudden, that monthly inspections are } \\
\text { required. }\end{array}$ \\
\hline $\begin{array}{l}\text { Hose storage rack, } \\
\text { Test }\end{array}$ & $\begin{array}{l}\text { Table } 3-1, \\
\text { refers } \\
\text { user to } \\
\text { NFPA } 1962, \\
\text { which says } \\
\text { nothing }\end{array}$ & $\begin{array}{l}\text { Monthly, per } \\
\text { NFPA } 25 \text { para } \\
\text { general para } \\
3-2.1\end{array}$ & $\begin{array}{l}\text { At same frequency as facility assessment is required, } \\
\text { not to exceed three years. } \\
\text { These are rugged devices, not subject to failures which } \\
\text { are so subtle and sudden that monthly inspections are } \\
\text { required. }\end{array}$ \\
\hline $\begin{array}{l}\text { Standpipe systems, } \\
\text { Alarm device, } \\
\text { Test }\end{array}$ & $3-3.3$ & Quarterly & $\begin{array}{l}\text { Quarterly, } \\
\text { Unless a site justifies a less frequent activity based } \\
\text { on their failure rates and obtains an approved DOE } \\
\text { equivalency to NFPA } 25 \text {. }\end{array}$ \\
\hline $\begin{array}{l}\text { Chapter } 4 \text {, Private } \\
\text { Fire Service Mains }\end{array}$ & & & \\
\hline $\begin{array}{l}\text { Mainline Strainers, } \\
\text { Inspection }\end{array}$ & $4-3.2 .3$ & Annually & $\begin{array}{l}\text { Inspection per manufacturers requirements, if used in } \\
\text { potable water systems. } \\
\text { Annually, if no manufacturer's recommendation or if } \\
\text { used in raw water applications. }\end{array}$ \\
\hline
\end{tabular}




\begin{tabular}{|c|c|c|c|}
\hline Item & $\begin{array}{l}\text { NFPA } 25 \\
\text { Reference }\end{array}$ & $\begin{array}{l}\text { MFPA } 25 \\
\text { Frequency }\end{array}$ & Recommended Frequency and Justification \\
\hline $\begin{array}{l}\text { Hydrants, } \\
\text { Dry Wail \& Het, } \\
\text { Inspection, } \\
\text { Test, \& Maintenance }\end{array}$ & $\begin{array}{l}4-3.2 .4 \\
4-3.2 .5 \\
4-5.3\end{array}$ & $\begin{array}{l}\text { I - } 6 \mathrm{mo}^{\prime} \mathrm{s} \\
\text { T }-1 \mathrm{yr} \\
M-1 \mathrm{yr} \\
\text { The valve to } \\
\text { the hydrant } \\
\text { should be } \\
\text { tested to } \\
\text { ensure it is } \\
\text { fully open. }\end{array}$ & $\begin{array}{l}\text { Annually } \\
\text { (combined I, T, M) } \\
\text { This is a hydrant flush rather than a quantitative test } \\
\text { of the hydrant flow. Hydrants are rugged devices. } \\
\text { Large municipal water supply systems generally test } \\
\text { these annually. The valve to the hydrant should be } \\
\text { tested to ensure it is fully open. }\end{array}$ \\
\hline $\begin{array}{l}\text { Hose/Hydrant Houses, } \\
\text { Inspection }\end{array}$ & $4-3.2 .7$ & Monthly & $\begin{array}{l}\text { Annually } \\
\text { These are rugged devices, not generally prone to } \\
\text { failure. }\end{array}$ \\
\hline \multicolumn{4}{|l|}{$\begin{array}{l}\text { Chapter } 5, \\
\text { Fire Pumps }\end{array}$} \\
\hline $\begin{array}{l}\text { Fire pumps } \\
\text { Heating system, } \\
\text { Inspection }\end{array}$ & $\begin{array}{l}\text { Table 5- } \\
2.2\end{array}$ & $\begin{array}{l}\text { Heekly during } \\
\text { heating season }\end{array}$ & $\begin{array}{l}\text { Weekly, during the heating season, if there is no } \\
\text { constantly-monitored low temperature alarm. } \\
\text { Monthly if the temperature is constantly monitored at } \\
\text { an attended location. }\end{array}$ \\
\hline $\begin{array}{l}\text { Fire pumps, } \\
\text { Vent louvers, } \\
\text { Inspection }\end{array}$ & $\begin{array}{l}\text { Table 5- } \\
2.2\end{array}$ & $\begin{array}{l}\text { Weekly during } \\
\text { heating season }\end{array}$ & $\begin{array}{l}\text { Weekly, during the heating season, if there is no } \\
\text { constantly-monitored low temperature alarm. } \\
\text { Monthly if the temperature is constantly monitored at } \\
\text { an attended location. }\end{array}$ \\
\hline $\begin{array}{l}\text { Chapter } 6 \text {, Water } \\
\text { Storage Tanks }\end{array}$ & . & & \\
\hline
\end{tabular}




\begin{tabular}{|c|c|c|c|}
\hline Item & $\begin{array}{l}\text { NFPA } 25 \\
\text { Reference } \\
\end{array}$ & $\begin{array}{l}\text { NFPA } 25 \\
\text { Frequency }\end{array}$ & Reconmended Frequency and Justification \\
\hline $\begin{array}{l}\text { Water storage tanks, } \\
\text { Water condition } \\
\text { (check for ice } \\
\text { buildup), } \\
\text { Inspection }\end{array}$ & $6-2.1$ & $\begin{array}{l}\text { Daily, during } \\
\text { the heating } \\
\text { season }\end{array}$ & $\begin{array}{l}\text { Site specific } \\
\text { Daily during the heating season unless the water } \\
\text { temperature is constantly monitored at an attended } \\
\text { location. } \\
\text { There were so many variations in frequencies for these } \\
\text { inspections, and varying degrees of risk of system } \\
\text { failure due to tank freeze-up, that the inspection } \\
\text { frequency was tied to freezing risk, water temperature } \\
\text { monitoring, and previous freezing experience. }\end{array}$ \\
\hline $\begin{array}{l}\text { Water storage tanks, } \\
\text { leating system, } \\
\text { Inspection }\end{array}$ & $6-2.8$ & $\begin{array}{l}\text { Daily, during } \\
\text { the heating } \\
\text { season }\end{array}$ & $\begin{array}{l}\text { Site specific } \\
\text { Daily during the heating season unless the water } \\
\text { temperature is constantiy monitored at a attended } \\
\text { location. } \\
\text { There were so many variations in frequencies for these } \\
\text { inspections, and varying degrees of risk of system } \\
\text { failure due to tank freeze-up, that the inspection } \\
\text { frequency was tied to freezing risk, water temperature } \\
\text { monitoring, and previous freezing experience. }\end{array}$ \\
\hline $\begin{array}{l}\text { Chapter } 7 \text {, Water } \\
\text { Spray Fixed Systems }\end{array}$ & . & & \\
\hline $\begin{array}{l}\text { Mainline strainers, } \\
\text { Inspection and } \\
\text { Maintenance, if } \\
\text { required }\end{array}$ & $\begin{array}{l}7-4.1 .5 \& \\
7-4.9\end{array}$ & $\begin{array}{l}I \text { - per } \\
\text { manufacturer } \\
M-5 \text { years }\end{array}$ & $\begin{array}{l}5 \text { years, } \\
\text { Combined I \& } M \text {, } \\
\text { If water is contaminated, the site should use } \\
\text { engineering judgement to set an inspection frequency to } \\
\text { allow for this condition. }\end{array}$ \\
\hline
\end{tabular}




\begin{tabular}{|c|c|c|c|}
\hline Item & $\begin{array}{l}\text { MFPA } 25 \\
\text { Reference }\end{array}$ & $\begin{array}{l}\text { NFPA } 25 \\
\text { Frequency }\end{array}$ & Recommended Frequency and Justification \\
\hline $\begin{array}{l}\text { Valve Enclosures, } \\
\text { cold weather, } \\
\text { Inspection }\end{array}$ & $7-4.1 .2$ & Weekly & $\begin{array}{l}\text { See recommended frequencies for valve/fire pump } \\
\text { enclosures in Chapters } 2,5 \text {, and } 9 \text { Recommendations }\end{array}$ \\
\hline $\begin{array}{l}\text { Pipe \& hangars, } \\
\text { Inspection }\end{array}$ & $7-4.4$ & Monthly & $\begin{array}{l}\text { Annually } \\
\text { These are robust components, not subject to sudden, } \\
\text { unknown failures which could not be detected via an } \\
\text { annual inspection. }\end{array}$ \\
\hline $\begin{array}{l}\text { Spray nozzles, } \\
\text { Inspection }\end{array}$ & $7-4.5$ & Monthly & $\begin{array}{l}\text { Annually } \\
\text { These are robust components, not subject to sudden, } \\
\text { unknown failures which could not be detected via an } \\
\text { annual inspection. }\end{array}$ \\
\hline $\begin{array}{l}\text { Individual Nozzle } \\
\text { strainers, water } \\
\text { spray \& foam } \\
\text { systems, Inspection } \\
\& \\
\text { Maintenance } \\
\end{array}$ & $\begin{array}{l}7-4.9 \& \\
8-3.8 .1\end{array}$ & Annualiy & $\begin{array}{l}\text { Annually, or after each flow test or operation of the } \\
\text { system }\end{array}$ \\
\hline $\begin{array}{l}\text { Drainage, } \\
\text { Inspection }\end{array}$ & $7-4.10$ & Monthly & $\begin{array}{l}\text { Annualiy } \\
\text { The presence or lack of adequate drainage will not } \\
\text { affect the ability of the system to extinguish fire; it } \\
\text { is a secondary effect only, with possible environmental } \\
\text { impact. There were no cases of failure of some factor } \\
\text { affecting drainage brought to the attention of the } \\
\text { Subcommittee. }\end{array}$ \\
\hline $\begin{array}{l}\text { Chapter } 8 \text {, Foam- } \\
\text { Water Sprinkler } \\
\text { Systems }\end{array}$ & & & . \\
\hline
\end{tabular}




\begin{tabular}{|l|l|l|l||}
\hline Item & $\begin{array}{l}\text { NFPA 25 } \\
\text { Reference }\end{array}$ & $\begin{array}{l}\text { NFPA 25 } \\
\text { Frequency }\end{array}$ & Recommended Frequency and Justification \\
\hline $\begin{array}{l}\text { Foam-water systems } \\
\text { Discharge device } \\
\text { location, position, } \\
\text { and check for } \\
\text { obstruction, } \\
\text { Inspection }\end{array}$ & $8-3.4$ & Monthly & $\begin{array}{l}\text { Annually } \\
\text { There were no reported cases of discharge devices being } \\
\text { moved or obstructed in the foam systems at Oak Ridge } \\
\text { Given that DOE facilities are not generally accessibie } \\
\text { to the public, particularly not sites where the hazard } \\
\text { requires a foam system, an annual basis for this } \\
\text { inspection was believed by the Subcommittee to be } \\
\text { acceptable. }\end{array}$ \\
\hline $\begin{array}{l}\text { Foam-water systems, } \\
\text { Foam concentrate } \\
\text { strainer, } \\
\text { Inspection }\end{array}$ & $8-5$ & Monthly & $\begin{array}{l}\text { Annually, for systems using AFFF foam and fresh water. } \\
\text { Monthly for other foam systems. }\end{array}$ \\
\hline $\begin{array}{l}\text { Foam-water systems } \\
\text { Drainage, } \\
\text { Inspection }\end{array}$ & $8-3.9$ & $\begin{array}{l}\text { There were no reported cases of clogging of foam } \\
\text { concentrate strainers in DOE AFFF foam systems at 0ak } \\
\text { Ridge. }\end{array}$ \\
\hline & Monthly & $\begin{array}{l}\text { Annually } \\
\text { The presence or absence of adequate drainage will not } \\
\text { have a direct impact on the system's ability to } \\
\text { extinguish fire; it is a secondary effect only, with } \\
\text { possible environmental impact. There were no cases of } \\
\text { failure of some factor affecting drainage brought to } \\
\text { the attention of the Subcommittee. }\end{array}$ \\
\hline
\end{tabular}




\begin{tabular}{|c|c|c|c|}
\hline Item & $\begin{array}{l}\text { NFPA } 25 \\
\text { Reference } \\
\end{array}$ & \begin{tabular}{|l} 
NFPA 25 \\
Frequency \\
\end{tabular} & Recommended Frequency and Justification \\
\hline $\begin{array}{l}\text { Foam-water systems, } \\
\text { Proportioning } \\
\text { systems, } \\
\text { Inspection }\end{array}$ & 8-3.10 & Monthly & $\begin{array}{l}\text { Configuration - Annually for fixed proportioners } \\
\text { Monthly for adjustable proportioners } \\
\text { Fluid level - } \\
\text { Monthly } \\
\text { For power systems' strainers - } \\
\text { Monthly } \\
\text { There were no reported cases of proportioning systems } \\
\text { failing A visual inspection would not necessarily } \\
\text { reveal internal problems with a proportioning system. }\end{array}$ \\
\hline $\begin{array}{l}\text { Foam-water systems, } \\
\text { Foam concentrate } \\
\text { pump power, } \\
\text { Inspection }\end{array}$ & $8-3.10 .3$ & Monthly & $\begin{array}{l}\text { Monthly, unless a site justifies a less frequent } \\
\text { activity based on their failure rates and obtains an } \\
\text { approved DOE equivalency to NFPA } 25 \text {. }\end{array}$ \\
\hline $\begin{array}{l}\text { Foam-water systems, } \\
\text { Foam concentrate } \\
\text { pump running, } \\
\text { Maintenance }\end{array}$ & $8-5.4(a)$ & Monthly & $\begin{array}{l}\text { Monthly, unless a site justifies a less frequent } \\
\text { activity based on their failure rates and obtains an } \\
\text { approved DOE equivalency to NFPA } 25 \text {. }\end{array}$ \\
\hline $\begin{array}{l}\text { Foam-water systems } \\
\text { Foam concentrate } \\
\text { strainer, } \\
\text { Inspection \& } \\
\text { Maintenance }\end{array}$ & $8-3.8 .2$ & Monthly & $\begin{array}{l}\text { Annually, for systems using AFFF foam and fresh water } \\
\text { Monthly for other foam systems. } \\
\text { Maintenance is only done if the strainer is clogged. } \\
\text { There were no reported cases of clogging of AFFF foam } \\
\text { concentrate strainers in DOE foam. systems at Oak Ridge. }\end{array}$ \\
\hline
\end{tabular}




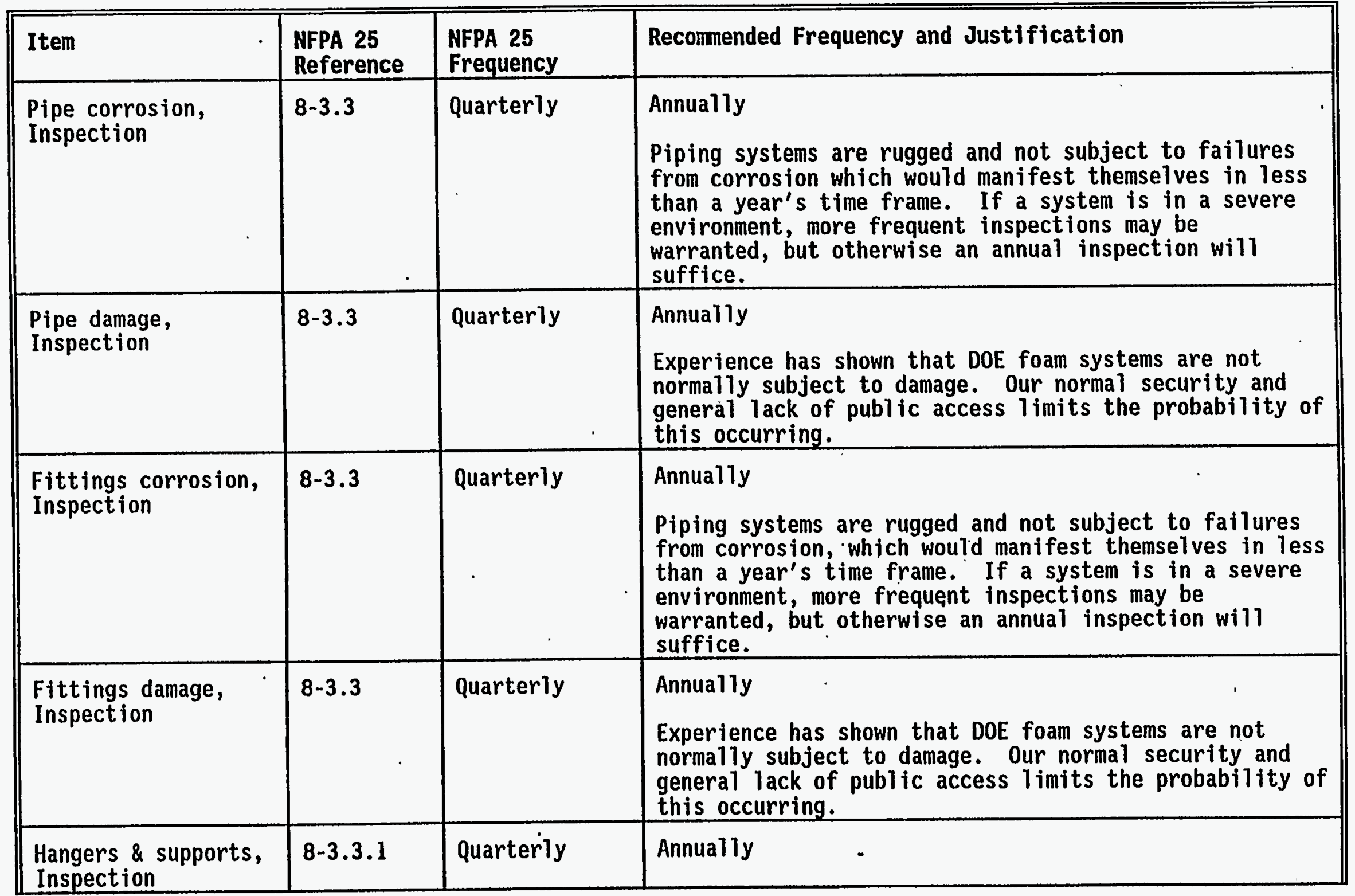




\begin{tabular}{|c|c|c|c|}
\hline Item & $\begin{array}{l}\text { NFPA } 25 \\
\text { Reference } \\
\end{array}$ & $\begin{array}{l}\text { NFPA } 25 \\
\text { Frequency }\end{array}$ & Recommended Frequency and Justification \\
\hline $\begin{array}{l}\text { Discharge device } \\
\text { location, position, } \\
\text { and obstruction, } \\
\text { Test }\end{array}$ & $8-4.3 .3$ & Annually & $\begin{array}{l}5 \text { years, or a frequency acceptable to meet } \\
\text { environmental requirements if they exist } \\
\text { DOE experience has shown that we do not have problems } \\
\text { with system changes once they have been adequately } \\
\text { acceptance tested and verified via that means. }\end{array}$ \\
\hline $\begin{array}{l}\text { Foam concentrate } \\
\text { strainers, } \\
\text { Test }\end{array}$ & $8-4 \cdot 3 \cdot 3$ & Annual7y & $\begin{array}{l}5 \text { Years } \\
\text { DoE experience has shown that we do not have problems } \\
\text { with system changes once they have been adequately } \\
\text { acceptance tested and verified via that means. }\end{array}$ \\
\hline $\begin{array}{l}\text { Proportioning } \\
\text { systems, a11, } \\
\text { Test }\end{array}$ & $8-4 \cdot 3 \cdot 3$ & Annually & $\begin{array}{l}5 \text { Years } \\
\text { DOE experience has shown that we do not have problems } \\
\text { with system changes once they have been adequately } \\
\text { acceptance tested and verified via that means. }\end{array}$ \\
\hline $\begin{array}{l}\text { Complete foam-water } \\
\text { systems, } \\
\text { Test }\end{array}$ & $8-4.3 .3$ & Annually & $\begin{array}{l}5 \text { Years } \\
\text { DoE experience has shown that we do not have problems } \\
\text { with system changes once they have been adequately } \\
\text { acceptance tested and verified via that means. If the } \\
\text { system is substantially modified, then another } \\
\text { acceptance test is warranted. }\end{array}$ \\
\hline \multicolumn{4}{|l|}{$\begin{array}{l}\text { Chapter } 9 \text {, Valves } \\
\text { and FD Connections }\end{array}$} \\
\hline $\begin{array}{l}\text { Aiarm valves, } \\
\text { Exterior Inspection }\end{array}$ & $9-4.1 .1$ & Monthly & $\begin{array}{l}\text { Quarteriy, } \\
\text { This would verify valve configuration. DOE sites. are } \\
\text { not generally accessible to the public, which would } \\
\text { result in the tampering that this inspection is trying } \\
\text { to catch. }\end{array}$ \\
\hline
\end{tabular}




\begin{tabular}{|c|c|c|c|}
\hline Item & $\begin{array}{l}\text { NFPA } 25 \\
\text { Reference } \\
\end{array}$ & $\begin{array}{l}\text { NFPA } 25 \\
\text { Frequency }\end{array}$ & Recommended Frequency and Justification \\
\hline $\begin{array}{l}\text { Hose connection, } \\
\text { Inspection }\end{array}$ & $9-5.2 .1$ & $\begin{array}{l}\text { Weekly } \\
\text { /Monthly }\end{array}$ & $\begin{array}{l}\text { Quarterly } \\
\text { DOE facilities are not generally accessible to the } \\
\text { public and we do not find the tampering with equipment } \\
\text { that sometimes results from that. Additionally, these } \\
\text { valves are rugged and not subject to failure that a } \\
\text { visual inspection would reveal. }\end{array}$ \\
\hline $\begin{array}{l}\text { Fire Department } \\
\text { connections, } \\
\text { Inspection }\end{array}$ & $9-7.1$ & Monthly & $\begin{array}{l}\text { Quarterly, } \\
\text { DoE facilities are not generally accessible to the } \\
\text { public and we do not find the tampering with equipment } \\
\text { that sometimes results from that. }\end{array}$ \\
\hline $\begin{array}{l}\text { Main drain, } \\
\text { Test }\end{array}$ & $9-2.6$ & Quarterly & $\begin{array}{l}\text { Quarterly, } \\
\text { Unless a site justifies a less frequent activity based } \\
\text { on their failure rates and obtains an approved DOE } \\
\text { equivalency to NFPA } 25 \text {. }\end{array}$ \\
\hline $\begin{array}{l}\text { Dry pipe valves: } \\
\text { Quick opening } \\
\text { devices, } \\
\text { Test }\end{array}$ & $9-4.4 .2 .4$ & Six months & $\begin{array}{l}\text { Six months, unless a site justifies a less frequent } \\
\text { activity based on their failure rates and obtains an } \\
\text { approved DOE equivalency to NFPA } 25 \text {. }\end{array}$ \\
\hline $\begin{array}{l}\text { Pre- } \\
\text { action/deluge/dry } \\
\text { pipe valve, } \\
\text { Inspection of } \\
\text { exterior }\end{array}$ & $\begin{array}{l}9-4.3 .1 \\
\text { and } \\
9-4.4 .1\end{array}$ & Weekly & $\begin{array}{l}\text { Quarterly } \\
\text { DOE facilities are not generally accessible to the } \\
\text { public and we do not.find the tampering with equipment } \\
\text { that sometimes results from that. }\end{array}$ \\
\hline
\end{tabular}




\begin{tabular}{|c|c|c|c|}
\hline Item & $\begin{array}{l}\text { NFPA } 25 \\
\text { Reference }\end{array}$ & $\begin{array}{l}\text { NFPA } 25 \\
\text { Frequency }\end{array}$ & Recommended Frequency and Justification \\
\hline $\begin{array}{l}\text { Valve enclosure, } \\
\text { Inspection }\end{array}$ & $9-4.3 .1$ & $\begin{array}{l}\text { During cold } \\
\text { weather: } \\
\text { daily, } \\
\text { or weekly if } \\
\text { temperature is } \\
\text { constantly } \\
\text { monitored }\end{array}$ & $\begin{array}{l}\text { Daily, if no temperature monitoring. } \\
\text { Monthly, if a temperature monitoring system exists } \\
\text { which provides indication of low temperature at a } \\
\text { constantly manned location, and provides an indication } \\
\text { of failure of the monitoring system, i.e., a broken } \\
\text { wire. } \\
\text { Weekly, if there is a monitoring system not meeting } \\
\text { these requirements. }\end{array}$ \\
\hline $\begin{array}{l}\text { Dry pipe valve } \\
\text { enclosure, } \\
\text { Inspection }\end{array}$ & $9-4.4 .1 .1$ & $\begin{array}{l}\text { During cold } \\
\text { weather: } \\
\text { daily, } \\
\text { or weekly if } \\
\text { temperature is } \\
\text { constantly } \\
\text { monitored }\end{array}$ & $\begin{array}{l}\text { Daily, if no temperature monitoring. } \\
\text { Monthly, if a temperature monitoring system exists } \\
\text { which provides indication of low temperature at a } \\
\text { constantly manned location, and provides an indication } \\
\text { of failure of the monitoring system, i.e., a broken } \\
\text { wire. } \\
\text { Weekly, if there is a monitoring system not meeting } \\
\text { these requirements. }\end{array}$ \\
\hline $\begin{array}{l}\text { Dry Pipe Valve's } \\
\text { Interior, Inspection }\end{array}$ & $9-4 \cdot 4 \cdot 1.4$ & Annually & $\begin{array}{l}\text { Annually } \\
\text { Unless a site justifies a less frequent activity based } \\
\text { on their failure rates and obtains an approved DOE } \\
\text { equivalency to NFPA.25. }\end{array}$ \\
\hline $\begin{array}{l}\text { Orifices, filters, } \\
\text { and strainers, } \\
\text { Inspection }\end{array}$ & $9-4.4 .1 .5$ & Five years & $\begin{array}{l}5 \text { years, unless a site justifies a less frequent } \\
\text { activity based on their failure rates and obtains an } \\
\text { approved DOE equivalency to NFPA } 25 \text {. }\end{array}$ \\
\hline
\end{tabular}




\begin{tabular}{|c|c|c|c|}
\hline Item & $\begin{array}{l}\text { NFPA } 25 \\
\text { Reference }\end{array}$ & $\begin{array}{l}\text { NFPA } 25 \\
\text { Frequency } \\
\end{array}$ & Recommended Frequency and Justification \\
\hline $\begin{array}{l}\text { Post Indicator } \\
\text { Valves, position, } \\
\text { Test }\end{array}$ & $9-3.4 .1$ & Quarterly & $\begin{array}{l}\text { Six months } \\
\text { DOE facilities are not completely accessible to the } \\
\text { general public. He do not experience tampering as some } \\
\text { sites which have general public access do. }\end{array}$ \\
\hline $\begin{array}{l}\text { Dry pipe valves: } \\
\text { priming water, Test }\end{array}$ & $9-4.4 .2 .1$ & Quarterly & $\begin{array}{l}\text { Six months } \\
\text { The loss of priming water could cause the dry pipe } \\
\text { valve to prematurely trip, which would be a nuisance, } \\
\text { but not a direct cause of a failure to extinguish a } \\
\text { fire. }\end{array}$ \\
\hline $\begin{array}{l}\text { Dry pipe valves: } \\
\text { low air pressure } \\
\text { alarms, } \\
\text { Test }\end{array}$ & $9-4.4 .2 .6$ & Quarterly & $\begin{array}{l}\text { Six months } \\
\text { L air pressure would cause a premature trip, but } \\
\text { wowld not be a direct cause for a failure of the system } \\
\text { to extinguish a fire. }\end{array}$ \\
\hline $\begin{array}{l}\text { Deluge/pre-action } \\
\text { valves: } \\
\text { priming water, Test }\end{array}$ & $9-4.3 .2 .1$ & Quarterly & $\begin{array}{l}\text { Six months } \\
\text { The loss of priming water could cause the valve to } \\
\text { prematurely trip, which would be a nuisance but not a } \\
\text { direct cause of a failure to extinguish a fire. }\end{array}$ \\
\hline
\end{tabular}




\section{APPENDIX-}

Much discussion ensued on the issue of testing of waterflow alarm devices. The Subcommittee initially recommended a four month frequency, but Oak Ridge has been doing this activity for 25 years at a six month frequency. The available data were reviewed. At Hanford, the four month frequency has resulted in 8 failures of pressure type devices in 2,781 tests $(0.29 \%)$ over 3 years and 4 failures in 1,953 tests $(0.2 \%)$ of paddle type devices over three years. Oak Ridge has found 14 failures in 2,766 tests $(0.5 \%)$ over 3 years at the six month frequency. Additional data received after the telecon, on testing at Portsmouth, indicates 9 failures in 902 tests $(1.0 \%)$ in a seven month period.

\begin{tabular}{llll} 
Test Frequency & Failure rates & \#Tests & \#Failures \\
\cline { 2 - 3 } 4 months & $0.29 \%$ & 2781 & 8 \\
4 months & $0.2 \%$ & 1953 & 4 \\
6 months & $0.5 \%$ & 2766 & 14 \\
6 months & $1.0 \%$ & 902 & 9
\end{tabular}

A factor which must be considered is that these are not predictive tests; they are only functional tests which indicate pass or fail. If an alarm device fails the day after it is tested, it will remain in a failed state, without the contractor having knowledge of its failed state, until the next test. The frequency of the functional test of the device is a measure of how long one is willing to tolerate not knowing that an alarm device has failed.

If we look at the problem from the number of failures in a given time period, we have the following data:

Hanford: $\quad 0.22$ failures/month, .88 failures in 4 months (avg.) 0.11 failures/month, .44 failures in 4 months (avg.) Oak Ridge: 0.39 failures/month, 2.34 failures in 6 months (avg.) Portsmouth: 1.3 failures/month, 7.8 failures in 6 months (avg.) 
These alarm devices fail not because we do not test them frequently enough - they fail because of corrosion, material aging, defective materials initially, build up of deposits from their watery environment, improper adjustment, and other factors in their immediate environment, all of which are completely independent of the testing frequency. If Oak Ridge were to increase their test frequency to 4 months, the following would result, based on their average of .39 failures per month:

Annual result: $\quad 4$ to 5 faijures in 1,383 tests, for a failure rate of $0.36 \%$

Hanford did 1,953 tests and experienced a failure rate of $0.2 \%$, which is 44\% less than what Oak Ridge would experience even at the same testing frequency. Oak Ridge would not achieve the same results that Hanford experiences even if they spent the additional funds for the increased testing frequency.

A failure of an alarm device does not prevent the automatic sprinkler system from functioning. It only prevents the alarm from being transmitted: To fail in the overall goal of prevention of unacceptable fire damage, we must first experience an ignition; the ignition must grow into a fire of sufficient magnitude to cause damage; the sprinkler system must fail to extinguish the fire, and the alarm device must fail to transmit the alarm to the site fire department so that they may respond and manually extinguish the fire. Failure of the alarm device itself is independent of the ability of the automatic sprinkler system to extinguish the fire, al though there are issues of notification of occupants to effect evacuation of the facility if the alarm device fails and potential criticality and environmental concerns. 



\section{memorandum}

DATE:

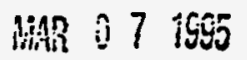

REPLYTO

ATTN OF:

Occupational Safety and Health Policy:Kubicki:3-4794

SUBJECT: INTERIM GUIDELINES FOR FIRE PROTECTION OF ABANDONED FACILITIES AND FOR FACILITIES UNDERGOING DECONTAMINATION AND DECOMMISSIONING

TO:

Distribution

The purpose of this memorandum is to provide interim guidance on the determination of appropriate levels of fire protection for facilities that are undergoing decontamination and decommissioning (D\&D). This includes all facilities that are abandoned and are otherwise undergoing a transition from a historic occupancy.

They have been developed as a result of numerous expressions of need that have been expressed by Department of Energy (DOE) field elements and contractors. This is due to a perceived insufficiency of guidance in the application of existing DOE criteria to facilities of this nature. These guidelines do not represent new requirements but are the means to appiy existing DOE fire safety poTicy in a more flexible and cost-effective manner.

The subject fire safety guidelines are provided in the Attachment. They were developed from technical input provided by the DOE and contractor representatives on the DOE Fire Safety Committee. The guidance represents a minimally acceptable level of effort. They are intended to be utilized by qualified fire protection engineers. They are intended to be utilized until such time as a more comprehensive policy governing the safety of D\&D facilities is promulgated by the Department.

If you have any questions, please contact me on 301-903-4794.

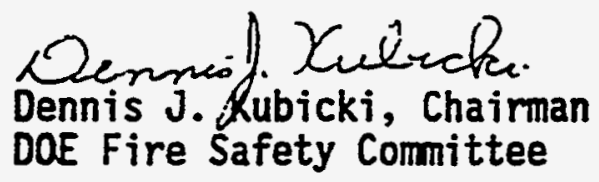

Attachment 
Chuck Ramsey, EH

Bill Boyce, EM

Matt Cole, ER

Carl Caves, NE

Bi11 Froh, DP

Dennis Kirson, AL

David Boy 7 , SR

Jim Hutton, OR

Dario Luna, NV

Patrick Smith, ID

Mike Saar, CH

Craig Christenson, RL

Don Kelly, OK

Peter Lee, RF

Nadine Gilmore, $\mathrm{OH}$

Derl Harper, Fernald

Terry Dembrowski, WAPA

David Heitz, Hound

Gordon Veerman, ANL-East

Bud Bucci, Hanford

Bruce Campbe 11, Rocky Flats

Bi11 Brown, Y-12

Wa7ter Maybee, LANL

Virginia Holtzclaw, Sandia Livermore

John Sharry, LLNL

Norm Hess, Savannah River

Ken Phillips, EG\&G Idaho

Dave Barreres, Yucca Mountain Project 


\section{FIRE SAFETY GUIDELINES FOR D\&D FACILITIES}

\section{Introduction}

The Department of Energy (DOE) is faced with decisions regarding the future operational status of certain fire protection systems in facilities that are planned to undergo decontamination and decommissioning (D\&D), as well as facilities that are abandoned or face occupancy changes for other reasons. These decisions are complicated by the fact that a number of these facilities are presently being used for other purposes, such as storage of hazardous or mixed waste materials. An additional factor is the cost associated with inspection, testing, maintenance and repairs of the fire protection systems.

Existing fire protection features in these facilities were originally provided on the basis of potential fire loss (in dollars), fire risks associated with active process operations, mission impact, and other design considerations. However, some of these risks may no longer be present. For the most part, these facilities have no significant present value and progranmatic interruption is no longer a factor, although this is not always the case.

As of the date of this guidance, DOE has issued no specific comprehensive policy governing safety requirements in abandoned facilities and facilities undergoing D\&D and safe shutdown. Work is currently underway within the Department to develop safety criteria for such facilities; however, promulgation dates are uncertain. Until such time as a comprehensive DOE policy is developed, fire protection decisions for these facilities have to be based on existing DOE fire safety criteria, as applicable.

Fire safety requirements relevant to this issue include DOE 5480.7A, "Fire Protection," DOE 6430.1A, "General Design Criteria," 29 CFR Part 1926, "Safety and Health Regulations for Construction," and National Fire Protection Association (NFPA) Standard No. 241, "Standard for Safeguarding . Construction, Alteration and Demolition Operations." Where conflicting criteria exist, resolution shall be the responsibitity of the DOE Authority Having Jurisdiction (AHJ). The fire protection requirements apply unless specific relief has been granted by the Department.

\section{Fundamental Principles}

Decisions relating to fire safety of abandoned facilities, as wetl as facilities and processes undergoing D\&D (including the surveillance and maintenance phase of D\&D) and safe shutdown, shall be made on the basis of the following principles:

- Pending deveiopment of a comprehensive DOE policy governing safety for these facilities, fire protection shall be governed by existing departmental fire safety requirements. (Refer to DOE 5480.7A.) 
- Pending development of an alternative decision making process in conjunction with D\&D safety policy, approval of alternate fire protection configurations shall be accomplished through "exemptions" or "equivalencies" as defined in DOE 5480.7A. An exemption or equivalency may be processed for each facility or for a group of facilities.

- The evaluation. of fire risks in relation to the need for fire safety features can be accomplished through a graded fire hazards analysis (FHA). (Refer to DOE 5480.7A and the DOE Fire Hazards Analysis Policy Statement of November 7, 1991.)

- The need for fire protection features in these facilities is governed by the fire risks to the public, workers, fire fighters and the potential release of hazardous and radiological materials to the environment. Property protection and program continuity are not normaliy factors to consider unless the facility possesses a definable value and/or mission as determined by the DOE AHJ.

- Fire hazards within these facilities may change over time. Fire protection must be adequate to deal with these changes. The FHA shall be revised as appropriate when significant changes in occupancy or hazard occur that affect fire safety.

- Fire safety features that have been required by DOE may be rendered inoperable or considered no longer needed if justified by the FHA. Such features may be abandoned in place until they are dismantled as part of planned demolition activities.

- The decision to deactivate automatic fire suppression systems in large facilities must reflect the possibility that emergency response forces may not be able to safely enter the facility to effect manual fire suppression. A "stand off and protect" tactical approach, which features exterior fire attack and protection of exposures, shall be approved by DOE as part of the fire department pre-plans or their standard operating procedures. This approach necessitates additional emphasis on maintaining communication and cooperation between facility personnel and emergency response groups to include: updating fire prepians and being aware of changes in occupancy and fire protection system status.

- Retained fire protection features in these facilities are not required to comply with all of the design and installation criteria of the governing NFPA standard if the DOE AHJ concurs that the system will function adequately during a fire in its current design mode. Concurrence should be documented in an appropriate manner after consultation with the cognizant DOE fire protection engineer.

- Retained fire protection features must be inspected, tested and maintained in a manner sufficient to assure that the features will function adequately during fire incidents. 
- Abandoned, safe shutdown and D\&D facilities and related procedures shouid be routinely inspected and reviewed by representatives of the site emergency response forces and fire protection engineering staffs consistent with established standard operating procedures and fire protection program criteria.

\section{Additional Considerations}

Prior to commencement of D\&D activities; appropriate procedures should be approved and implemented (including worker training) governing the control of potentially hazardous operations including, but not 7 imited to, cutting and welding, handling of combustibles, and smoking.

The fire risks associated with materials and processes used as part of the D\&D process must be evaluated by a fire protection engineer. Fire protection features must be adequate to minimize these risks to an acceptable TeveT.

The deactivation of process lines containing hazardous materials as well as flammable or combustible liquids must be, preceded by an anaiysis or performed under a work $\mathrm{plan}$ which addresses the methods used to control related hazards during the deactivation process. Appropriate safeguards shall be in place to minimize the accidental release of residual materials that may remain in piping and tanks.

Buitding emergency egress features are required to be maintained consistent with the requirements for buildings under construction, as a minimum, as modified by the FHA. These include emergency lighting and exit signage. Locked and abandoned facilities where there is no human occupancy would not need to maintain emergency egress features. Literal conformance with the provisions of the Life Safety Code, NFPA Standard 101, is not required for conditions that have no significant impact on the ability of occupants during D\&D to safely evacuate a building during a fire.

Where no automatic system exists, an effective means for manually summoning the site emergency response forces and for communicating with personnel inside of a building is required. This can take the form of an exterior fire alarm pull station or call box, telephone (fixed or mobile), radio or some combination of the above based on the accessibility of the devices to personnel and their reliability.

All retained interior fire protection systems shall be maintained operational while interior D\&D activities are taking place. Verification of operable status should include appropriate inspection and testing in accordance with established procedures. Complete deactivation is anticipated at such time as shell demolition occurs. Temporary deactivation of fire protection features should be treated as an impairment, with appropriate interim compensatory measures implemented until such time as the feature is returned to fuil operational mode. 
The site and facility fire water distribution system, including hydrants, siamese connections to sprinkler systems, and interior standpipe systems, must be maintained in an operable mode. Access for mobile apparatus for emergency response. shall be maintained. (Refer to fire department pre-fire. plans.)

Periodic tours of the D\&D facilities should be conducted by the site emergency response force to familiarize them with existing conditions and to revalidate fire pre-plans. Drills and training exercises should also be conducted at these locations at an appropriate frequency commensurate with the fire risks and complexity of the facility.

To the extent that the FHA validates the need to maintain fire protection features during D\&D activities, such features shall be inspected, tested and maintained, consistent with established procedures, sufficient to assure that they will function effectively during a fire. This implies that defects or design deficiencies that are not critical to effective performance, as determined by the AHJ, may remain as is.

The authority to resolve other issues related to fire safety for D\&D facilities that are not explicitly addressed by this document resides with the DOE AHJ.

\section{Decision Making Process}

The Fire Hazards Analysis is the mechanism for reassessing the need for fire protection features in any facility. The "exemption" or "equivalency" process is the means to obtain formal approval for aiternate fire protection configurations. Exemptions for fire protection are only necessary when a fire safety requirement, as explicitly stated in a DOE Order, cannot be met. Acceptable variances from NFPA codes and standards should be processed as an equivatency.

The process, as applicable to this issue, may begin with a facility walkdown by cognizant safety professionals, including fire protection engineers, so as to quickly ascertain potential areas where a reduced fire protection profile may be justified.

Justification for reducing fire safety features shall be based on a graded fire hazards analysis, which comprehensively considers the consequences of a fire on the health and safety of the public, as well as the safety of building occupants, fire fighters and the environment. Additional considerations are the maximum possible fire loss (which must include a reasonable determination of anticipated cleanup costs based on established practice) and possible impact to DOE missions and programs. (It is anticipated, however, that programmatic impact will be nil for a D\&D facility uniess there is explicit evidence to the contrary.)

Guidance on the performance of a graded FHA was provided in a memorandum dated November 7, 1991, by the DOE Office of Environment, Safety and Health and the Office of Nuclear Safety Policy and Standards. Specific 
requirements for a graded FHA are contained in DOE 5480.7A. The DOE (draft) Model Fire Hazards Analysis may be used as a guide. It should be emphasized that the scope and depth of the analysis, as well as the related documentation, should be commensurate with the complexity of the facility, the nature of the fire risks, and the type of D\&D activities. The FHA represents the fire safety "envelope" that governs subsequent D\&D activities.

If the FHA concludes that an unmitigated fire will result in no significant adverse consequences (see above), a technical basis would exist for deactivating existing automatic fire suppression systems. It must be emphasized, however, that deactivating fixed fire suppression systems may leave no practical al ternative for suppressing a fire. This is especially true of the larger process buildings where entry by emergency response forces would not be safe under anticipated fire conditions. The absence of active suppression activities or active fire protection features during a fire may not be considered acceptable from the standpoint of public perception. An effort should be made to anticipate the public reaction to an unmitigated fire and to factor this reaction into a decision to deactivate a fire.protection system.

If a decision is made to deactivate a fire suppression system in a given area or facility, it is necessary to assure that the use of the area does not change in such a manner as to result in the reintroduction of commodities or activities that would significantly increase fire risk. Consequently, the conclusions of the initial fire hazard analysis must be reassessed if a decision is made to significantiy alter D\&D activities in an area where sprinkler protection has been deactivated. If existing fire protection is insufficient to mitigate the fire hazards, the fire suppression system should be reactivated and other safety features provided, as appropriate. This reassessment and the provision of supplementary fire-protection should occur prior to the change. Based on favorable conclusions from the FHA, a decision to proceed with an exemption or equivalency request can then be made. The exemption/ equivalency package should be prepared by the fire protection technical staff of the M8O contractor and address the applicable DOE requirements, the reasons these requirements cannot be met, the impact on safety resulting from noncompliance, a description of compensatory or other risk mitigating features, and potential cost savings. (The additional project costs for a fire protection feature(s) are not considered an acceptable reason that a DOE requirement cannot be met.) It is suggested that the draft exemption/equivalency request be distributed to the responsible DOE technical experts so as to provide an opportunity to address questions and concerns. Once this has been accomplished, the "official" request should be processed for concurrence by the cognizant DOE officials as described in DOE 5480.7A. 


\section{memorandum}

DATE: April 14, 1995

REPLY TO Office of Occupational Medicine and Medical Surveillance: Donald Lentzen:3-9845

SUBJECT:

GUIDELINES FOR DEVELOPING MEDICAL STANDARDS FOR FIREFIGHTERS

TO: Martha A. Krebs, ER-1

The purpose of this memorandum is to provide guidance on the implementation of the National Fire Protection Association (NFPA) Standard 1582, "Medical Requirements for Firefighters." This standard has been in effect since its promulgation in 1992 and has been applicable to the Department of Energy (DOE) through the requirements del ineated in DOE Order 5480.4,

"Environmental Protection, Safety and Health Protection Standards," and DOE Ordèr 5480.7A, "Fire Protection."

The above referenced NFPA Standard was developed by a joint task force representing both the medical and fire protection communities as a way to reduce the significant number of documented fatalities and injuries that are suffered by fire service personnel as a direct result of their medical conditions.

The subject guidelines, which are inciuded as an attachment, were developed for DOE based on requests for assistance from both DOE and contractor medical and fire service representatives. This guidance was perceived to be needed to facilitate the application of the standard to the unique circumstances that characterize DOE and its emergency response organizations. Neither this memorandum nor the attached guidelines impose new requirements on the Department or its contractors. To the extent that a) ternate approaches can be developed that will achieve an acceptable level of firefighter safety, these approaches can be implemented based on the "Equivalency Concept" that is sanctioned by DOE Order 5480.7A and NFPA.

Questions pertaining to the above position should be directed to George R. Gebus, M.D., M.P.H., on 3-7385.

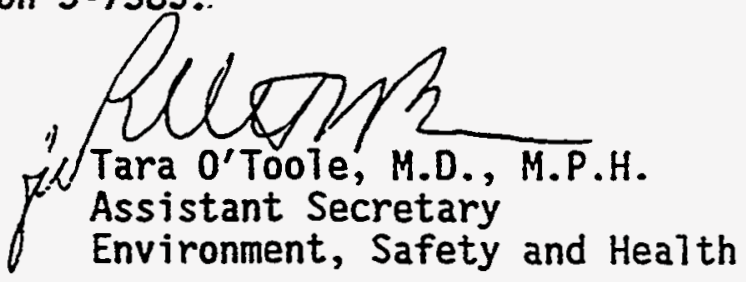

Attachment 


\section{memorandum}

DATE: April 14, 1995

AEPLY TO Office of Occupational Medicine and Medical Surveillance:

Donald Lentzen:3-9845

SUBJECT:

GUIDELINES FOR DEVELOPING MEDICAL STANDARDS FOR FIREFIGHTERS

To: Thomas P. Grumb7y, EM-1

The purpose of this memorandum is to provide guidance on the implementation of the National Fire Protection Association (NFPA) Standard 1582, "Medical Requirements for Firefighters." This standard has been in effect since its promulgation in 1992 and has been applicable to the Department of Energy (DOE) through the requirements delineated in DOE Order 5480.4, "Environmental Protection, Safety and Health Protection Standards," and DOE Order 5480.7A, "Fire Protection."

The above referenced NFPA Standard was developed by a joint task force representing both the medical and fire protection communities as a way to reduce the significant number of documented fatalities and injuries that are suffered by fire service personnel as a direct result of their medical conditions.

The subject guidelines, which are included as an attachment, were developed for DOE based on requests for assistance from both DOE and contractor medical and fire service representatives. This guidance was perceived to be needed to facilitate the application of the standard to the unique circumstances that characterize DOE and its emergency response

organizations. Neither this memorandum nor the attached guidel ines impose new requirements on the Department or its contractors. To the extent that alternate approaches can be developed that will achieve an acceptable level of firefighter safety, these approaches can be implemented based on the "Equivalency Concept" that is sanctioned by DOE Order 5480.7A and NFPA.

Questions pertaining to the above position should be directed to George R. Gebus, M.D., M.P.H., on 3-7385.

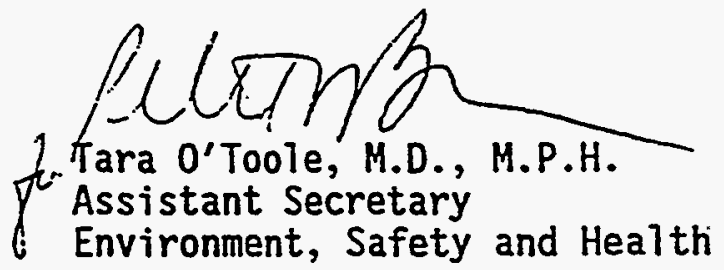

Attachment 


\section{nemorandum}

DATE: April 14, 1995

REPLYTO Office of Occupational Medicine and Medical Surveillance: Donald Lentzen:3-9845

SUBJECT

GUIDELINES FOR DEYELOPING MEDICAL STANDARDS FOR FIREFIGHTERS

To: Jack S. SiegaT, FE-1

The purpose of this memorandum is to provide guidance on the implementation of the National Fire Protection Association (NFPA) Standard 1582, "Medical Requirements for Firefighters." This standard has been in effect since its promulgation in 1992 and has been applicable to the Department of Energy (DOE) through the requirements delineated in DOE Order 5480.4 ,

"Environmental Protection, Safety and Health Protection Standards," and DOE Order 5480.7A, "Fire Protection."

The above referenced NFPA Standard was developed by a joint task force representing both the medical and fire protection communities as a way to reduce the significant number of documented fatalities and injuries that are suffered by fire service personnel as a direct result of their medical conditions.

The subject guidelines, which are included as an attachment, were developed for DOE based on requests for assistance from both DOE and contractor medical and fire service representatives. This guidance was perceived to be needed to facilitate the application of the standard to the unique circumstances that characterize DOE and its emergency response organizations. Neither this memorandum nor the attached guidelines impose new requirements on the Department or its contractors. To the extent that alternate approaches can be developed that will achieve an acceptable level of firefighter safety, these approaches can be implemented based on the "Equivalency Concept" that is sanctioned by DOE Order 5480.7A and NFPA.

Questions pertaining to the above position should be directed to George R. Gebus, M.D., M.P.H., on 3-7385.

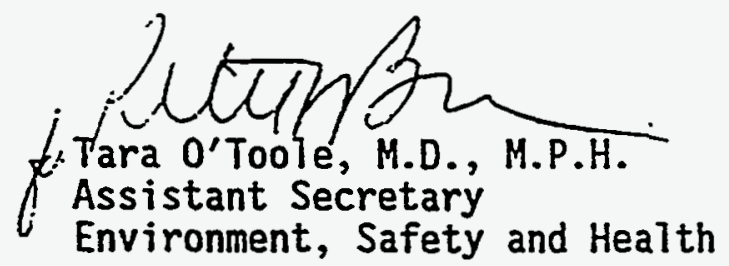

Attachment 
DATE: April 14, 1995

AEPLYTO Office of Occupational Medicine and Medical Surveillance: Dona7d Lentzen:3-9845

SUBJECT:

GUIDELINES FOR DEVELOPING MEDICAL STANDARDS FOR FIREFIGHTERS

To: Orin F. Pearson, EH-3

The purpose of this memorandum is to provide guidance on the implementation of the National Fire Protection Association (NFPA) Standard 1582, "Medical Requirements for Firefighters." This standard has been in effect since its promulgation in 1992 and has been applicable to the Department of Energy (DOE) through the requirements delineated in DOE Order 5480.4 , "Environmental Protection, Safety and Health Protection Standards," and DOE Order 5480.7A, "Fire Protection."

The above referenced NFPA Standard was developed by a joint task force representing both the medical and fire protection communities as a way to reduce the significant number of documented fatalities and injuries that are suffered by fire service personnel as a direct resuit of their medical conditions.

The subject guidelines, which are included as an attachment, were developed for DOE based on requests for assistance from both DOE and contractor medical and fire service representatives. This guidance was perceived to be needed to facilitate the application of the standard to the unique circumstances that characterize DOE and its emergency response organizations. Neither this memorandum nor the attached guidelines impose new requirements on the Department or its contractors. To the extent that a)ternate approaches can be developed that will achieve an acceptable level of firefighter safety, these approaches can be implemented based on the "Equivalency Concept" that is sanctioned by DOE Order 5480.7A and NFPA.

Questions pertaining to the above position should be directed to George R. Gebus, M.D., M.P.H., on 3-7385.

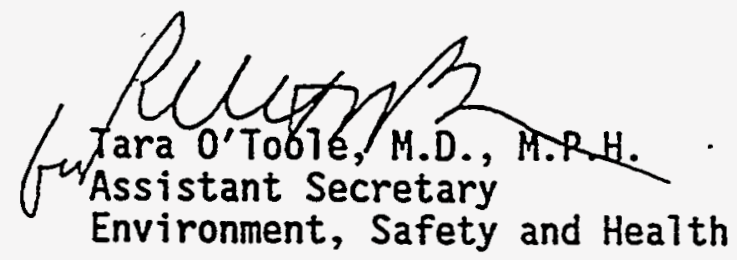

Attachment 


\section{memorandum}

DATE: 'APR 1 \& 1995

REPLY TO

ATTN OF: EH-61:Donald Lentzen:3-9845

SUBJECT: GUIDELINES FOR DEVELOPING MEDICAL STANDARDS FOR FIREFIGHTERS

TO: Distribution

The purpose of this memorandum is to provide guidance on the implementation of the National Fire Protection Association (NFPA) Standard 1582, "Medical Requirements for Firefighters." This Standard has been in effect since its promulgation in 1992 and has been applicable to the Department of Energy (DOE) through the requirements del ineated in DOE Order 5480.4, "Environmental Protection, Safety and Health Protection Standards," and DOE order 5480.7A, "Fire Protection."

The above referenced NFPA. Standard was developed by a joint task force representing both the medical and fire protection communities as a way to reduce the significant number of documented fatalities and injuries that are suffered by fire service personnel as a direct result of their medical conditions.

The subject guidelines, which are included as an attachment, were developed for DOE based on requests for assistance from both DOE and contractor medical and fire service representatives. This guidance was perceived to be needed to facilitate the application of the standard to the unique circumstances that characterize DOE and its emergency response organizations. Neither this memorandum nor the attached guidelines impose new requirements on the Department or its contractors. To the extent that alternate approaches can be developed that will achieve an acceptable level of firefighter. safety, these approaches can be implemented based on the

"Equivatency concept" that is sanctioned by DOE Order 5480.7A and NFPA.

Questions pertaining to the above position should be directed to George R. Gebus, M.D., M.P.H., on (301), 993,7385 ?<smiles>C1C[C]2C[C]12</smiles>

PauT J./Séligman, M.D., M.P.H.

Deputy Assistant Secretary for Health Studies

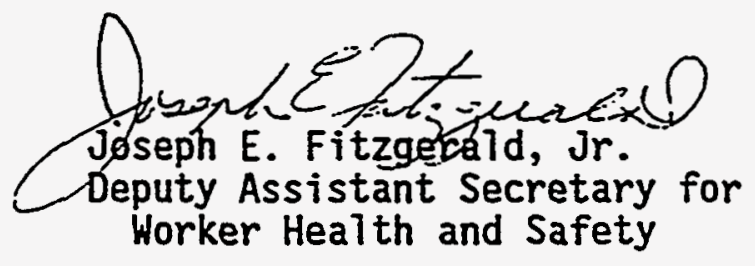

Attachment

cc w/attachment:

Tara 0'Toole, EH-1 
Headquariters Organizations:

Victor H. Reis, DP-1

Terry R. Lash, NE-1

Archer L. Durham, HR-1

Thomas P. Grumbiy, EM-1

Patricia Godley, FE-I

Martha Krebs, ER-1

Everet Beckner, DP-2

Ray Hunter, NE-47

Linda Sye, HR-8

Richard Guimond, EM-2

Craig Zamuda, FE-6

Rick Jones, EH-52

Robert Barber, EH-53

Donald Knuth, DP-30

Victor Stel10, DP-6

Dan Rhoades, DP-6.2
Charles Gibert, DP-9

R. Adm. Charles Beers, DP-20

Gerald Gears, DP-624

Garry Gibbs, ER-9l

Joe Maher, ER-8

Braj K Singh, EH-34

Carl Caves, NE-32

Bruce DeMars, NE-60

E. James Vajda, HR-8

Randal Scott, EM-20

John Bartholomew, FE-41

A. Seepo, SNR, Thru: NE-60

E. Shollenberger, PNR, Thru: NE-60

A. Kakrets, KAPL, Thru: NE-60

Mark Matarrese, FE-64

\section{Field Organizations:}

Michael A. Deiht, Administrator, Alaska Power Administration

Dennis Krenz, Assistant Manager, Office of Environment, Safety and Health, Albuquerque Operations Office

David Alleman, Safety and Health Manager, Bartlesville Project Office

Aubrey A. Stanford, Safety Manager, Bonneville Power Administration

MichaeT Flannigan, Director, Environment, Safety and Health Division, Chicago Operations Office

George E. Dials, Assistant Manager for Site Engineering and Support, Idaho Operations Office

Daniel L. McCollum, Safety Manager, Morgantown Energy Technology Center

Daniel Newquist, Director, Contracts Surveillance/Administrative, Naval Petroleum and 0 il Shale Reserves in CO, UT, WY

Mike Ruiz, Manager, Safety and Health Division, Naval Petroleum Reserves, California

Bruce Church, Assistant Manager, Office of Environment, Safety and Health, Nevada Operations Office

Wayne Hibbits, Deputy Assistant Manager for Environment, Safety and Quality, Oak Ridge Operations Office

George Bellas, Director, Engineering, Environment, Safety and Health Division, Pittsburgh Energy Technology Center

John Keating, Assistant Manager for Technical Support, Richland Operations Office

Shirley 01 inger, Director, Safety and Health Division, Rocky Flats Office Joseph Juetten, Director, Environmental/Operational Safety Division, Oak7 and Operations Office

J.E. Anderson, Director, Safety Division, Savannah River Operations Office

Carol Rice, Personnel Management Special ist, Southeastern Power Administration

Darlene Low, Occupational Safety and Health Manager, Southwestern Power Administration

Melissa Smith, Director, Environmental, Safety/Health Division, Strategic Petroleum Reserve

Dennis Fankhauser, Assistant Safety Manager; Western Area Power Administration, Collider Project officer 


\section{U.S. DEPARTMENT OF ENERGY}

OFFICE OF OCCUPATIONAL MEDICINE AND

MEDICAL SURVEILLANCE

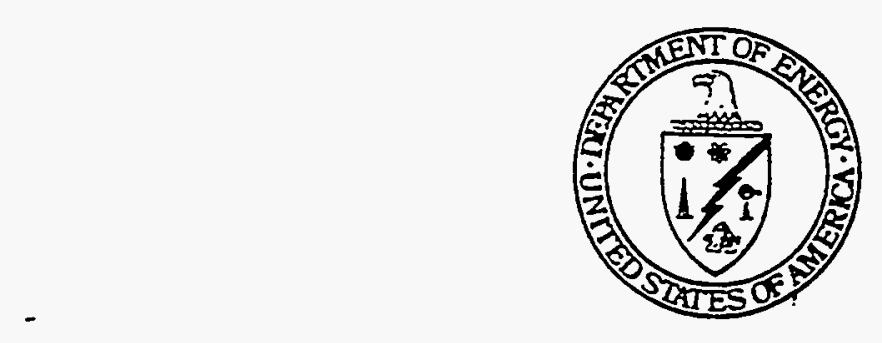

Implementation Guide of Medical Standards for

Department of Energy

FIREFIGHTERS 
1. BACKGROUND:

Department of Energy (DOE) Order 5480.4, "Environmental Protection, Safety, and Health Protection Standards," requires DOE sites to comply with the National Fire Protection Association (NFPA) - National Fire Code (NFC) as a matter of mandatory policy. DOE Order 5480.4 covers DOE contractor employees who perform the essential functions of firefighters on fire brigades. On August 14, 1992, NFPA 1582, "Standard on Medical Requirements for Firefighters:" became NFPA's National Fire Code. The NFPA's requirements 7 ist diagnoses that immediately disqualify individuals from being firefighters and diagnoses that require evaluation of the individuai on a case-by-case basis.

The Americans with Disabilities Act (ADA), 42 U.S.C. 12102 et seg., requires that individuals be evaluated for a job based on their ability to perform the essential functions of the job, not on the basis of the mere presence of a disease or disability. For example, under the ADA, a person may not be disqualified from a position simply because his or her medical history includes a myocardial infarction, coronary bypass or coronary angioplasty. Instead, an evaluation must be made on a case-by-case basis as to whether the person can perform the essential functions of the job with or without reasonable accommodation and without posing a direct threat to self or others. Because the NFPA's medical standards do disqualify individuals with these diagnoses (NFPA 1582, Chap. 3-7.1.1(e)), Category $A$ medical conditions requiring DOE contractors to implement current NFPA medical standards would, in effect, require them to violate the ADA.

These guidelines were prepared to assist the DOE contractor site occupational medical programs in developing NFPA-based firefighter standards that comply with the ADA. Within these guidelines, NFPA 1582 sections are quoted in the left column. Interpretive guidance, as it applies to DOE and in compliance with the requirements of ADA, appears in the adjacent right column. When no interpretive guidance appears, the NFPA guidance stands as written. Where the requirements of NFPA and the ADA conflict, the ADA standard should be followed.

The essential functions of a firefighter position are 1isted in Section 3: "Essential Fire Fighting Functions." Listed with each essential function are medical conditions that might interfere with an individual's ability to perform that particular function. The physician performing the evaluation must then determine if the medical problem is present and, if it is, whether the condition would interfere with the individual's ability to perform the essential function. This section replaces the section in the NFPA's medical standards that violates ADA by listing the specific disabilities, diseases, or previous medical history that automatically disquatify an individual.

In Tieu of the term "fire department physician," which is used in the NFPA standard, these guidelines use the term "Designated Physician." Within DOE, the Designated Physician is the physician authorized to do the work that the NFPA standard designates to the fire department physician. 
These guidelines apply to all firefighter applicants and current firefighters at DOE contractor sites, including those individuals in fire brigades who perform the essential functions of DOE firefighters. A medical evaluation will be performed on all firefighter applicants prior to their appointment. Management wi17 provide the DOE Designated Physician with a specific job task analysis prior to the medical evaluation of any firefighter applicant or current firefighter. The medical evaiuation will be performed by the DOE Designated Physician, and the specific contents of the evaluation will be based on the essential functions of the job.

The essential functions described in this document are considered to be core essential functions. It is recognized that additional site-specific essential functions may be added to this 1 ist by the site as appropriate. The essential functions of a firefighter include those listed in these guidelines and those associated with the site-specific job tasks.

Sites are required to have a physical fitness program for all firefighters. The specific fitness program requirements have not as yet been defined. Pending issuance of a document defining these requirements, fire departments are responsible for developing and implementing an appropriate physical fitness program.

The Secretarial officer (SO) is responsible for ensuring that these guidelines are disseminated.

The Site Occupational Medical Director (SOMD) is responsible for the performance of the Designated Physician, and for ensuring that the Designated Physician is knowiedgeable with regard to the essential functions and job tasks of the firefighters. The Designated Physician is the licensed medical professional responsible for medically certifying . that all firefighters are medically fit to perform their duties.

Pending the appointment of a Designated Physician for firefighters, the Designated Physician for security and protective forces will serve in this capacity. 


\section{GUIDELINES:}

Medical Requirements for Firefighters

\section{NFPA Standards}

Chapter 1

1-1 Scope.

1-1.1 This standard contains medical requirements for firefighters, including fult-time or part-time employees and paid or unpaid volunteers.

1-1.2 These requirements are applicable to organizations providing rescue, fire suppression, and other emergency services, including public, military, private, and industrial fire departments.

1-1.3 This standard does not apply to industrial fire brigades, which also may be known as emergency brigades, emergency response teams, fire teams, plant emergency organizations, or mine emergency response teams.

\section{1-2 Purpose.}

1-2.1 The purpose of this standard is to specify minimum medical requirements for candidates and current firefighters.

\section{DOE Interpretive Guidance}

Chapter 1

1-1 Scope.

1-1.3 These guidelines also apply to DOE fire brigades or plant emergency organizations whose members perform the essential functions of a firefighter, such as search and rescue and fire suppression, as defined in NFPA Standards 600 or 1500 . These guidelines do not apply to individuals who provide a support function in conjunction with emergency response and who are not subjected to the physical demands of a firefighter, as determined by the Authority Having Jurisdiction.

\section{1-2 Purpose.}

1-2.1 The purpose of these guidelines is to specify minimum medical requirements consistent with the essential functions of both candidates and current firefighters. 


\section{Standard}

1-2.2 The implementation of the medical requirements outlined in this standard will help ensure that candidates and current firefighters will be medically capable of performing their required duties and will help to reduce the risk of injuries and illnesses.

1-2.3 Nothing herein is intended to restrict any jurisdiction from exceeding these minimum requirements.

\section{1-3 Impiementation.}

1-3.1 For candidates, the medical requirements of this standard shall be implemented when this standard is adopted by an authority having jurisdiction on an effective date specified by the authority having jurisdiction.

\section{Interpretivè Guidance}

1-2.2 The implementation of the medical requirements out 7 ined in these guidelines will help ensure that candidates and current firefighters will be medically capable of performing the essential functions of a firefighter without posing a direct threat to themselves or others.

1-2.3 Nothing herein is. intended to restrict DOE or a DOE contractor from exceeding these minimum requirements. However, if site management proposes to establish requirements other than those listed, notice of such variance shall be submitted through the SO to the Director, Office of Occupationai Medicine and Medical Surveillance. Variances from these guidelines should be justified and approved in accordance with the procedures establ ished for "equivalencies" and "exemptions" as defined in DOE Order 5480.7A, "Fire Protection."

\section{1-3 Implementation.}

1-3.1 DOE Order 5480.4 requires DOE sites to comply with the NFPA National Fire Codes as a matter of policy. On August 14, 1992, NFPA 1582, "Standard on Medical Requirements for Firefighters," became effective. 


\section{Standard}

1-3.2 When this standard is adopted by a jurisdiction, the authority having jurisdiction shall set a date or dates. for current firefighters to achieve compliance with the requirements of this standard and shall be permitted to establish a phased-in schedule for compliance with specific requirements of this s.tandard in order to minimize personal and departmental disruption.

\section{1-4 Definitions.}

Approved. Acceptable to the "authority having jurisdiction."

Authority Having Jurisdiction. The authority having jurisdiction is the organization, office, or individual responsible for "approving" equipment, an installation, or a procedure.

Candidate. A person who has made application to commence performance as a firefighter.

Category A Medical Condition. A medical condition that would preclude a person from performing as a firefighter in a training or emergency operational environment by presenting a significant risk to the safety and health of the person or others.

\section{Interpretive Guidance}

1-3.2 An implementation plan for compliance with these guidelines shall be submitted to the So for review and approval within 120 days of publication. A copy of the implementation plan shall also be submitted to the Director, Office of Occupational Medicine and Medical Surveillance.

\section{1-4 Definitions.}

Authority Having Jurisdiction (AHJ). Except as directed by the Secretarial officers, the decisionmaking authority in matters concerning fire protection is the Heads of Field Organizations or their designees.

Candidate. A candidate is a person who has applied for and who has been offered a position as a firefighter, or a current employee who has made an application to commence performance as a firefighter.

Medical Condition. The DOE guidelines require that an individual who cannot perform all essential functions of the job, with or without reasonable accommodation, without posing a direct threat to self or others is not qualified to perform the essential functions of a firefighter. The individual's inability may be associated with a medical condition or conditions. Every individual's capabilities 
$\underline{\text { Standard }}$

Category B Medical Condition. - medical condition that. based on its severity or degree. may preclude a person from performing as a firefighter in a training or emergency operational environment by presenting a significant risk to the safety and health of the person or others.

Current Firefighter. A person who is already a member and whose duties require the performance of essential fire-fighting functions.

Drug. Any substance, chemical, over-the-counter medication, or prescribed medication that may affect the performance of the firefighter.

Emergency Conditions. Activities of the fire department relating to

\section{Interpretive Guidance}

will be individually assessed to ensure that qualified individuals are not rejected on the basis of a mere diagnosis of a medical condition, even if such a condition would usually be assumed to be associated with inability to perform; e.g., Category A medical condition listed in NFPA 1583 (Chap. 3.7.1.1(e)). The medical standards are addressed in section 3 by essential function, rather than by body system or disease.

A A 


\section{Standard}

rescue, fire suppression, and special operations, including response to the scene of the incident and all functions performed at the scene.
Evaluation. See Medical Evaluation.

Fire Department Physician. The licensed doctor of medicine or osteopathy who has been designated by the fire department to provide professional expertise in the areas of occupational safety and health as they relate to emergency services.

Firefighter. A member of a fire department whose duties require the performance of essential firefighting functions or substantially similar functions.

Medical Evaluation. The analys is of information for the purpose of making a determination of medical certification. Medical evaluation may or may not include a medical examination.
Interpretive Guidance

drills and exercises, relating to rescue, fire suppression, and special operations, including response to the scene of an incident and all functions performed at the scene.

Essential Functions of the Job. The essential functions are those fundamental job duties of firefighters that must be performed with or without reasonable accommodation.

Designated Physician. The T:icensed doctor of medicine or osteopathy who has been designated by the SOMD and approved by the SO with the concurrence of the Director, Office of Occupational Medicine and Medical Surveillance, to provide professional expertise in the areas of occupational medicine as it relates to the essential functions of firefighters (See section 2-2.2).

Firefighter. A member of a fire department, fire brigade, or an emergency response team whose duties require readiness and response to the performance of essential fire-fighting functions, or substantially similar functions, as those listed in section 5 . 


\section{$\underline{\text { Standard }}$}

Medical Examination. An examination performed or directed by the fire department physician that incorporates the components described in 2-4.1.4.

Medically Certified. A determination by the fire department physician that the candidate or current firefighter meets the medical requirements of this standard.

Member. A person invoived in performing the duties and responsibilities of a fire department. under the auspices of the organization. A fire department member may be a ful1time or part-time employee, or a paid or unpaid volunteer, may occupy any position or rank within the fire department, and may or may not engage in emergency operations.

\section{Interpretive Guidance}

Medical Examination. An examination performed or directed by the Designated Physician that incorporates the components described in section 2-4.1.4.

Medically Certified. A determination by the Designated Physician that the candidate or current firefighter meets the medical requirements of the standard.

\section{Site Occupational Medical}

Director. The physician responsible for the overall direction and operation of the site occupational medical program.

\section{Site Occupational Medical} Program. The occupational medical program or occupational medical department established by the contractor as required by DOE Order $5480.8 \mathrm{~A}$.

\section{Chapter 2 Medical Process}

\section{2-1 Medical Evaluation Process.}

2-1.1 The fire department, in cooperation with the SOMD, shall establish and implement a medical evaluation process for candidates and current firefighters. establish and implement a medical evaluation process for candidates and current firefighters: 


\section{Standard}

2-1.2 The medical evaiuation process shall include preplacement medical evaluations, periodic medical evaluations, and return-toduty medical evaluations.

\section{2-1.3 The fire department sha11} ensure that the medical evaluation process and all medical evaluations meet all the requirements of this section.
2-1.5 Each candidate or current firefighter shall, on a timely basis, report to the fire department physician any exposure or medical condition that may interfere with the ability of the individual to perform as a firefighter.

\section{2-2 Fire Department Physician.}

2-2.1 The fire department physician shall be a licensed doctor of medicine or osteopathy.
Interpretive Guidance

2-1.3 The fire department, in cooperation with the SOMD, shall ensure that the medical evaluation process and all medical evaluations meet all the requirements of this section.

2-1.4 Each candidate or current firefighter sha11 cooperate, participate, and compiy with the medical evaluation process and shall provide complete and accurate information to the fire department physician.

2-1.5 Each candidate or current firefighter shall report to the Designated Physician any exposure or medical condition that may interfere with the ability of the individual to perform the essential functions of a firefighter. The firefighter shall report to the site occupational medical program facility for a determination of fitness for duty by the Designated Physician when medication is started or when the dosage is changed for a medication that could cause a change in the individual's ability to perform the essential functions of a firefighter.

\section{2-2 Designated Physician.}

2-2.1 The Designated Physician shail be a licensed doctor of medicine or osteopathy who is associated with a DOE site occupational medical program. 


\section{Standard}

2-2.2 The fire department physician should be qualified to provide professional expertise in the areas of occupational safety and health as they relate to emergency services. .

2-2.3 For the purpose of conducting medical evaluations, the fire department physician shal1 understand the physiological and psychological demands placed on firefighters and shall understand the environmental conditions under which firefighters must perform.

2-2.4 The fire department physician shall evaluate the person to ascertain the presence of any medical conditions listed in this standard.
Interpretive Guidance

2-2.2 The Designated Physician should be qualified to provide professional expertise in the areas of occupational medicine as they relate to essential functions of firefighters. This qualification is reviewed and approved by the Director, Office of Occupational Medicine and Medical Surveillance, at the time of the initial designation following submission of a request for such approval, through the SO, from the SOMD. The letter describes the relevant training, experience and licensure, and includes copies of the physician's curriculum vitae and his/her current, valid medical 7 icense. The Designated Physician is required to report problems with his or her licensure or hospital privileges to the SOMD within 10 working days. The SOMD shal1 monitor the performance and annually provide the Office of Occupational Medicine and Medical Surveillance with the current status of each Designated Physician.

2-2.3 For the purpose of conducting medical evaluations, the Designated Physician shall be responsible for understanding the physiological and psychological demands placed on firefighters and the environmental conditions under which firefighters must perform. Management shall provide the Designated Physician with each firefighter's specific job task anaiysis before each comprehensive medical evaiuation.

2-2.4 The Designated Physician shall ascertain the ability of the individual to perform the essential functions of the job, using such examination, consultation, and testing elements as necessary. 


\section{Standard}

2-2.4.1 When medical evaluations are conducted by a physician other than the fire department physicjan, the evaluation shall be reviewed and approved by the fire department physician.

\section{2-3 Preplacement Medical Evaluation.}

2-3.1 The candidate shall be certified by the fire department physician as meeting the medical requirements of chapter 3 of this standard prior to entering into a training program to become a firefighter or performing in an emergency operational environment as a firefighter.

2-3.2 The candidate shall be evaluated according to the medical requirements of chapter 3 of this standard to assess the effect of medical-conditions on the candidate's ability to perform as a firefighter.

\section{2-3.3 A candidate shall not be} certified as meeting the medical requirements of this standard if the fire department physician determines that the candidate has any Category $A$ medical condition specified in chapter 3 of this standard.

\section{Interpretive Guidance}

2-2.4.1 The Designated Physician shall conduct or supervise the examination and interpret and document the associated medical information and the presence of medical conditions in the site occupational medical record. The decision of the Designated Physician must be conveyed in writing to management and to the examinee. The Designated Physician shall identify any essential functions the individual cannot perform and may recommend rehabilitation or other actions necessary for the individual to attain this ability.

\section{2-3 Preplacement Medical Evaluation.}

2-3.1 The candidate shall be certified by the Designated Physician as meeting the medical requirements of these guidelines prior to entering into a training program to become a firefighter or performing in an emergency operational environment as a firefighter.

2-3.2 The candidate shall be evaluated according to these guidel ines to assess the effect of medical conditions on the candidate's ability to perform the essential functions of a firefighter.

2-3.3 A candidate shall not be certified as meeting the medical requirements of these guidelines if the Designated Physician determines that the candidate cannot perform each of the essential functions of a firefighter with or without reasonable accommodation and without posing a direct threat to self or others. 


\section{Standard}

2-3.4 A candidate shall not be certified as meeting the medical requirements of this standard if the fire department physician determines that the candidate has a Category $B$ medical condition specified in chapter 3 of this standard that is of sufficient severity to prevent the candidate from performing, with or without reasonable accommodation, the essential functions of a firefighter without posing a significant risk to the safety and health of the candidate or others.

2-3.4.1 The determination of whether there is reasonable accommodation shall be made by the authority having jurisdiction in conjunction with the fire department physician.

2-3.5 If the candidate presents with an acute medical problem or newly acquired, chronic medical condition that interferes with the candidate's ability to perform the functions of a firefighter, medical certification shall be postponed until the person has recovered from this condition and presents to the fire department for review.

\section{2-4 Periodic Medical Examination.}

2-4.1 The current firefighter shall be annualiy certified by the fire department physician as meeting the medical requirements of chapter 3 of this standard to determine that firefighter's medical ability to continue participating in a training or emergency operation environment as a firefighter.
Interpretive Guidance

2-3.4.1 The determination of whether there is reasonable accommodation shall be made by contractor management in conjunction with the Designated Physician.

2-3.5 If the candidate has acute medical problems or a newly acquired, chronic medical condition that interferes with the candidate's ability to perform the essential functions of a firefighter, medical certification shall be postponed until the person has recovered from this condition and reports to the fire department for review.

\section{2-4 Periodic Medical Examination.}

2-4.1 The current firefighter shal7 be annually certified by the Designated Physician as medically able to perform all of the essential functions of a firefighter. 


\section{Standard}

2-4.1.1 The components of the annual medical evaluation specified in 2-4.1.2 of this section shall be permitted to be performed by qualified personnel as authorized by the fire department physician. When other qualified personnel are used, the fire department physician shall review the data gathered during the evaluation.

2-4.1.2 The annual medical evaluation shall consist of:

(a) an interval medicai history;

(b) an interval occupational history, including significant exposures;

(c) height and weight: and

(d) blood pressure.
2-4.2 A current firefighter shall not be certified as meeting the medical requirements of this standard if the fire department physician determines that the firefighter has any Category $A$ medical condition specified in chapter 3 of this standard.

2-4.3 A current firefighter shall not be certified as meeting the medical requirements of this standard if the fire department physician determines that the firefighter has a Category $B$

\section{Interpretive Guidance}

2-4.1.1 The components of the annual medical evaluation specified in section 2-4.1.2 of these guidelines may be performed by qual ified personnel, as authorized by the Designated Physician remains responsible to interpret and sign the certification. The other occupational health examiner should be under the personal supervision of the Designated Physician.

2-4.1.2 The annual medical examination shall inciude the elements of the comprehensive medical examination listed in DOE Order 5480.8A, and:

(a) Additional medical tests, consultations or evaluations, as deemed necessary by the Designated Physician, to determine the candidate's ability to perform the essential functions of a firefighter or the need for temporary work restrictions; and

(b) All examination elements, tests, or measurements that are necessary for required, concurrent medical certifications or medical surveillance programs for which the firefighter is enrolled, including pulmonary function testing necessary to evaluate the ability to use respirators.

2-4.2 A current firefighter shall not be certified if the Designated Physician determines that the candidate cannot perform all the essential functions of $a$ firefighter. These essential functions include those functions listed in these guidelines and those associated with the specific job task anajysis.

2-4.3 A current firefighter shall not be certified if the Designated Physician determines that the candidate cannot perform the essential functions of a firefighter. Section 5 of the 


\section{$\underline{\text { Standard }}$}

medical condition specified in chapter 3 of this standard that is of sufficient severity to prevent the firefighter from performing, with or without reasonable accommodation, the essential functions of a firefighter without posing a significant risk to the safety and health of the firefighter or others.

2-4.3.1 The determination of reasonable accommodation shall be made by the authority having jurisdiction in conjunction with the fire department physician.

\section{2-4.4 If a current firefighter} presents with an acute illness or recently acquired, chronic medical condition, the evaluation shali be deferred until the firefighter has recovered from the condition and presents to the fire department to return to duty.

\section{2-5 Return-to-Duty Hedical Evaluation.}

2-5.1 A current firefighter who has been absent from duty for a medical condition of a nature or duration that may affect performance as a firefighter shall be evaluated by the fire department physician before returning to duty.

\section{Interpretive Guidance}

guidelines may be used as a checklist of conditions that may be associated with an inability of the individual to perform each essential function. If a listed or similar condition is diagnosed, the Designated Physician shall document in the medical record why the individual with that condition is, or is not, able to perform the essential functions of a firefighter.

2-4.3.1 A determination of reasonable accommodation shall be made by management in conjunction with the Designated Physician.

\section{2-4.4 If the current firefighter} presents with an acute medical problem or newly acquired, chronic medical condition that interferes with the candidate's ability to perform the essential functions of a firefighter, medical evaluation. may be postponed untit that person has recovered from the condition and presents to the occupational medical program for review.

\section{2-5 Return-to-Work Medical Evaluation.}

2-5.1 A current firefighter who has been absent from duty for a medical condition of a nature or duration that may affect performance as a firefighter shall be evaluated by the Designated Physician before returning to duty. A11 such return-to-work evaluations shal7 be reviewed and signed by the Designated Physician. The responsibility for giving medical clearance for return to work as a firefighter rests with the Designated Physician. 


\section{Standard}

2-5.2 The fire department physician shall not medically certify the current firefighter for return to duty if any Category $A$ medical condition specified in chapter 3 of this standard is present.

2-5.3 The fire department physician shall not medically certify the current firefighter for return to duty if any Category $B$ medical condition specified in chapter 3 of this standard is present that is determined to be severe enough to affect the firefighter's performance as a firefighter. The fire department physician, in conjunction with the authority having jurisdiction, shall take into account the firefighter's current duty assignment and a7ternative duty assignments or other programs that would allow a firefighter to gradual7y return to full duty.

\section{2-6 Medical Evaluation Records,} Results, Reporting, and Confidentiality.

2-6.1 All medical information collected as part of a medical evaluation shall be considered confidential medical information and shall be released by the fire department physician only with the specific written consent of the candidate or current firefighter.

2-6.2 The fire department physician shall report the results of the medical evaluation to the candidate or current firefighter, including any medical condition(s) disclosed during the medical evaluation and the recommendation as to whether the candidate or current firefighter is medicaliy certified to perform as a firefighter.

\section{Interpretive Guidance}

2-5.2 \& 2-5.3 -A firefighter wishing to return to work shall not be certified if the Designated Physician determines that the candidate cannot perform all of the essential functions of a firefighter.

\section{2-6 Medical Evaluation Records, Results, Reporting, and Confidentiality.}

2-6.1 ATl medical information collected as part of a medical evaluation shall be considered confidential medical information and shall be released only with the specific written consent of the candidate or current firefighter, except as permitted or required by 1 aw or regulation.

2-6.2 The Designated Physician shall report the results of the medical evaluation to the candidate or current firefighter, including any medical condition(s) disclosed during the medical evaluation and the recommendation as to whether the candidate or current firefighter is medically certified to perform as a firefighter. 
including any medical condition(s) disclosed during the medical evaluation and the recommendation as to whether the candidate or current firefighter is medically certified to perform as a firefighter.

2-6.3 The fire department physician shall inform the fire department only as to whether or not the candidate or current firefighter is medically certified to perform as a firefighter. The specific written consent of the candidate or current firefighter shall be required to release confidential medical information to the fire department.

\section{ESŚENTIAL FIREFIGHTING FUNCTIONS:}

These essential functions are those that firefighters are expected to perform at emergency incidents and may be required to perform in training dril1s and emergency exercises. They are derived from the performance objectives stated in NFPA 1001, "Standard for Firefighter Professional Qual ifications."

3-1 General Essential Functions. The examinee shall possess mental, sensorial, and motor skills as required to perform safely and effectively all essential job duties described below and those additional essential functions that are derived from the specific jobtask analysis that is developed for each firefighter. The specific job task analysis will be submitted to the Designated Physician prior to each medical evaluation of the candidate or current firefighter. The general essential functions include:

3-1.1 The ability to be stable with regards to consciousness and the control of voluntary motor functions, and to have the functional capacity to respond appropriately to routine and emergency situations of the job;

3-1.2 The ability to maintain the mental alertness, deductive and inductive reasoning, memory, and reliable judgment necessary to perform all essential functions without posing a direct threat to self or others;

3-1.3 Acuity of senses and ability of expression sufficient to allow essential, accurate communication by written, spoken, audible, visible, or other signals, while using required personal protective or other equipment; and 
3-1.4 Motor power, dynamic strength, range of motion. neuromuscular coordination, stamina, gross body coordination, and dexterity adequate to perform essential functions -under all required, routine and emergency duties.

3-2 Specific Essential Functions. Each standard, firefighter essential function is 7 isted with examples of medical conditions that may affect the ability of the individual to perform that function. These conditions, or others, when found to be present, require the Designated Physician to determine and record why that individual is, or is not, qualified to perform all the essential functions.

3-2a The individual must be stable with regard to consciousness and the control of voluntary motor functions and have the functional capacity to respond appropriately to routine and emergency situations.

3-2a Examples of medical conditions that may affect performance include:

1. All uncontrolled seizure disorders.;

2. Myocardial insufficiency;

3. Congestive heart failure;

4. Documented predisposition to heat stress;

5. Malignant diseases not in remission;

6. Severe congenital deformities of the spine, trunk, or Timbs; and

- 7. Narcolepsy.

3-2b Operate both as a member of a team and independently at incidents of uncertain duration.

3-2b Examples of medical conditions that may affect performance include:

1. Diabetes mellitus requiring careful control through management of diet, timed exercise, and/or insulin;

2. Sleep disorders;

3. Addison's Disease (adrenal insufficiency);

4. Allergic respiratory disorder; and

5. Disorders producing orthostatic hypotension.

3-2c Spend extensive time outside exposed to the elements.

3-2c Examples of medical conditions that may affect performance inciude:

1. Congenital ectodermal dysplasia;

2. Raynaud's Syndrome;

3. Chronic sinusitis;

4. Bronchial asthma; and

5. Severe arthritis. 
3-2d Tolerate extreme fluctuations in temperature while performing duties. Must perform physically demanding work in hot (up to $400^{\circ} \mathrm{F}$ ), humid (up to $100 \%$ humidity) atmosphere while wearing equipment that significantly impairs body-cooling mechanisms.

3-2d Examples of medical conditions that may affect performance include:

1. Bronchial asthma;

2. Diabetes mellitus;

3. Pregnancy (after lst trimester);

4. Chronic sinusitis:

5. Use of neuroleptic drugs (e.g., Thorazine); and

6. Eczema.

3-2e Experience frequent transition from hot to cold and from humid to dry atmospheres.

3-2e Examples of medical conditions that may affect performance include:

1. Bronchial asthma;

2. Chronic sinusitis;

3. Arthritis; and

4. Eczema.

3-2f Work, including walking, standing, pulling, and pushing in wet, icy, or muddy areas.

3-2f Examples of medical conditions that may affect performance include:

1. Neuromuscular injuries to the spine, or lower extremities with residual dysfunction of gait;

2. Cerebral Palsy:

3. Amyotrophic lateral sclerosis;

4. Muscuiar atrophies;

5. Arthritis;

6. Cerebral vascular accident with residual dysfunction of gait; and

7. Neurological disorders with ataxia.

3-2g Perform a variety of tasks on slippery, hazardous surfaces, such as on rooftops or ladders.

3-2g Examples of medical conditions that may affect performance include:

1. Labyrinthine or vestibular disorders with vertigo;

2. Severe limitations of motion of joints;

3. All uncontrolled seizure disorders;

4. Ataxias; and

5. Progressive muscular dystrophy. 
3-2h Work in areas where sustaining traumatic or thermal injuries are possibie.

3-2h Examples of medical conditions that may affect performance inciude:

1. Impaired immune system;

2. Diabetes mellitus;

3. Predisposition to heat stress;

4. Hemophilia, Von Willebrand's disease, and other clotting/bleeding disorders;

5. Anemia;

6. Peripheral vascular disease;

7. Raynaud's Disease; and

8. Congenital multiple telangiectasia.

$3-2 i$ Ability to wear or use personal protective equipment without obstruction to prevent exposure to carcinogenic dusts, such as asbestos; toxic substances, such as hydrogen cyanide; acids; carbon monoxide; or organic solvents, either through inhalation or skin contact.:

3-2i Examples of medical conditions that may affect performance include:

1. Emphysema;

2. Eczema, including dyshidrotic types;

3. Asthma;

4. Chronic sinusitis; and

5. Malignancies.

3-2j Face exposure to infectious agents, such as Hepatitis B or HIV.

3-2j Examples of medical conditions that may affect performance include:

1. Impaired immune system;

2. Hemophilia;

3. Severe eczema or other dermatitis;

4. Cirrhosis; and

5. Pregnancy (after the 1st trimester).

3-2k Wear personal protective equipment that' weighs approximately 50 pounds while performing fire-fighting tasks.

3-2k Examples of medical conditions that may affect performance include:

1. Hernia;

2. Joint and Timb deformities so severe that it would interfere with movement and flexibility;

3. Arthritis;

4. Ataxias; and

5. Multiple sclerosis. 
3-21 Perform physically demanding work while wearing positive pressure breathing equipment with 1.5 inches of water column resistance to exhalation at a flow of $40 \%$ iters per minute.

3-21 Exampies of medical conditions that may affect performance inciude:

1. Emphysema;

2. History of previous pneumothorax;

3. Eczema;

4. Asthma;

5. Spinal dysfunctions; and

6. Chronic lung diseases.

3-2m Perform complex tasks during 1ife-threatening emergencies.

3-2m Exampies of medical conditions that may affect performance include:

1. Psychological conditions;

2. Cardiovascular conditions, including angina;

3. Severe hypertension;

4. Substance abuse;

5. Migraine; and

6. Progressive dementias.

3-2n Work for long periods of time, requiring sustained physical activity and intense concentration.

3-2n Examples of medical conditions that may affect performance include:

1. Neuromuscular injuries to the spine, or lower extremities with residual dysfunction of gait;

2. Cerebral Palsy;

3. Amyotrophic lateral sclerosịs;

4. Muscular atrophies;

5. Arthritis; and

6. Cardiac conditions, including angina.

3-20 Make life or death decisions during emergency conditions.

3-20 Examples of medical conditions that may affect performance inciude:

1. Psychological conditions;

2. Cardiovascular conditions;

3. Severe hypertension;

4. Substance abuse;

5. Migraine;

6. Suicide threat or attempt; and

7. Cardiac conditions, including angina. 
3-2p Be exposed to grotesque sights and smells associated with major trauma and burn victims.

3-2p Examples of medical conditions that may affect performance include:

1. Psychological conditions;

2. Cardiac conditions, including angina;

3. Recurrent syncope;

4. Substance abuse; and

5. Hypertension.

3-2q Make rapid transitions from rest to near maximum exertion without warmup periods.

3-2q Examples of medical conditions that may affect performance include:

1. Cardiovascular conditions;

2. Arthritis and other chronic joint diseases;

3. Chronic, obstructive or restrictive lung diseases;

4. Progressive muscular dystrophy;

5. Labyrinthitis; and

6. Poor physical conditioning.

$3-2 r$ The ability to properiy and effectively wear protective equipment.

3-2r Examples of medical conditions that may affect performance include:

1. Deformities of the skull, congenital or developmental facial deformities;

2. Oropharyngeal dysfunction, causing inability to communicate effectively;

3. Contraction of neck muscles, inability to rotate head;

4. Inflammatory skin diseases;

5. Pulmonary functions diseases;

6. Tracheostomy;

7. Branchial cleft or other oropharyngeal fistulas; and

8. Perforated eardrum.

3-2s Freedom from frequent episodes of pain or inability to perform work, or sudden incapacitation.

3-2s Examples of medical conditions that may affect performance include:

1. Pancreatitis;

2. Ulcers;

3. Acute hepatitis;

4. Severe hemorrhoids; 
5. Hernia;

6. Chronic severe osteoarthritis; and

7. Lumbar disc disease or other low back pain syndromes.

3-2t Ability to maintain balance under adverse conditions, weight loads, and at aboveground heights; and maintain body flexibility.

3-2t Examples of medical conditions that may affect performance include:

1. Labyrinthitis;

2. Amputation or deformity of joint or Timb;

3. Cerebral arteriosclerosis;

4. Multiple sclerosis;

5. Muscular dystrophy;

6. Chemical, drug, or medication abuse;

7. Obstructive or restrictive lung disease;

8. Ankylosing spondylitis; and

9. Chronic back conditions with decreased range of motion or pain.

3-2u Operate in environments of high noise, poor visibility, limited mobility, aboveground heights, and in closed or confined spaces.

3-2u Examples of medical conditions that may affect performance include:

1. Hypertension;

2. Hearing loss, recruitment, or other hearing-related conditions;

3. Claustrophobia;

4. Psychological conditions;

5. Ulcers;

6. Labyrinthine or vestibular disorders subject to vertigo;

7. Syncope; and

8. Acrophobia.

3-2v Use manual and power tools in the performance of duties.

3-2v Examples of medical conditions that may affect performance include:

1. Progressive muscular dystrophy;

2. Neuromuscular injuries to the spine or limbs;

3. Hearing loss;

4. Arthritis and other chronic joint diseases;

5. Cerebral Palsy; and

6. Carpal tunnel syndrome. 
3-2W Ability to maintain balance under adverse conditions, weight loads, and at aboveground heights; and maintain body flexibility.

3-2w Examples of medical conditions that may affect performance include:

1. Labyrinthine or vestibular disorders subject to vertigo;

2. Amputation or deformity of joint or limb;

3. Cerebral arteriosclerosis:

4. Multiple sclerosis;

5. Muscular dystrophy;

6. Chemical, drug, or medication abuse;

7. Syncope;

8. Acrophobia; and

9. Chronic back conditions with decreased range of motion or pain.

3-2x Rely on sense of sight, hearing, smell, and touch to help determine the nature of the emergency; maintain personal safety; and make critical decisions in a confused, chaotic, and potentially life-threatening environment throughout the duration of the operation.

3-2x Examples of medical conditions that may affect performance include:

1. Hearing impairment with inability to hear the whispered voice at 12 feet in a quiet environment;

2. Recurrent sinusitis;

3. Visual acuity uncorrected worse than $20 / 100$; and

4. Anosmia.

3-2y The ability to identify colors and to read placards and street signs or to see and respond to imminently hazardous situations in less than standard visual lighting conditions.

3-2y Examples of medical conditions that may affect performance include:

1. Color blindness;

2. Retinal detachment;

3. Progressive retinopathy;

4. Optic neuritis;

5. Radial keratotomy prior to full healing; and

6. Cataracts.

3-2z The ability temporarily to have useful vision in the event eyeglasses are broken or displaced by emergency activity.

3-2z Example of a medical condition that may affect performance: uncorrected vision worse than 20/100. 
3-2aa Ability to smell smoke and other odors that might indicate hazardous conditions.

3-2aa Examples of medical conditions that may affect performance inciude:

1. Anosmia; and

2. Severe sinusitis.

3-2ab Ability to verbally communicate effectiveiy under noisy circumstances with a potential for voice obstruction by personal protective equipment.

3-2ab Examples of medical conditions that may affect performance include:

1. Hearing loss;

2. Speech pathology;

3. Laryngectomy;

4. Tracheostomy;

5. Bronchial asthma; and

6. Congenital acquired deformities of the face and neck that interfere with speech.

3-2ac Ability to distinguish low intensity voice sounds from background noise in order to respond to imminently hazardous situations.

3-2ac Example of a medical condition that may affect performance: hearing loss, including presbycusis.

3-2ad Ability to work in closed or confined spaces.

3-2ad Example of a medical condition that may affect performance: claustrophobia.

3-2ae Ability to judge distances closer than 13 feet demonstrated either by testing of depth perception or by a practical field test.

3-2ae Examples of medical conditions that may affect performance include:

1. Monocular vision; and

2. Amblyopia anopsia. 


\section{IMPLEMENTATION GUIDE for use with \\ DOE ORDERS 420 and 440.1 \\ FIRE SAFETY PROGRAM}

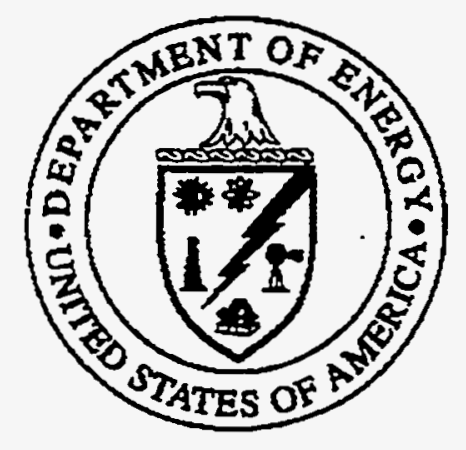

OFFICE OF WORKER HEALTH AND SAFETY

FINAL 


\section{FOREWORD}

1. This. Department of Energy (DOE) Implementation Guide is approved for use by the Office of Environment, Safety and Health and is available to all DOE components and their contractors.

2. Specific comments (recommendations, additions, deletions, and any pertinent data) to enhance this document should be sent to:

Dennis Kubicki

Office of Environment, Safety and Health

Office of Worker Health and Safety

Bellemead Building

U.S. Department of Energy

19901 Germantown Road

Germantown, MD 20874-1290

3. DOE implementation guides are part of the DOE directives system and are issued to provide supplemental information'regarding the Department's expectations for fulfilling its requirements as contained in rules, Orders, notices, and regulatory standards. The guides may also provide acceptable methods for implementing these requirements. Implementation guides are not substitutes for requirements, nor do they replace technical standards that are used to describe established practices and procedures for implementing requirements.

4. Applicable standards and additional guidance documents are listed in Appendix A. 
CONTENTS

Paragraph

$\underline{\text { Page }}$

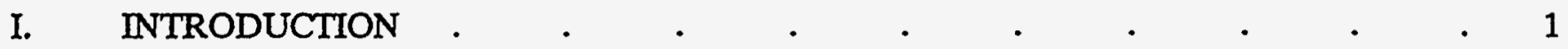

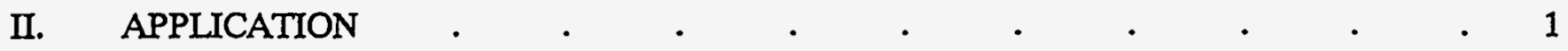

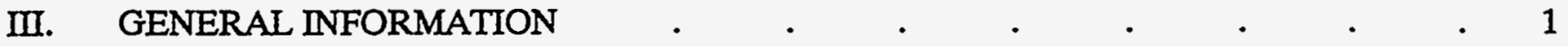

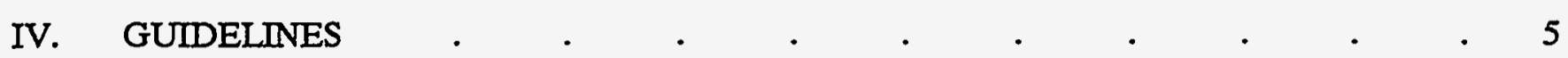

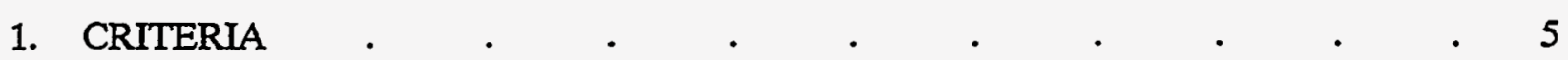

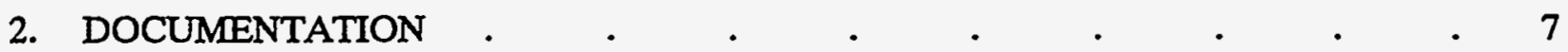

3. INSPECTION, TESTING, AND MAINTENANCE $\quad$ - $\quad$ - $\quad$ • $\quad$. $\quad$. $\quad$ - 8

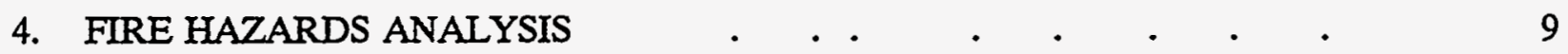

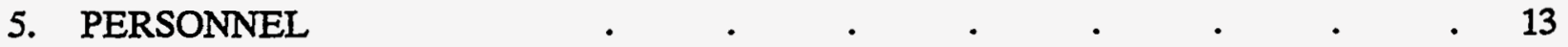

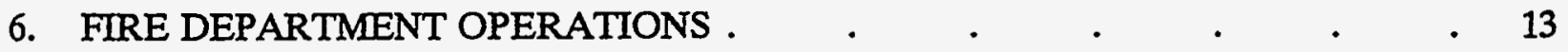

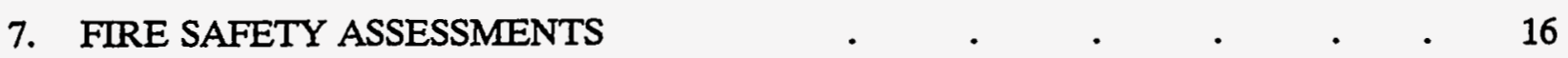

8. FIRE SAFETY EXEMPTIONS AND EQUTVALENCIES . . . • . 19

9. FIRE PROTECTION DESIGN BASIS . $\quad$. $\quad$ - $\quad$. $\quad$. $\quad$. 20

10. PROTECTION FOR ABANDONED FACILITIES $\quad$ - $\quad$ - $\quad$ - . $\quad$ - 22

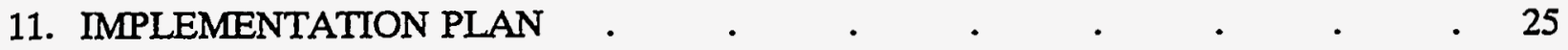

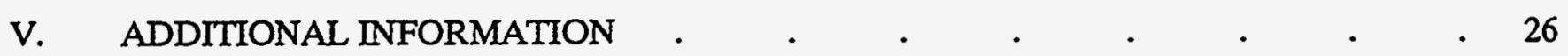

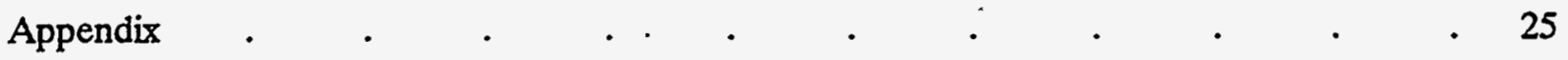




\section{Section I. INTRODUCTION}

The purpose of this Implementation Guide is to facilitate the development, implementation, and maintenance of a comprehensive fire protection program so as to achieve the policy objectives and fulfill the requirements delineated in DOE 420, "Facility Safety," and DOE 440.1, "Worker Protection Management for DOE Federal and Contractor Employees."

This is done by explaining the interrelationship between these Orders and the other related requirements, guidance and technical standards that, along with site-specific criteria, define an acceptable fire protection program.

Also included are supplementary guidance and procedures that will facilitate the implementation and maintenance of the program, its continuing evaluation, and potential future revision, update and enhancement.

\section{Section II. APPLICATION}

The Guide applies to all Departmental Elements as delineated in DOE 420 and DOE 440.1. Because the guidance contained herein does not offer precise suggestions for resolution of all fire safety issues, it is expected that judgment will need to be utilized in the application of this Guide.

Nothing in the Guide prevents or discourages the implementation of alteriate or innovative fire protection configurations and practices that will achieve a level of fire safety comparable to that attained by literal conformance with DOE fire safety criteria or those established by the fire protection industry through the consensus standards process. To the extent that an alternate configuration is proposed, it should be evaluated and approved as equivalent by the DOE Authority Having Jurisdiction (AHJ) for fire protection.

\section{Section III. GENERAL INFORMATION}

1.0. DOE 420 and 440.1 establish minimum requirements for a comprehensive fire protection program, including site fire departments. The fire protection program requirements from these Orders are repeated in this Section for expedient reference and application. An acceptable fire protection program includes those fire protection policies, requirements, technical criteria, analyses, 
administrative procedures, systems and hardware, apparatus and equipment, plans, and personnel that comprehensively ensure that DOE objectives relating to fire safety are achieved. Such a program should be characterized by a level of fire protection sufficient to fulfill the requirements for the best protected class of industrial risks ("Highly Protected Risk" or "Improved Risk") and should have protection to provide "defense-in-depth." This means that fire safety should be an integral part of all activities and that facilities should be designed with both active and passive fire protection features such that reliance will not be placed on only one means to assure an acceptable level of fire safety. This is also characterized by the demonstration of a continuing, sincere interest on the part of management and employees in minimizing losses from fire and related hazards and the implementation of preventive features necessary to ensure the satisfaction of objectives related to fire safety.

2.0. To achieve this level of fire protection, site operations and facilities should meet a minimum level of fire protection as further defined below.

3.0. An acceptable fire protection program should meet the minimum requirements established by the National Fire Protection Association (NFPA) and other referenced fire safety criteria (or exceed them when necessary to meet fire safety objectives), unless explicit relief has been granted by DOE.

4.0. Basic elements of an acceptable program include:

4.1. A policy statement that incorporates the requirements of this Order, related DOE directives, and other applicable Federal, state and local fire protection requirements. The statement should affirm management's commitment to support a level of fire protection and fire suppression capability sufficient to minimize losses from fire and related hazards consistent with the best class of protected property in private industry.

4.2. Comprehensive, written fire protection criteria that reflect additional site-specific aspects of the fire protection program, including: the organization, training and responsibilities of the fire protection staff; administrative aspects of the fire protection program; and requirements for the design, installation, operability, inspection, maintenance and testing of fire protection systems.

4.3. Written fire safety procedures governing the use and storage of combustible, flammable, radioactive, and hazardous materials so as to minimize the risk from fire. Such procedures should also exist for fire protection system impairments and for activities such as smoking, hot 
work, safe operation of process equipment, and other fire prevention measures which contribute to the decrease in fire risk.

4.4. A system to ensure that the requirements of the DOE fire protection program are documented and incorporated in the plans and specifications for all new facilities and for significant modifications of existing facilities. This includes a documented review by a qualified fire protection engineer of plans, specifications, procedures, and acceptance tests.

4.5. Fire hazards analyses (FHA) for all nuclear facilities, significant new facilities and facilities that represent unique or significant fire safety risks. The FHA should be developed using a graded approach. The conclusions of the FHA should be incorporated in the Safety Analysis Report (SAR) Accident Analysis and should be integrated into design basis and beyond design basis accident conditions.

4.6. Access to a qualified and trained fire protection staff, including a fire protection engineer(s), technicians and fire fighting personnel to implement the requirements of this Order.

4.7. A "baseline" needs assessment that establishes the minimum required capabilities of site fire fighting forces. This includes minimum staffing, apparatus, facilities, equipment, training, fire pre-plans, off-site assistance requirements, and procedures. Information from this assessment should be incorporated into the site Emergency Plan.

4.8. Written pre-fire strategies, plans, and standard operating procedures to enhance the effectiveness of site fire fighting forces, where provided. Such procedures include those governing the use of fire-fighting water or other neutron-moderating materials to suppress fire within or adjacent to moderation controlled areas. Restrictions on the use of water should be fully justified on the basis of criticality safety.

4.9. A comprehensive, documented fire protection self-assessment program, which includes all aspects (program and facility) of the fire protection program. Assessments should be performed on a regular basis at a frequency established by DOE.

4.10. A program to identify, prioritize and monitor the status of fire protection-related appraisal findings/recommendations until final resolution is achieved. When final resolution will be significantly delayed, appropriate interim compensatory measures should be implemented to minimize the fire risk.

4.11. A process for reviewing and recommending approval of fire safety "equivalencies" and "exemptions" to the DOE AHJ for fire safety.

4.12. Access to a fully equipped, staffed and trained emergency response force that is capable of 
effectively responding to a fire and other emergencies in a timely manner.

5.0. DOE facilities and sites should meet the applicable building code and National Fire Protection Association Codes and Standards, unless explicit written relief has been granted by DOE. The applicable codes and standards are those in effect when facility design commences ("code of record"). When significant modifications to a facility occur, the current edition of the code or standard should apply to the modification.

6.0. DOE Elements and contractors should develop, implement and maintain a comprehensive fire protection program for facilities that inciudes:

6.1. A reliable water supply of adequate capacity for fire suppression.

6.2. Noncombustible or fire-resistive construction, where appropriate. Complete fire-rated barriers that are commensurate with the fire hazard to isolate hazardous occupancies and to minimize fire spread and loss potential consistent with defined limits as established by DOE.

6.3. Automatic fire extinguishing systems throughout all significant facilities and in all areas subject to loss of safety class systems, significant life safety hazards, unacceptable program interruption, or fire loss potential in excess of defined limits.

6.4. Redundant fire protection systems in areas where safety class systems are vulnerable to fire damage and where no redundant safety capability exists outside the fire area. In new facilities, redundant safety class systems should be in separate fire areas. Redundant fire protection systems should also be provided in areas where the maximum possible fire loss (MPFL) exceeds limits established by DOE.

6.5. A means to summon the fire department in the event of a fire, such as a fire alarm signalling system.

6.6. A means to notify and evacuate building occupants in the event of a fire, such as a fire detection or fire alarm system and illuminated, protected egress paths.

6.7. Physical access and appropriate equipment to facilitate effective intervention by the fire department, such as an interior standpipe system(s) in multi-story or large facilities with complex configurations.

6.8. A means to prevent the accidental release of significant quantities of contaminated products of combustion and fire-fighting water to the environment, such as ventilation control and filter systems and curbs and dikes. Such features would only be necessary if required by the FHA 
or SAR in conjunction with other facility or site environmental protection measures.

6.9. Fire and related hazards that are unique to DOE and are not addressed by industry codes and standards should be protected by isolation, segregation or use of special fire control systems, such as inert gas or explosion suppression, as determined by the FHA.

6.10. Fire protection systems should be designed such that their inadvertent operation, inactivation or failure of structural stability will not result in the loss of vital safety functions or inoperability of safety class systems as determined by the SAR.

\section{Section IV. GUIDELINES}

\subsection{CRITERIA}

1.1. DOE Order 420, paragraphs 4.2.1.1 through 4.2.1.3, and DOE Order 440.1, Attachment 1, Section 2, require DOE elements and contractors to develop site-specific criteria as part of a comprehensive fire protection program.

1.2. The technical basis of an acceptable program is a body of policies, requirements, codes, standards, guidelines, and interpretations that define as completely as possible the minimum expectations regarding all aspects of the fire protection program.

1.3. DOE has in the past and will continue to promulgate fire safety-related criteria if a need for such criteria exists and that need is not being met by the fire protection industry through the model building code and consensus standard development process.

1.4. To the extent that DOE fire safety criteria may not in themselves define a comprehensive technical basis for an acceptable fire protection program based on site-specific considerations, it is the Department's expectation that its contractors develop and/or adopt site-specific criteria that, combined with DOE criteria, establish an acceptable technical basis for the program. Such a need should be identified by the contractor fire protection staff. Promulgation of such supplementary criteria should be thoroughly coordinated within the contractor's technical staff and should be reviewed and approved by the DOE AHJ for fire protection. Because fire protection is a mature and generally successful program within the Department, it is not expected that wholesale program enhancements related to criteria are necessary. 
1.5. It is expected that fire protection criteria will need to evolve to reflect technological and other developments. The Department expects that the technical basis for the fire protection program will change by the adoption of new or revised codes and standards. Implementation plans for this Order should reflect a commitment to adopt the most recent version of codes or standards. If a pending code or standard represents an unnecessary burden on the Department, DOE will promulgate a Department-wide implementation plan (based on recommendations by the DOE Fire Safety Committee) that reflects the Department's perspective. Such implementation plans have been developed in the past for fire department operations and for testing and maintenance programs.

1.6. With regard to facilities, the fire protection-related codes and standards in effect when facility design commences (code of record) remain in effect for the life of the facility. When modifications of a substantial nature occur, the current edition of the code will apply to the modification. An exception would be if there is a significant hazard that endangers building occupants or the public as determined by the AHJ. In such cases, the facility should be upgraded to the requirements of the current edition of the code or standard to mitigate that hazard. For older facilities for which the code of record may be unknown, the current edition of the code or standard should be applied with judgment in the assessment of the adequacy of fire protection.

1.7. The Department encourages a rational and flexible approach to the implementation of fire safety criteria. When a complete and comprehensive technical analysis concludes that an alternate approach achieves a comparable level of safety to that attained by literal conformance with a particular aspect of DOE fire safety criteria, DOE would conclude that the alternate approach satisfies its overall fire safety policy. The content and conclusions of such an analysis would have to be reviewed by the DOE AHJ for fire protection, after consultation with the cognizant DOE fire protection engineer(s). Concurrence by the AHJ would constitute a determination of technical "Equivalency." 


\subsection{DOCUMENTATION}

2.1. DOE Order 420, in Section 4.2.1, establishes requirements for fire protection program documentation.

2.2. The program should be completely documented (such as in the Standards Requirements Identification Document). This includes a description of applicable fire safety requirements in contracts and leases, where appropriate.

2.3. Documentation should also include a description of the fire protection organization and its roles and responsibilities in relation to other organizational entities. It is preferable, although not always essential, to have all fire protection-related line activities under a single line manager to avoid unnecessary duplication and costs.

2.4. Training and qualification records of individuals having fire protection program responsibilities should be readily available and in an auditable form.

2.5. Appropriate fire protection documentation includes copies of all fire hazards analyses and at least the two most recent facility assessment reports in a continually updated filing system. The fire hazards analyses and facility assessment reports may be combined, provided that they address all essential elements as defined below. (The DOE Fire Protection Resource Manual contains copies of "models" of separate and combined FHAs and assessment reports.) Facility documentation should also include copies of any Exemptions and Equivalencies that have been approved by DOE.

2.6. Construction projects should feature a file in which all significant decisions and reports concerning fire protection can be found. Critical documents in this file should be maintained for future reference.

2.7. The organization(s) responsible for inspection, testing, and maintenance of fire protection features should maintain records of recent (not less than one year) activities as well as a file(s) of all inspection, testing and maintenance procedures. Unnecessary duplication of procedures is discouraged. A single governing procedure with unique system- or facility-specific conditions 
highlighted is considered acceptable.

2.8. Site fire departments and other related emergency response organizations (such as brigades or emergency squads) should maintain a current file with all Standard Operating Procedures and fire pre-plans. A program should be in place to ensure that this documentation is updated at appropriate intervals. Pre-plans should be developed on the basis of input from the site fire protection engineering staff as well as emergency responders.

2.9. Emergency response records should conform with DOE reporting requirements and should be based on national standards of fire incident reporting (NFPA 902M) in lieu of site-specific reporting formats. This will facilitate consistent reporting across the Department.

2.10. Nothing in this section prevents or discourages the use of computerized information management techniques for the creation, maintenance and dissemination of relevant documentation pertaining to the fire protection program.

\subsection{INSPECTION, TESTING, AND MAINTENANCE}

3.1. DOE Order 420, paragraph 4.2.1.2, requires the development of site criteria for inspection, testing and maintenance of fire protection systems.

3.2. The inspection, testing and maintenance program for fire protection features, apparatus and equipment should be based on industry standards, such as those established by the NFPA. To the extent that an adequate technical basis exists to justify deviations from the inspection and test frequencies delineated in these standards, DOE would accept well-documented alternatives, provided that operability was reasonably assured.

3.3 Minimum requirements to establish "operability" should be developed for fire protection features, including fire detection and suppression systems, fire doors and dampers, and fire protection water supplies. "Model" operability requirements and technical specifications are contained in the DOE Fire Protection Resource Manual (Handbook). Periodic inspections and tests at an appropriate frequency should be conducted to verify operability. When fire protection systems are inoperable for a significant period of time, interim compensatory 
measures, such as fire watchers, should be implemented in accordance with established procedures until operability is restored.

3.4. Data on fire protection system performance should be continually collected and maintained so as to be able to provide a sound technical basis for the fire protection inspection, testing and maintenance program. Trends in system performance should be monitored so as to be able to determine if significant degradation of system performance is occurring over time. Such degradation would justify revising the inspection, testing, and maintenance program to feature more conservative frequencies.

\subsection{FIRE HAZARDS ANALYSES}

4.1. DOE Order 420, paragraph 4.2.1.5, requires the development of an FHA for select facilities under certain circumstances. Examples of facilities for which an FHA should be performed are nuclear and high hazard facilities (as defined by DOE), buildings in which significant quantities of hazardous materials are stored or processed, and structures featuring equipment of considerable value. These examples encompass new facilities as well as significant renovations to existing facilities. Examples of facilities not generally requiring an FHA include small utility buildings, trailers, and office buildings.

4.2. The purpose of an FHA is to comprehensively and qualitatively assess the risk from fire within individual fire areas in a DOE facility so as to ascertain whether the DOE fire safety objectives, which are delineated in the above referenced Orders, are met. This must include an assessment of the risk from fire and related hazards (direct flame impingement; hot gases, smoke migration. fire-fighting water damage, etc.) in relation to existing or proposed fire safety features to ensure that the facility can be safely controlled and stabilized during and after a fire. To the extent that this analysis completely addresses the following issues, an FHA will satisfy the requirements for a traditional "Fire Protection Safe Shutdown Analysis." In accordance with the "graded approach" concept, the level of detail necessary for an acceptable FHA is directly related to the compiexity of the facility and the potential risk to the public and facility operators. The scope and content of an FHA should be limited to only those issues that are relevant to the facility. To facilitate the development of graded fire hazards analyses, "model" FHAs have been developed. These models can be found in the DOE Fire Protection Resource 
Manual (Handbook).

4.3. A preliminary FHA should be performed for all significant new facilities early in the design phase to ensure that an acceptable level of protection is being incorporated in the evolving design. It should be updated when significant changes occur within an individual fire area and should form the basis for the post-construction facility FHA.

4.4. An FHA should be performed under the direction of a qualified fire protection engineer, with support from systems, electrical, and mechanical engineers, as well as operations staff, as needed.

4.5. An FHA should contain, but not be limited to, a conservative assessment of the following fire safety issues:

. Description of construction

. Description of critical process equipment

. Description of high-value property

- Description of fire hazards

- Description of operations

. Potential for a toxic, biological and/or radiation incident due to a fire

. Natural hazards (earthquake, flood, wind) impact on fire safety

. Damage potential: Maximum Possible Fire Loss (MPFL)

. Fire protection features

. Protection of essential safety class systems

. Life safety considerations

. Emergency planning

- Fire Department/Brigade response

. Recovery potential

. Security and Safeguards considerations related to fire protection

. Exposure fire potential and the potential for fire spread between two fire areas

. Effect of significant fire safety deficiencies on fire risk

4.6. The FHA should assume and evaluate the consequences of a single, worse-case automatic fire 
protection system malfunction. This could be a detection system that also functions to activate a pre-action type sprinkler system.

4.7. In determining the value of the MPFL, which is used in part to assess the need for fire protection systems, the basic assumption should be that there is no automatic or manual fire suppression. This loss determination should include all direct and indirect costs associated with the fire and clean-up operations.

4.8. If redundant automatic fire protection systems (as defined by DOE) are provided in the area, only the system that causes the most vulnerable condition is assumed to fail. Passive fire protection features, such as blank fire-rated walls or continuous fire-rated cable wraps, are assumed to remain viable for their rated fire endurance period to the extent that they are properly constructed and maintained.

4.9. The focus of the FHA should be the individual fire areas that comprise the facility. A fire area is defined as a location bounded by fire-rated construction, having a minimum fire resistance rating of 2 hours, with openings protected by equivalently-rated fire doors, dampers or penetration seals. The boundaries of exterior fire areas (yard areas) should be as determined by the AHJ or delegated authority. Where a facility is not subdivided by fire-rated construction, the fire area should be defined by the exterior walls and roof of the facility.

4.10. An important element of an acceptable FHA for nuclear facilities is an inventory of all safety class systems within the fire area that are susceptible to fire damage. This includes those primary and supporting mechanical and electrical systems that must function effectively during and after a fire event to ensure safety, including safe shutdown where applicable. For example, loss of the building ventilation system in a fire (due to damage to power cables) may result in an ambient air temperature rise, which may cause the failure of sensitive electrical safety class components, such as relays. Such safety class systems may include, but are not limited to, process monitoring instrumentation, instrument air, the facility hydraulic system, and emergency lighting system.

4.11. All credible fire-related failure modes of safety' class systems should be considered. For 
example, it is insufficient to assume that fire will merely cause the loss of function of safety class equipment when power cables to that equipment are within the fire area. It is also necessary to consider the potential for spurious signals which may cause the maloperation of such equipment. Similarly, fire-induced electrical faults may trip upstream electrical disconnect devices in such a way as to render inoperable other safety class systems that may not even be located within the fire area. In addition, the effects of combustion products, manual firefighting efforts, and the activation of automatic fire suppression systems should be assessed.

4.12. Fire propagation and the potential for fire-induced radiological dispersal through the facility air distribution system should be considered. These effects should be considered for the normal operating mode of the air distribution system as well as alternate modes, such as shutdown, that may result from the fire.

4.13. A tool that may be used in the development of an FHA is a fire model, such as those developed by the National Institute of Standards and Technology, as applied by qualified fire. protection engineers. However, the use of such models is predicated on their being conservative and validated. As of this date, DOE has not sanctioned the use of any one model for use in an FHA. DOE acceptance of individual models will be considered on a case-by-case basis. Alternately, an assumption can be made that all potentially vulnerable systems will be damaged within the fire area. Acceptable exceptions to this assumption are water-filled steel pipes, tanks, and similar components of superior structural integrity with welded fittings and adequate pressure relief.

4.14. The quantity and associated hazards of flammable and combustible materials that can be expected to be found within the fire area should be factored into the analyses. Consideration should also be given to the presence of transient combustibles associated with storage and maintenance activities. Averaging combustible loading as a means to characterize the fire severity is not considered an acceptable technique.

4.15. FHAs for high bay locations should consider the effects of smoke/hot gas stratification that may occur at some intermediate point below the roof or ceiling. Similarly, the effect of smoke movement through doors and dampers held open by fusible links needs to be addressed. 
4.16. The fire hazards analysis, including all assumptions, should be documented. When both an FHA and a SAR are developed for a facility, the developmental effort should be coordinated to the maximum extent possible to avoid duplication of effort. It is recognized, however, that because an FHA is based on the premise that a fire will occur and considers fire safety issues (property loss and program discontinuity potential) that are not normally considered in the SAR, the conclusions of the FHA may be more conservative than would normally be developed by a SAR alone. Nevertheless, the FHA and its conclusions should be addressed in the facility SAR in such a manner as to reflect all relevant fire safety issues as defined in Paragraph 4.2.0.1 of DOE 420 and Section 2 of Attachment 1 of DOE 440.1.

\subsection{PERSONNEL}

5.1. DOE Order 420, Paragraph 4.2.1.6, and DOE Order 440.1, Attachment 1, Section 2, require DOE elements and contractors to have access to a qualified and trained fire protection staff.

5.2. A sufficient number of qualified fire safety professionals (fire protection engineers, fire department personnel and technicians) should be on staff to develop, implement and maintain the fire protection program. Staffing levels should be based on a "needs assessment," "work load analysis" or similar analysis that provides a technical basis for the fire safety staff. In those instances where a site is of insufficient size to warrant a fire protection staff or emergency response force, such capability should be achieved by other means, such as reliance on off-site fire departments and fire protection engineering support contractors.

\subsection{FIRE DEPARTMENT OPERATIONS}

6.1. DOE Order 440.1 , Attachment 1 , Section 2 , requires access to a fully staffed, equipped and trained fire department.

6.2. Responsibilities of DOE fire fighting forces include:

- Fire Suppression

- HAZMAT Response (where assigned)

- Training

- $\quad$ Search and Rescue

- Inspection, Testing and Maintenance (where applicable) 
$\therefore \quad$ Emergency Medical Services (where assigned)

- Confined Space Entry

- Off-Site Assistance

6.3. The actual organization of site emergency response forces to accomplish the above responsibilities should be determined on the basis of a "Needs Assessment," "Operational Basis Document," or equivalent analysis. This analysis should be based on conformance with applicable industry standards, such as those promulgated by the NFPA, the Department of Defense (DOD Instruction 6055.6), as well as supplementary guidance developed by DOE. It should include organizational responsibilities, collateral duties, facility hazards, response time requirements, personnel levels, required apparatus and equipment. In addition, the document should describe the organization's various programs which support its personnel. This should include training, physical fitness and medical programs relating to emergency responders. To facilitate this effort, a DOE "model" baseline needs assessment was developed and is contained in the DOE Fire Protection Resource Manual (Handbook).

6.4. In developing a comprehensive needs assessment, the basic assumption should be that there is only one emergency incident (such as a fire) occurring on site, with a casualty requiring emergency medical assistance. However, the document should also describe how the fire department would respond if a second incident occurred while the first was underway. The second response capability could be based on documented mutual aid agreements and utilization of some percentage of off-duty personnel over time. To the extent that an unacceptable response capability would exist for this second emergency, a basis would exist to supplement existing emergency response forces to be able to deal effectively with it.

6.5. A critical factor in any such analysis is the minimum response time necessary to begin active fire suppression activities. The determination of a minimally acceptable response time should be based on risk and should reflect "alarm handling," "travel time," and "access time." In the absence of explicit DOE criteria for response time, Department of Defense fire safety criteria may be used, with provisions for deviations with justification.

6.6. The minimum number of trained fire fighters necessary to begin interior structural fire fighting 
should be five, in line with long-standing DOE policy. (It is recognized that, where lives may be at risk, the on-scene commander has the authority and responsibility to effect rescue with less than this minimum if, in his judgment, it is safe to do so.) Additional emergency response personnel will be necessary where multiple hose lines are required to effectively suppress a fire and to support other fire ground activities such as search and rescue.

6.7. The minimum number of personnel required for exterior fire fighting, hazardous material incidents, specialized rescue or other related events should be based on DOE fire protection criteria (see Section V, Appendix), pre-planning where possible, and the judgment of trained and experienced fire department officers.

6.8. When no site fire department or brigade exists and when reliance will be placed on off-site fire departments, a plan should be developed that details how such forces will be expected to respond in conjunction with the site emergency plan and how appropriate training and site familiarization will be provided to ensure that the off-site fire departments will be prepared for fires that occur on site. Appropriate drills should be performed periodically to verify the effectiveness of the plan.

6.9. Training of emergency responders should be based on existing requirements such as those delineated in 29 CFR Parts 1910 and 1926, as well as criteria developed by the NFPA. In addition, emergency responders should be provided with sufficient site-specific training and familiarization to enable them to deal effectively with the unique conditions which characterize DOE facilities. As part of this effort, regular facility tours should be conducted utilizing current pre-plans.

6.10. Drills and exercises should be structured to emphasize realistic scenarios and feature standard fire department tactical evolutions. Such drills should also be scheduled, as appropriate, during weekends and evening shifts when normal activities are reduced.

6.11. Emergency radio communication should be compatible with other organizations involved with emergency response and should be designed to be effective in areas subject to structural interference. 
6.12. The "fleet" of fire department apparatus should reflect all site-specific response requirements including those delineated in the first paragraph above. Other examples include rough terrain rescue and wild land fire response. Periodic replacement programs for apparatus should be structured to avoid excessive "down time" and repair costs and should reflect the industry norm of useful life cycles (e.g., 20 years).

6.13. Fire stations, where provided, should be designed to provide sufficient capacity for mobile apparatus, including maintenance functions. Living quarters should provide a comfortable, private and safe environment for personnel, consistent with industry norms. This includes adequate sleeping quarters, kitchen facilities, training rooms, physical fitness areas and other ancillary needs. To the extent that related occupancies such as alarm rooms, maintenance rooms, and personnel areas are co-located within the same facility, appropriate fire-rated physical separation, ventilation and exhaust, and other fire protection features should be provided to prevent interference and to ensure the viability of individual areas in the event of a fire.

6.14. Fire stations should be "centrally" located to the facilities protected so as to minimize response time. Station location should also reflect prevailing traffic patterns, railroad tracks and other sources of delay.

6.15. Consistent with the training needs identified above, adequate facilities should be provided for training. This includes "live fire" training, confined space entry, vehicle extrication, hazardous material response, and other site-specific conditions. Where on site training facilities are unavailable, arrangements should be made for appropriate training for fire department personnel off site.

\subsection{FIRE SAFETY ASSESSMENTS}

7.1. DOE Order 420 , paragraph 4.2.1.9, requires a comprehensive fire protection self-assessment program.

7.2. The principle objective of a fire safety assessment is to identify significant fire safety deficiencies that would prevent the achievement of DOE's fire safety policy objectives. 
7.3. Facility and programmatic assessments should be performed by a fire protection engineer with an appropriate level of knowledge and experience in the application of fire safety codes and standards to diverse facilities. Fire department assessments should be performed by an individual with an appropriate level of knowledge and experience in all facets of fire department organization, equipment, and operations. Assessments should encompass the following elements of the fire protection program:

\subsubsection{Program-related:}

- Comprehensiveness of the fire protection program

- Procedures for engineering design and review

- Procedures for maintenance, testing, and inspection

- Fire protection engineering staff (number, qualifications, training)

- Fire suppression organization (personnel and training)

- Emergency medical response organization

- Hazardous material release containment and emergency cleanup organization

- Fire suppression mutual aid agreements

- Management support

- Exemptions and documented equivalencies

\subsubsection{Facility-related:}

- Fire protection of safety class equipment

- Life safety considerations

- Fire protection of vital programs

- Fire protection of high-value property

- Fire suppression equipment

- Water runoff

- Pre-fire plans

- Fire apparatus accessibility

- Completeness of fire hazards analyses

- Fire barrier integrity

- Completeness of fire loss potential (MPFL) determinations

- Fire safety training 


\subsubsection{Combined Aspects (Program and Facility):}

- Conformance with applicable Orders, codes and standards

- Inspection, testing, and maintenance reports

- Adequacy of facility appraisal reports

- Tests, inspections, procedures, and records for maintaining fire protection systems and features

- Administrative controls

- Temporary protection and compensatory measures

- Status of findings from previous assessments

7.4. Conformance with applicable but outdated consensus standards may not, in itself, justify a conclusion that a facility has achieved an acceptable level of safety. The code of record may be significantly nonconservative in terms of current design requirements, such as seismic design criteria. In such instances, the most recent code or standard may be applied selectively in the assessment as a basis for drawing conclusions regarding the adequacy of fire protection.

7.5. The frequency of assessments should be as follows:

7.5.1. Annual fire protection assessments should be made of facilities valued in excess of $\$ 100$ million; where considered to be a high hazard, or in which vital programs are involved as defined by DOE.

7.5.2. Remaining facilities should be assessed at least every 3 years or at frequencies determined by the AHJ.

7.5.3. Comprehensive assessments of fire protection program elements should be made every 2 years.

7.6. Assessment reports should include a description of what was done during the effort (areas toured, documents reviewed, people interviewed). It should feature a "baseline" description of the facility, hazards and other occupancy considerations, and fire protection features. In addition, the report should document changes of significance that have occurred within the 
facility since the last assessment that affect fire safety, and it should list all noted deficiencies, along with a recommendation for remediation and interim compensatory measures, if necessary, pending resolution.

\subsection{FIRE SAFETY EXEMPTIONS AND EQUTVALENCIES}

8.1. DOE 420, paragraph 4.2.1.11, requires the development of a process for reviewing and approving fire safety "exemptions" and "equivalencies."

8.2. An "Exemption" is the approved deviation from an Order, non-statutory code or standard. An "Equivalency" is a determination by the DOE AHJ that a code or standard has been met by alternate means.

8.3. The process begins with a determination that a basis for an exemption or equivalency determination exists. This could be done by either DOE or the contractor. An analysis is then developed to evaluate its potential acceptability. This is usually prepared by the contractor for submittal to DOE.

8.4. The level of documentation necessary to support an exemption or equivalency will vary, depending on the issue. As a minimum, DOE would expect that each analysis identify the specific site location or condition at issue; the paragraph/section of the code or standard which addresses the issue; a discussion as to why the literal requirements of the code or standard cannot be met; and a discussion which justifies the conciusion that the alternate configuration is acceptable or equivalent from a safety perspective to what is stipulated in the code or standard.

8.5. When a positive determination is made in support of the exemption or equivalency, the documentation should refiect the signatures of all those involved in the decision, including that of the cognizant DOE fire protection engineer. 


\subsection{FIRE PROTECTION DESIGN BASIS}

9.1. DOE 420, Section 4.2.2, and DOE Order 440.1, Attachment 1, Section 2, establish fire protection design requirements for DOE facilities.

9.2. Design aspects of new DOE facilities as well as modifications to existing facilities should be based on the provisions of the applicable requirements of the Code of Federal Regulations (CFR), the local building and fire code, as well as the applicable NFPA Codes and Standards. Where conflicts arise in the application of these criteria, the most cost-effective solution should be adopted. The design process should include appropriate oversight by a qualified fire protection engineer of plans, specifications, and testing of fire protection features.

9.3. Life safety provisions should be provided for all facilities in accordance with the Life Safety Code (LSC), NFPA Standard 101. The methods outlined in NFPA 101A, "Alternate Approaches to Life Safety," may be applied with judgment to all facilities to obtain an equivalent level of life safety where strict compliance with the LSC is not cost-effective. Additional or modified exit requirements for toxic and explosive environments should be as determined by the DOE AHI. In addition, for explosives environments, exits should reflect the criteria contained in the DOE Explosives Safety Manual (DOE/EV 06194). Where noncompliance with some LSC provisions may be required for public safety, as in some containment structures, additional fire protection features and personnel limits should be maintained. Compliance with the ISC is considered by DOE to satisfy the exit requirements of the applicable building code and 29 CFR 1910.

9.4. There are many unique aspects of DOE facilities that are not addressed or are insufficiently addressed by the CFR and other applicable codes. DOE has developed or adopted supplemental fire safety criteria as listed in Section V. as an Appendix and include fire protection design criteria. These criteria are considered guidance. Alternate design configurations may be adopted when justified.

9.5. A fundamental precept of the DOE Fire Protection Program is that all facilities of significance (new and existing), including facilities where a fire could cause unacceptable off-site or on-site consequences to health and safety, should be protected by automatic fire suppression systems 
(usually sprinkler systems).

9.6. The need for an automatic fire suppression system may be revealed on the basis of conclusions resulting from a fire hazards analysis or SAR. The FHA should be predicated on the assumption that a fire will occur. The nature of that fire depends on the hazards present at any given time within the facility. The resulting protection should be designed to ensure that a fire will be successfully controlled until such time that emergency response forces arrive to complete extinguishment.

9.7. Because the Department does not benefit from or pay premiums for insurance coverage as does private industry, DOE has an obligation to provide protection for its facilities such that a fire will not result in an unacceptable program delay or property loss. Consequently, the Department considers any facility in excess of 5,000 square feet in ground floor area and any facility with a MPFL of $\$ 1$ million as warranting protection by an automatic fire suppression system. This is consistent with building code requirements and insurance industry practice. Additionally, when the MPFL exceeds $\$ 50$ million, a redundant fire protection system should be provided that, despite the failure of the primary fire protection system, will limit the loss to below $\$ 50$ million. Such redundant protection could be a fire-rated barrier system or a smoke detection system in conjunction with a fully capable fire department, among other options. A decision not to provide protection for such facilities would need to be thoroughly justified and approved by the DOE AHJ.

9.8 It may be necessary to exceed or supplement the requirements of the applicable NFPA code or standard when designing fire protection systems designated as safety class in the SAR, or whose loss of structural integrity could jeopardize such systems. Such additional design requirements would only be required when justified on the basis of the conclusions of the SAR. 


\subsection{PROTECTION FOR ABANDONED FACILITIES}

10.1. DOE 420, Section 4.2.2, and DOE 440.1, Attachment 1, Section 2, establish fire protection requirements for DOE facilities. All of these requirements may not be appropriate for abandoned facilities and facilities undergoing decontamination and decommissioning (D\&D) and safe shutdown. Decisions relating to fire safety of such facilities should be made on the basis of the following principles:

10.2. The evaluation of fire risks in relation to the need for fire safety features can be accomplished through a graded fire hazards analysis (FHA).

10.3. The need for fire protection features in these facilities is governed by the fire risks to the public, workers, fire fighters and the potential release of hazardous and radiological materials to the environment. Property protection and program continuity are not normally factors to consider unless the facility possesses a definable value and/or mission as determined by the DOE AHJ or if a fire would significantly increase the cost of clean up.

10.4. Fire hazards within these facilities may change over time. Fire protection must be adequate to deal with these changes. The FHA should be revised as appropriate when significant changes in occupancy or hazard occur that affect fire safety.

10.5. Fire safety features that have been required by DOE may be rendered inoperable or considered no longer needed if justified by the FHA. Such features may be abandoned in place until they are dismantled as part of planned demolition activities.

10.6. The decision to deactivate automatic fire suppression systems in large facilities must reflect the possibility that the fire department may not be able to safely enter the facility to effect manual fire suppression. A "stand off and protect" tactical approach, which features exterior fire attack and protection of exposures, should be approved by DOE as part of the fire department preplans or their standard operating procedures. This approach necessitates additional emphasis on maintaining communication and cooperation between facility personnel and the fire department to include: updating fire pre-plans and being aware of changes in occupancy and fire protection system status. 
10.7. Retained fire protection features in these facilities are not required to comply with all of the design and installation criteria of the governing NFPA standard if the DOE AHI concurs that the system will function adequately during a fire in its current design mode. Concurrence should be documented in an appropriate manner after consultation with the cognizant DOE fire protection engineer.

10.8. Retained fire protection features should be inspected, tested and maintained in a manner sufficient to ensure that the features will function adequately during fire incidents.

10.9. Abandoned, safe shutdown and D\&D facilities and related procedures should be routinely inspected and reviewed by representatives of the fire department and fire protection engineering staffs consistent with established standard operating procedures and fire protection program criteria. Tours of the D\&D facilities should also be conducted by the fire department to familiarize them with existing conditions and to revalidate fire pre-plans. Drills and training exercises should also be conducted at these locations at an appropriate frequency commensurate with the fire risks and complexity of the facility.

10.10. Prior to commencement of D\&D activities, appropriate procedures should be approved and implemented (including worker training) governing the control of potentially hazardous operations including, but not limited to, cutting and welding, handling of combustibles, and smoking.

10.11. The fire risks associated with materials and processes used as part of the D\&D process should be evaluated by a fire protection engineer. Fire protection features must be adequate to minimize these risks to an acceptable level.

10.12. The deactivation of process lines containing hazardous materials as well as flammable or combustible liquids should be preceded by an analysis or performed under a work plan which addresses the methods used to control related hazards during the deactivation process. Appropriate safeguards need to be in place to minimize the accidental release of residual materials that may remain in piping and tanks. 
10.13. Building emergency egress features are required to be maintained consistent with the requirements for buildings under construction, as a minimum, as modified by the FHA. These include emergency lighting and exit signs. Locked and abandoned facilities where there is no human occupancy would not need to maintain emergency egress features. Literal conformance with the provisions of the Life Safety Code (NFPA Standard 101) is not required for conditions that have no significant impact on the ability of occupants during D\&D to safely evacuate a building during a fire.

10.14. Where no automatic system exists, an effective means for manually summoning the fire department and for communicating with personnel inside of a building is required. This can take the form of an exterior fire alarm pull station or call box, telephone (fixed or mobile), radio or some combination of the above based on the accessibility of the devices to personnel and their reliability.

10.15. All retained interior fire protection systems should be maintained operational to the extent possible while interior D\&D activities are taking place. Verification of operable status should include appropriate inspection and testing in accordance with established procedures. Complete deactivation is anticipated at such time as shell demolition occurs. Temporary deactivation of fire protection features should be treated as an impairment, with appropriate interim compensatory measures implemented until such time as the feature is returned to full operational mode.

10.16. The site and facility fire water distribution system, including hydrants, siamese connections to sprinkler systems, and interior standpipe systems, must be maintained in an operable mode. Access for mobile apparatus for emergency response should be maintained. (Refer to fire department pre-fire plans.)

10.17. To the extent that the FHA validates the need to maintain fire protection features during D\&D activities, such features should be inspected, tested and maintained, consistent with established procedures, sufficient to ensure that they will function effectively during a fire. This implies that defects or design deficiencies that are not critical to effective performance, as determined by the AHJ, may remain as is. 


\subsection{IMPLEMENTATION PLAN}

11.1. The implementation plan for fire protection should include a commitment to comply with DOE 420 and 440.1 and to conform with the other fire safety criteria that DOE has established as its basis for a comprehensive program (see Section V. Appendix). This should also include a commitment to develop site-specific policies, programs, practices and procedures as necessary to address any aspect of the program that is not encompassed by DOE criteria.

11.2. When aspects of a comprehensive program are not currently in place, the plan should clearly identify existing deficiencies, specify the measures that will be implemented to address these deficiencies, identify the resources necessary to fulfill the commitment, and identify appropriate interim compensatory measures that will be put in place to ensure an acceptable level of fire safety. 


\section{Section V. ADDITIONAL INFORMATION}

\section{Appendix. DOE REFERENCED FIRE PROTECTION CRITERIA}

- Code of Federal Regulations (CFR) 29, Part 1910, Occupational Safety \& Health Standards

. CFR 29, Part 1926, Safety \& Health Regulations for Construction

- National Fire Protection Association (NFPA) Codes and Standards

- Other DOE Orders and statutory requirements, not listed above, that contain requirements of a more limited extent relating to the DOE Fire Protection Program

. DOE-STD-1088-95, "Fire Protection for Relocatable Structures"

- DOE-STD-XXXX-9X, "Fire Protection Design Criteria" (In draft)

- DOE Explosives Safety Manual, DOE/EV/06194

- Uniform Building Code or local building code (if the local code is enforced on site) and the companion fire code for the governing building code.

- DOE Fire Protection Resource Manual, October 18, 1991

. Department of Defense Instruction Number 6055.6, December 15, 1994, "Fire and Emergency Services Program"

- National Fire Protection Association Handbooks, Guides and Recommended Practices

- Factory Mutual Loss Prevention Data Sheets

- Society of Fire Protection Engineers (SFPE) Handbook

- American Petroleum Institute Guidelines

. USNRC Guidelines on Fire Protection for Fuel Cycle Facilities, (Vol.) 57 Federal Register, (Pages) 35607-13, August 10, 1992. 
. 